
(4)

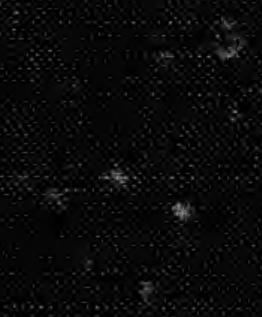



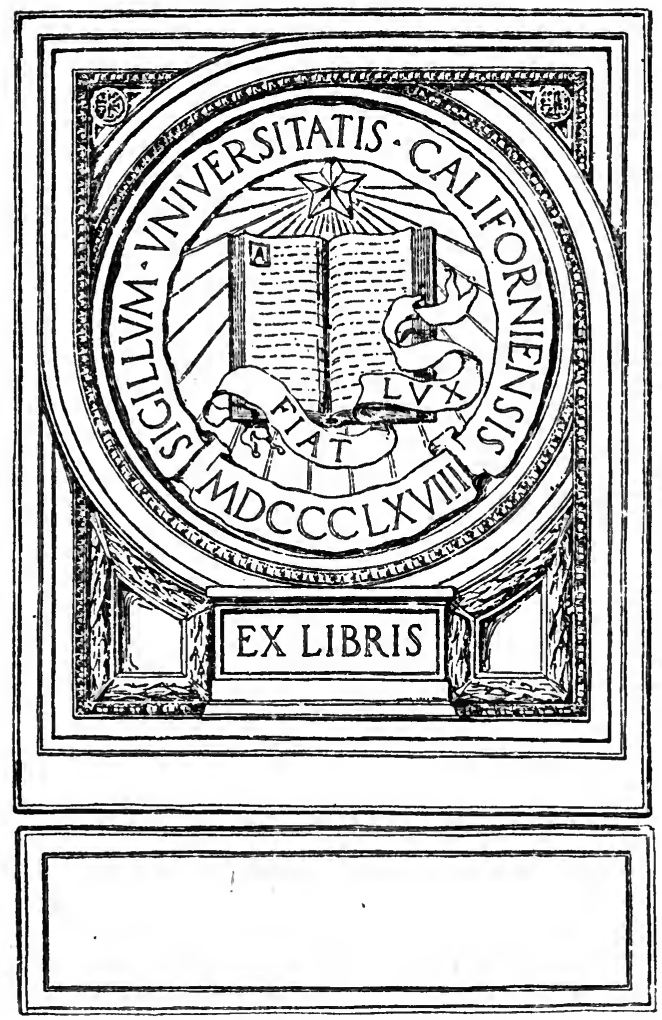
Digitized by the Internet Archive in 2007 with funding from Microsoft Corporation 1 


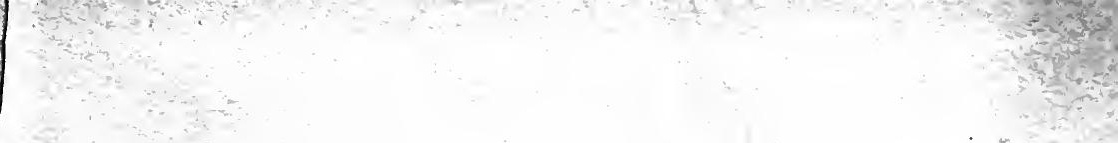





\section{A PHILOSOPHICAL STUDY OF CHRISTIAN ETHICS}




\title{
A PHILOSOPHICAL STUDY OF CHRISTIAN ETHICS
}

\author{
BY \\ G. F. BARBOUR \\ D. PHIL., EDIN.
}

" Be a moralist of the Mount,

An Epictetus in the Faith, And Christianize thy Notions."

-Sir Thomas Browne.

\section{WILLIAM BLACKWOOD AND SONS}

EDINBURGH AND LONDON

MiC M(X I) 
PUII251

Bo 3 
TO

A NOBLE BROTHERHOOD

FROM THE LEAST OF ITS MEMBERS

IN GRATITUDE FOR

THE FRIENDSHIP OF THE LIVING

AND THE

ABIDING MEMORY AND INFLUENCE

OF THE DEAD. 



\section{PREFACE.}

THE first seven chapters of this volume were originally written, under the title Some Philosophical Aspects of Christian Ethics, as a thesis for the degree of Doctor of Philosophy, and were accepted by the examiners of. Edinburgh University in the spring of 1910. These chapters have been revised since they were submitted in thesis form; but, while the changes made have been numerous, they have been almost entirely of a minor character, designed to improve the form of the argument and to remove obscurities of expression, rather than to alter its substance or its main direction. The only part of the thesis which has been substantially altered is Chapter VII. In the central part of this chapter further reflection has led me to modify the relative emphasis on certain points; and a few paragraphs have been transferred from the latter part of the chapter to Chapter XIII. (pp. 378-80). Throughout the chapters which composed the thesis a few additional references have been added, while some of the longer notes have been transferred to the end of the book. I should also state that Chapter IV. is based upon an article, entitled Green 
and Sidgwick on the Community of the Good, which appeared in the Philosophical Review for March 1908. The last six chapters of the book, except the short passage already referred to, are entirely new.

I should like to take this opportunity of thanking Professor Campbell Fraser, whose work, extending over two-thirds of a century, has done so much to bring philosophical and theological thought into close and vital contact, for his interest in the doings of a philosopher of the third generation. To Professor PringlePattison and Professor Seth I am indebted for much help and stimulus, given at first in the class-room, but afterwards in a freer and wider relation than that of lecturer and student. Of other friends who have assisted by criticism and suggestion, I must especially acknowledge my indebtedness to $\mathrm{Dr} \mathrm{D}$. M. Ross, and to the Rev. J. M. Shaw, who has spent much time and care on the correction of the proofs.

The main purpose of the present volume is, I think, clearly expressed in the words of Sir Thomas Browne which stand on the title-page. To "christianise" certain of the great "notions" (or, as we should now say, concepts) of Moral Philosophy, that is, to show how certain of the persistent problems of ethics appear in the teaching of the New Testament, and to examine the specifically Christian answer to them-such is its object; and, in so far as this attempt is successful, it may give some added clearness to our understanding of the ethical teaching of the New Testament, and at the same time show how that teaching forms the completion and crown 
of the ethical thought both of Greece and of the modern world.

Thus in the introductory chapter, which deals with the form of Christian Ethics, the Aristotelian doctrine of virtue as the Mean is dismissed as inadequate to the expression of the Christian ideal; since that ideal is essentially positive, as the highest type of morality must be, while the Aristotelian doctrine lends itself to a negative interpretation. But the contrasted doctrine of virtue as synthetic-as the union of opposite tendencies towards good-which is suggested by Plato, is found to have just that positive character of which we are in search. In the second part of the chapter it is shown that the New Testament exemplifies this union and harmony of opposites in regard to several of the fundamental moral qualities; and in the concluding paragraphs the Christian idea of the infinity of virtue is stated in contrast to the Aristotelian view.

The two following chapters deal with the Value of the Individual. Chapter II. treats of the preconditions of the Christian doctrine; on the positive side, the tendencies of evolution and of history which worked towards it and prepared the way for its coming, and on the negative side, the forces which hinder its acceptance and realisation are passed in review. Chapter III. attempts to show how the former are reinforced and the latter are repelled, first by the great moralists, and especially by Kant in his ethical theory, and then by the simpler teaching of the Gospels; and the chapter concludes by pointing out the dynamical and redemptive character of the Christian doctrine, and the fact that 
the true worth of the individual life can only be realised in the life of a community. This leads at the beginning of Chapter IV. to a statement of the theory that the true Good is necessarily common and non-competitive. It is shown that this theory can be based either on the idea of the Good as purely inward (as abstract goodness of will), or on a concrete conception of it as depending on the activities of an ethical society. The difficulty of maintaining either view in isolation leads to the attempt to rise to a higher point of view in which both may be harmonised, and such a synthesis is found in the idea of the ethical end as contribution to a Common Good. In Chapter V. the same ideas are traced in the somewhat different forms which they assume in the New Testament; and here the synthesis appears in the idea, essentially akin to the philosophic thought, but simpler and more direct, of Service inspired by Love. Chapter VI. gathers up the results of the four previous chapters in a characterisation of Christian Universalism (1) as dynamical, pointing less to an accomplished fact than to a task, and (2) as combining unity with the widest diversity. This diversity appears both in the varied discipline gained through the infinitely varying circumstances of life, and also in the varied functions, which are as manifold as the needs, physical, intellectual, and spiritual, of mankind. Chapter VII. is devoted to an attempt to show how these various aspects of ethical theory are reflected in the idea of the Kingdom of God, which appears in the teaching of Jesus as both present and future, both a gift and a task.

With Chapter VIII. the second part of the work 
begins. It deals with a different set of problems, concerning more especially the individual life, and the inspiring and directing forces within it which make the highest goodness possible. Chapters VIII. and IX. deal with the motive of virtue, and the question of the place of reward in the moral life. The former traces the problem as it is worked out in the ethics of Plato and Kant; and shows that, while the hope of reward and the fear of punishment are absolutely inadmissible as the mainspring and centre of morality, yet the rationality and coherence of the moral life point to a higher and more spiritual form of reward-that which is found in the prospect of continuance in virtue and the hope that goodness will ultimately be supreme. Chapter IX. is devoted to proving that the same thought is the dominant one in the New Testament, and that in its thought the idea of reward as a legal equivalent for service gives place to that of a trust to be fulfilled. In Chapter $\mathrm{X}$. an attempt is made to show that the idea of Moral Continuity, to which the two previous chapters have led up, is not inconsistent with that proclamation of the possibility of new beginnings which has a central place in the Christian message. It is pointed out that the latter meets a practical rather than a theoretic demand, and that it is based not on a legal but on a teleological view of morality. This raises the question of the nature of the Christian Law. Law there must be in any ethical system; but the problem is to find a law that is universal in scope, and yet consistent with Freedom and with a thoroughly teleological point of view. Chapter XI. deals with the Christian Law as Personal, and shows that, so far from 
being limited by its personal character, it gains thereby a universality of obligation that cannot be attained by any abstract or formal code. Chapter XII. treats the Christian Law as Positive, and that in a double sense; since Christianity both holds up a positive ideal, and also furnishes a moral dynamic, through which the outward law is superseded by an inward nisus towards what is good. Thus the old antithesis between Law and Freedom is overcome in so far as the "liberty of the Spirit" becomes an actual experience. The final chapter gathers up the results of the whole discussion in a contrast between the life of man as a member of the Natural and of the Spiritual Order.

It only remains to add that this book makes no claim to completeness. There are great aspects of Christian Ethics which are hardly touched on here. These chapters are of the nature of preliminary studies, and their value can only be the value of prolegomena. My aim has been to open up avenues of thought; and I shall feel fully rewarded if the work here done should in any degree induce or assist other workers, whose theological equipment is greater than mine, to press further into the heart of the subject and to explore it more fully.

G. F. BARBOUR.

Fincastle, Pitlochry,

September, 1911. 


\section{CONTENTS.}

CHAP. PAGE

I. INTRODUCTORY : THE SYNTHETIC CHARACTER OF ChRISTIAN ETHICS • . . . . 1

II. THE VALUE OF THE INDIVIDUAL - CONFLICTING TENDENCIES .

III. THE VALUe OF the INDIVIdUal IN PHILOSOPHY AND

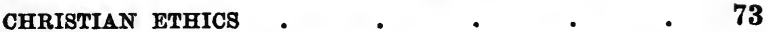

IV. THE PHILOSOPHICAL DOCTRINE OF THE COMMON GOOD 103 V. THE COMMON GOOD AND THE INWARD AND OUTWARD ASPECTS OF VIRTOE IN THE NEW TESTAMENT • 140

VI. THE NATURE OF CHRISTIAN UNIVERSALISM • 162 vII. THE KINGDOM OF GOD AS PRESENT AND AS FUTURE. 180 VIII. THE PLACE OF REWARD IN MORAL PHILOSOPHY - 208

IX. THE PLACE OF REWARD IN THE NEW Testament • 226

X. MORAL CONTINUITY AND THE POSSIBILITY OF NEW BEGINNINGS • $\quad$ • $\quad$. $\quad$ - $\quad$ - 254

XI. THE CHRISTIAN IDEA OF LAW AS PERSONAL • • 292 XII. THE CHRISTIAN IDEA OF LAW AS POSITIVE-LAW AND FREEDOM $\quad$ • $\quad$ • $\quad$ • $\quad$ • $\quad 326$

×II. THE NATURAL AND THE SPIRITUAL ORDER • $\quad 355$ 


\section{NOTES.}

A. THE POSITIVe AND Negative ELEMENTS IN THE GREeK

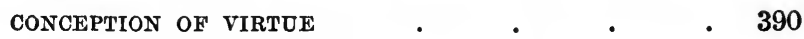

B. NEWMAN ON THE PARADOX OF CHRISTIAN CHARACTER . 394

C. THE UNION OF SEVERITY WITH MERCY IN THE CHARACTER OF JESUS $\quad$ • $\quad$ •

D. SLAVERY IN THE REPUBLIC $\quad$ • $\quad$ • $\quad$ • $\quad 395$

E. ECONOMICS AND THE INDIVIDUAL . • • 396

F. THE TWO CONCEPTIONS OF THE INFINite . • 398

G. GEORgE ELIOT ON THE VALUE OF THE INDIVIDUAL • 398

H. THE Meaning of "competition" AND "competitive" 399

I. GREEN'S DOCTRINE OF THE COMMON GOOD • • 400

K. DANTE ON THE COMMUNity OF THE GOOD • . 400

L. THE PLACE OF HEALING IN JesU' Ministry • • 401

M. CHRISTIANity AND THE USE OF MATERIAL GOODS • 402

N. THE CONTRAST BETWEen GABE AND AUFGABE • . 403

o. KANT ON THE PLACE OF HAPPINESS IN MORAL PHILOSOPHY 404

P. LOTZE AND BERGSON ON SPONTANEOUS OR CREATIVE

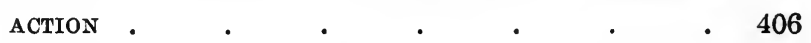

Q. THE CONCEPtion OF PUNishment as ReFormatory • 409

R. KANT'S FINAL THEORY OF LAW AND PERSONALITY • 410

S. THE CHARACTER OF JeSUS AS THE UNIVERSAL IDEAL • 415

T. POSITIVE AND NEGATIVE FORMS OF THE "GOLDEN RULE" 416

U. Chalmers on the Defects OF Mere Feeling as a MORAL DYNAMIC $\quad . \quad$. $\quad$. $4 \quad$. 418

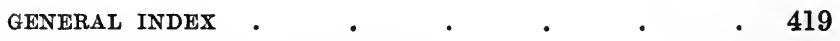

INDEX OF BIBLICAL REFERENCES . . . . . 433 


\title{
A PHILOSOPHICAL STUDY OF CHRISTIAN ETHICS
}

\author{
CHAPTER I. \\ INTRODUCTORY : THE SYNTHETIC CHARACTER OF \\ CHRISTIAN ETHICS.
}

Philosophy has been defined as the criticism of categories; and whenever an attempt is made to provide an intellectually consistent form for the spiritual content of Christianity, Philosophy, so understood, has a function of its own to perform. Since the days of Alexandrian thought, it has helped to mould the form of Christian doctrine; and although at times theologians have sought to make their study independent of philosophical presuppositions, yet that effort can never be completely successful. Religion may exist in its own right independently of Philosophy, but Theology, which is its statement in terms of the intellect or reason, cannot afford to use intellectual terms and categories without first inquiring what metaphysics has to teach regarding the range of their validity. 
Nor is this true of theological or doctrinal study alone. In the more practical study of conduct, a similar contact between Moral Philosophy and Christian Ethics may take place to the benefit of both. For, as soon as the student of the latter attempts to set forth his results in order and to show their significance in the advance of human thought and effort, he finds himself compelled to borrow many of the terms and concepts of the former. If we take up the attempt, which is as old as the writings of St Paul, to relate the simple and direct moral teaching of the Gospels to the great systems of belief and conduct which lie outside the earliest Christianity, then it becomes necessary for us to inquire into the exact meaning of those concepts through which we seek to give a reasoned expression to the Christian view of life. Hence it is the aim of the following chapters to examine certain of these ideassuch as the Value of the Individual; the Community of the Good, and the relation of its inward and outward aspects; Reward, the Disinterestedness of Virtue, and Moral Continuity; Law and Freedom-in order so to gain a clearer idea of their use and their validity, first in the sphere of Moral Philosophy, and later in the interpretation of the ethical teaching of the New Testament.

The justification for this order, which will be followed in most of our discussions, is that, while in its content Christian Ethics is in the highest degree original, in regard to its form and the categories which it employs it is largely dependent on speculative thought. The ethical concepts which have just been named, and others which will meet us in the course of our inquiry, all have their origin in the thought of Greece, and all have 
developed with the development of modern ethics from Spinoza to the present day. Hence on the formal side Christian Ethics may gain from a preliminary examination, such as is here attempted, of certain trains of thought which, originating in the territory of philosophy, have provided natural and fitting lines of advance for the moral reflection of Christianity. But while formally Christian Ethics may acquire increased precision and clearness from the concurrent study of Moral Philosophy, it is not less possible that, on the side of ethical content, Moral Philosophy may gain in fulness and depth when it is brought into close relation to the wealth of ethical experience which is to be found in the New Testament.

First of all it is needful to inquire under what form the Christian conception of virtue may be most adequately expressed. And, though formal, this question is not unimportant. For our whole view of Christian Ethics will depend on whether we are able to show that its form is positive, or whether we accept the view of certain modern critics of Christian morality that it is essentially negative, a matter of renunciation and escape from sin rather than a positive achievement of goodness and completeness of character. Now this criticism can only be met in one way-by finding a positive form in which to express the Christian ideal, and by showing that any merely negative statement of it is inadequate and misleading.

The systematic exposition and classification of the different forms of virtue has never been more thor- 
oughly and impressively carried out than in Aristotle's Ethics; and thus his doctrine of virtue as a mean between excess and defect has gained a great ascendancy in the history of ethical thought. But at the first glance it must strike us that, on the surface at least, this is a doctrine of avoidance, while we have set out to find a theory which lays stress not on mere avoidance of excess and defect but on the attainment of a positive virtue. Thus if the Doctrine of the Mean proves too narrow for our purpose, is there any other philosophical theory which may provide an ampler and freer expression for the varied wealth of Christian character?

Now, before we attempt to answer this question directly, a distinction must be drawn between two senses of the term "virtue." The character of every man has as its basis certain natural qualities lovable or unlovely. These qualities are part of the original endowment with which he faces the world; and they are commonly and popularly described as "virtues" and "vices." But this description is not according to strict philosophic usage; for these purely natural qualities are not the outcome of struggle or of indolence; they are given to each man rather than wrought out by him. They are rather the raw material of character than its component parts, and so are more properly the subject of æsthetic than of strictly ethical appreciation. For "character" in the full sense implies effort, self-determination, conscious purpose; and hence, if the ethical meaning of the term is to be safeguarded, "virtue" must be understood as the result of the organisation of these natural impulses and aptitudes by a ruling principle into a consistent whole. Thus we may follow Aristotle 
in describing moral virtue as the actualisation of natural capacities for good, and in saying that we receive from Nature the disposition or capacity for virtue, but that virtue itself is gained by the habitual use of the powers implanted in us. ${ }^{1}$

This distinction between the natural capacity for different kinds of goodness and the developed good character, both of which are in turn described by the word "virtue" in ordinary speech, is important for our present purpose because the positive or negative character of a philosophy of conduct depends largely on the view which is taken of the relation between these

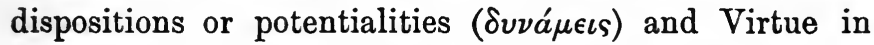
the higher and wider sense. Two such views may be held, and both are found in Greek ethics. First there is the famous Doctrine of the Mean, which we have already referred to. In it virtue is defined as a middle course between the extremes of excess and defect towards which conduct ever tends to diverge. Thus it seems to lay the chief emphasis on the element of avoidance in the guiding of the moral life; and in so far as it concentrates attention on the excess or deficiency which is opposed to virtue it has a negative character. ${ }^{2}$ But there is another contrasted theory which demands a fuller description, both because it is less familiar and because it brings us nearer to the ideal of goodness which we find in the New Testament.

This other method proceeds positively, not by defining complete virtue as a correction of natural tendencies to wrong conduct, but by regarding it as a synthesis or

1 Eth. Nic., II., 1103 a 25.

${ }^{2}$ Cf. below, pp. 37 ff., and note A, p. 390, "The Positive and Negative Elements in the Greek Conception of Virtue." 
union of opposite qualities which tend in the direction of virtue. ${ }^{1}$ In the ideal of character so interpreted limitation is no longer the ruling motive, but it is considered as harmonising those various dispositions to good which in undisciplined human nature often appear as hostile. This theory recognises that "the virtues," as they figure in common thought and speech, are often at war among themselves. There are few men born into the world without some admirable quality. Few natures are so poor as to be without some point of conspicuous strength. But the rare thing is to find a man in whom these natural virtues are not balanced by corresponding deficiencies in the other regions of character. Thus some men are naturally generous but deficient in prudence and forethought. In others courage is found without gentleness and considerateness, or gentleness is balanced by lack of courage. In fact, as Plato saw, the enemies of the higher virtue seem to spring up within its own sphere. The difficulty arises from the one-sided exclusiveness of the various "virtues" which ought to form its component elements. ${ }^{2}$ To borrow a distinction from formal logic, while the contradictory of any special virtue is undoubtedly a vice, its contrary is rather another virtue. Thus the problem of moral education may be stated in Hegelian terms as that of combining two partial, and at the outset apparently inconsistent, virtues in a higher synthesis or unity. We say of the ordinary man that he has the "defects of his qualities"; but in the character of the completely virtuous man this opposition of the "dissimilar and divergent virtues" has

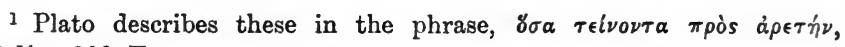
Polit., 308 E.

${ }^{2}$ Rep., $503 \mathrm{CD}$; Theat., $144 \mathrm{AB}$; and especially Polit., 306 B, $307 \mathrm{C.}$ 
disappeared, and they are united as by "a divine bond." 1

The first hint of this doctrine in Plato occurs in the Second Book of the Republic, in the course of the discussion on the character and training of the "guardians." They must of course be brave and high-spirited, but the question arises whether they will not on account of these qualities be dangerous to their fellow-citizens as well as to enemies. "What then," asks Socrates, "shall we do? Where shall we find a character at once gentle and high-spirited? For I suppose a gentle nature is the opposite of a spirited one?" "Apparently it is." "Nevertheless a man who is devoid of either gentleness or spirit cannot possibly make a good guardian. And as they seem to be incompatible, the result is, that a good guardian is an impossibility." 2 The solution of the difficulty is found in the consideration, that if the guardians are trained in philosophy as well as in martial exercises, their courage will be tempered with gentleness. Through philosophy they will learn the right occasions for spirited and for gentle action, like well-trained watch-dogs, who are fierce in encounter with enemies, but never towards their friends.

The same subject recurs in the following book, where "gymnastic" and "music," in the wide meaning which they bore in the Greek theory of education, are being discussed. Plato argues that an excess of the former discipline makes character harsh and rough, while a too exclusive devotion to music tends to softness and feebleness. But by a fitting use of both gymnastic and music

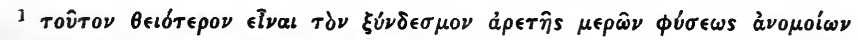

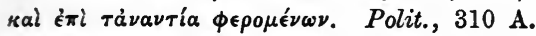

2 Rep., $375 \mathrm{C}$ (tr. Davies and Vaughan). 
the two temperaments may be harmoniously developed; and, he concludes, "whosoever can best blend gymnastic with music, and bring both to bear on the mind most judiciously, such a man shall we justly call perfect in music and a master of true harmony." 1

But the fullest development of this idea in Plato is found at the close of the Politicus, where the art of the statesman is compared to that of the weaver who unites different strands in the same web. The Eleatic Stranger, who conducts the argument, propounds "a strange theory" that temperance and courage ( $\sigma \omega \phi \rho o \sigma v ́ \nu \eta \kappa a i$ à $\delta \rho \epsilon i a)$, though both "parts of virtue," are in reality examples of "two principles which are full of hatred and antagonism to one another, and pervade a great part of nature." A discussion of the two groups of qualities follows. "Sharpness, quickness, hardness," are placed on the one side as tending to violence, and "slowness and gentleness" on the other as tending to cowardice; and the conclusion is reached "that these qualities, and in general the temperance of one class of characters and the manliness of another, are arrayed as enemies on opposite sides, and do not mingle with one another in their respective actions; and ... that considerable portions of virtue are at variance with one another, and give rise to a similar opposition in the characters who are endowed with them."

To remedy this defect and harmonise this discord is the task of the statesman. In the first instance he must eliminate those natures which have no tendency to virtue by exile or the heaviest punishments. Only when this has been done are there fitting materials for the weaving of the "royal web." Thereafter, "the rest

$$
1 \text { Rep., } 412 \text { A. }
$$


of the citizens, of whom, if they have education, something noble may be made, and who are capable of social science, the kingly art blends and weaves together; taking on the one hand those whose natures tend rather to courage, which is the stronger element and may be regarded as the warp, and on the other hand those which incline to order and gentleness, and which are represented in the figure as spun thick and soft, after the manner of the woof-these, which are naturally opposed, she seeks to bind and weave together." For "in this single word, the whole process of royal weaving is comprised-never to allow temperate natures to be separated from the brave, but to weave them together, like the warp and the woof, by common sentiments and honours and opinions, and by the giving of pledges to one another." And the dialogue concludes with these words :- "This, then, according to our view, is the perfection of the web of political action. There is a direct intertexture of the brave and temperate natures, when the kingly science has drawn the two sorts of lives into communion by unanimity and kindness; and having completed the noblest and best of all the webs which civic life admits, and enveloping therein all other inhabitants of cities, whether slaves or freemen, binds them in one fabric and governs and presides over them, omitting no element of a city's happiness." 1

This idea, which we have traced in the Republic and Politicus, was not unfamiliar to Aristotle. In one passage of the Politics he speaks of the political capacity of the Hellenic race as due to the fact that they combined

${ }^{1}$ Polit., 306-311 (tr. Jowett). The metaphor of the web recurs in Laws, $735 \mathrm{~A}$; and a similar idea with a different metaphor (that of the mingling of wine and water), ibid., 773. 
the intellect of the Asiatic peoples with the courage of the northern nations; and he adds the remark that " a people which is to be easily guided by the lawgiver in the path of virtue should be at once naturally intelligent and spirited." 1 Perhaps we have here a reminiscence of the famous description and eulogy of the Athenian character which Thucydides ascribes to Pericles in the funeral oration; for the idea of political and military success as depending on the fortunate combination of the powers of reflection and action is the same in both. In another passage Aristotle quaintly remarks in criticism of the brutalising influence of the Spartan training, that courage does not commonly accompany the most savage natures, but rather such as are "gentle and lionlike." 2

It is true that in these two references to the conception of virtue as consisting in the union of courage with intellect or gentleness, Aristotle has in view the natural temperament which is best fitted to respond to wise legislation and government; whereas Plato, with perhaps deeper insight, looks on the attainment of such a harmony of opposite virtues as the highest aim of the political art. In the one case it appears as a presupposition of outstanding political excellence, in the other as its rarest flower and result. But the chief point to remark is not this distinction, but the fact that the conception of virtue as a synthesis or harmony of opposite qualities has a distinct place in the ethical thought of Greece. And indeed we may trace it beyond the theories of Plato to the character of his master, with

${ }^{1}$ IV. (VII.), 1327 b 36 (tr. Welldon, p. 181).

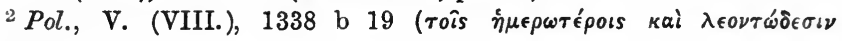
$\forall \theta \in \sigma i \nu)$. 
whose personality and teaching Moral Philosophy began. So rich and varied a personality as that of Socrates cannot be explained on the theory that virtue consists merely in the observance of a just mean between opposite defects. It was the combination in him of the most opposite gifts and faculties which charmed and baffled his contemporaries, as the study of his character fascinates men still. He was at once brave and temperate, serious and playful, more critical and argumentative than the Sophists, and yet a loyal servant of Apollo and of the "divine voice" within. He was both rationalist and preacher, and the two most divergent schools of ethical thought both claimed him as their founder; for he showed in himself virtues which in ordinary men only exist fragmentarily and in isolation.

This view of moral excellence ( $\left.\dot{a} \rho \epsilon \tau \eta^{\prime}\right)$ as consisting in a balance or harmony of apparently opposite characteristics, which is suggested by the character of Socrates not less than by the passages quoted from Plato, and which underlies Thucydides' appreciation of the Athenian character and polity, was emphasised in a wider connection by one of the most sympathetic of recent writers on Greek subjects. The late Professor Butcher drew attention to "that balance of contrasted qualities, that reconciliation of opposites, which meets us at every turn in the distinguished personalities of the Hellenic race, and which is too often thought of, in a merely negative way, as the avoidance of excess, rather than as the highest outcome of an intense and many-sided vitality." 1 Thus, we find a double strain in Greek ethical thought. Alongside of the Doctrine of the Mean, with its emphasis on the avoidance of excess, there

1 Harvard Lectures on Greek Subjects, Pref., p. vii ; cf. pp. 164-168. 
runs a tendency to look on virtue as consisting in a process of moral synthesis, in which the stress is laid on the addition of one virtuous characteristic to another, on the interweaving of contrasted strands into the varied yet harmonious fabric of a perfectly developed manhood.

We have thus found an alternative theory of virtue by which we may more adequately define that type of character which forms the Christian ideal, and which is wide enough to comprise all those moral facts which fall within the sweep of Christian Ethics. Our next task will be to examine some of its more notable illustrations in the New Testament; and although we can only do so in outline, yet even a rapid survey of the possible applications of the doctrine of Virtue as a Moral Synthesis in the specifically Christian sphere, may enable us at the close of the chapter to see wherein the Christian ideal differs from and transcends the Greek conception embodied in the Doctrine of the Mean. And at the same time we may gain some impression of the comprehensiveness and variety, as well as of the positive nature, of the moral ideal as it is portrayed in the New Testament.

II.

(1) Courage and Gentleness.

The view of virtue whose presence in Greek thought we have just traced is finely expressed in a passage in Pascal's Pensées, which we may take as our startingpoint in passing to the Christian ideal. "Je n'admire point l'excès d'une vertu, comme de la valeur, si je ne vois en même temps l'excès de la vertu opposée, comme 
en Épaminondas, qui avoit l'extrême valeur et l'extrême bénignité; car autrement ce n'est pas monter, c'est tomber. On ne montre pas sa grandeur pour être à une extrémité, mais bien en touchant les deux à la fois, et remplissant tout l'entre-deux." 1

It is interesting to note that here Pascal fastens on the same union of courage with gentleness or kindliness which had appealed to Plato as the mark of the highest virtue, whether in the individual or the state, and which was also the ideal of the noblest mediæval chivalry. $\mathrm{He}$ uses an example drawn from a classical source, but the narrative of the New Testament also illustrates this combination of opposite virtues, though in its pages they appear in an altered form. It is important to emphasise the fact that early Christianity was a school of bravery and endurance, as well as of those more feminine virtues - gentleness, forbearance, kindness, brotherly love which we more readily associate with the teaching of Jesus. It is indeed true that the latter was the side on which His influence was most distinctive and original, for in the ancient world the lesson of courage had been thoroughly learned and the sterner virtues stood little in need of reinforcement. Thus the familiar statement that Christianity effected a "transvaluation of values" is accurate, if it be understood in the sense that a new rank and standing were now given to qualities which formerly had been but grudgingly admitted into the accepted catalogue of virtues; but it is misleading if it is taken in the Nietzschean sense, that Christianity introduced a "slave-morality" which left no place for manliness or the more heroic elements in human nature. For the real effect of Christian morality was not to

1 XXV., ix. Cf. XVI., xiii. 
dethrone the virtue of courage or to disparage heroism, but rather to set up a new ideal of courage, and to sever it from that association with arrogance and brutality which Aristotle condemned in the case of Sparta, ${ }^{1}$ and which was hardly less characteristic of Rome.

It is true that there was a "transvaluation of values" -a decisive alteration of relative emphasis. In the forefront of the teaching of Jesus the author of the First Gospel has placed the Beatitudes, in which a new appreciation appears of those gentler virtues which formerly had as a rule been neglected or despised. In the "royal web" of Plato the warp or groundwork is courage, the woof gentleness and temperance: in the teaching of Jesus it is rather love or gentleness that forms the groundwork, and yet the necessity for courage is not only recognised but emphasised throughout. Even in the Beatitudes this is the case; for in that which refers to the peacemaker a duty is enforced which often requires a higher type of courage than that shown by the combatants whom he seeks to reconcile; and the list closes with the blessing pronounced on those who are persecuted and suffer calumny and reproach for righteousness' sake. ${ }^{2}$ And this is but the first hint of one of the dominant characteristics of the New Testament-the high value which is consistently attributed to the patient endurance of suffering for the sake of the faith.

This was not indeed a new or unknown virtue. From the days of Socrates onwards in the Greek and Roman

1 Vide supra, p. 10. An American scholar has said that "the difference between the Greek and the Christian courage is not so much in the attitude of mind as in the enemies one must withstand." Mathews, The Messianic Hope in the New Testament, p. 278.

2 Matt. v. 9-11. 
world, it had been proclaimed that truth was more important than life; and thus the passive and enduring type of courage had been assigned a place beside the actively daring type,-that of the Sage beside that of the Soldier. ${ }^{1}$ This was the chief element in the fortitude which the Stoics constantly enjoined and which they often so nobly practised. The history of the Old Testament also, especially in its later stages, was a long education in the constancy which endures and waits. . This virtue found its most conspicuous example in the patient endurance of Jeremiah, and its highest ideal expression in the figure of the Suffering Servant; and in both cases, the actual and the ideal, its moral nobility and efficacy had come to be clearly seen, because the suffering of the one innocent and righteous man was recognised as a burden laid upon him for the redemption of his erring brethren. It was through the unfaltering loyalty of one that help was to come to many.

But while this patient courage, inspired by the love of truth or of mankind, had been recognised as noble and heroic before the time of Jesus, it gained a new and central place in the New Testament. And at the same time it recovered something of the spontaneity and gladness which are leading characteristics of the martial spirit, but which hardly appeared in even the highest fortitude of the prophet or the sage. There had been many who faced suffering and death calmly for the sake

1 Cf. the identification of the two in Plato, Apol. 28, and the contrast in the Gorgias between the boastful, overbearing courage represented by Callicles, with his contempt for those slavish natures who "praise temperance and justice out of cowardice," and the quiet fortitude of Socrates, who holds that suffering and death are no real evils in comparison with the evil of doing injustice. (Cf. 483, 484 A with 511, $512,522$. 
of the best they knew; but it was a new thing when men were summoned to do so gladly, to "rejoice in persecutions," and when they found strength to obey the summons. ${ }^{1}$ Throughout the New Testament there are few subjects of more frequent exhortation than this; indeed, it may be said that the duty of constancy and cheerfulness under trial occupied a place in the thought of the Early Church second only to that of love and goodwill. ${ }^{2}$

The harmony and balance of both these groups of virtue is most perfectly exemplified in the life of Jesus. The writer of the Epistle to the Hebrews rightly considered that no appeal against faint-heartedness could be so effective as the appeal to "consider him that hath endured such gainsaying of sinners." 3 In the story of His life, wholly given to the service of others, but passed amid the constant misunderstanding of His friends and the ever-deepening hatred of those who should have been the first to accept His message, men of every age may behold that highest form of courage which pursues the appointed path, even when unsupported by any human sympathy. 4

The full impressiveness of that example will only

1 Matt. v. 12 ; Rom. v. 3 ; and Sanday and Headlam's note ad loc.; 2 Cor. xii. 10 ; James i. 2 f. ; 1 Peter iv. 13. Cf. Acts xvi. 23-25.

2 It will be sufficient to cite the following passages: Mark xiii. $7 \mathrm{ff}$. and parallels ; John xvi. 33 ; 1 Cor. xvi. 13 ; Eph. vi. 10 ff. ; 2 Tim. i. 8, ii. 1 , 3 ; Heb. x. 23 ; James v. 11 ; 1 Pet. iii. 14 ; Rev. ii. 10.

3 Heb. xii. 3 (I quote throughout from the Revised Version).

4 A writer in the Hibbert Journal (Oct. 1908, p. 22) has reported a conversation on the subject of the Christian religion with one of the leading Chinese statesmen of the reforming school, who said that the deepest impression made on his mind by a study of the Gospels was that of the courage of Jesus. This testimony has exceptional weight as coming from an eminent man who approached the New Testament narrative with an entirely fresh and unbiassed mind. 
be felt when it is borne in mind that such perseverance in the face of misunderstanding and calumny must have been harder for Jesus than it is for those men of sterner nature whose courage is untempered by sympathy. But in truth, just because the perfect balance of contrasted virtues is a noble thing, it is also difficult of attainment. Throughout all the instances which we have to consider, it will be found that the very bent and trend of nature which make a certain virtue easy render its contrary and complement more than ordinarily difficult. To the man of ardent and generous impulse prudence and forethought are difficult, just as charity in judgment is to one with a strong natural sense of justice. And so it is with gentleness and courage.

But it is just this union which is so strikingly exemplified in the Gospel story. In the moments of severest personal danger or conflict, Jesus is never represented as self-absorbed, but always as ready to sympathise both with the joys and the sorrows of those about Him. On His last journey to Jerusalem, $\mathrm{He}$ has leisure and detachment to receive the children gladly $;^{1}$ and in the account of His last days in the Third and Fourth Gospels we may recognise in more than one saying that courage which can forget personal danger in the concern and thought for others- "I told you that I am he: if therefore ye seek me, let these go their way." "Daughters of Jerusalem, weep not for me, but weep for yourselves, and for your children." 2

It is recorded in the Book of Acts that after the death of Jesus the "unlearned and ignorant men," to whom He left the carrying on of His work, compelled the

1 Mark x. 13.

2 John xviii. 8 ; Luke xxiii. 28 . Cf. John xix. 26. 
wonder of the rulers and proved their connection with Him by their boldness. ${ }^{1}$ This tradition of courage long continued in the Church; and passages which at once come into memory in this connection are the long list given by St Paul of sufferings endured for the sake of the Gospel, and the stirring roll-call of the heroes of Israel by whose memory the writer of the Epistle to the Hebrews exhorts to constancy and patience ; ${ }^{2}$ while the Book of Revelation, like other apocalyptic writings, is one sustained call to the same virtues-a call which was nobly answered by the Early Church.

The question may now perhaps arise whether there is any real bond, any organic connection, between two virtues which at first sight seem so different as courage and gentleness; but the answer lies near at hand. It is found as soon as we consider that both share the same altruistic character, and both are inspired by the motive of service. The Christian spirit of love, with its ready assumption of responsibility for the welfare of others, shows itself not only in the avoidance of every form of injury and the doing of positive acts of kindness, but also in resistance to the fear of pain. Cowardice may cause others to suffer not less than cruelty. No man can do any great service to the world without cost to himself: if he would save others, he cannot save himself $;^{3}$ and so the principle of both courage and gentleness is seen to be the will to serve. We saw that in the Republic Plato taught that both virtues were necessary for the true guardian, for only by showing both in turn could he give complete protection and do full service to those who depended on him for help

1 Acts iv. 13 ; cf. 19 ff. $\quad 22$ Cor. xi. 23 ff. ; Heb. xi. 32 ff. 3 Mark xv. 31. 
and safety. And so it is also in Christian thought. Or we may set the question in a different light by saying that in the New Testament both virtues are founded on the same high estimate of human life and destiny. Because man is of so great value, courage is needed to hold fast his highest good; but it is also a duty to show kindness to the least and weakest member of the race. Christ's exhortation to courage in confession is strengthened by the assertion that the destiny of His followers is of high moment; just as the duty of considerateness is enforced by the proclamation that even the small and weak are of value to God. ${ }^{1}$

\section{(2) Earnestness and Equanimity.}

Following the same contrast between the active and the passive elements in human nature, we may now look on the harmony of opposites which is shown by the developed Christian character from a somewhat different point of view, but one which is of great importance for Christian Ethics. Much might be said regarding the effect of Christianity in fusing different emotions, and in combining in itself at once the darkest and the brightest judgments on the world and the history of man. It is significant that it has been described at different times as the Religion of Joy and the Religion of Sorrow; and Jesus Himself admitted that there was room in the Kingdom of God for men who displayed both types of character. When the Jews of His day contrasted His own joyful and natural attitude to life with the severity of John the Baptist,

1 Cf. Matt. x. 26-33 with xviii. 6, 10. (Mark ix. 42.) Cf. infra, Ch. III. 
and found fault with both, $\mathrm{He}$ attacked their narrowness of view, and proclaimed that both elements had a necessary place in the life and experience of His kingdom. For, as He said, "wisdom is justified of all her children." 1

But it will be best to consider two qualities which are more clearly of the nature of duties than joy and sorrow. In facing the problems of the world the Christian is encouraged in the New Testament, both by example and admonition, to maintain a double attitude, and is directed to a double type of virtue. On the one hand there is impressed upon him the duty of strenuousness in service, on the other that of confidence and quiet trust; and this contrast is expressed by Paul in the metaphor of a soldier's equipment, which includes both offensive and defensive armour, "the sword of the spirit" and "the shield of faith." ${ }^{2}$ Here the antithesis is essentially that expressed by the heading of this section-Earnestness and Equanimity.

Under the former head there fall the exhortations to courage and endurance already referred to; and also such passages as the parable of the Talents, ${ }^{3}$ in which the coming of the Kingdom of God is represented as relatively distant, and the leading thought is that of the strenuous use of every faculty in the interest of His cause until it draws nigh. To these must be added the many sayings which bear on the cost of service, such as

${ }^{1}$ Luke vii. 35. $\pi \alpha{ }^{\prime} \nu \omega \nu$, standing at the end of the sentence, is emphatic.

${ }^{2}$ Eph. vi. $16 \mathrm{f}$. There is a similar reference to offensive and defensive weapons in 2 Cor. vi. 7 , "by the armour of righteousness on the right hand and on the left."

s Matt. xxv. $14 \mathrm{ff}$. Cf. Luke xix. $12 \mathrm{ff}$. 
the warning against looking back when once the hand has been set to the plough. ${ }^{1}$ Nor is it needful to multiply instances from the Epistles to show how strenuous a thing the Christian life was to those who first practised it. Paul's statements are typical of their attitude- "I therefore so run, as not uncertainly; so fight $I$, as not beating the air"; "seeing we have this ministry, we faint not"; "one thing I do, . . . I press on toward the goal." 2 To the same end are directed the exhortations of the Epistle to the Hebrews, that want of earnestness be not allowed to result in "drifting away," and that Christians maintain an unwavering confession and "provoke one another to love and good works." 3 The spirit of the New Testament is a spirit of energetic, fervent, unwearied activity; the hours of daylight are precious because the night is at hand."

But not less conspicuous than the energy of the Christian ideal is its spirit of calm and repose. From the story of Moses' command to the Israelites-"Fear not, stand still, and see the salvation of the Lord " ${ }_{5}$ - on through the course of Old Testament history, the duty emphasised is often less that of active endeavour than that of trustful and patient waiting for the sure working out of the divine ends. The keynote of the teaching and policy of Isaiah in face of the imminent Assyrian invasion may be found in the words, "in returning and rest shall ye be saved; in quietness and confidence shall be your strength" $; 6$ just as that of the apocalyptic

1 Luke ix. 57-62.

21 Cor. ix. 26 ; 2 Cor. iv. 1 ; Phil. iii. 13 f.

3 Heb. ii. 1 ; x. 23 f.

"John ix. 4 (R. V., "We must work the works," \&c) ; Rom. xii. 11 ; xiii. 13 ; Gal. vi. 9 f.
5 Ex. xiv. 13.
6 Is. $\mathrm{xxx} .15$. 
literature which arose when the earthly kingdom passed away from Israel lies in the blessing upon him that waiteth. ${ }^{1}$

This emphasis on the thought of salvation as not merely to be worked for, but to be waited for, is one of the points in which the New Testament was in contact with Jewish apocalyptic thought. But the duty of confidence and hope in the religious life was placed by Jesus on a much wider foundation than the merely apocalyptic. He went back rather to that trust in the divine protection and rule which the greatest of the psalmists and prophets had held, before any definite conception of the establishment of the Messianic Kingdom had been formulated. In instructing $\mathrm{His}$ disciples, $\mathrm{He}$ applied the same principle to the material needs and cares of ordinary life in the present as to the great persecutions and trials of the future. In neither case was anxiety encouraged, or indeed allowed. ${ }^{2}$ This, then, is the complementary duty to that of earnest endeavour - the complementary feeling to that of personal responsibility for the progress of the Kingdom. The two attitudes differ widely: they belong naturally to very divergent types of character; and yet they must in some way be combined by every one who would obey the precept, "Strive," or agonise, " to enter in by the narrow door," and at the same time live in the spirit of the saying, "Fear not, little flock; for it is your Father's good pleasure to give you the kingdom." 3 In the teaching of Paul also there is the same conjunction of

1 Dan. xii. 12.

2 Cf. Matt. vi. 25-34 with x. 19, $26 \mathrm{ff}$.

3 Luke xiii. 24 ; xii. 32 . This contrast will be more fully dealt with when we come to discuss the different aspects of the Kingdom of God. (Infra, Ch. VII.) 
emphasis on the need of diligence and of confidence. He repeats the admonition, "in nothing be anxious," ${ }^{1}$ and it is by his example that Newman illustrates, in his sermon on "Equanimity," the union of diverse virtues which we are considering as characteristic of Christian Ethics. ${ }^{2}$

There is an interesting parallel to the teaching of the New Testament in this respect in the Discourses of Epictetus. He says that "it seems to many to be a paradox" of the philosophers that confidence (or courage) and caution should both be displayed by the good man; but he meets the objection by seeking to show that both virtues are necessary, and that they are not inconsistent. This he does by applying the distinction, which played so important a part in Stoic thought, between the things that are and those that are not in the power of the human will. "Where things are not dependent on the will, there you should employ confidence, but where they are dependent on the will, there you should employ caution," or care. The discourse concludes as follows: "Do you labour at thinking about death, chains, the rack, exile; and do all things with confidence and reliance on him who has called you to these sufferings, who has judged you worthy of the place in which being stationed you will show what things the rational governing power can do when it takes its stand against the forces which are not within the power of our will. And thus this paradox will no longer appear either impossible or a paradox, that a man ought to be at the same time cautious and courageous: courageous towards the things which do not depend on the will,

1 Phil. iv. 6.

2 See Note B, p. 394, "Newman on the Paradox of Christian Character." 
and cautious in the things which are within the power of the will." 1

Have we then in this Stoic distinction the key to the New Testament paradox? Does this double duty rest on an absolute division between inward and outward? We may at once admit that the teaching of Epictetus has here a close affinity to that of Jesus. In both the classes of sayings referred to above $\mathrm{He}$ recalls $\mathrm{His}$ disciples' thoughts from anxiety regarding the course of events which lie beyond their control, and urges them to concentrate on the things which are actually in their power-" Seek first the kingdom of God and His righteousness; and all these things shall be added unto you." 2 A clear line of division seems here to be drawn between those opportunities of definite and personal service which come as an immediate call to the will, and the external chances of life which, in the view of Jesus, should prove the occasion not of foreboding but of equanimity and trust.

But it has often been pointed out that the Stoic division of all things into those absolutely within, and those absolutely beyond, the power of the will is based on an abstraction, useful for purposes of moral appeal, but impossible to apply universally as a strict philosophical principle. There is no such absolute dichotomy in fact between man's will and his surroundings. Thus the Stoic solution of the paradox has a false simplicity from the standpoint of Christian Ethics. In particular, it is hard to believe that Jesus would have confined the divine action, with the correlative duty of trust, to the outward

1 Disc., Bk. II. ch. 1 (tr. Long). The Fifth Discourse in the same book, "How Magnanimity is consistent with Care," is to the same effect.

${ }^{2}$ Matt. vi. 33 (A.V.). 
sphere, or denied that the inner life of man was also the sphere of God's work. In the Fourth Gospel the contrary view is very clearly set forth, ${ }^{1}$ and it is constantly present in the apostolic teaching. And in truth the problem of finding an adequate philosophical basis for the reconciliation of the two duties is too complex to be solved by so simple a distinction as that of Epictetus. It carries us far into the ultimate question of philosophy; for the duty of earnestness rests on the fact of human freedom, and on man's sense that the moral progress of the world depends in great measure upon his own efforts; while that of equanimity is based on the belief in a Divine Purpose controlling all things and leading men onwards towards its great ends, whether they follow willingly or rebel. ${ }^{2}$ Thus the practical paradox is closely connected with the speculative antinomy; and the attempt to discuss the latter fully would lead us too far from our present purpose. But a practical answer may at once be given. For the two points of view have in fact been combined, and their union has led to the development of the highest degree of moral energy.

This union is to be found in a bold passage, in which Paul links together the two thoughts as if they were inseparable in his experience: "Work out

1 Especially John iii. 7 f.; xv. 5. Cf. i. 13.

2 Cf. the noble prayer of Cleanthes, quoted by Epictetus (Ench., lii.), and finely translated by Myers-

"Lead, lead Cleanthes, Zeus and holy Fate,

Where'er ye place my post, to serve or wait :

Willing I follow; were it not my will,

A baffled rebel, I must follow still."

Stoicism did after all, like Christianity, acknowledge both human responsibility and divine government. 
your own salvation with fear and trembling; for it is God which worketh in you both to will and to work, for His good pleasure." 1 Here the two duties are evidently looked on, not as irreconcilable, but as complementary, or rather as involving one another. It is not indeed easy to rise to the point of view suggested by this passage; but even those in whose thought the two aspects alternate rather than coalesce may see the defect of either taken alone. One mark of the greatness of Christian Ethics is that it has not neglected either for the sake of simplification or philosophical consistency. That the quietist attitude of trust taken by itself is dangerous needs no proof. "Quietness," says Newman in the sermon already referred to, "is a grace, not in itself, only when it is grafted on the stem of faith, zeal, self-abasement, and diligence." 2 Men need the belief that their strivings count for something to spur them to the greatest effort. And we, more than the early Christians, are forced to believe that moral and spiritual progress depends in large measure on human effort; for not otherwise can we explain the failure of historical Christianity to fulfil its early ideals and to achieve its promise of a regenerated world.

But the other side, though perhaps less obvious, is not less important. If men are to work with the fullest energy and success, it is not enough that they should feel their own responsibility for the attainment of the desired result. The sense of responsibility alone may oppress and retard, and a constant anxiety for the wider issues of the conflict can hardly fail to do so.

1 Phil. ii. 12 f.

2 Parochial and Plain Sermons, Vol. V. p. 71. 
The force and decision lent by Calvinism to the Puritan character have been remarked on as an anomaly; but it was in truth the very sense of an all-powerful purpose directing the forces of the world which gave the Puritans such vigour in doing their several portions of the great work, just as the absence of such a belief in many of the best men of our day divides their energy and lessens the effectiveness of their endeavour. It is where the two points of view, held together, lead to the union of strenuousness and calm that the highest and most effective effort becomes possible. Thus the Christian life has been well defined as "a trustful activity." 1 Thus also, in the poem entitled "Heroes," Browning truly describes the access of fresh power to fulfil the nearest duty, which comes to those who believe that the guiding of the whole battle for the Good is in stronger hands :-

" How of the field's fortune? - That concerned our leader.

Led, we struck our stroke, nor cared for doings left or right ;

Each as on his own head, failer or succeeder,

Lay the blame or lit the praise.-No care for cowards : Fight!"

(3) Severity and Mercy.

But the Christian character necessarily shows its especial stamp not only in action, but also in the standard which it applies to the deeds of others. Here again we meet with a union of apparently opposite characteristics in the teaching and attitude of Jesus-a combination of mercy, gentleness, readiness to forgive, with severity and moral stringency. As in the first

1 Haering, The Ethics of the Christian Life (Eng. tr.), p. 141. Cf. infra, p. 383. 
example, the former element is so familiar and so universally recognised that it scarcely needs illustration. But it is important to give due emphasis to the other, sterner side; for mercy gains an entirely new character when it is associated with a burning anger against selfishness and $\sin ^{1}$

This element of severity may be felt both in the acts and the sayings of Jesus. It stands forth in the account of His cleansing the Temple courts and driving out of those who trafficked there for the sake of gain. Of this incident it has been truly said that "anger is often selfish, but may also be one of the purest and most costly forms of self-sacrifice. The disciples, who saw the exhaustion to which it put our Lord, said of Him, the zeal of Thine House hath eaten me up." 2 The same severity appears in such sayings as that regarding the sin against the Holy Spirit. ${ }^{3}$ Again, Jesus never disguised the fact that His mission would not wholly nor at once tend to peace: "Think not that I came to send peace on the earth: I came not to send peace, but a sword." 4 He never was willing to secure an easy but delusive peace by silence regarding wrongdoing $;^{5}$ and he attacked the self-righteousness, the pedantry, the exclusiveness and narrowness of sympathy, which marked the religious class among the Jews, in language of wellnigh unmeasured indignation and scorn; so that history has almost forgotten the virtues of the Pharisees, and their name is now

1 Cf. Note C, p. 395, "The Union of Severity with Mercy in the Character of Jesus."

${ }^{2}$ George Adam Smith, Jerusalem, ii. 343. John ii. 17; Mark xi. $15 \mathrm{ff}$.

3 Mark iii. 29.

4 Matt. x. 34.

5 Cf. Jer. vi. 14 ; viii. 11. 
used only to denote those faults which Jesus saw and scourged in them.

But His call to repentance was not addressed to the Pharisees alone. John the Baptist had reproved the sins of all classes, and summoned all alike to repentance, and it is recorded that the ministry of Jesus began with a similar summons. ${ }^{1}$ As His ministry went on, it became clear that there were certain sins which more especially roused Him to anger. Such were yindictiveness and the absence of mercy. The saying, "If ye forgive not men their trespasses, neither will your Father forgive your trespasses," occurs both as a comment on the petition for forgiveness in the Lord's Prayer and as the moral of the Parable of the Unforgiving Servant.2 Closely related to this is the condemnation of those who place hindrances in the way of the weak, and thus show a want of consideration for the good of others. "Woe to that man by whom the offence cometh!" "Woe unto you, scribes and Pharisees, . . . for ye enter not in yourselves, neither suffer ye them that are entering in to enter." 3 No judgment could in Christ's view be too severe for those who so acted.

But if His sternest condemnation fell on those who sinned against others, $\mathrm{He}$ also applied a severe standard to those who hesitated to renounce those things which stood in the way of their spiritual life. Thus beside mercilessness, and the causing of offence to the weak, we must place hesitation as a quality which called

1 Mark i. 4, 14 ff. Cf. Luke iii. 8 ff. and xiii. 3, 5.

2 Matt. vi. 15 ; xviii. 35 . Cf. 2 Sam. xii. 6, "Because he had no pity."

3 Matt. xviii. 7 (A.V.); xxiii. 13. 
forth the "element of the inexorable" in the character of Jesus. It appears in the stringent tests which $\mathrm{He}$ applied to those who professed willingness to follow Him, but pled for delay. It appears also in the warnings that the time in which repentance was possible had strict limits, and that beyond these lay the danger of utter loss. ${ }^{2}$

In other passages we find the two characteristics of gentleness and severity shown at the same time; and this suggests that they were never far apart in the thought and actions of Jesus. The great attack on the sins of the scribes and Pharisees, the rulers of the Jewish nation, which introduces the especially eschatological section of the Gospel of Matthew, closes with the lament over Jerusalem. ${ }^{3}$ This passage of unmatched tenderness and pathos, following the bitter invective of the rest of the chapter, shows that even in His anger Jesus was moved by a deep love for the Holy City, and that His grief over her apostasy was due to His sense of the greatness at once of the part that she had played in His country's history, and of the destiny that she was failing to fulfil.

Again, in Mark's account of the question addressed to Jesus by the rich young ruler, it is said that "Jesus, looking upon him, loved him." " This phrase shows that the searching demand which Jesus proceeded to make of him - a demand to which he proved unable to respond-was prompted not by mere severity, but by a love which saw and welcomed the latent powers of his nature, and yet saw also that only by a decisive act of renunciation could these powers be brought into

1 Luke ix. 57-62.

${ }^{3}$ Matt. xxiii. 37 ff.
2 Luke xiii. 9 ; Matt. xxv. 1-13.

4 Mark x. 21. 
full exercise. Jesus required a strong proof of devotion from a character which $\mathrm{He}$ recognised as strong and noble - hence the apparent severity of His demand. Nor was this an isolated case; for throughout His life we feel that it was His high estimate of the capacities and the worth of man which made Him set so high a standard before His followers, and which prevented His treating as small or negligible offences against Humanity, whether they took the form of shrinking from personal duty or of indifference to the welfare of others. In this respect the character of Jesus is best understood when $\mathrm{He}$ is recognised as the great Example of all those who have "hated wickedness that hinders loving."

In this respect also one might compare Christianity with Stoicism. It is true that in the development of the latter both the elements referred to played an important part; but they were never held in the same balance and union as by Jesus. The Ideal of the Sage in its earlier form did indeed set a high estimate on the capacity for virtue of human nature, but at the expense of gentleness and pity. These qualities found an increasing recognition among the later Stoics, and Marcus Aurelius showed them in a very high degree. But in his case their development was accompanied by the decline of the old robust faith in the worth of ordinary humanity; and at times he found an argument against anger in the very poverty and insignificance of the natures among whom he moved. Is it worth while, he seems to ask, to expect much of such men or to be perturbed or distressed when they act basely ? ${ }^{1}$ Now, it may well be that even the 1 IV. 48 ; V. 10, 33 ; VI. 15 ; VIII. 21. 
virtue of pity is won at too dear a price, if it rests upon the denial of man's responsibility and capacity for good. There is even a danger in its development to the exclusion of that strictness of moral judgment which comes from a strong belief in the universal and categorical nature of the claim of the good upon the human will. "There is reason, indeed, to fear," as the late $\mathrm{Mr}$ F. W. H. Myers said in his essay on Marcus Aurelius, "that Marcus loved his enemies too well; that he was too much given to blessing those that cursed him. It is to him, rather than to any Christian potentate, that we must look for an example of the dangers of applying the gospel maxims too unreservedly to the business of the turbid world." 1 But to this remark of Myers' we should add that the "gospel maxims" referred to do not represent the whole of Christian teaching, but that they must be taken along with those other passages which thrill with hatred of sin, and condemn all who place hindrances in the way of the advancing Kingdom of God.

Thus it becomes clear that it is contrary to the spirit of Christian Ethics to base the duty of pity and forgiveness on a deterministic denial of man's responsibility or power for good; just as we have seen that the passive quietism of the fatalist is alien from that spirit. Jesus clearly distinguished between more and less conscious forms of sin-as the strict determinist can hardly do,treating its deliberateness as an essential factor in $\mathrm{His}$ judgment of its guilt. ${ }^{2}$ Nor did he argue from the weakness and valuelessness of human nature to the

1 Essays, Classical, p. 199.

2 Luke xii. 47. Cf. John ix. 41. For the contrasted view, see Marcus Aurelius, VII. 22 ; IX. 42. 
need of forgiveness and forbearance. This duty also he based on a firm belief in the worth of man. It was not mere pity, but even more a great hopefulness, which supported His exercise of mercy and His exhortations to practise it. There was always some ground or preparation for forgiveness - "some good thing towards the Lord," ${ }^{1}$ which others might not perceive, but which was visible to His sympathy and insight. Whenever He saw any movement of faith or love, any desire for higher things, His mercy was shown in readiness to meet and encourage the effort after goodness. ${ }^{2}$ Thus the Christian virtue of mercy is neither weak nor sentimental. It is practical and energising, involving a lofty view of human nature and destiny and ever directed to its realisation. But on this very account it has that strong and bracing quality, which marks the judgment of those whose high estimate of the worth of man will not allow them to regard as of little moment those actions which degrade him, or prevent his capacity for goodness from reaching its true development.

\section{(4) Other instances.}

The same principle might be followed into other regions of character and conduct; but it will be sufficient to mention two or three further instances. The Christian attitude to the past and the future is one that combines Reverence and Independence. In the life of Jesus these qualities were united in a remarkable degree. His mission was grounded on a deep loyalty to the past. Not only did He know the Scrip-

11 Kings xiv. 13.
2 Luke vii. 47, 50. Cf. Matt. v 6. 
tures of the Old Testament intimately, but He regularly performed the recognised religious duties of His day, and in certain instances enjoined conformity to the ceremonial law. ${ }^{1}$ His aim was not to overturn the Jewish religion, but to complete and perfect it by leading the nation to understand and to fulfil its deeper meaning and purpose. ${ }^{2}$ But along with His reverence for the history of His people and His appreciation for their past, there was much in His message that was new, and $\mathrm{He}$ claimed the right to amend and even abrogate all that contradicted or fell short of it. Nor would $\mathrm{He}$ allow Jewish tradition to check Him in carrying out the work $\mathrm{He}$ had undertaken. ${ }^{3}$ His independence and refusal to be fettered by the past were most clearly expressed in the metaphor of the new wine and the old wine-skins; but even here, if we accept the sequence of this discourse as given in the Third Gospel, we see that $\mathrm{He}$ did not let this lesson stand alone, but proceeded to state the complementary truth in the words, "No man having drunk old wine desireth new : for he saith, the old is good." 4

Now, it is doubtless true that the attitude of sovereignty over all former statements of truth which Jesus assumed cannot be reproduced in the Christian life; for the New Testament, and especially the Gospels, have a normative value for the Christian such as the Old Testament did not possess for Christ. Yet there remains a wide sphere in which the Christian is called upon to exercise both these virtues, to be loyal to the

${ }^{1}$ Mark i. 39,44 ; vi. 2 ; xiv. 12 ff.; Matt. ix. 35 ; xxiii. 3 ; Luke iv. $16 \mathrm{ff}$.

2 Matt. v. $17 \mathrm{ff}$. Cf. Luke x. $25 \mathrm{ff}$.

3 Matt. v. 21 ff. 27 ff. ; Mark ii. 23 ff. ; x. 2 ff. Also Mark vii. 1-23.

Luke v. 37-39. Cf. Mark ii. 18-22. 
past and yet to be independent and willing to strike out new paths both in thought and action. And the assurance that they may be brought into harmony is to be found in that strong sense of continuity between the past, the present, and the future which Jesus, in spite of all that was revolutionary in His mission, never lost. ${ }^{1}$ The same conflict goes on in varying forms, and an appreciation of and sympathy with the past is one of the strongest incentives to faithfulness in the present. ${ }^{2}$ In Christian experience there is a freshness as of that which is wholly new, yet at the same time the familiarity of a truth long known and loved; for the "new commandment" is one that has been of old, even "from the beginning." 3

Other examples of this harmony of opposites might be found in the union of personal humility with the sense of a great and dignified vocation, which has been remarked on as characteristic of Christianity; or in the union of veracity with considerateness which is pointed to in Paul's exhortation to "speak the truth in love "; 4 or again in the contrasted sayings of Jesus which proclaim the duty of combining reticence with outspoken courage. ${ }^{5}$ But enough has been said to in-

1 Cf. E. Caird, Lay Sermons and Addresses, pp. 161 f.

2 Matt. v. 12 ("So persecuted they the prophets which were before you ").

31 John ii. 7 f. Cf. John xiii. 34.

4 Eph. iv. 15. Cf. Prof. Robert Mackintosh's little book on Christian Ethics, p. 133.

5 The saying, "Give not that which is holy unto the dogs" (Matt. vii. 6) may be contrasted with "What ye hear in the ear, proclaim upon the housetops" (x. 27); or "Take heed that ye do not your righteousness before men" (vi. 1) with "Let your light so shine before men, that they may see your good works" (v. 16). Cf. Stalker, The Ethic of Jesus, pp. $73 \mathrm{ff}$. 
dicate that this is one main characteristic of the Christian character, and that any attempt to treat Christian Ethics as dealing with one set of virtues alone must fail of adequacy and completeness. If Christianity is the greatest school of the gentler virtues - patience, forbearance, resignation, pity, gentlenessit does not therefore neglect to develop the other side of human character; for it exalts the virtues of constancy, strenuousness, courage, and sternly condemns all that is base and mean. Nor does it fear the excess of any one virtue, provided only that it is balanced by the presence of that which forms its complement. Thus the Christian character is formed by a process of addition rather than of limitation, and cannot be readily or accurately described in terms of the doctrine of virtue as a Mean. It is too varied and too positive to find expression in such a scheme. Thus it is rather to the Hegelian idea of a union of contraries in a higher synthesis, which, as we have seen, goes back in its ethical form to Plato, that we must look for an adequate expression of the form of Christian virtue. So we are justified in defining Christian Ethics as essentially synthetic. There is something which necessarily transcends the limits of the Aristotelian formula in its ideal, if that ideal is truly described by Newman when he speaks of it as "the paradox which scripture enjoins." 1

1 See Note B, p. 394. This point of view has been vigorously stated by Mr Chesterton: "Christianity is a superhuman paradox whereby two opposite passions may blaze beside each other. The one explanation of the Gospel language that does explain it, is that it is the survey of one who from some supernatural height beholds some more startling synthesis." Orthodoxy, p. 270 ; cf. Ch. VI. passim. 


\section{III.}

Are we, then, forced to conclude, in the face of all common preconceptions in regard to Hellenism and Hebraism, that Christian Ethics is essentially positive, and Greek Ethics, as formulated in the Doctrine of the Mean, essentially negative? This would indeed be an inaccurate description of the Aristotelian point of view ${ }^{1}$ -save in so far as omnis determinatio est negatio. Undoubtedly "determination," in its original sense, plays so large a part in the typically Greek idea of the formation of character that the whole process may be conceived as one of negation. But the Greek standpoint rather looks on ethical progress as directed towards and conditioned by an ideal of humanity which is perfectly definite, and which cannot be described as ascetic. The difference between Greek and Christian ethical thought is rather that, while both aim at a positive result, this result is in the former case essentially limited and lacks the wide sweep of the Christian ideal. This may be traced to a difference of attitude

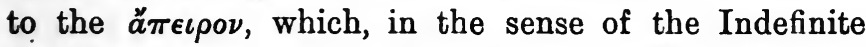
and Formless, represented the antithesis of all Hellenic ideals; but which, as the Infinite, has been in Christian thought the expression of the immeasurable possibilities and demands of the moral life. To this difference of the result aimed at there corresponds a difference of method, the element of restriction necessarily taking a more prominent place in the Greek system; and both these distinctions may be illustrated by the consideration of three passages from the Nicomachean Ethics.

1 Cf. Note A, p. 390. 
(1) In the first Aristotle draws a practical conclusion from his theory of virtue: "As it is difficult then to hit the mean exactly, we must take the second best course, as the saying is, and choose the lesser of two evils, and this we shall best do in the way that we have described-i.e., by steering clear of the evil which is further from the mean. We must observe also the things to which we are ourselves particularly prone, as different natures have different inclinations, and we may ascertain what these are by a consideration of our feelings of pleasure and pain. And then we must drag ourselves in the direction opposite to them; for it is by removing ourselves as far as possible from what is wrong that we shall arrive at the mean, as we do when we pull a crooked stick straight. But in all cases we must especially be on our guard against what is pleasant and against pleasure, as we are not impartial judges of pleasure." 1

Now, in part the injunctions of this passage are based on the common ground of all practical morality - that men ought to avoid things and places which they have found to be dangerous to virtue, and that where the danger is extreme the measures taken against it must be extreme also. There is probably no system of morality which does not admit the negative element of avoidance in these cases; and this duty is expressed in the New Testament with a vehemence of appeal which contrasts with the restraint of the philosopher - "If thy hand or thy foot causeth thee to stumble, cut it off and cast it from thee: it is good for thee to enter into life maimed or halt, rather than

${ }^{1}$ Eth. Nic., II., 1109 a 34 ff. (tr. Welldon, p. 56). The italics are mine. 
having two hands or two feet to be cast into the eternal fire." 1

But there is this difference, that while the maxim and the accompanying illustration of the bent stick seem to be applied by Aristotle to the conduct of life generally, the command to cut off an offending member is given as exceptional in the New Testament. The general rule is undoubtedly the positive one of Love. The Gospels and Epistles agree in this; and Paul expresses the principle of the new life in the words, "Walk by the Spirit, and ye shall not fulfil the lust of the flesh." 2 Thus while the Greek pursuit of virtue is marked by a certain timidity and self-consciousness, which comes out in the idea that "it is by removing ourselves as far as possible from what is wrong that we shall arrive," the morality of the New Testament is marked by a great freedom and spontaneity. It rests on the principle expressed in Chalmers' famous phrase- " the expulsive power of a new affection "; ${ }^{3}$ and while it recognises that every character needs to be developed in some directions and repressed in others in order to attain to completeness and harmony, the chief stress is laid on the former need. For it is not by contemplating the defect that is to be eradicated so much as the virtue that is to be strengthened that a man can attain to this harmony; and the mere removal of faults may be worse than useless if a positive impulse towards goodness do not enter into their place. 4 The New Testament urges men to direct their thoughts, neither complac-

1 Matt. xviii. 8 (Mark ix. 43 ff.). Cf. 1 Cor. ix. 27, Gal. v. 24, Col. iii. 5, and the petition, "Lead us not into temptation" (Matt. vi. 13, A. V.).

2 Gal. v. 16.

3 Commercial Discourses, Disc. ix.

Matt. xii. $43 \mathrm{ff}$. 
ently to their own dignity or merits, ${ }^{1}$ nor anxiously to the pleasures which may seduce them, but to an ideal above themselves which remains steadfast and fixed. ${ }^{2}$ There is a closer analogy to Christian thought in this respect in the passages in which Plato speaks of the secret of virtue as resting in a steady vision of the beauty and truth of the eternal world. ${ }^{3}$

(2) The second passage is that in which Aristotle concludes his definition of the Good for Man with the

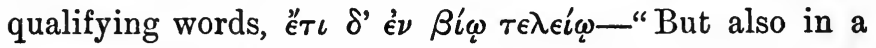
complete life." 4 The thought is that, unless a life is long enough to develop into completeness and allow of the full and unhampered exercise of all human powers,

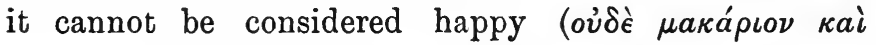

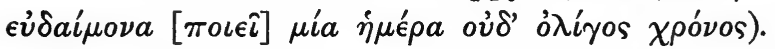

Now, when it is argued that man cannot completely attain the ethical end in a shortened life, it is clearly implied that it can be attained in a life of full or normal duration. The ideal of virtue is fashioned to the measure of the ordinary span of human life, on the analogy of full development in the region of organic physical life, or of the completeness with which a painting or a statue may express the idea in the artist's mind. This point of view harmonises with the Doctrine of the Mean. For if the perfection of human character

${ }^{1}$ As in Aristotle's description of the $\mu \epsilon \gamma \alpha \lambda \delta \psi v \chi o s$, Eth. Nic., Bk. IV., c. iii. Contrast the description of the Christian ideal in 1 Cor. xiii. $4 \mathrm{f}$.

22 Cor. iii. 18 ; Phil. iv. 8 ; Heb. xii. 2.

3 Rep., 490, 517, 521 ; Phaedrus, $248 \mathrm{ff}$.

${ }^{4}$ Eth. Nic., I., 1098 a 18 . It is clear that this contrast also would need to be modified if Plato instead of Aristotle were taken as the representative moralist of Greece. 
consist in the avoidance of excess, and the attainment of a due balance and harmony of powers, both in body and mind-then the lifetime of a man, if it be well employed, may prove sufficient for such perfection to be reached. But if the clue to the nature of progress be looked for in the full and unfettered exercise of each several virtue, if there be no fear of any one being overdeveloped, but only of its being developed to the prejudice of others, and so if the perfect symmetry of character be sought not by limitation, but by the addition of virtue to virtue,-then there is no limit to the greatness of the task, and an endless horizon opens. ${ }^{1}$

It is this positive view of the making of character as a process of building up which marks the thought of the New Testament; and there is in it no apprehension lest the different virtues should be carried too far, but rather a sense of the difficulty of complete attainment in any one direction, much more in all. Thus if Aristotle's standard of a complete life as one in which complete virtue can be acquired be applied to the ideal of Christian character, we are led straight to Kant's argument for immortality - that an infinite task requires an endless time for its fulfilment.

(3) This conclusion may be strengthened by the consideration of another passage in which Aristotle, following the Pythagoreans, connects good and evil with the ideas of the Limit and the Unlimited :-

"There are many different ways of going wrong; for evil is in its nature infinite, to use the Pythagorean figure, but good is finite. But there is only one possible

${ }^{1}$ Luke xrii. 10. Cf. Phil. iii. $12 ; 2$ Pet. i. 5 ff. 


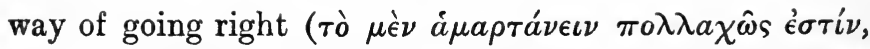

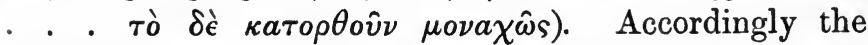
former is easy and the latter difficult; it is easy to miss the mark, but difficult to hit it. This again is a reason why excess and deficiency are characteristics of vice and the mean state a characteristic of virtue.

'For good is simple, evil manifold !'" I

Here we find the description of virtue by the spatial metaphors of the Limit and the Mean, carried to the logical conclusion that it is a single point in the wide field of possible action. This exactness of determination tends to exclude the recognition of variety in virtue, and thus to narrow the scope of goodness. But the truth is rather that any single virtue has as many subtle varieties as the opposing vice, and offers as wide a scope for the expression of the most delicate shades of individuality. In an important sense there are as many ways of doing a right action as a wrong one; and no misconception is more fatal than the idea that wrong-doing gives free play to individuality, while goodness means the close following of a strictly determined and monotonous path. If growth in virtue be an adding of stone to stone in the edifice of character, then there is no limit to the variety and interest of the life of goodness. For Christian thought, it is vice and not virtue which circumscribes the powers of man and narrows his outlook, while goodness is the enlarging and emancipating power in life. ${ }^{2}$ This contrast underlies the striking words of Dr Rainy, "Sin is in its nature

${ }^{1}$ Eth. Nic., II., 1106 b 28 ff. (tr. Welldon).

${ }^{2}$ John viii. $32-36$; Rom. vi. 17 ff. ; 1 Cor. iii. 22 ; 2 Cor. iii. 17 ; Gal. v. 1, 13. Cf. infra, pp. $343 \mathrm{ff}$. 
limited: you soon come to the end of what can be got out of a sin. But the Christian life is eternal, for God is inexhaustible."

This, then, is the Idea of the Infinite as it appears in Christian Ethics. It is not the boundless "indeterminate" from which the thought of the Greeks recoiled, nor is it the entire negation of Form and Measure. It rather provides the assurance that, though each step on the pathway of moral progress is clearly defined, that path does not lie across a boundless and featureless plain, but leads upwards to ever new interests and new experiences. Nor can there ever come a time when there will be no further need to add virtue to virtue in the upbuilding of character.

Yet in truth perfection, in the sense of a full union and harmony of diverse forms of goodness, is hardly to be looked for in the sphere of the individual character. For this idea of virtue which we have been following out has a wider scope; and the final harmony lies rather in the union of many varied personalities, each with its dominant characteristic, and each bringing some special contribution of talent or virtue to the common wealth of all. It is neither possible nor needful that all should excel in the same virtue, but it is the part of each man to contribute something of his own to the wider harmony; and the same thought may be applied to the different nations and races which together form the great whole of Humanity. ${ }^{1}$ The thinkers of Greece held that men of every rank and office were needed to form a perfect and happy state; and Paul applied the same idea in the sphere of religion by teaching that, only when all Christians

${ }^{1}$ Cf. Bishop Gore's Bampton Lectures, pp. 169 f. 
had brought their various gifts into the common service, could they "attain unto the unity of the faith" and "unto a full-grown man."1 In Sir Thomas Browne's phrase, "Tis well if a perfect Man can be made out of many Men, and, to the perfect Eye of GoD, even out of Mankind." 2 Thus for Christian thought Plato's metaphor of the "royal web" passes into that of the "seamless robe," which is the type of the ideal unity of the Church Universal.

${ }^{1}$ Eph. iv. 13.

${ }^{2}$ Christian Morals, Part I., sect. xxviii. 


\section{CHAPTER II.}

\section{THE VALUE OF THE INDIVIDUAL-CONFLICTING} TENDENCIES.

THus far we have been engaged in considering the positive character of Christian Ethics, and we may now turn to its other great characteristic, that of universality. It hardly needs to be pointed out that when we speak of Christianity as universal, the predicate is by no means used in the abstract logical sense in which the universal is defined in opposition to, or is treated as the negation of, the particular or the individual. Such a conception of universality has no relation to the Christian idea, which consists in the exaltation of the individual man and the assertion that his being is of infinite worth. The universality of Christian Ethics is based wholly on the claim of Christianity to bring a message to all men, and to discover a unique value in each. But while this is its foundation, we shall find at the close of our discussion that we are led beyond the mere isolated individual to the idea of the community in which alone his true life can be fully unfolded. So, while Christian Universalism begins with the individual and with the proclamation of the value of each, it ends with the community and with the ideal of a social life, the life of all. 
Now, this doctrine of the value of the individual from which we set out is so familiar, and has been so often treated as the essence of Christian teaching and as its most original contribution to ethical thought, that it might be felt that little that is new remains to be said, and that a fresh discussion can only traverse ground that has been often fully explored. ${ }^{1}$ But the very importance of the subject makes it needful that the Christian point of view should not only be studied in itself, but that it should be related to other tendencies of thought whether in the past or in the present. There are such tendencies, and they inevitably influence the Christian doctrine, some supporting the claim of infinite value for the individual life, others opposing and negating it. If we devote the present chapter to a survey of the more important among these tendencies-those which exalt and those which depress the individual-we shall be better able in the next chapter to state the doctrine in its positive forms, both philosophical and religious.

I.

Our first task, then, is to glance at certain of the facts and theories which have prepared the way for the acceptance of the Christian estimate of the individual, and which help to make that acceptance possible at the present time. Here we are met by the theory of evolution in one of its aspects. For it has been maintained that the whole course of development, both biological and historical, has tended to just such an exaltation of

1 We have already seen its importance in making possible the moral synthesis of Christian Ethics (supra, pp. 19, 33). 
the individual as Christianity proclaims. Every stage of evolution has been regarded as showing an advance in the prominence of individuals, and in their differentiation and specialisation. More and more they are singled out from the throng and acquire an independent importance; and the successive steps of upward progress are marked by the fact that mere numbers become of less account, and the perfection of single organisms of greater account.

Among the lower types of life the great weapon in the struggle for existence is fecundity; for, other things being equal, the type which reproduces itself most readily and rapidly will survive. And so of this stage in the history of life it may be said that "it was probably on the whole a better arrangement to produce a million and let them take their chance, than to produce one and take special trouble with it." 1 But only in so far as this primitive form of race-preservation was replaced by a method of less diffusion and more individualisation did progress become possible. The higher orders of life could only come into being when Nature began to "produce one" -or at least a small number-at a time, and to "take special trouble with it." For one thing, such a concentration on the forming of individuals of that reproductive energy which had formerly been dispersed in the production of hundreds or thousands, gave for the first time to these individuals plasticity enough to adapt themselves to, and ultimately in the case of Man to control, the most varied environments. This change in the character of the evolutionary process is, it may be said, veiled in metaphor when we speak of Nature

${ }^{1}$ Henry Drummond, The Ascent of Man, p. 348. 
ceasing to work through numbers and fecundity in reproduction, and beginning to "take trouble" with the fashioning of individuals; but whether we personify "Nature" or not, the fact so described cannot escape us. The individual is beginning to emerge from the throng and to acquire an independent significance.

This aspect of evolution is not an unfamiliar one; and the two writers who some years ago brought it vividly home to both sections of the English-speaking worldJohn Fiske and Henry Drummond-both emphasised the importance of two factors in the change from the lower to the higher state of evolution. Of these the first is the limitation of offspring to a number low enough to call out the individualising interest and care of the parent. The other is the lengthening of the period of infancy; and this in turn is significant in two directions, for the parent and for the offspring. As regards the former, the lengthened period during which the new life is a helpless and dependent one makes an ever greater demand on parental care and patience. Affection is strengthened by the very strength and continuance of the call made upon it; and "the cosmic roots of love and self-sacrifice," to borrow Fiske's phrase, have time to strike deep and firm into the soil of the parental nature. But this fact has immense importance for the younger life as well. When a child comes into the world it does not bring with it a fixed character and an all but complete equipment for the battle of life, as do the young of the lower orders. The long period of dependence is also the time of that plasticity and adaptability to which I have already referred: while it lasts education is possible, and character is slowly formed by reaction upon the environment of childhood and youth. 
Indeed in the highest members of the human race this plasticity is retained beyond the period of youth, and the capacity for learning, i.e., for fresh reactions upon environment, only comes to an end with life itself. Nor is it hard to see how closely the possibility of variety in character, of what we commonly refer to as "individuality," is bound up with the extension of the period during which responses to stimuli are still readily variable, and have not hardened into the "secondarily automatic" type.

It is worth while to pause for a moment on this double character of the individualisation which is the mark-or at all events one mark-of the higher stages of evolution. On the one hand (to reverse the order of our previous statement) it implies that individuals vary more notably from a common type. The Law of Continuity may indeed forbid us to suppose that any two members of the same order, however low in the scale of being, can be wholly alike, even though their differences should evade the closest and most exact observation. But it can hardly be denied that, with every advance in the evolutionary process, these differences become more visible and pronounced; and at the higher levels they give a very large part of its interest and variety to life. The individual no longer arouses interest merely as a specimen of his type; he ceases to be describable in merely generic terms, and comes to have a character and idiosyncrasy of his own; and, as Professor Royce has suggestively argued, we may regard the end of the whole process, which lies far before us in the future, as consisting in the transcendence of all merely common and generic characteristics, and in the attainment of a completely distinctive individuality. 
But along with this increase in the variety of character among members of the higher orders, and particularly of the human race-this development of individuality in the objective sense-there is also a more subjective development. Self-consciousness, with all that it involves of distinction from the world and from other selves, begins to awaken; and, what is more closely involved in our present argument, the power of sympathy begins to make it possible to enter into the thoughts and interests of others. We have already seen that an early source of sympathy is found in the love of offspring, the solicitude and care which is called out by the helplessness of those who are too immature to care for themselves; and the very need for this prolonged and unremitting care awakens an interest in its object which is at once stronger and more penetrating than that of an ordinary observer. It is by the quickened observation of this sympathy and interest that individuality is first recognised, as is apparent from the commonly noted fact, that individuality and uniqueness are attributed to the human child by its nearest relatives at a stage in its life-history when to the unsympathetic outsider it appears to be exactly like all other members of its class.

Thus we find that this new element of individuality develops in two directions; or it would perhaps be more accurate to say that two aspects, an outer and an inner, can be observed in it with increasing clearness. Objectively, the individual comes to vary more widely from his fellows; and he thus gains in interest for them, and in the ability to serve the social body in some more or less highly differentiated function. And subjectively, a power is developed of entering into the interests and feelings of others, and of realising that each regards the 
universe from his own point of view and makes his own demands upon it. Before the close of this discussion we shall be able to appreciate the importance for our subject of the second point of view in particular, that of imaginative sympathy.

But by this time we have passed beyond the stage of infra-human development; for self-consciousness and the use of special powers to perform a specialised function are the distinctive marks of human society. From this point forward we may follow the guidance of Hegel in his Philosophy of History. His thesis is that human history should be interpreted as the development and extension of the idea of Freedom. In this process he distinguishes three main stages. In the great empires of the East, one is free (the monarch), and society beneath him resembles in its monotony the vast level plains of the Eastern rivers; in Greece and Rome some are free (those enjoying full rights of citizenship), and in the former especially the variety of character and life reflects the varied landscape of mountain and sea amid which the Greeks had their home; finally, in the modern world under the influence of Christianity, all are free, and the goal of History is reached. ${ }^{1}$ Now, it might perhaps be objected that Hegel's argument relates to the extension of freedom to all, whereas we are concerned with a different category and are tracing the developing idea

1 The Philosophy of History, treating as it does of the extension of freedom from one to all, has a more democratic tone than some of Hegel's other works. Yet, in a characteristic passage in the Introduction (tr. Sibree, p. 70), he argues that the great individuals of the world's history are to be considered as raised above criticism by the moral standards which apply to ordinary men. (On the elements in Hegel's philosophy which are opposed to the Christian view of the Individual, vide M'Taggart, Studies in Hegelian Cosmology, $\S \S 157,180,254$ f.) 
of the worth of all, or more accurately of each. But for Hegel such a distinction hardly existed, since he thought of freedom not only in a negative way as emancipation from the control of the external and material, but as Self-consciousness and Self-determination, the distinctive attribute of Spirit, founded in the nature of the Divine Being. Thus the extension of freedom to all meant that each individual acquired the full dignity of a spiritual being. ${ }^{1}$

Now, when Hegel describes the transition from the East to Greece as a transition from the stage at which only one is free to that at which some are free, he is only repeating the distinction the Greeks themselves drew between the despotic rule of the Persian king under which all save the king himself were slaves, and their own reasonable liberty. As the narrative of Herodotus passes back and forward between Persia or Egypt and Greece, no reader can miss the contrast between the great empire in which the greatest and the most inconspicuous alike held life and possessions at the mercy of the royal caprice, where too a city might be sacked or a thousand men butchered at the king's pleasure, and the free republics of Greece, where every citizen felt that his action in the Ecclesia or on the battlefield had a definite importance and a definite bearing on the welfare of the state. In the former the royal will was enforced by compulsion in some form; in the latter Law was supreme because its sway was willingly accepted by every citizen. ${ }^{2}$

1 Philosophy of History, Introduction. "Freedom can exist only where Individuality is recognised as having its positive and real existence in the Divine Being" (tr. Sibree, p. 53).

2 See especially the speech of Demaratus to Xerxes (Herod., VII. 104). 
We cannot hold that the Greeks overestimated the importance of the contrast. The rise of the free citystate marked a very definite stage in the progress of the idea which we are tracing. A new value accrued to the individual when he was set free to render a willing instead of an enforced service to the state, and when he became fully conscious of the responsibility laid upon him for his share of the work of government or of national defence. And this was the actual achievement of the Greek spirit on the stage of history. But the importance of the Hellenic development for our purpose does not end here. Greek thought advanced beyond Greek achievement, and pointed the way to a still further development of the principle of freedom.

It was indeed impossible that it could remain at the Aristotelian standpoint, which represents the "commonsense" of reflective Hellenism in its highest development. For Aristotle, the culture and liberty of the minority, who must have leisure for virtue, rest upon the all but complete exclusion of the majority from participation in either. In the best ordered state a mechanic or labourer ( $\beta a ́ \nu a v \sigma o s)$ will be excluded altogether from citizenship, or at least will not be considered as showing the virtue of a true citizen; for it is impossible for one so employed to give himself to the practice of virtue. ${ }^{1}$ And when this position is assigned to the free labourer or artisan, it is not surprising to find the slave treated as hardly a human being in the full sense. Aristotle's

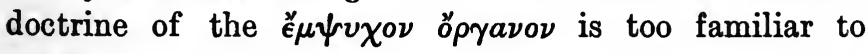

${ }^{1}$ Pol., III., 1278 a 8 ff., 21. In another passage (V. (VIII.), 1337 b 12) the term $\beta d \nu \alpha v \sigma o s$ is defined as including both such occupations as impair the wellbeing of the body, and "mercenary occupations" ( $\mu \iota \sigma \theta a \rho \nu t \kappa a l$

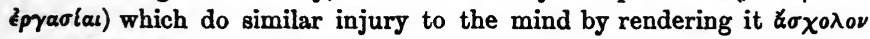

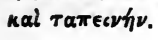


require discussion here; but it may be worth while to quote the passage in which it occurs, as showing the hesitation which Aristotle felt in carrying it to its logical conclusion. "There is nothing in common between a master and his slave; the slave is an animate instrument, and the instrument an inanimate slave. It is impossible therefore to be friends with a slave qua slave, but not with a slave qua man, for there would seem to be a possibility of justice between every man and any one who is capable of participation in law and covenant, and therefore in friendship, in so far as he is man." ${ }^{1}$ This qualified recognition of the common humanity which unites master and slave has a parallel in the discussion in the Politics, where Aristotle speaks of the relation subsisting between them as one of mutual helpfulness and friendship $;^{2}$ and in such passages there is seen the deeper idea of a common humanity not altogether crushed by the harsh logic of slavery.

But in the thought of Aristotle's two great predecessors there were currents flowing which eventually carried ethical reflection completely beyond the region of Greek "common-sense," and far in the direction of Christianity. The first of these is to be found in

1 Eth. Nic., VIII., 1161 b 3-8 (tr. Welldon, pp. 270 f.).

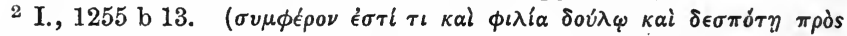

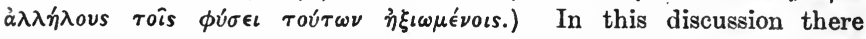
is a hesitation somewhat similar to that in the quotation from the Ethics above. A slave is "only so far rational as to understand

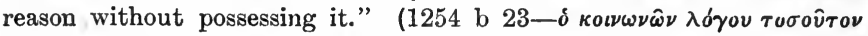

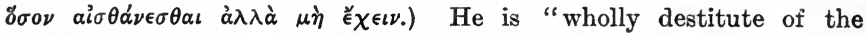
deliberative faculty." (1260 a 12-

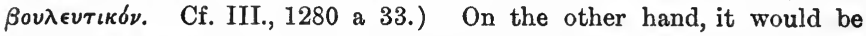

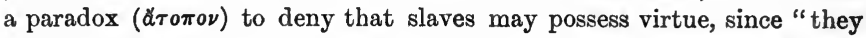

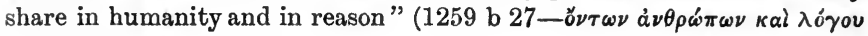

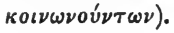


Plato's doctrine of the nature of the soul, which came to him from the far East through the Pythagoreans. It is true that the theory of Transnigration does on one side tend to connect man with the animal world, and so represents a lower point of view than the Greek separation and idealisation of humanity; but at the same time it breaks down such distinctions as depend on the merely external world, and gives to the life of man a new scope and significance. ${ }^{1}$ It is needless to dwell on the effect of the Platonic theory in raising the whole estimate of the destiny of the good and noble soul; but in the earliest passage in which Plato sets forth the Pythagorean doctrine we may, without over-subtlety, see a suggestion which, if followed out, would have led straight to ethical universalism. I refer to the incident in the Meno, in which Socrates is represented as using his "maieutic art" to elicit from one of Meno's slaves the proof of a geometrical proposition. ${ }^{2}$ Now, if the Doctrine of Reminiscence was capable of such an application, and if skilful questioning could enable a slave-boy to rediscover in his inner consciousness the theorem of the great Pythagoras, then the Greek estimate of the relation and comparative value of the different orders of mankind needed to be reconstructed from the foundation. How far Plato saw this in his later works is a question on which

1\%Hegel emphasises both points in his section on Egyptian thought (Phil. of Hist., I., III. iii.), but especially the latter, when he finds in the belief in Immortality the discovery that Spirit is independent of matter, and that "the human individual inherently possesses infinite value." (On the influence of Indian ideas-including metempsychosison'Egyptian and Greek thought during the Persian period, see Flinders Petrie, Personal Religion in Egypt before Christianity, pp. 57, 82 f.)

2 Meno, $82 \mathrm{ff}$. 
different opinions have been held. ${ }^{1}$ But in spite of the limitations imposed by Plato's own aristocratic sentiment and by the contempt of his successors, the NeoPlatonists, for what they considered gross and material, there can be no doubt as to the weighty influence of the Pythagorean and Platonic philosophy in preparing the way for the Christian view of the worth of Man.

But there was another influence which did more than even the Platonic doctrine of immortality and the nature of the soul to prepare the ancient world for the Christian assertion of the worth of the individual. Its full development is to be found in the Stoicism of the Roman Empire, but to understand its origin we must once more turn to the character and life of Socrates. One of the features in his character which most deeply impressed both his contemporaries and the men of succeeding centuries was independence. From the time of Socrates we find a new importance

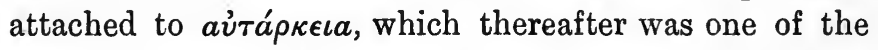
master-thoughts of Greek ethics. In some directions Socrates fell short of the typical Hellenic grace of form and character; but just on that account he showed more conclusively of how little importance is any external characteristic, when contrasted with the inner qualities of strength and purity of will, and entire devotion to truth. His outward form might be a "mask of Silenus," but those who penetrated beneath the surface knew that the mask concealed the "image of a god within"; and in the same way, though his talk was all of "pack-asses and smiths, and cobblers and curriers," those who once understood his words found them the best of all words, "abounding in fair ex-

1 Cf. Note D, p. 395, "Slavery in the Republic." 
amples of virtue, and extending to the whole duty of a good and honourable man." 1 In this studied informality of the Socratic discourse, this determination "not to despise even the meanest things" 2 in the search for truth, there is an implied criticism of Greek exclusiveness which surely is due to more than mere irony. Even if the incident of the slaveboy in the Meno be not literally historical, it was a characteristic idea which Plato attributed to his master, in representing him as drawing a proof of the highest philosophical doctrine from so unpromising a source. There are indications also that Socrates held those occupations which involve manual labour in higher esteem than did most of his contemporaries. As Zeller says, "Socrates speaks as the son of a poor labourer, Xenophon and Plato as men of rank and property." 3

It is a point of no small importance that the founder of Moral Philosophy was one who owed little to external qualities, but much to the unaided pursuit of virtue; one who taught his followers to depend most of all on the power of the will and to be independent of outward conditions; one who habitually looked for illustrations of the nature of virtue in humble vocations and among unlikely people. Into the subsequent developments of the Socratic teaching-its exaggeration into Cynicism, and its eloquent statement by the greater Stoics-it is needless here to enter; but two passages may be quoted from Epictetus to show the point to which the Stoic doctrine of the dignity of

1 Symp., 215, 221 f. (tr. Jowett). Cf. Zeller, Socrates and the Socratic Schools, cc. iv. and vii. (Eng. tr., pp. 70, 131 f.).
2 Parm., 130.
3 Op. cit., p. 139 note. 
Man and its corollary of universal brotherhood had been raised soon after the appearance of Christianity :-

"If a man should be able to assent to this doctrine as he ought, that we are all sprung from God in an especial manner, and that God is the father both of men and of gods, then he would never have any ignoble or mean thoughts about himself. But if Cæsar should adopt you, no one could endure your arrogance; and if you know that you are the son of Zeus, will you not be elated?... Since then it is of necessity that every man uses everything according to the opinion which he has about it, those, the few, who think that they are formed for fidelity and modesty and a sure use of appearances, have no mean or ignoble thoughts about themselves." Nor will they think meanly of any other man, not even of a careless slave. "Will you not bear with your own brother, who has Zeus for his progenitor, and is like a son from the same seed and of the same descent from above?... Will you not remember who you are, and whom you rule?- that they are kinsmen, that they are brethren by nature, that they are the offspring of Zeus?" 1

The successive stages of the process which we are considering might be described in terms of religion, as well as of political freedom or philosophical reflection. The prevailing attitude of religion to the individual is a not inaccurate index of the rank assigned to the latter at any given point in history. Thus Hegel

${ }^{1}$ Discourses, I. iii., xiii. (tr. Long). It is worthy of remark that, while in the Platonic idealism and in the development of Jewish religion the ideas of the value of the individual and of immortality were closely interwoven, in Stoicism the former doctrine came to be held more and more independently of the latter. 
takes as the first type of religion in this respect that of China, in which "the Emperor alone approaches heaven"; while "individuals, as such, enjoy no such privilege." 1 A definite advance was made by the religion of Persia which, as Herodotus tells us, allowed the single worshipper to sacrifice, but enjoined him not to ask anything for himself alone, but only to pray for the king and the whole body of the Persians, of which he was a member. ${ }^{2}$ In Greece the worship of the Olympian gods held a somewhat similar position; for religion was looked on less as an individual duty or privilege than as a state function, and the temples of the gods were often regarded chiefly as necessary to the completeness of a "beautiful and ample city." 3 Any attempt on the part of the individual to obtain access to the gods by ways independent of the ritual of the state was looked on with disfavour; and the bitterness with which Socrates was attacked by the orthodox party in Athens was in part due to the feeling that his claim to possess direct spiritual guidance by means of the "divine sign" involved a certain ádıcía, and a claim to special religious insight, which no individual could rightly make. Again, Aristotle held that no mechanic nor husbandman ought to be appointed to the priesthood; and we may measure the advance made by Christianity by the fact that, even in the midst of mediæval feudalism and class separation, this

1 Phil. of Hist., Part I., sect. 1. (tr. Sibree, p. 138).

2 Herodotus, I., 132. Cf. Plato, Laws, 909.

3 "The Old Oligarch," quoted by Miss Harrison, Prolegomena to the Study of Greek Religion, p. 2. The above statement does not apply to certain of the later developments of Greek religion. Orphism in particular made its chief appeal to the longing of the individual for purification and union with the Divine. 
calling which, according to the teaching of the Church, was the highest of all, stood open even to those of the humblest birth. ${ }^{1}$

In the case of Greece, religion cannot be said to have led the progress towards a fuller recognition of the claims of the individual. In Jewish thought, on the other hand, it was entirely through a deepening religious experience that the worth of the single soul came to be felt. Yet here also the psalmists and prophets, in emphasising the supreme importance of personal purity of heart and of a right attitude of will to the law of God, often came into sharp collision with the priestly party, who relied on established ritual and understood the meaning of the covenant with God in a purely external and national sense. ${ }^{2}$ The Greek and Jewish developments were alike in this also, that the individual first attained to consciousness of his independent worth, as a member of a relatively small state for which his activity and loyalty had a measurable importance; and thus, even while his part in the divine calling was still mediated through the nation, his individuality was not lost in a multitude so great as to destroy all sense of responsibility.

But while this was a first step, it was not final; and the principle attained full recognition in Jewish thought only when freedom was lost, and when the nation became a hardly distinguishable element in the vast heterogeneous population of an Eastern empire. It might have been expected that this calamity would

${ }^{1}$ Politics, IV., 1329 a 28 ; Hegel, Phil. of Hist., Part I., sect. ii. (tr. Sibree, p. 154).

${ }^{2}$ E.g., Ps. li. 16 f.; Jer. xxxi. 31 f. ; Mic. vi. 6-8. 
have crushed out all sense both of individuality and of nationality; but the former principle was by this time too deeply rooted to be readily overturned, and the destruction of the nation as a separate political whole only served to implant it the more firmly. So we find that, just as the destruction of the free city states of Greece provided the opportunity for Stoicism, and the philosopher was at once thrown back on his own inner life, and thrown out upon the whole world of those who sought the truth,-so the prophets of the Exile through the quenching of all political aspirations came to realise the hidden possibilities of the spiritual life within, and the fact of individual responsibility for obedience, ${ }^{1}$ and at the same time became conscious of a wider religious message than ever before, a message which embraced all the nations of the earth. It was at the same period that the idea of "evangelical poverty" arose-the idea that the divine promises were rather for the poor than for the rich, not because poverty was in itself a virtue, but because it disciplined the heart to feel the pressure of spiritual needs and to long for their satisfaction; and with this conception there came the belief in immortality as the answer to the demand that those who had suffered in the calamities of their people and for their sake should have a share in the triumph of the future. ${ }^{2}$

Any one of the subjects at which we have glanced

1 "Every soul is mine," Ezek. xviii. 4. Cf. Jer. xxxi. 29 f. ; Is. Ivi. $3 \mathrm{ff}$.

2 Is. xxvi., especially vv. 16-19. On the date of this section of Isaiah and on the connection of the idea of "evangelical poverty" with that of immortality and with the Beatitudes of the New Testament, see Principal George Adam Smith's chapters on "God's Poor" and "The Resurreotion." (The Book of Isaiah, I., cc. xxix. and xxx.) Cf. also Is. Ivii. 15. 
might be treated at length; and in particular it might be shown how these tendencies continued to gather strength throughout the centuries which remained until the rise of Christianity. Among the Greeks not only Stoicism but the later forms of Greek religion-Orphism, the cult of Asclepius, and the Mysteries-addressed an increasingly direct appeal to the individual, and so helped to strengthen the seuse of the independent personality as the true unit of spiritual value. Among the Jews the Diaspora continued the work begun by the Exile; and even after the Temple was rebuilt the growth of the Synagogue provided a centre of worship and prayer for their now widely scattered communities, and rendered the pious Jew in great measure independent of the national religion of ceremony and ritual still observed at Jerusalem. ${ }^{1}$ Religious ideas and observances now passed rapidly from land to land, and their acceptance came to depend on the individual's sense of what met his own soul's need, instead of on the tradition of his nation.

But enough has already been said if it has been made clear that there was a preparation, both in history and in the earlier processes of evolution which lie behind history, for the Christian view of the Value of the Individual. This view may be, and has been, regarded as the end to which all these tendencies of life and thought point the way, and hence as no isolated or unsupported phantasy of the imagination, but as "the main stream of history and of science, and the only current set from eternity for the progress of the world and the perfecting of a human race." ${ }^{2}$

1 Fairweather, The Background of the Gospels, pp. 24-37. But on the spirit of exclusiveness which still persisted, cf. pp. 148, 194.

2 Drummond, The Ascent of Man, p. 441. 
From the thesis of our argument we now pass to the antithesis, from the tendencies which helped to prepare the way for the Christian estimate of the Individual to those which have hindered its acceptance and still hinder its realisation. Of such counteracting and thwarting influences which have tended to depreciate the individual and obscure his independent value, the most important may be summed up under two heads, (1) physical, and (2) economic. The former merge the isolated man in the vastness of the cosmic process; the latter lose sight of his individuality in the mass of his fellow-men.

(1) In the last section we touched on that interpretation of nature which exalts the individual man by representing him as the highest product of evolution. But there are other points of view from which the study of nature has a quite opposite effect. The Ancient World, in which the Western nations first began to reflect upon the character and destiny of man and to set so high a value on the individual, was a small and compact world. Geographically it was limited to the Mediterranean and the lands which bordered on it, and astronomically it was generally considered as the centre of the Cosmos. It was a world which could be explored and comprehended by the imagination. Further, it was a world the whole span of whose history was to be reckoned in hundreds or at most thousands of years. The lives and achievements of great men bore a measurable ratio to the whole course of things; and the Greeks especially counted their noble families to be but 
a few generations removed from the gods from whom they sprang, though the Greek imagination was at once fascinated and alarmed by the far-stretching history and chronology of Egypt. ${ }^{1}$ And so it was also among the Jews, although their greater thinkers felt once and again the hopeless insignificance of man when contrasted with the measureless sweep and majesty of the divine work in nature.

What is true of the Ancient World in this respect is true also of the Middle Ages. The cosmology of Dante belongs to the time when the universe was still looked on as limited, measurable and symmetrical; and moral characteristics could still be expressed in terms of spatial position. But with the Renaissance and the rise of science, especially astronomical science, all this was changed. It is true that the full implications of the change were not at first understood, for the Copernican theory, while making the sun instead of the earth the centre of the solar system, did not at once displace the solar system from its position as the supposed centre of the universe. But the initial step had been taken, and in time the inevitable conclusion was reached, that the geocentric view of the universe was a sheer error, and that the home of man was but one of the less conspicuous of countless worlds scattered through infinite space. Thus at the very time when the Reformation was reasserting the dignity of the individual, and his right and duty to approach God without any human or ecclesiastical mediation, astronomy had begun to break down all the limits and barriers of his world, and to call him to look forth on a universe infinite both in space and time, whose vastness baffled and paralysed his imagin-

${ }^{1}$ Herodotus, II., 43, 53, 142-5; cf. Plato, Tim., 21 ff. 
ation, humbling him with a sense of unutterable insignificance and weakness. To those under the power of this overmastering sense of the greatness of the physical universe, the assertion of the ultimate worth of the human soul and the divine significance of human history has often seemed utterly incredible and vain.

It was not mere prejudice or intellectual confusion which made the defenders of orthodoxy fear the effect on belief of scientific thought, especially of astronomy, the boldest of the sciences. The pious Greeks who attacked Anaxagoras as a dangerous innovator because he declared that the sun was a glowing stone, "as large as the Peloponnese," and the inquisitors who, centuries later, sought to stamp out the "heresy" of Galileo, were not without justification for their fears. In the latter instance, the new astronomy was gradually but surely breaking down the framework within which Christian belief had developed; nor was it entirely unreasonable to suppose that the destruction of the geocentric view of the physical universe might involve also the abandonment of the anthropocentric view of the moral universe. The framework within which the Christian view of history had grown up gradually fell away, and men were forced to strain their imaginations in the vain attempt to compass spaces and eras beside which the whole long drama of human life and history shrank to nothingness. Thus modern astronomy has placed a new and often overpowering emphasis upon the words of the Hebrew poet, "Lo, these are but the outskirts of his ways; and how small a whisper do we hear of him! But the thunder of his power who can understand?"1 and on the question which inevitably follows close upon this

1 Job xxvi. 14 ; cf. xxxvi. 26. 
thought, "What is man that thou are mindful of him, and the son of man that thou visitest him?"1

Now, it may be said that the feeling of awe in face of the grandeur of the material universe, which oppresses one who looks upward on a starry night, and tries to realise the least part of the majestic sweep of the cosmic times and spaces, in comparison with the insignificance and the shortness of human life, belongs only to the earlier and more primitive stages of religious experience ; that this antithesis between the physically finite and infinite is soon transcended, and the problem of man's relation to the world takes other forms. We may freely admit that this is not the final statement of the ethical or religious problem, nor the highest form in which it arises. And yet this difficulty cannot be disregarded; nor can the power of material immensity to oppress the human mind and dwarf the individual life be considered as wholly limited to the past. It is still felt, and this for two reasons. In the first place the victories of thought are not achieved once for all: they have to be won afresh by each new generation. To borrow the illustration which Sabatier uses in this connection, just as physiologists have found in the human organism traces of all the previous forms through which it has developed, so we find in the consciousness of the individual some trace of every phase of the moral and religious evolution of the race. ${ }^{2}$ The other reason is that in modern times science has placed in stronger relief than ever before the disproportion between the material insignificance of man, and the greatness of the value

1 Ps. viii. 3 f. ; cf. Is. xl. 26 f.

2 The Religions of Authority and the Religion of the Spirit (Eng. tr.), p. $368 \mathrm{ff}$. 
which Christianity claims for even the humblest of men.

That this problem is no trivial or antiquated one is proved by the part which it played in determining the thought of Pascal, and also by the place which it holds in the philosophy of Kant. Early in the nineteenth century the extraordinary popularity of Chalmers' Astronomical Discourses was not only a tribute to the genius of the preacher, but also a proof that he had good ground for his belief in the influence of what he called "the astronomical objection against the truth of the Gospel." The same difficulty is faced by Tennyson more than once; ${ }^{1}$ and one of the leading thinkers of our own day, in arguing that the old forms of religious belief have become inadequate and untenable, bases his contention largely on the removal of those limits to the universe both in space and time, which ancient thought had established-or rather had taken for granted-and within which theology had been at home for so long. ${ }^{2}$

Thus from each period of the modern world proofs may be drawn of the crushing effect of the new conception of cosmic grandeur which astronomy has borne in on the human mind. And apart from the vastness of the material universe-a fact which is always present to those who reflect on the meaning of life-there come at intervals such great catastrophes as the earthquakes of Lisbon or Messina, compelling even the most thoughtless to reflect on the feebleness of man, and on the insecurity of his tenure of life in the midst of forces which take no account of individuals and involve good and bad alike in a common doom. ${ }^{3}$ Thus we are

1 Especially in the poem entitled "Vastness."

2 Höffding, Philosophy of Religion, pp. 41-55. 3 Cf. Gen. xviii. 25. 
forced to consider the greatness of the material universe and the apparent pitilessness of its forces-not as an influence which can be disregarded, or as a problem which has been for ever set at rest, but as a real" challenge to the Christian exaltation of the individual.

(2) The other tendency of which account must be taken may be described as economic. The individual man is here considered merely as one among an incalculable number of his fellows; and it is the vastness of humanity, not the infinity of space, which threatens to absorb and annihilate his personality. In the earlier part of this chapter we considered the evolutionary process as one which more and more tends to distinguish the individual from all the others of his kind, and to give him independent interest and worth. But if this is one main tendency of evolution, there are many things which show how far it still is from having attained complete fulfilment, and which suggest that there are powerful forces working in a contrary direction. It is a significant fact that the Darwinian theory had as its forerunner the teaching of Malthus. It was only after the effect of overpopulation and the consequent tendency to pressure on the means of subsistence had been recognised in the case of human society, that the wider generalisation regarding the struggle for existence throughout all nature was reached. In the last section I referred to the rapid multiplication of the species as characteristic of the lower stages of the evolutionary process; but a century ago its effect in hindering the development of the individual and the progress of the race was first observed in human society, and only thereafter came 
to be recognised in its wider bearing on the lower orders of life.

From this point of view society is still marked by many of the traits of the infra-human cosmic process. It may be considered merely as a mass of competing units, not yet possessed of any distinct individuality, and swayed by influences as general as those which determine the behaviour of members of the animal kingdom. The sting of Malthusianism lies in thisthat, although it may be criticised as a one-sided and partial doctrine, yet there is a side or aspect of life to which it does undoubtedly apply. Further, apart from the extended range of those economic forces which bear upon the material needs of society, their operation is now more widely understood than in the past, and their impersonal character is more keenly realised. Here also the old limits of our world have been broken down, and we are forced to look forth upon the working of laws whose full sweep was in great measure hidden from the imagination of earlier times. Our very knowledge of the conditions of life in distant parts of the world, and of the increasing rapidity with which economic influences spread from one continent to another, tends to confirm and deepen our impression of their non-moral character, and of the helplessness and insignificance of the individual whose life in all its material aspects lies at their mercy. There is indeed the same indiscriminateness and indifference in the operation of these forces, whether they originate in physical events such as drought or in changes in the customs of society, as that which impresses us in the "blind" working of nature in the earthquake or the tempest.

There is also a sense in which not only economics, 
but political theory and practice tend to disregard the individual, and so to cast a shadow of doubt upon the value of his life. Nor has this aspect of political action escaped recognition in the past; for in spite of the great reverence for law which distinguished the thought of Plato and Aristotle, they both recognised that law is defective in so far as its "generality" prevents it from taking note of individual differences and adapting itself to the endless variety of life. Hence Plato compared it to an ignorant and unfeeling ruler who seeks to apply an entirely rigid rule to infinitely varied circumstances $;^{1}$ while Aristotle held that Law must be supplemented by

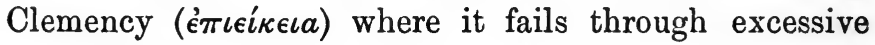
generality. ${ }^{2}$

Now, in the ancient city-state it was possible to look for the "rectification of Law" in the personal judgment of a wise ruler, as Plato and Aristotle did; but the rulers of a great modern state are as far from being able to apply "the leaden rule of Lesbian architecture," which adapts itself to the varied angles and facets of individual character, as is the most rigid code of written law. In an age which seeks to reduce even "charity" to rule, we can hardly dispute the saying of Bentham that "the legislator can know nothing of individuals"; for he must only interfere with their action "with respect to those broad lines of conduct in which all persons or very large and permanent descriptions of persons may be in a way to engage." 3 It is as impossible for the ruler of a great community to legislate for individuals as it would be unwise for the economist to confuse his generalisations

1 Polit., 294.

2 Eth. Nic., V. 1137 b 26.

3 Cited by Bonar, Philosophy and Political Economy, p. 228. 
by trying to give an account of the variety of their tastes; and it is this necessary limitation of law which has led such thinkers as John Stuart Mill to desire the restriction of state action within the narrowest possible limits, in order that the principle of individuality may have the freest possible play. ${ }^{1}$ It is indeed inevitable that both legislators and economists should show the same "tendency to confide in large numbers and averages"; and it is instructive to find that even Kant, the greatest defender of freedom in the moral sphere, is at one with Hume in holding that the law of averages holds good when applied to the collective action of large bodies of men. ${ }^{2}$

In recognising this tendency of political economy to disregard the individual, we do not necessarily accept as justified all the jibes that have been directed against "the dismal science." The point of view of the economist or the statesman is a necessary one $;^{3}$ and the fruitful results of political and economic science prove that it truly describes a large section of the circle of human experience. Yet, as we have seen, it tends to disregard that element of individuality which is one of the chief characteristics of the Christian view of the world. And in so far as it is taken as all-inclusive, or even as the standard by which all other facts or theories are to be estimated, it suggests a point of view from which it is hard to justify the Christian separation and exaltation of the individual man. In so far as our thinking is dominated by purely economic categories, we are com-

1 Cf. especially On Liberty, ch. iii., "Of Individuality, as one of the Elements of Wellbeing."

2 Bonar, op. cit., pp. 121, 277, 386.

3 More than this, it is capable of subserving high ethical ends. See below, pp. 175 ff., and Note E, p. 396, "Economics and the Individual." 
mitted to the method of averages, and so are forced to look on the individual not as a person but as a mere unit, subject to or actuated by wide impersonal forces. But to do so is to fall short of the ideal of Christian thought; and in so far as the life of our time can be adequately and completely described in these terms, society has failed to reach the level at which this ideal becomes a concrete fact. 


\section{CHAPTER III.}

THE VALUE OF THE INDIVIDUAL IN PHILOSOPHY AND CHRISTIAN ETHICS.

I.

THE facts which we considered in the latter half of the last chapter make it very clear that there have been, and are, great forces working against the acceptance of the Christian view of the individual. Nineteen centuries have elapsed since Jesus proclaimed the infinite value of the soul of man; yet His teaching does not yet constitute an axiom either of thought or of action, however readily it may be formally acknowledged. The Christian doctrine is still, in some measure at least, on its defence, and its opponents, as we have seen, are still powerful; hence it is a question of real importance whether philosophy can contribute anything to that defence. When man is awed by the sight of the starry heavens and feels himself of no account in a universe which so surpasses the utmost range of his imagination, or when he is borne helplessly along on the current of economic change or physical catastrophe, has philosophy any thought that may relieve the sense of paradox and irony with which the high claim that his life has infinite worth falls on his ears? 
(1) The first answer to this question is based on the nature of thought itself. One of the recurrent topics of philosophy has been the power of the mind to transcend local and temporal conditions; and the conclusion has often been drawn that the mind is in some sense superior to these conditions, and may gain an inner freedom independent of the limitations of merely material existence. In the inner life of thought and feeling there may be found a satisfaction and a sense of abiding worth which, to those who have known this experience, make all questions of physical magnitude wholly irrelevant. Hence Hegel and others have argued that the attempt to escape from the sense of finitude by sending the imagination ever further and further into the recesses of the physical universe is a vain and hopeless one. To do so is to pursue the "false infinite," which consists merely in endless repetition. And however far such repetition be carried, it brings us no new truth or insight into the real nature of the world; for, according to the Greek saying, "it is the same to say a thing once, and to say it for ever." 1 Such an attempt to reach a purely quantitative infinite only takes us further away from the discovery that the true meaning of the world lies in the thought and the objective work of the human spirit, which satisfies the desire for the Infinite by providing an ever-deepening and widening content of experience and reflection. In seeking to transcend the finite by the method of spatial and temporal addition, the human spirit is traversing an alien region; but in its return upon itself, and its discovery that the meaning of life lies within, it is

1 Encycl., $\$ 104$ (Wallace, The Logic of Hegel, pp. 194 ff.). Cf. Note F. p. 398, "The Two Conceptions of the Infinite." 
emancipated from bondage to the categories of quantity and number and enters the world of inner freedom.

But there is another and simpler way of stating the same truth. We may accept to the full all that has been said as to the overwhelming grandeur of the physical universe, and yet hold that this grandeur bears some close and necessary relation to the mind which apprehends it, even when sinking oppressed by its magnitude. The mind is judged by other standards than that of spatial extent; yet even by this standard the faculty which measures the stars is comparable in greatness to the stars themselves. Without the presence of intelligent beings, fitted to comprehend the significance of the universe, it has been said that the heavens themselves would be in the strict sense insignificant $;^{1}$ while a modern poet has expressed the same thought in the words :-

"And the departing sun his glory owes

To the eternal thought of creatures brief,

Who think the thing that they can never see." 2

There is thus a real sense in which the greatness of the Macrocosm depends upon the power of Man, the Microcosm, to apprehend it; and in which the mind of the thinker shares the magnitude of the spaces and times which form the object of his thought. ${ }^{3}$

The argument may be carried a step further. Even when the mind has to confess its weakness, and to fall

1 J. Clark Murray, Handbook to Christian Ethics, p. 124.

2 Stephen Phillips, Marpessa.

Cf. Sir Thomas Browne, Religio Medici, II. xi., "The earth is a point not only in respect of the Heavens above us, but of that heavenly and celestial part within us. . . . Whilst I study to find how I am a Microcosm, or little World, I find my self something more than the great." 
back before a vastness which surpasses thought, yet this consciousness of failure is in itself a sign of greatness. For a meaner being this sense would be impossible; but in the very recognition of that which transcends his finite nature, man shows that he is not wholly finite. "He is very great because he knows his weakness." The clear perception of the greatness which is implied in man's recognition of his own limitations is the great contribution of Pascal to modern thought. ${ }^{1}$ In his physical powerlessness man, the "thinking reed," confronts the universe and transcends, because he comprehends it. By the very reach of his imagination and the height of the standard by which he judges his own life, he bears unconscious witness to his own grandeur.

There are thus two different lines of argument by which we may approach the same conclusion. The one dwells on the inner life of spirit as exhibiting a completeness, a wealth of meaning, and an inner harmony which give to it a higher order of magnitude than that of the external and material world. The other looks out upon this world, and shows that the mind which understands and measures it is also great, and that even man's sense of his own insignificance is a tribute to his greatness, as one who cannot rest satisfied with the limitations of his experience in time and space. These are indeed only slightly different paths to the same conclusion-that the mind must be judged by its own standards, and not by those of spatial or temporal extent. And to this right there corresponds the duty of finding the highest exercise for the powers of thought. Thus Pascal draws the fitting conclusion from his famous argument in the words, "Man is clearly made to think:

1 Pensées, XVIII. viii.-xii, 
here lies all his dignity and all his merit, and his whole duty is to think aright."

(2) This, then, is the first answer to the theories which reduce man to an insignificant place in the universe. On one side of his nature he is but " the quintessence of dust," but on the other he is a being "of large discourse, looking before and after." 1 It is on this side, by his power of encompassing the world by reason, that he is raised above all material magnitude. But this argument is in itself insufficient as a defence of the Christian view of the individual because of its entirely intellectual character. In the Christian view, the purely intellectual and rational elements of man's nature are neither the highest nor the most characteristic; and Pascal's statement, that the whole duty of man is to "think aright," would need to be understood in a wider sense than that which at first sight it bears, before it could be accepted as the verdict of Christian Ethics. ${ }^{2}$ The appeal of Christianity has always been made to a wider circle than that of the thinkers, to a wider range of human faculties than the merely intellectual; and especially in its beginning it depended little upon the logical reason. ${ }^{3}$ Hence, while the argument from the greatness

1 Hamlet, II. ii. 321 ; IV. iv. 36.

2 There is another passage in the Pensées (IX. 1) which distinguishes this intellectual point of view from that of the New Testament, and definitely advances from the former to the latter: "Tous les corps, le firmament, les étoiles, la terre et ses royaumes, ne valent pas le moindre des esprits ; car il connoît tout cela, et soi ; et les corps, rien. Tous les corps ensemble, et tous les esprits ensemble, et toutes leurs productions, ne valent pas le moindre mouvement de charité ; car elle est d'un ordre infiniment plus élevé." In the last sentence Pascal brings his thought into direct relation to that of 1 Cor. xiii.

3 Mark xii. 37 (cf. Dr Whyte, The Walk, Conversation, and Character of our Lord, pp. 170 f.) ; 1 Cor. i. 20, ii. 4, xiii. 2. 
of man's rational nature is of value as a refutation of the naturalistic estimate of man as a mere part of the physical world, yet it is possible to find a nearer approach to, and consequently a more telling defence of, the Christian view in another form of philosophical theory. The essential element in that view has received a philosophical statement in the Kantian doctrine of "the Primacy of the Practical Reason," and it is from Kant that we may most suitably borrow the next stage of our argument.

The ethics of Kant have as their starting-point his famous assertion of the absolute worth of the Good Will. All other things, whether gifts of fortune or endowments of nature, have only a conditional value which depends on the use made of them by the will. But the will itself, as that which directs the use and determines the value of all other things, has a higher and intrinsic worth. ${ }^{1}$ Every material "good," and even every capacity of the mind (understanding) or of the emotional nature, has a contingent character from the point of view of morality; for all these things are merely instrumental to the ends of the free moral agent. Now it was inconceivable to Kant that this contingency should run through all experience, or that there should be no fixed point of value, itself raised above contingency, from which the relative and instrumental value of material objects or mental powers might be derived. Consequently he drew a distinction between Things (Sachen) and Persons (Personen), of which absolute value belonged to the latter alone, but also to all the latter.

1 Grundlegung, init. (IV. 393 f. ; cf. V. 60 ; Abbott, pp. 9, 10, 151). I refer to the pages of the "Akademie Ausgabe" of Kant's Works, and to the Fifth Edition of Abbott's translation. 
This distinction is in harmony with that previously drawn in the Critique of Pure Reason between the constructive work of the mind and the flux of contingent phenomena. We may perhaps bring out the parallelism between the two spheres, apart from the special form of the Critical Philosophy, by saying that, just as the knowing mind gives to material objects a character and a greatness which cannot be assigned to them as apart from knowledge (even assuming that they can exist in such isolation); so also the will of man as a rational being gives them a new value by relating them as means to the attainment of ethical ends. The organising and vitalising work of knowledge has its counterpart in the activity of the moral nature, or "practical reason" of man. Now these statements may each be taken in two different senses. They may be taken in the sense usually attributed to the formula of Protagoras, that "Man is the Measure of all things"; and in this case the argument only proves that objects gain a new value for us when they are worked into the fabric of our knowledge, or used as means to the ends which we desire. Or we may take both statements in an objective sense, holding that our point of view has more than a merely relative validity, and that in the subordination of material things to the principle of personality some end of positive and universal value is attained.

It is hardly necessary to say that the second is the point of view of Kant in his practical philosophy, with which alone we are immediately concerned. The end gained in morality is objective because, not we alone, but all rational beings, are unable to treat their moral nature, in its subjection to the Law of Duty, as a mere 
means to the ends of others. Humanity has an absolute worth, and so the practical imperative of duty assumes the form of a command to treat it "in oneself or others, always as an end, never as a means." 1 Hence it follows that the predicate of "value" is applied in a different sense to things and to persons, or rather that a different predicate is needed to mark the distinction in rank between them; and so Kant reaches the distinction between Value (Preis) and Dignity (Würde). ${ }^{2}$

"In the kingdom of ends everything has either Value or Dignity. Whatever has a value can be replaced by something else which is equivalent; whatever, on the other hand, is above all value, and therefore admits of no equivalent, has a dignity. ... That which constitutes the condition under which alone anything can be an end in itself, this has not merely a relative worth, i.e., value, but an intrinsic worth, that is dignity. Now morality is the condition under which alone a rational being can be an end in himself. . . . Thus morality, and humanity as capable of it, is that which alone has dignity." 3

If it should now be asked on what grounds Kant

1 Grundlegung, II. (IV. 428 f. Abbott, pp. 46 f.).

2 Kant distinguishes Preis into Marktpreis and Affektionspreis. But if we take the other distinction between "value-in-use" and "value-inexchange," the result is the same. Both are economic categories, and on Kant's principles neither can rightly be used in the ethical sphere. Because a man as a moral being is unique he cannot be exchanged or replaced, and because he is an end in himself he ought not to be used (i.e., treated as a mere means). It would have been more strictly accurate to have used the term worth (Kant's Wert) or dignity of the individual throughout this discussion, thus marking its distinction from the economic idea of value; but the phrase "Value of the Individual" is so well-established in this connection that it is enough to indicate the distinction here.

3 Tr. Abbott, p. 53 (IV. 434 f.). 
claims this unique worth for humanity, we may distinguish two elements in his thought. (a) The first emphasises man's relation to the Moral Law and to the intelligible, or in the language of subsequent idealism the spiritual, world; and (b) the second, which is adumbrated rather than clearly developed, suggests that from the point of view of the inner life each man has a unique value for the universal life.

(a) Kant's whole conception of the moral life is that of obedience to a supreme and unconditional law. Such a law cannot be found in Nature; and if it were found there, it would not satisfy the definition of morality, for it would be merely external, that is to say, imposed from without. But a free and responsible being cannot be bound by any law of conduct which does not spring from, and make its appeal to, his own inmost nature. It is when he recognises and obeys such an inward command that he becomes truly a man and truly free. But in the very fact that he can and must conceive himself free to obey the law of conscience, there is sufficient proof that he is no longer completely ruled by natural and external law. $\mathrm{He}$ is a subject of the realm not of Nature but of Freedom: he has taken his place as a "member of the kingdom of ends." This principle of "the Autonomy of the Will" is one of Kant's greatest contributions to ethical thought, and on it he was prepared to base the whole argument for the supreme worth of man. ${ }^{1}$

As has already been remarked, Kant did not confine

1 "Autonomie ist also der Grund der Würde der menschlichen und jeder vernünftigen Natur."-Grundlegung, IV. 436. Cf. 440 ff., and $K r$. der Prakt. Vernunft, V. 47 f. (Abbott, pp. 54, 59-73, 137.) 
this attribute of autonomy to a few specially favoured individuals; he saw in it a universal characteristic of human nature in every rank or condition. Whenever any man resists the promptings of impulse and follows the command of duty, he is by the very act raised above the casual sequence of the physical order, and, in obeying the law of his own higher nature, he asserts his freedom and gives proof of his dignity as a moral being in the face of all the forces of the sensible world. To such an action a greatness belongs which surpasses all the conventional distinctions and dignities of society. But such actions are possible to all men alike; and they awaken in us a feeling of Respect (Achtung), whatever be the rank of the man who performs them. "Fontenelle says, ' $I$ bow before a great man, but my mind does not bow.' I would add, before an humble plain man, in whom I perceive uprightness of character in a higher degree than $I$ am conscious of in myself, my mind bows whether I choose it or not." ${ }^{1}$ Ultimately, the object of respect is the same Moral Law which we recognise as binding on ourselves; but the man whom we respect as exemplifying it shares in its dignity, whether he be rich or poor, learned or simple.

As the late Professor Paulsen-himself, like Kant, a North-German and a man of the people-has said, "Kant here stands in close connection with the Christian view of life and attitude toward it. ... To the Christianity of the heart and will, as it was and still is practised among the common people, his relation was

1 Kr. der Prakt. Vernunft, V. 76 f. Cf. Grundl., IV. 401 anm. (Abbott, pp. 169, 17 n.) Achtung corresponds to Würde, of which it is the subjective recognition, and like it extends only to persons, as exhibiting the power and dignity of the Moral Law. 
close and intimate. Indeed one may say that his morality is nothing but the translation of this Christianity from religious language to the language of reflection." 1

We cannot pass from the ethics of Kant without recalling the great passage at the end of the Critique of Practical Reason, in which he sums up his thought on the relation of man to the twofold universe in which human life and experience lie: "Two things fill the mind.with ever new and increasing admiration and awe, the oftener and the more steadily we reflect on them: the starry heavens above and the moral law within. . . The former view of a countless multitude of worlds annihilates, as it were, my importance as an animal creature, which after it has been for a short time provided with vital power, one knows not how, must again give back the matter of which it was formed to the planet it inhabits (a mere speck in the universe). The second, on the contrary, infinitely elevates my worth as an intelligence by my personality, in which the moral law reveals to me a life independent of animality and even of the whole sensible world-at least so far as may be inferred from the destination assigned to my existence by this law, a destination not restricted to conditions and limits of this life, but reaching into the infinite." 2

This is in truth the grandest answer that philosophy has given to the objection that the rank claimed by Christianity for man is inconsistent with his humble

1 Immanuel Kant, His Life and Doctrine (tr. Creighton and Leferre, p. 339). The eloquent passage from which these sentences are taken is well worthy of study in this connection.

${ }^{2}$ V. 161 f. (Abbott, p. 260). 
position in the great universe of space. It calls us to consider the inner greatness of the free personality which is able to take its stand against all the forces of nature, and to obey a law which these forces could neither create nor annihilate-a law bearing the impress of a higher order which lends grandeur to what is least in the scale of merely physical being. Nor, for all its boldness, is this a new conception. It is rather a statement in modern language, and in face of our modern knowledge of the infinite magnitude of the universe of space and time, of the old thought that the secret of man's destiny is not afar off in the heavens, but that it is "very nigh"-a word and a law which are in our hearts, that we may do them. ${ }^{1}$

(b) If this conception of the Moral Law as raising man above the natural order and its standards of greatness meets the first type of objection against the Christian view of the individual, an answer to the other type, which we distinguished as the economic, may be found in the other line of thought suggested by Kant. This relates to the uniqueness of the moral individual. Now there is here a distinct limitation in Kant's thought. His abstract way of conceiving the universality of the Moral Law prevented him from working out the idea of uniqueness on its objective side - the idea of each individual as making his special and distinctive contribution to the good of all, and hence as acquiring a unique value for the outward and visible life of the whole. But just because of his limitation in this direction, he was able to lay down more clearly the foundation for the doctrine on its subjective side. We have already seen something of the importance of this

1 Deut. xxx. 11-14. 
element in the estimate of individuality, but it must be developed somewhat further at this stage.

The recognition of the subjective worth of the individual means that the standpoint of the outside spectator is departed from, and the fact recognised that any true estimate of a man's worth must take into account his own inner attitude to life and his sense of its value and import. Now the political or economic standpoint is simply that of the spectator who surveys men in masses. It is that of the manufacturer who reckons his "hands" in hundreds, or of the general who counts the thousands of his troops, estimating their value by their total or corporate efficiency. Or, in so far as individuals are considered, it is on the ground of what they can do through some special natural gift or acquired aptitude.

But over against this external estimate idealistic ethics places that of inner feeling. It contends that a man's place in the world cannot be rightly determined merely from the outside. To understand him in his real worth we must know something of his ideals as well as his deeds; nor may we forget that he has been made what he is by inward conflicts which remain hidden from even the keenest and most sympathetic observer. But much has been gained when it is recognised that he does possess such interests and ideals, such incommunicable hopes and fears, and that the eyes with which he looks out upon the world are indeed his own. Thus, however much he may resemble others from the outer point of view, and however commonplace his utmost contribution to the common stock of human thought or achievement may appear, yet his universe is his own, and his life has value for himself at least. But it will also have value for others just in so far as they have 
insight enough to respect the individuality of another's outlook. So we may apply Leibnitz' saying regarding the "monads" and hold that each intelligent being reflects the universe from an independent standpoint, and that, although the mind is "without windows" inasmuch as no one can enter into another's consciousness, yet it is possible to realise that each has such a unique and inalienable view of life. It is clear that this view acquires much support from the Kantian doctrine of the Autonomy of the Will. No moral person can promulgate the law for any other. To each it must come as a call from his own highest nature, and in so far as he obeys it he is entitled to an inalienable respect.

The importance of this standpoint of imaginative sympathy is finely brought out in one of the late Professor James' most brilliant and incisive passages, at the close of his lecture on Human Immortality. $\mathrm{He}$ first states the view that the claim of infinite value for the individual, with the consequent doctrine that immortality does not belong to a few outstanding spirits but may be the heritage of all, imposes an intolerable strain and burden on the imagination. For of what use can be the preservation of innumerable commonplace and undistinguished lives? He then points out that this argument is only cogent from the purely external point of view, from which the most essential fact is overlooked. "Not a being of the countless throng is there whose continued life is not called for, and called for intensely, by the consciousness that animates the being's form. That you neither realise, nor understand, nor call for it, that you have no use for it, is an absolutely irrelevant circumstance. 
That you have a saturation-point of interest tells us nothing of the interests that absolutely are. The universe, with every living entity which her resources create, creates at the same time a call for that entity, and an appetite for its continuance,-creates it, if nowhere else, at least within the heart of the entity itself. . . Each new mind brings its own edition of the universe of space along with it, its own room to inhabit; and these spaces never crowd each other. ... The inner significance of other lives exceeds all our powers of sympathy and insight. If we feel a significance in our own life which would lead us spontaneously to claim its perpetuity, let us at least be tolerant of like claims made by other lives, however numerous, however unideal they may seem to us to be."

In the same way another modern writer has pointed out the importance for philosophy of the stage in experience at which it becomes possible to identify one's own interests with those of another. For in this relation (love) the externality of knowledge and volition are overcome. The object is no longer interesting for his qualities, but for himself ; that is to say, the life of another is regarded from the same standpoint of inner appreciation from which he himself regards it. "Reference to the object tends to become equivalent to reference to self. ...We feel that this dependence on another is as directly and truly self-realisation as is the dependence of others on us. All through life self-surrender is the condition of self-attainment. Here for the first time they become identical." 1

In this recognition of the importance of entering into

1 J. E. McTaggart, Studies in Hegelian Cosmology, §§ 296, 298. 
the interests of others in order to estimate truly the worth of their lives, there is a close approximation to the Christian standpoint. Here in truth Moral Philosophy only gives a reasoned expression to the principle which underlies the Christian estimate; and, if the principle had not first been stated as an intuitive truth and as a direct moral duty, it is probable that the philosophical formulation might never have been reached. But the Christian attitude has not only been reflected in the trend of ethical thought especially in modern times, it has also inspired many of the masterpieces of literature. There is a sense in which all great tragedy depends for its effect on the dignity of the individual man, and the essential kinship of spirit between men of the most widely separated ages and characters. If our minds are " purified by pity and terror" in reading Edipus Coloneus or King Lear, this is not primarily due to the kingly rank of these heroes of tragedy. That is a relatively accidental or conventional matter, while the essential features of the drama-the serene dignity of Edipus when he has borne the punishment of his guilt to the end, or the agony and madness of Lear-belong to that fundamental humanity which in its capacity for suffering and endurance is the same in every age. Tragedy is universal just in so far as it speaks the language of this common experience; and in recent times the real nature of its universality has been made more evident by the abandonment of the convention that heroes must be of royal rank, and by the discovery and representation of the highest degree of pathos and heroism in common life. $^{1}$

${ }^{1}$ Cf. Note G, p. 398, "George Eliot on the Value of the Individual." 


\section{II.}

The same principle, that only through some measure of identification, in imagination at least, with the lives of others can an adequate estimate of their worth be reached, is exemplified in the history of the Jewish nation. It was through their harsh and repeated experience of the sorrows of exile that the Jews were enabled to transcend their natural exclusiveness, and that their noblest thinkers came to see that strangers and homeless folk had the same right to consideration and justice as was acknowledged in the case of fellow-countrymen. It is true that the feeling of a special obligation towards those who lacked the ordinary protection of citizenship was not unknown among the Greeks, and that throughout Greek literature we find the saying that "strangers and suppliants come from Zeus." 1 But the "autochthonous" Athenian or the conquering Dorian invader could never feel his kinship with or his duty to the stranger with the same intimacy as the Israelite, on whom it was enjoined with the added stress of the often repeated words, "for ye know the heart of a stranger, seeing ye were strangers in the land of Egypt." 2

Again, the feeling of ethical obligation to help others, or to refrain from injuring them, cannot but lead on from a respect for their rights to the recognition of their worth. When humanity to those of humbler rank, or to the defenceless, is held up as an incontestable moral

1 From Homer to Plato, Laws, $729 \mathrm{f}$.

2 Ex. xxiii. 9, also xxii. 21 ; Lev. xix. 34 ; Deut. v. 15; x. 19. Cf. Clark Murray, op. cit., pp. 56, 96. 
duty, as in a remarkable passage in the Book of Job, ${ }^{1}$ the feeling that such men have an inner value cannot be far distant. To recognise an obligation to any man is implicitly to feel that he has an independent value, that he is more than a mere chattel and must be treated as a moral person.

When we come to the teaching of the New Testament, we find this principle clearly embodied in the rule, "All things whatsoever ye would that men should do unto you, even so do ye also unto them: for this is the law and the prophets." ${ }^{2}$ To those who fully accept the Christian estimate of the worth of every human being, this maxim might indeed seem needless; for to obey it would be the necessary consequence of a vital belief in the principle which underlies it. But there is also a converse relation between the maxim and the principle, and the attempt to obey the former may be the best, nay the only, way of gaining a firm hold upon the latter. The effort to help others has often proved the surest way of coming to feel the hidden worth of their lives. Active help is not only the consequence of sympathy and appreciation: it is often the condition of their growth.

It thus becomes possible to appreciate the importance of seeking to apply the practical rule of considerateness, if we would penetrate to the truth of the gospel doctrine of the worth of the individual. How infinite its importance was in the eyes of Jesus is shown by the place given in His account of the Judgment in Matt. xxv. to deeds of kindness to the obscure and the suffering. The man who had made no practical effort to place himself beside such humble sufferers, and to help them, was unworthy

${ }^{1}$ xxxi. 13-22. Cf. Ecclus. iv. 5 f., 10.

2 Matt. vii. 12. 
of the Kingdom. He had failed to recognise that they were worthy of his help, with a worthiness which Jesus even compared and identified with His own. This judgment is indeed a stern one, but the reason for its severity becomes clear when we remember how far the acceptance of the Christian estimate of the individual depends on the practical attitude to individuals. $\mathrm{He}$ who judges their worthiness of help by purely external standards must remain outside the standpoint-of the Gospels; but he who seeks to exercise the double sympathy of feeling and of active help may well pass from without to within, nor can he fail to learn something of the inner worth of their lives. There is no need to enlarge on the unique degree in which Jesus Himself habitually entered into the hopes and the difficulties of those among whom $\mathrm{He}$ lived. Men instinctively applied to Him such passages as those of the Second Isaiah, " $A$ bruised reed shall he not break, and smoking flax shall he not quench"; "Himself took our infirmities, and bare our diseases." 1 There was in His ministry at once a new appreciation of the possibilities of neglected lives, and a limitless willingness to penetrate to their secrets, and win their confidence through a voluntary sharing of their distress. ${ }^{2}$

In other ways also the ethical doctrine which we have sought to trace is in harmony with the teaching of the Gospels. They most clearly proclaim the truth that for each man the secret of life lies within, and that, when the inward Good is subordinated to even the widest possible appropriation of the goods of the material world, the result must be the loss of all that

1 Matt. xii. 20 ; viii. 17. (Isa. xlii. 3 ; liii. 4.)

2 Cf. Matt. xi. 28 f. 
gives human life its ultimate significance. "What doth it profit a man, to gain the whole world, and forfeit his life? For what should a man give in exchange for his life?" 1 The same judgment of value underlies the saying, "A man's life consisteth not in the abundance of the things which he possesseth," and the parable of the Rich Fool which follows it. ${ }^{2}$ Each man's first concern must be for his inner life, for the rightness of his own will, and not for the outward and material, which he must be willing, if need be, wholly to renounce. Only by such renunciation does the true life of the spirit become possible: thus only can the claim of its exaltation above all the forces of the material world be immovably established.

Since this is so, it is not hard to see how the absence of engrossment in worldly possessions and rivalries is the necessary condition of a receptive attitude to the spiritual good of the Kingdom of God. Hence wealth and position are treated rather as a hindrance than as a help to the attainment of this highest good. ${ }^{3}$ At one time a child is taken as a typical subject of the Kingdom : ${ }^{4}$ at another the qualification for admission to it is said to be meekness and poverty-poverty of heart in the first instance, but also to some extent external poverty, for the two ideas were interwoven in Jewish thought far more than with us. ${ }^{5}$ Or again, the emphasis is laid on openness of mind, the attitude of one who has not been confused or sophisticated by involved discussions, but is ready to accept that which

1 Mark viii. $36 \mathrm{f}$.

3 Mark iv. 7, 19 ; x. 24.

5 Matt. v. 3,6. On the real identity of the first Beatitude in its two forms in Matt. and Luke (vi. 20), see Harnack, What is Christianity? (1st Eng. ed., pp. 92 f.), and cf. p. 61 n. above. 
is intellectually simple as the highest truth. ${ }^{1}$ But in every case the thought is the same, that the "good soil" in which the words of Jesus may readily strike root is to be found in open, receptive hearts, without pride either of knowledge or possessions, who feel the need of a deeper satisfaction than the world is able to give. Only where there is this sense of want and imperfection can the new life enter; and it is most likely to be found among the obscure and the humble, among those who are not endowed so liberally with the goods of this world as to have no longing for a better order without or within.

At the same time it is clear that Jesus did not teach that outward poverty is the invariable condition of spiritual receptiveness. The parable of the Pharisee and the Publican suggests the opposite view - that riches, if accompanied by humility, are not an impassable obstacle against entry into the Kingdom. It is because the Publican shows the feelings of self-dissatisfaction and desire for a nobler life, which are possible to the rich as well as to the poor, that he is commended. ${ }^{2}$ This is not inconsistent with the severity of the judgment of Jesus on the rich, for it is based on the fact that they "have received their consolation," and so are often less ready to feel the "hunger and thirst after righteousness." 3 We may therefore sum up this aspect

1 Matt. xi. 25 ; cf. 1 Cor. i. 18 ff.

2 Luke Iviii. 9-14. This parable has at times been treated as showing an antinomian tendency to minimise the sins of the Publican's life and discount the righteousness of the Pharisee. But this is a misconception. It is not the righteousness but the self-righteousness of the Pharisee which is condemned, just as the Publican is commended not for his past life, but for his recognition of its baseness and longing for something higher.

3 Luke vi. 24 ; Matt. v. 6. 
of the teaching of Jesus by saying that, while the absence of outward distinction is no barrier against any who would enter the Kingdom, the barrier which is serious, nay insurmountable, is that confidence in either wealth or knowledge which stifles the aspiration of the heart after a higher good or is offended by His call to simplicity of heart and life.

From the condemnation of wealth, regarded as an end in itself apart from the use to which it is put and the character of the user, Jesus passes naturally to the complementary truth that the wealth of this world, though not intrinsically or invariably a good, gains a borrowed virtue from the good will of the man or woman who uses it. This is most clearly shown in the saying regarding the poor widow who cast two mites into the treasury"Verily I say unto you, This poor widow cast in more than all they which are casting into the treasury." 1 This incident may be taken in conjunction with that of the anointing by Mary of Jesus' feet, and of His rebuke when the onlookers condemned the wastefulness of the deed-"She hath wrought a good work on me. . . She hath done what she could." 2 From these two stories may be gathered the attitude of Jesus towards the use of wealth and His teaching regarding its real value. The size of the gift is not indifferent, but neither is it the essential thing: it has value-but a derived value only - in relation to the spirit of the giver, and as manifesting the completeness of his or her devotion. ${ }^{3}$

These two incidents point to another fact which

1 Mark xii. 43.

Mark xiv. 6, 8.

3 Cf. Jesus' command to the young Ruler (Mark x. 21), and Ruskin's passage on "The Lamp of Sacrifice." (The Seven Lamps of Architecture, chap. i., sect. viii.) 
bears directly on our subject. This is the powerful influence of Jesus' character and teaching in raising the estimate of the dignity of woman's life and work. This thought is perhaps less familiar than that of His appreciation of childhood, but it is hardly less important, and it is shown in many ways in the Gospels. The very fact that $\mathrm{He}$ placed so high a value on the gentler virtues, and on the inner qualities of devotion and sympathy, sufficed to destroy the old prejudice as to the inferiority of woman's powers, and to set in a new and bright light her special aptitudes and the special function which she had to fulfil in the Kingdom. Again, the teaching in regard to marriage which, to the contemporaries of Jesus, seemed so exacting and so revolutionary, tended to the same end. By giving "a new reading of old texts," $\mathrm{He}$ at once rebuked and reversed the low Jewish estimate of the worth of woman and the nature of marriage $;^{1}$ and so dealt one of the most telling blows against all exclusive and particularist views of virtue.

But it is the teaching of Jesus regarding the "Childelement" in religion which takes us furthest into the heart of our subject. For in the last resort His claim that the life of the individual has value, not only for himself or as a call on the active love of others, but for God-that it has an absolute as distinct from all relative and derived value - rests upon the thought of the Fatherhood of God. Into this region it is hard, perhaps impossible, for philosophic thought to follow. The words in which Jesus makes His mighty claim, founding it upon the Fatherhood of God, and drawing from it the practical lessons of freedom from distracting anxiety and

1 Matt. xix. 3 ff. (Mark x. 2 ff.), and Bruce's note in the Expositor's Greek Testament. 
of respect for "these little ones," are among the simplest and most familiar in the New Testament; ${ }^{1}$ but in their simplicity they transcend in an especial degree both the experience of the "practical man" and the speculations of the philosopher. Those who have understood and accepted them have done so by rising into an atmosphere of clear intuitive vision, in some measure like that in which Jesus Himself lived and taught; although the principles so learned have not seldom proved their power, when brought back and applied in the world of ordinary experience.

One thing, however, stands out clear from our previous discussion-that this side of Jesus' teaching gives the highest expression to all those tendencies which have helped to set the individual man in relief, to separate him from the multitude, and to treat him as possessing independent interest and value. And the Christian religion makes the claim that these tendencies are the strongest force in the universe, by teaching that they are in harmony with the character of God. If the idea of Fatherhood, as distinct from Power or Sovereignty, be the most adequate conception that we can form of the Divine Nature, then the worth of the individual is grounded in the deepest of all realities. The politician and the scientist may still treat men in masses and aggregates, but their view does not represent the ultimate truth of things. "The individual citizen may be lost in the crowd of the sovereign's subjects; the Father's child can never be lost in the crowd; he is

1 Matt. vi. 25 ff., x. 29 ff. ; Luke xii. 32 ; Matt. xviii. 10, 14. "I say unto you that in heaven their angels do always behold the face of my Father. . . Even so it is not the will of your Father which is in heaven, that one of these little ones should perish." 
singled out as the object of the Father's individualising love." 1

There still remains one aspect of the Christian teaching on this subject which must be referred to before this chapter is brought to a close, and which will serve to lead on to the Christian doctrine of the community. The attitude of Christianity to the individual is essentially dynamical. It does not merely declare that he has intrinsic value, as a new fact or aspect of truth may be declared. Still less does it make a sentimental assertion of the value of humanity, and leave the assertion standing. Christianity not only proclaims, but creates, the fact. In other words its character is redemptive; and it is in this light that its claim of the worth of the individual soul is to be judged. For the highest attestation of that claim is to be found in the fact that $\mathrm{He}$ who made it, was willing to suffer even death for those whose value He proclaimed. Heine once said that he too might have died to save men, had he not shrewdly suspected that they were not worth saving; and this remark, by displaying the absolute contrast and antithesis to the attitude of Jesus, makes that attitude more luminously clear. Whatever interpretation be placed upon the saying, "The Son of man came ... to give his life a ransom for many," 2 the fact for which it stands has done more than anything else to raise the individual men for whom this sacrifice was made to a higher level; and it must ever be the most powerful influence in transforming the Christian assertion of their supreme value from an ideal into a fact.

This view of the Christian teaching is clearly implied

1 D. M. Ross, The Teaching of Jesus, p. 92.

2 Mark x. 45. 
wherever such metaphors as "healing" or "search" are used to describe the work of Jesus. The value of the souls of men depends on their relation to His work; and hence that value-is asserted less as an accomplished and unalterable fact than as a great possibility. No other view is consistent with the severity of His judgment on those classes of men whom He perceived to be hindering the advance of His kingdom. ${ }^{1}$ The lives of such men as they actually were, not only failed to show positive value, they were definitely opposed to all true value, and it had been better for them never to have begun to live. The definiteness with which $\mathrm{He}$ distinguished between those who were on the side of the good and those who were its enemies, wholly separates Jesus from those who apply the idea of the value of humanity in an indiscriminate and merely sentimental way to all alike. For Him the human soul had real value only on certain conditions.

But the universalism of Jesus' teaching lay in the assurance which $\mathrm{He}$ gave that these conditions were open to all who would accept His message. In philosophic language, while we cannot hold that He taught that every soul has actual or realised value, yet $\mathrm{He}$ did believe in the potential value of all. And it is as the possibilities of good in each life are drawn out into activity, that that life acquires value in the absolute sense. In the words of Jesus Himself, "there is joy in the presence of the angels of God over one sinner that repenteth." 2 His work was to "call sinners," to be the physician of the sick; and the recovery of one such was worth the monotonous uniformity of many respectable lives. ${ }^{3}$ But the whole conception of the value of the wanderer or the

1 See references above, pp. 28 f.

2 Luke xv. 10.

${ }^{3}$ Mark ii. 17 ; cf. Luke xv. 7, 32 ; xix. 10. 
sufferer turns on this word, recovery. If the Christian teaching regarding the worth of man had been merely the proclamation of a fact which had already full existence, this emphasis on recovery would have been needless; but because the Gospel was an affirmation at once of the need and of the possibility of a complete change in life and of its acquiring an entirely new value, this conception is fundamental.

When this point is grasped, part of the difficulty of the Christian view disappears. It does not demand that we should so far disregard the facts which are sternly forced upon us when we look out on the world, as to attribute actual moral value to lives which are ranged on the side of evil rather than of good; nor are we called upon to declare that moral beauty exists where only meanness and deformity can be seen. So far, the Christian doctrine is easier to accept than any attribution of an actual developed value to every human soul; for it recognises the fact of evil and the present degradation of many lives. But at the same time it asserts that evil may be conquered and that each life may become valuable, or, if we choose to put it so, that each life has value in virtue of its hidden possibilities of good. And this is a sufficiently daring challenge to all the conclusions of ordinary experience - a hard enough and exacting enough creed to hold and to apply seriously. Perhaps there is no other doctrine to which it is so fatally easy to pay lip-homage as this of the value of the individual, while we are far from realising its full import, and fall yet further short of carrying it steadily into practice. It has always been the mark of a great Christian to practise it fully-to care for all and to despair of none. Pauci, dis geniti potuere. 


\section{"Servants of God! -or sons Shall I not call you ? because Not as servants ye knew Your Father's innermost mind, His, who unwillingly sees One of His little ones lost." 1}

But if this be the true view, and if the doctrine of the worth of man be a task and a challenge as well as a truth, then it follows that it cannot be taken as proved once for all. It is one of those practical truths which must be rediscovered and applied anew by every generation of men. This is indeed a characteristic of all the highest truths; but it holds good especially of those which concern the will rather than the abstract intellect. Under the influence of the theory of evolution, we are at times apt to assume too easily that the achievements of one generation are passed on entire and unimpaired to form the starting-point for fresh endeavours, and that a higher ethical point of view, once attained, is never abandoned. But the facts of history contradict this facile view. They rather suggest that constant effort is needed if the results of past progress are to be conserved, and that the possibilities of retrogression are no less real than those of fresh advance. Hence, if we hold to the finality of the teaching of Jesus on this subject, we must also believe that to every age His declaration of the worth of man comes as a problem to be worked out afresh amid its own conditions. If we accept the statement that Jesus "was the first to bring the value of every human soul to light, and what he did no one can any more undo," we must balance this truth, as Harnack does, by recognising "what a paradox

1 Matthew Arnold, Rugby Chapel. 
it all is," and how directly it "flies in the face of things as they are actually constituted." 1 That there is this direct opposition between the Christian ideal and the actual constitution and judgments of society needs no elaborate proof. Here also "we see not yet all things subjected unto him "; ${ }^{2}$ and if the light kindled by Jesus has never been extinguished, it is often obscured by the world's mist and driving spray. It is better to regard His teaching as paradox than as platitude; for then the problem meets us, how this doctrine which is now both an ideal and a paradox can be made to dominate the recalcitrant facts of life.

When this question is asked seriously, it will be seen that by considering the Christian view of the individual as a task to be carried out, and not only as a principle to be assented to, we come into contact with encouraging as well as discouraging facts. For when those tendencies which tell against the Christian position are examined from this standpoint, it becomes clear that in many cases they are not so rigid and so unalterable as at first appeared. Especially is this true of economic influences. Some of these exist not "by nature" but merely "by convention," and so may be modified; and even those which seem most deeply embedded in the character of man as a natural being may be changed by the action of ethical and spiritual forces. Thus we may give the fine saying of Ruskin regarding Malthusianism a wider application, and hold that the man's increase both in numbers and in inner worth "is limited only by the limits of his courage and his love." 3

Finally, the dynamical or redemptive view of our sub-

1 What is Christianity? pp. 67-69.

2 Heb. ii. 8.

3 Unto This Last, § 78. 
ject leads us beyond the mere isolated man. In the Third Gospel, Jesus is represented as defending the healing of a deformed woman and marking the moral recovery of the publican, Zacchæus, by pointing out their right to share in the heritage and the hopes of the nation from whom they were sprung. "A daughter," "a son, of Abraham" had claims on the mercy of Jesus and the forbearance and sympathy of their fellow-countrymen which neither physical nor moral deformity could annul. ${ }^{1}$ And the words with which the evangelist brings his account of Zacchæus to a close, "the Son of man came to seek and to save that which was lost," suggest that the restoration of Zacchæus to the fellowship of his people, no less than the initial claim which his nationality gave him upon the interest of Jesus, is referred to in the words, "He also is a son of Abraham." But wherever the work of Jesus is referred to as a search, this further truth is implied. Recovery is incomplete without restoration to the body from which the lost one had been severed. The assertion that the individual man has value cannot be taken to mean that he has value in isolation. Rather his value can only be attained in the life of the community to which, even when isolated and alone, he truly belonged; for his will and his affections alike need an object, and can only develop as they act and react on those of other men. But this point need not be laboured; for both Christian teaching and philosophy mean by the value of the individual a value which, however deeply hidden may be its source, manifests itself outwardly in a life shared with others, in the contact and the harmony of a community of moral natures.

${ }^{1}$ Luke xiii. 16 ; xix. 9 f. 


\section{CHAPTER IV.}

THE PHILOSOPHICAL DOCTRINE OF THE COMMON GOOD.

AT the close of the last chapter, it became clear that the Christian doctrine of the value of the individual soul cannot remain merely subjective. If we would state it in its completeness, we are forced to take a wider field into view, and to consider the individual man in relation to that wider whole, in and through which he can reach full development and realise that value which Christianity attributes to his life. Thus the question of the relation of the moral individual to the community, and of his good to the wider good, must inevitably arise. The Greeks stated this problem by asking whether the Good of the state and of the citizens who compose it was the same or different. ${ }^{1}$ For us it takes the more general form, as to the extent to which the true Good is common to all who partake in it, and so non-competitive in nature. ${ }^{2}$

On the one side it has often been argued that, when the nature of the Good is rightly defined, there can be no

1 Arist., Pol., IV. (VII.), 1, 2.

2 Cf. Note H, p. 399, "The meaning of Competition and Competitive." 
opposition of individual interests in its attainmentthat it is in the strict sense a common good. Thus Augustine says that "the blessedness of a community and of an individual flow from the same source; for a community is nothing else than a harmonious collection of individuals." 1 But against this view it has been held that the wider and narrower good are not necessarily coincident, but that there is a certain degree of inevitable divergence between that which is good for any particular individual and for other individuals or for the community; that, in short, such a conflict of claims to the good or desirable is not, as Augustine elsewhere suggests, a result of human "corruption," 2 but that it is the necessary accompaniment of the moral life lived under the conditions that we know.

The question gains importance from the part played by this theory of the Community of the true Good at many points both in Greek and Christian ethics, and from the central place assigned to it in modern times by Spinoza, as well as by T. H. Green and other writers under the influence of Kant. But its importance is not merely historical. For it is clear that this characteristic is closely involved in the moral ideal of Christianity. We must indeed recognise that in regard to the ordinary "goods" or advantages of daily life men's interests do not always coincide, and that "competition" for material goods appears to be inevitable, in the sense that the things which one man enjoys another must forego. But it is hard to reconcile such a view of ultimate good with the spirit of Christianity. In the spiritual sphere, which

1 De Civ. Dei. (tr. Dods), I. 15.

2 Ibid., XII. 27. "There is nothing so social by nature, so unsocial by its corruption, as this race." Cf. XV. 3. 
for Christian Ethics is the highest and most important, such competition would seem to contradict the whole conception of harmony with others and joy in their good. The truly spiritual man will not offend the least of his brethren, nor can he rest satisfied that the development of his higher life should depend upon their spiritual loss or disadvantage. This principle is most clearly stated and worked out in its practical bearing by Paul. He insists that the morally strong ( $\dot{\eta} \mu \epsilon \hat{i}$ oi Svvaroi) have no right to disregard the good of their weaker brethren or to advance in the exercise of spiritual freedom at their expense. ${ }^{1}$ Thus the Christian view of life demands that, however wide the sphere of competitive goods, there should be beyond it a region in which the enjoyment of the good is not limited or exclusive, but capable of being shared by all alike; and that whatever is really essential for the deepest well-being should lie within this region.

There are, indeed, not a few facts in the moral life, accessible to common observation, which go far to support this view. It is easy to see that those things or qualities which we think of as "goods" can be classified according to the degree in which they are necessarily competitive or not. At one end of the scale, typical of all competitive goods, are those material things of which the supply is limited, and of which the possession and enjoyment is confined to a few men to the definite exclusion of their fellows. At a higher point are found those objects of desire whose attainment depends partly on material conditions but partly also on social conditions; and here, because comradeship is a necessary element in the pursuit and enjoyment of such goods,

${ }^{1}$ Rom. xv. 1-3. Cf. xiv. 21 ; 1 Cor. viii. 9, 11 ; x. 24, 33. 
there is an approximation to the nature of common good. Finally, in goodness of character there is that which rises above the conflict of interests, for its presence in one life is a help and not a hindrance to its development in others. Goodness is seen to have a self-propagating tendency, when we think of it not merely as an abstract good will, but as manifesting itself in actual and concrete form in purity of motive and devotion of will. In this respect it may be contrasted with pleasure; for, while pleasure is to a limited extent self-propagating, yet the enjoyment of one individual often rests on pain suffered by another, or by reaction causes pain to the same man at a later time. Goodness, on the other hand, is not limited in this way. It is cumulative for the individual and contagious in its tendency to pass from one to others, and thus may be taken as the type of that higher order of good which is superior to the law of f reciprocal gain and loss.

This characteristic is an important one for ethical theory. For if pleasure be taken as the Good, endless difficulties are encountered in determining the distribution of the means by which it may be gained, and in adjusting the claims of different men and classes of men to possess these means. But if the Good be thought of as goodness in the sense defined, including fidelity to duty as an essential constituent, this conflict of divergent claims tends to vanish; and just in so far as the Good is shown to have a truly non-competitive character the difficulties of Hedonism disappear. ${ }^{1}$ This fact has in-

${ }^{1}$ In his criticism of Green's theory of the Common Good Sidgwick freely admits the advantage which this theory, if it could be established, would have over his own Universalistic Hedonism, in avoiding the difficulty of thus adjusting divergent claims. (Lectures on the Ethics of T. H. Green, Mr Herbert Spencer, and J. Martineau, p. 65.) 
fluenced many thinkers; but one of its most impressive practical applications is to be found in the political writings of Mazzini, with their strong insistence that no theory of rights can overcome the clash of various conflicting interests; but that harmony can only be attained when the emphasis is transferred from rights to duties. For, from this ethical point of view, the conflict of interests gives place to the concord of many diverse wills each striving along its own line for the realisation of the Common Good. "Once admit the principle of duty, and the possibility of strife has gone." 1

It may, then, be concluded that the establishment of this view of the Good would be of great importance for general ethical theory, but especially for Christian Ethics; and that there is reason to think that the highest type of good transcends those limitations of outward "goods," owing to which their exclusive possession by one man renders it impossible that they should benefit another. But a closer examination is requisite before we can either affirm or deny the theory that the true Good is necessarily common, and that it may be enjoyed in equal measure by all who rightly apprehend its nature and sincerely follow after its attainment.

First of all, we find that there are two arguments by which the doctrine may be defended. In the first, stress is laid on the inwardness of virtue, the power of thought and will to transcend material conditions and conquer external influences, the independence of the inner life ; and on this ground it is argued that for each man the possibility of a good life does not depend on the action

1 The Duties of Man, ch. i. ; Faith and the Future (Dent's ed., pp. 11 ff., 169). 
of other men or on circumstances, but solely on his own fidelity to duty. Virtue, it is said, is too entirely personal a concern to be subject to the law of competition, nor can its possession by one man ever interfere with its exercise by another. The other argument depends on the conception of the ethical end as social; and it emphasises the fact that man can only exercise his higher activities in the society and through the cooperation of his fellows. He is so constituted that any good which he seeks to keep jealously to himself soon escapes his grasp; while, in sharing the labours and enjoyments of others, he gains a width of life and a richness of experience which he could never attain in isolation.

Now when these two arguments are thus baldly stated in their contrasted terms, their difference is at least as apparent as their agreement. Indeed, it may be said that the position of this theory of the Community of the Good must be a singularly unstable one, if its twin supports are the belief that the Good is purely individual and that it is purely social. And this criticism is, as we shall see, a concise summary of the objections to the theory. Yet the two lines of thought have again and again been combined; and from Plato to Green there has been hardly any exponent of the theory who has not used them both, though now one and now the other has been more prominent. This suggests the question as to whether some synthesis of the two is really impossible. But before a synthesis can be attempted the alternative arguments must be placed in a clearer light. 
PHILOSOPHICAL DOCTRINE OF THE COMMON GOOD. 109

II.

The first argument, which depends on the inwardness of virtue and the independence of the good will, need not here be stated at great length, both because it is simple in itself and because the ethical bearing of these ideas has been indicated in the last chapter. But it may be illustrated by a reference to what may be called the Stoic tradition in philosophy. We have already seen how much this tradition owed to the character and teaching of Socrates, and in particular to the impression

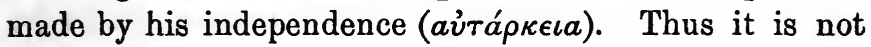
surprising to find that in the earlier part of the Republic this independence is referred to by Plato as one of the acknowledged characteristics of the brave man; for his personality shows in itself in the highest degree those qualities which are necessary to the good life, and he is distinguished from others by his power to dispense with outward things. ${ }^{1}$ And this judgment carries with it a universal consent, for at all times it has been looked on as the mark of the highest manhood to be able to rise above misfortune, and to possess a calm and security of spirit which adversity cannot touch, while lower and feebler types of virtue depend on the support of others or the help of favouring circumstances.

Again, the moralist or preacher who rises to a high level of intensity and enthusiasm inevitably appeals to the power and duty of each man to decide for right without counting the cost. Thus it is in Plato's great argument in the Gorgias, that it is better to suffer than to

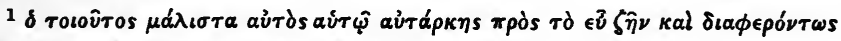

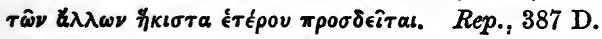


do injustice. In this dialogue the inward evil of consent to injustice and the corruption which it brings on the soul are set forth as far outweighing any external advantage which may follow an unrighteous act, and the single good of a soul purified by discipline and obedience is held to be of greater importance than any outward loss; while in the myth which closes the dialogue, all the outward conditions of action and the trappings of circumstance are represented as being at the last torn away from the soul, which goes forward naked to judgment in its own inherent beauty or deformity. ${ }^{1}$

This appeal to the power of the will to decide for good in the face of the strongest conjunction of hostile influences is constantly repeated by the Stoics. "Nothing which is independent of the will can hinder or damage the will, and the will can only hinder or damage itself." ${ }^{2}$ The man who has won inner freedom by controlling his own impulses cannot be moved by any outward event. Others cannot harm him, for his desire is wholly set on those qualities of purity and faithfulness to duty which lie within the power of his own will. ${ }^{3}$ The will is indeed strong enough in itself completely to transform outward events, which are, when rightly considered, but the formless matter on which it may impress its own image. This is the complement of the view which we found in the New Testament that the most favourable outward circumstances may become the occasion of $\sin$; and it is incisively stated in one of the Discourses of Epictetus, entitled "That we can derive advantage from all external things." 4 "Is

1 Corg., 469 ff., 508 to end.

2 Epictetus, Disc., III. xix.

3 Ibid., IV. i. Cf. Plato, Apol., 39.

4 III. xx. (tr. Long). 
my neighbour bad? Bad to himself, but good to me; he exercises my good disposition, my moderation. Is my father bad? Bad to himself, but to me good. This is the rod of Hermes; touch with it what you please, as the saying is, and it will be of gold. I say not so; but bring what you please, and I will make it good. Bring disease, bring death, bring poverty, bring abuse, bring trial on capital charges; all these things through the rod of Hermes shall be made profitable."

In the same spirit Marcus Aurelius says, "Material things cannot touch the soul at all, nor have any access to it: neither can they bend or move it. The soul is bent or moved by itself alone, and remodels all things that present themselves from without in accordance with whatever judgment it adopts within." For it "can convert and change everything that impedes its activity into matter for its action; hindrance in its work becomes its real help, and every obstruction makes for its progress." 1

Thus to the wise man everything external is in its own nature indifferent, but all things are alike capable of being moulded to the uses of the human will. Nor is any outward circumstance essential to his happiness, for

"The mind is its own place, and in itself Can make a heaven of hell, a hell of heaven."

When so lofty a view is taken of the power of the will and of the independence which virtue confers, it is natural that this inner strength of purpose to which all else must bend should be looked on as alone truly good, while the gifts of fortune are at most preferable

1 V. 19, 20 (tr. Chrystal). 


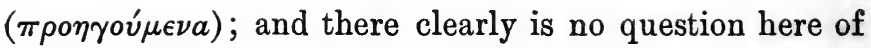
any conflict of interests in the Good, for its progress is helped by obstruction and its enjoyment becomes secure in adversity.

The ethical teaching of Spinoza also illustrates this form of thought. For he traces a very close and intimate relation between the two characteristics of the true Good, as common and as inward. From this point of view he draws a sharp distinction between the evil life in which the passions bear rule, and the good life which is under the rule of reason. Those who live according to the former rule are the slaves of external events, controlled by causes, and carried away by the desire for objects, which lie outside their own proper nature. Thus, since outward events are constantly changing, passion leads to all that is inconstant and variable in human nature; and it also leads to discord between those who are actuated by desires for the same external object. Hence arise the frequent contradiction and incompatibility of human desires; and hence the discord between those who pursue things which cannot be possessed in common. ${ }^{1}$

All this can only be avoided if those whose material interests conflict can join in the pursuit of some higher good which has a uniting instead of a dividing influence. Nor has Spinoza any doubt as to the existence of such an object which can give satisfaction to all alike; for it belongs to his faith in the unity of reason to hold that, when its guidance is steadily followed, it cannot but lead to a good in which all may share. ${ }^{2}$ But although this faith in reason doubtless underlies Spinoza's argument, and gives it a certain intellectualist character, his

1 Ethics, IV. xxxii.-sxxiv.

2 IV. xxxv. 
account of the nature of this Common Good soon passes into the language of religion.

"The highest good of all those who follow virtue is common to all, and therefore all can equally rejoice therein." For "to act virtuously is to act in obedience to reason, and whatsoever we endeavour to do in obedience to reason is to understand; therefore the highest good for those who follow after virtue is to know God; that is a good which is common to all and can be possessed by all men equally, in so far as they are of the same nature. ... The good which every man in so far as he is guided by reason, or in other words, follows after virtue, desires for himself, is to understand; wherefore the good which each follower of virtue seeks for himself, he will desire also for others. . . This love towards God is the highest good which we can seek for under the guidance of reason, it is common to all men, and we desire that all should rejoice therein; therefore it cannot be stained by the emotion of envy, nor by the emotion of jealousy; but, contrariwise, it must needs be the more fostered, in proportion as we conceive a greater number of men to rejoice therein." 1

At this point we may trace a connection between the theory of Spinoza and that of Kant. For the love of God in which Spinoza teaches that all men may unite is a disinterested love; and the words last quoted immediately follow the famous proposition, "He who loves God cannot endeavour that God should love him in return." 2 Now Kant lays the greatest stress on the fact that only a disinterested will can be universal, i.e., can lay down laws valid for all alike; because only such a

1 IV. xxxvi., xxxvii. ; V. xx. (tr. Elwes).

2. V. xix. 
will can aim at a good which transcends personal differences and is open to all men without distinction. ${ }^{1}$ There is undoubtedly a wide difference between the form given by Spinoza and by Kant to their ideas of the good, between the "intellectual love of God" and the "good will"; but their systems, in most respects so dissimilar, agree in their identification of the morality of a principle with its universality, ${ }^{2}$ and in the emphasis which they lay on the inwardness of the good. Both think of virtue as consisting in the escape from enslavement to desires for external things, and the gaining of inner freedom, and so as a possession or a function of the soul which all men may share.

\section{III.}

From this view that the true good is inward, and so non-competitive, we turn to the consideration of its social character. The argument that in this sense it is common is also ultimately derived from Greek ethics; indeed it is more characteristic of Greek thought than are those ideas which we have just traced. For in the main the Greek spirit was objective. It went forth

1 Grundlegung, IV. 432 f. (Abbott, pp. 50 f.).

$2 \mathrm{Dr}$ Duff points out this parallel (Spinoza's Political and Ethical Philosophy, p. 130), but adds that Spinoza's point of view is rather " that only a moral principle can be universally willed, than that only a principle capable of being universally willed can be a moral one." But from whichever side it is made-and Spinoza's makes it from both-the important point is the identification of morality and universality, and the distinction between such a moral principle and all cases in which the ends are personal and lead to conflict between man and man. Dr Duff gives an admirable statement of Spinoza's doctrine of the Common Good and its place in his system (op. cit., Chh. VIII.-XI.), as Green (Works, II. 128 f.) more briefly does of the same idea in Kant. 
eagerly to meet the beauty and variety in the world; and the self-absorption of one side of the Platonic thought and of the teaching of the Stoics harldy represented its distinctive genius. The typical idea of a $\rho \epsilon \tau \dot{\eta}$ was that of a many-sided excellence developed through a varied contact with the world, and drawing all outward forms of goodness and beauty into the circle of its own individuality; and those who held this rich and concrete ideal naturally refused to identify the good of man as a whole with his inner life alone, or to allow that the development of that type of virtue which is independent of outward circumstances, could make up for the absence of many other forms of human excellence which flourish only in a favouring environment.

From this point of view the theory that true virtue is purely individual and inward has often been criticised. It may be argued that the attempt to render man independent of outward circumstances constantly defeats itself; that the ascetic seldom enjoys the highest type of freedom, and is apt in the end to identify the good life with the absence of worldly goods, just as the ordinary man identifies it with a state in which they are abundantly present. Thus a sort of inverse bondage to material things arises in the form of a constant dread of their corrupting influence, and a state of outward poverty comes to be looked on as the necessary condition of virtue. It may well be argued that the protest of Cyrenaicism against this tendency, exemplified in the case of the Cynics, was well grounded. ${ }^{1}$ If the attempt to eliminate and negate the influence of

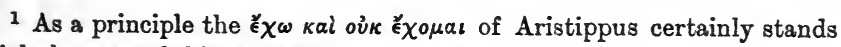
high, however dubious its actual applications. 
material things in human life thus tends to result in a new form of bondage to them, this forms a valid criticism of the purely inward view of the ethical end. ${ }^{1}$

Thus the typically Greek view of life, which in this respect is also the view of "common-sense" both ancient and modern, meets the depreciation of external goods by affirming that these are necessary to the development of virtue in many of its forms. And when a wide view is taken of the manifold demands of life, it does indeed seem that the virtue of the hero or martyr, who is prepared to follow the highest good disregarding all suffering or outward loss, belongs only to the greater crises of life, while other less splendid virtues are needful for its daily work. But the latter virtues lie closer to the ordinary needs of man-needs of the body for protection and sustenance, and of the mind for knowledge and the beautiful; and so their exercise must be dependent on the presence of material instruments. If such instruments are wanting, certain activities which cannot be regarded as indifferent from the standpoint of the Common Good may be altogether brought to an end; while they can only be carried to perfection when many outward conditions favour their development. But if this be admitted, the contention that virtue is independent of such favouring conditions falls to the ground.

The writings of Aristotle may be taken as typical of this view; though there are two distinct tendencies in his treatment of the subject, which correspond to his division of virtue into "theoretic," and "practical" or "moral virtue."

(a) We may consider the latter first, since it

1 Cf. Zeller, Socrates and the Socratic Schools, pp. 282, 311 n. 
falls within the sphere of practical life and ordinary morality which has just been referred to. Here Aristotle's view is that, although happiness (the ethical end,

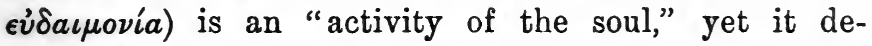
pends for its complete realisation on the presence of external goods, which provide the material and the arena for the actual exercise of this activity. Without these it remains incomplete and indeed unrealised, just as the best tragedy would fail of its end if, through lack of a choregus to provide for its production, it were never actually performed. ${ }^{1}$ When the idea of $a \rho \epsilon \tau \eta^{\prime}$ is held in this objective form, and when it is seen to depend for its realisation upon the presence of favourable outward conditions, it is clear that the idea of self-sufficiency must be in some degree modified. Thus in one passage in

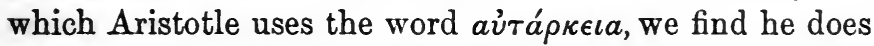
not apply it to the "independence" of the good will, but that he uses it as it is popularly used to-day, as describing a sufficiency of possessions for a good (i.e., complete or happy) life. Such a sufficiency, he says, is not unlimited in amount, but he clearly implies that it cannot be dispensed with. ${ }^{2}$

' 1 Eth. Nic., I., 1099 a 31 ff., 1101 a 15 ; VII., 1153 b 18. We may contrast the view in the last passage, of outward goods as necessary to an " unimpeded activity," with Marcus Aurelius' claim that the activity of virtue cannot be impeded (supra, p. 111).

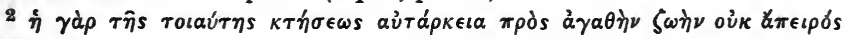
'́ $\sigma \tau \iota \nu$ (Pol., I., $1256 \mathrm{~b}$ 31. But on the subordination of material goods, necessary in their own place, to virtue, cf. IV. (VII.), 1323 a 38-1323 b 29). It may be added that even Kant, once at least in each of his three chief ethical writings, admits that it may be a duty to provide for happiness, and the means, "including skill, wealth, riches," for the performance of duty which are associated with happiness; because their absence " might easily become a great temptation to transgression of duty" (Grundlegung, IV. 399 ; Kr. der Prakt.-Vernunft, V. 93 ; Metaph. Anf. der Tugendlehre, Introd., V.B.-Abbott, pp. 15, 187, 299). 
Still clearer is the verdict on the needfulness of the immaterial good of society and companionship, which is expressed in the words: "Friendship $(\phi i \lambda i a)$ is a kind of virtue, or implies virtue. It is also indispensable to life. For nobody would choose to live without friends, although he were in possession of every other good." 1 Further, Aristotle holds that the State is prior to the individual, who cannot reach complete individuality apart from it; so that he who professes such entire independence of it as to have no need of association with others is not truly a man, but is "either a beast or a god." 2 Thus the conclusion is that

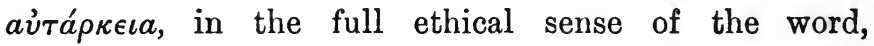
cannot be attributed to the individual as such. It is fully realised only in the State, which possesses in itself all that is needful, not for life only, but for the good life $;^{3}$ and it is to the political community alone the attribute of self-sufficiency, which is the mark of ethical completeness and perfection, rightly belongs. ${ }^{4}$ But when the State and not the individual is taken as the complete ethical unit, it is clear that there is at least a possibility of conflict between the interests of the individuals who compose it. The share of those material conditions which are held to be necessary to the full development of virtue will vary from man to man; and in so far as the possession of them is an

1 Eth. Nic., Book VIII. ad init., 1155 a 4 ff. (tr. Welldon). Cf. the fuller discussion in the following book, $1169 \mathrm{~b} 2 \mathrm{ff}$.

2 Pol., I., 1253 a 28 f. Cf. Eth. Nic., I., 1097 b 8 ff.

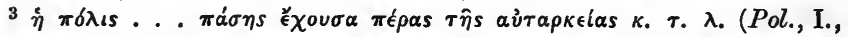
$1252 \mathrm{~b} 28$ ). The conjunction of these two significant words, $\pi \dot{t} \rho \alpha s$ and av่ $\alpha \rho \kappa \epsilon \iota \alpha$, is a striking illustration of the place of the State in Greek thought.

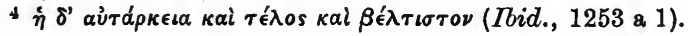


essential condition of the Good, its attainment by individuals will be competitive rather than common.

(b) When we turn to Aristotle's picture of the contemplative or "theoretic" life, we find that this conclusion is modified, but that the difficulty is not entirely overcome. It has often been remarked that there is a certain dualism between the two sides of Aristotle's thought; and this appears in the fact that, in the concluding book of the Nicomachean Ethics, he does to a great extent claim that the contemplative life brings selfsufficiency even to the individual. For while justice, courage, and the other "moral" virtues can only be practised in society, and are essentially related to social life, the philosopher stands alone in his contemplation. Although it may be " better for him to have fellow-workers,"

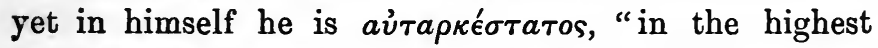
degree self-sufficient." 1 Here Aristotle anticipates the Stoic ideal of the Wise Man, and yet this view of the Sage is not wholly inconsistent with that already quoted from the Politics; for it is there said that the entirely self-sufficient life is either that of a beast or of a god, and in this culminating passage in the Ethics it is clearly taught that the contemplative life, in this high sense, is more than human, and is attainable by man only in so far as he shares in the nature of the divine. ${ }^{2}$ But even so, it is not raised above all conditions. One of these remains, for leisure at least is needed by the philosopher; and thus other men who provide for his bodily needs contribute to a good which they do not share. ${ }^{3}$ The contemplative life is not strictly

1 Eth. Nic., X., 1177 a 27-34.

2 Ibid., 1177 b 26 ff.

3 Ibid., 1177 b 4. The same view appears in Hebrew garb in the long passage in which Ben Sira praises the life of the Wise Man 
common or non-competitive, but is rather the privilege of a few; while most men are shut out from participation in it by the physical needs of themselves and others.

This suggests a doubt regarding the argument of Spinoza, quoted above, that the highest life is possible to all; for his description of that life has points of close contact with Aristotle's. The criticism would take the form of an inquiry as to the precise character of Spinoza's ideal. If it is one of pure self-absorption, the retreat of the human spirit within itself, the meditation

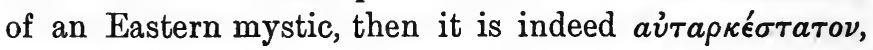
and, as far as any human activity ean be, it is equally open to all. But there are many indications that Spinoza's ideal is in reality a more concrete one, and that, by the intuition which he commends as the highest type of knowledge and as bringing the greatest "acquiescence of spirit," he understands something other than mere rapt contemplation of . the idea of the Infinite. Thus he argues that "we can never arrive at doing without all external things for the preservation of our being, or living so as to have no relations with things which are outside ourselves. Again, if we consider our mind, we see that our intellect would be more imperfect, if mind were alone, and could understand nothing besides itself. There are, then, many things outside ourselves, which are useful to us, and are therefore to be desired." 1 Still more conclusive is

(Ecclus. xxxviii. 24-xxxix. 11), beginning, "The wisdom of a learned man cometh by opportunity of leisure : and he that hath little business shall become wise. How can he get wisdom that holdeth the plough, and that glorieth in the goad?" This passage quite suggests the Greek contempt for the $\beta$ davavoos, though the dependence of his fellow-citizens on his labour is fully recognised (v. 32).

1 Ethics, IV. xviii. schol. (tr. Elwes). 
the short proposition which states that "the more we understand particular things, the more do we understand God," when it is remembered that the action of the mind in "understanding particular things" implies that the body is capable of being "affected in many different ways." 1 Thus knowledge, like the Greek á $\rho \epsilon \tau \eta^{\prime}$, proves to be to some extent at least implicated in physical conditions, the moment that we attempt to consider it in a wide and a concrete sense; and although, as Aristotle and Spinoza both rightly affirm, the higher Good is far from being as exclusive in its nature as the material "goods" for which men strive against one another in ordinary life, yet it is not wholly raised above the sphere of competition. For even knowledge depends upon conditions external to the mind, in which one man is more favoured than another, and in which his gain is not necessarily the gain of all.

Thus we find that the ideal of virtue, which may be distinguished as Hellenic, aims at the inclusion of all the faculties of man and the relations of political life, including wisdom, theoretic and practical, as well as inner virtue and the good will; and that the inclusion of this wide range of material involves at all events a prima facie conflict between the claims of individuals to share in the Good. Yet the bearing of the Greek view of life on our subject is by no means entirely negative: it also brings a definite and essential contribution to the doctrine of the Common Good, which must not be passed over without mention here.

The nature of that contribution has already been suggested by Aristotle's argument, which is no less

${ }^{1}$ V. xxiv. Cf. IV. xxsviii. 
characteristic of Plato, that man's good is not something solitary, but is essentially social. It is perhaps the greatest achievement of Greek ethics to have made it clear for all time that no man can reach the full development of his nature save in association with other men, and in the service of an ideal wider than his own private interests. The Good is common, in

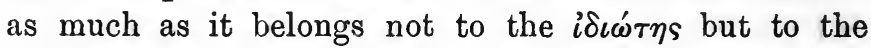
$\pi o \lambda i \tau \eta s$, and is won by the efforts of many workers striving for the same end, and not by the exertions of any isolated individual. As long as man lives for and by himself, his nature remains stunted and incomplete on every side, but in co-operation with others it is drawn upwards to perfection; and so the larger good which could not have been attained by any man alone, becomes a corporate good in which all may share. Thus, if in the last resort Greek ethics fails to accept the argument that the Good is non-competitive, because it has its seat in the heart of man and is unaffected by the outward events of his life; yet from the other side it gives a fuller content to the idea of the Good as common, both by emphasising its wealth and variety, and by proving that this wealth belongs to those alone who are willing to dismiss their private aims and interests, and to find their life in the wider life of the community.

IV.

There are thus two aspects of the theory of the Community of the Good, which are approached by two different lines of thought; and the question to be answered is whether these aspects can be reconciled 
in a single view, or whether they are radically divergent. The latter position is that of Sidgwick, who defends it at length in his searching criticism of Green's theory. His position may be stated in the form of a dilemma :either take the good in the Stoic or Kantian sense, in which case it is strictly non-competitive but entirely without content; or in the Greek sense, when it becomes concrete but loses its non-competitive character. The substance of Sidgwick's argument is given in a passage in which he charges Green with having "allowed his thought to swing like a pendulum between a wider and a narrower ideal of true good, sometimes expanding it to Culture, sometimes narrowing it to Virtue and the Good Will. When he thinks of full realisation of human capabilities, he brings in the development of artistic faculties and the cultivation of taste, as well as the development of scientific faculties and the pursuit of knowledge of all kinds; when he wants to bring out its non-competitive character, we find it shrunk to virtue and goodness of will." 1

Now, we may admit that it is of the highest importance to appreciate the significance of these two distinguishable points of view, without thereby conceding that they are incapable of being brought into harmony. The assumption that they are necessarily contradictory is closely connected with the view which Sidgwick shared with Mr Bradley, that there is a radical divergence in all ethical reflection between the form of theory which sets forth the highest good of the individual as the ethical end, and that which places it in the pursuit of the widest possible good for others; and both writers agree in holding in their widely differing ways that

${ }^{1}$ Lectures on T. H. Green, p. 71. 
this dualism shows itself at every stage of the moral life, and thus can only be transcended in the region where ethics passes over into religion. ${ }^{1}$ Now whether the opposition be stated in hedonistic terms, as that of Reasonable Benevolence and Reasonable Self-love, or in the language of idealism, as that of Self-sacrifice and Self-realisation, the view taken is fundamentally the same; and the antithesis, if not absolutely identical with that between the inward and outward aspects of virtue which we have examined, is very closely related to it. For the Stoic conception of virtue as an attitude of will, and as independent of outward events because it is the entire negation of natural impulse, has a clear affinity to the idea of Self-sacrifice; while that of Self-realisation is no less clearly related to the objective Hellenic view of virtue as the harmonious development of human capacities. In whichever form the problem is stated, the solution must be sought for along the same lines.

We may, after this explanation, go back to the dilemma as stated in Sidgwick's criticism of Green. His argument that the Good must either be considered as inward and non-competitive but void of content, or as objective and concrete but competitive, implies that the "formal" and "material criteria of virtuous action" are mutually exclusive and that their application leads to contradictory results. ${ }^{2}$ But is it not possible that either criterion by itself is incomplete, and that the full doctrine of the Common Good would do justice to both formal and material elements? Sidgwick's separation of the two seems to

1 Cf. the Concluding Chapter of The Methods of Ethics with Mr Bradley's well - known chapter on "Goodness" (Appearance and Reality, Ch. XXV.).

${ }^{2}$ Cf. Lectures on T. H. Green, p. 72. 
rest upon a double assumption-in regard to the former that the Good Will is purely abstract, "a will that wills nothing"; and in regard to the latter that the exercise of the varied powers of human nature, which is connoted by the Greek term $\dot{a} \rho \epsilon \tau \eta^{\prime}$, is purely self-regarding.

Both these assumptions may be questioned. In regard to the first, it is impossible consistently to carry out the idea of a purely inward good. The Good Will necessarily expresses itself in outward action, and a large part of its activity must lie among "those things which admit of being given and taken." 1 It is defined by Green as "the settled disposition on each man's part to make the most and best of humanity in his own person and in the persons of others " ${ }^{2}$ and this description breaks through the rigidity of the strict Stoic theory and combines the two ideas which Sidgwick insists must be held apart. Even the idea of Self-sacrifice cannot rightly be held apart from that of some end to be achieved, some effect to be wrought in the objective world-order by its means.

The other assumption, that the exercise of the intellectual and æsthetic faculties is necessarily self-regarding, is still more open to criticism. The truth is rather that in these activities the claims of the Common Good may be no less readily recognised and steadily kept in view than in many more obviously altruistic or philanthropic forms of endeavour. This point, however, calls for some further exposition, for it is often supposed that there is something peculiarly self-centred in the pursuit of knowledge or of artistic excellence, and that these activities necessarily stand outside the idea of the Good as common

1 Prolegomena to Ethics, § 256.

2 Ibid., § 244 ; and see Note I, p. 400, "Green's Doctrine of the Common Good." 
rather than individual. Nor is this merely a popular impression. It underlies all the criticisms which we have been considering, and it has been most vigorously and categorically stated by Professor Taylor. In arguing for the ultimate dualism of self - realisation and selfsacrifice he says, "By agreeing to call anything in which I am interested myself you can, with some violence to language and some confusion of thought, continue to make all morality wear the shape of self-satisfaction, but there is no conceivable device, short of boldly denying the facts, by which you can make it all look like self-surrender or self-forgetfulness." 1

Before so confident an attack as this the mere layman in matters artistic might well feel it prudent to retreat; but fortunately for the present argument he can shelter behind the opinion of those who are admittedly qualified to express a judgment. And first he may appeal to the greatest of English critics:-

"The love of nature is the first thing in the mind of the true poet: the admiration of himself the last. . . . He who thinks much of himself, will be in danger of being forgotten by the rest of the world. . . . They cannot be expected to admire his works because they are his; but for the truth and nature contained in them, which must first be inly felt and copied with severe delight, from the love of truth and nature, before it can ever appear there. Was Raphael, think you, when he painted his pictures of the Virgin and Child in all their inconceivable truth and beauty of expression, thinking most of his subject or of himself ?. . . Do you imagine that Shakespeare, when he wrote Lear or Othello, was thinking of anything but Lear and Othello? . . . No:

1 The Problem of Conduct, pp. 193 f. 
he who would be great in the eyes of others, must first learn to be nothing in his own." 1

It may, indeed, be said that, even if we accept this view of art, it is by no means proved that the true artist works with a view to the Common Good, but rather that his attention is fixed on the object. But this is in itself sufficient to undermine the theory that all exercise of artistic faculty is self-regarding, and to show that only as far as the artist ceases to think of his own powers and their realisation and loses himself in the object, can he find the noblest expression for his vision of it. Thus it is not by "boldly denying the facts" but by facing them impartially, that we are led to the conclusion that there is an essential element of "self-surrender" and "self-forgetfulness" even in those activities which are least akin to the ordinary forms of altruism. The same truth is implied in Hegel's view of Art as one means of reaching the Universal. But the truly Universal can only be reached in the measure in which the artist transcends the limitations of his own individuality, and rises above "particularity" and mere mannerism. "Phidias has no mannerism." 2

But when true Art is thus looked on as the Universal, it becomes possible to relate it to the idea of the Common Good which expresses universality on another side. We may take the example suggested by Hegel, that of Phidias and the Parthenon. In the supreme work of Phidias and Ictinus, there is no trace of self-assertion. Their whole endeavour was to give a worthy embodiment and expression to a great ethical idea-the idea of united wisdom, courage and liberty, which was per-

1 Hazlitt, Lectures on the English Poets, Lect. VIII. ad init.

${ }^{2}$ Hegel, Philosophy of Right, § 15, addition (tr. Dyde, p. 26). 
sonified in the figure of Athene, and in some measure realised in the polity of Athens. Just as truly as the unknown masters who raised the Gothic cathedrals, their whole personality found its fulfilment in the service of an ideal; and wide as was the difference between the Greek and Christian conceptions of the Divine Nature and of religious service, the result was alike in this, that the building raised in honour of the divinity became a $\kappa \tau \hat{\eta} \mu a$ '́s $\dot{a} \epsilon \dot{\imath}$, -a possession for all generations of men.

It is possible, however, to show a still more direct connection between the two ideas. Professor Murray has recently pointed out that in classical times Art, and especially Poetry, were valued and judged according to their effect in furthering or hindering the Common Good, to an extent that the modern æsthete would cry out against as Philistine and utilitarian. ${ }^{1}$ In a later age Dante began his De Monarchia by saying that the lover of truth, who has gained knowledge of the ways of men, will be "far astray from his duty if he cares not himself to contribute aught to the public good." For then he is like "the devouring whirlpool, ever engulfing, but restoring nothing." 2 And in our own day the principle which we are seeking to establish has been expressed in the legend which Watts inscribed on his picture, Sic transit, and which well expresses the character of his own life, "What I spent I had: what I saved I lost: what I gave I have." ${ }^{3}$ Finally we may appeal to the authority of the greatest modern prophet of Self-

${ }^{1}$ The Rise of the Greek Epic, pp. 1,2; cf. p. 24, and the striking quotation, p. $28 \mathrm{n}$.

2 De Mon., I. i. (tr. Church.)

${ }^{3}$ For the original form of this epitaph, see Gibbon's "Digression on the Family of Courtenay," Decline and Fall, Ch. LXI. 
realisation. In the second part of Faust, Goethe represents the salvation of his hero as only attained when he gives his strength to unselfish work for the good of others; and in the chorus of the angels which marks the completion of his deliverance, he is referred to not as an isolated individual, but as "the noble member of the spirit world." 1

We are thus led to the conclusion that on the one hand the Good Will must become operative in the external world and that the form of its operation must depend upon material conditions, and on the other that the idea of the Common Good is wide enough to embrace the most varied forms of human excellence and activity. With these two facts in view, it may be possible to bring together both the elements which we distinguished into a consistent theory. This can only be done by recognising that external things are indeed of importance for the moral life, but that they must be regarded from the point of view of contribution and not from that of acquisition. Just in as far as they are so regarded, they acquire true value as the means of expressing the good character and furthering moral ends. The Good Will is not "a will that wills nothing," but one that uses external things for its own purposes. The objective results of its action will indeed depend on many things external to itself; but no combination of outward circumstances can render it wholly ineffective, for goodness has a power of impressing its stamp on the most unyielding material. The essential rule of conduct -and hence the central category of ethics-is neither

1 Faust, Part II. Act V. :-

"Gerettet is das edle Glied

Der Geisterwelt vom Bösen." 
self-sacrifice nor isolated self-realisation, but the use of whatever power each man may possess for the furtherance of the Common Good.

This view of moral progress as an advance from the spirit of acquisition to that of contribution is no new one. The antithesis is the same as that between rights and duties already referred to in the teaching of Mazzini, or that between competition and co-operation proclaimed by Maurice and the "Christian Socialists" and echoed by many thinkers since. But all its modern forms may be traced back ultimately to the ruling idea of Plato's Republic, that all the weakness and misgovernment of actual states is due to the conflict of interests and desires among their citizens, and that, for the building up of a strong and stable polity, the one great need is that conflict of interests should give place to unity of desire and aim. The first step towards this end is the recognition that the happiness of the whole State is of more importance than that of any individual or class within it. ${ }^{1}$ It is further needful that the objects which can be shared by all should be of more account than those which cause rivalry between different citizens; while the supreme principle of the Platonic legislation is that "the lawgiver does not seek to procure an exceptionally favoured life for any one class in the State; but works for the accomplishment of this end in the State as a whole, binding the citizens together by persuasion or by constraint, and so causing them to share with others the particular contribution which each can make to the common weal, to the end that each man

1 Rep. 420 B. Cf. 462 , and Cromwell's saying, "If there be any one that makes many poor to make a few rich, that suits not a commonwealth" (Morley's Cromvell, p. 339). 
should not turn aside at his own pleasure, but that all should be of service for the welding together of the State." 1

Nor is this principle to be considered as purely Platonic, in the sense that it is inseparable from the literal communism of the Republic. Plato had in this respect no more severe critic than Aristotle; yet Aristotle fully accepted the principle though he rejected many of its applications. While vigorously defending the institution of private property, he taught that property must be held ready for the use of friends or of country when it was needed by either. "Private possession with common use" was his formula for the best form of property, and he repeated with approval the Pythagorean proverb, "Friends' goods, common goods." 2 His defence of private property may be said to rest upon the principle of possession as a means to contribution; for what each man gives to his friends or the state will have greater worth if it is a free gift of that which he himself values. Thus Aristotle only supports the institution of private property on condition that it is not allowed to obscure the higher principle, that all things should be at the service of the community when it stands in need of them.

We may now ask how far this view of the Good, as the will to contribute to the needs of the social whole, meets the objections which have been urged against the theory that the Good is essentially common. At the outset, it must be emphasised that this view does

1519 E-520 A. The central words of this passage are of especial im-

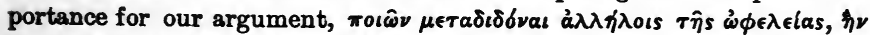

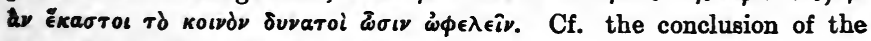
quotstion from the Politicus, supra, p. 9.

${ }^{2} P o l$. II., 1263 a 22 ff. —ко 
not depend on any supposed equality in the lives of individuals, either when estimated subjectively by the standard of pleasantness, or objectively by the concrete and measurable value of their work. Such equality cannot be completely attained; and, in any society which we can think of as possible, differences must continue to exist, both in the inner fulness and the outward effectiveness of various lives. But is it therefore impossible to imagine a polity in which all desires and efforts would be directed to and would converge upon a Common Good? In view of what has already been said, this does not seem impossible; for the solution of the difficulty is to be looked for in the fact that all those endowments, both inward and outward, which cause the inevitable differences in breadth and intensity of various lives, are, from the higher point of view, regarded as given for the service of all, and not, in the first instance, for private enjoyment or advantage.

In a community ruled by this principle, those to whom had fallen the duller and more monotonous tasks would realise that these, no less than the more attractive and conspicuous, were needful for the Common Good; while they would feel that the faithfulness of their labour was not unappreciated nor its difficulty ignored. For the complement of the principle of Contribution, of the Good Will as directed to the Common Good, is that with which our last chapter dealt-that the ultimate standard of value is what a man is, rather than what he does, that it is not the outward effectiveness of his work, but the sincerity with which his work is performed. If such a standard of judgment were not only formally recognised but consistently applied, 
the sense of injustice and lack of due appreciation which causes much embittered feeling between class and class would of itself pass away. But more than this, the true application of such a standard on the part of those who are more liberally endowed with the opportunities of knowledge and culture would lead-does in a measure already lead-to the endeavour to distribute these opportunities more widely and equally, so that every citizen may have a wider enjoyment than in the past of the wealth of the corporate life, and may more fully understand how his task contributes to the well-being of the whole. Such an understanding would make far easier that willing acceptance of a relatively humble place in the economy of the nation, which, even now, may often be found.

In such a voluntary surrender to the interest of the whole-whether it be made by one who occupies a great or an obscure station-we see the principle of human instrumentality reappear in a changed form. Now it has in truth become a moral principle; for, while it is wholly contrary to the spirit of Christianity that men should be used as means for the attainment of ends in which they have no personal share, it is of the essence of Christian morality that they should be ready to sacrifice their own immediate advantage to the forwarding of a wider good, and so become instruments indeed, but willing instruments, in its realisation.

Thus, as Plato saw, the well-ordered state will be that in which each section loyally performs its own function. ${ }^{1}$ Those to whom fall the less outwardly desirable forms of labour will be supported in their tasks by nothing so much as the knowledge that those in higher station

1 Rep., Book IV., especially 433, 443 f. 
are no less steadily moved by the desire to contribute to, and not to live upon, the common weal. To borrow the classification of the Republic, when Wisdom and Courage are shown by the rulers of the State, then the complementary virtue of Self-control will be shown by those in other ranks, who know that, although their station be less conspicuous, they are not cut off from participation in the Common Good.

\section{V.}

There remain two objections, which must be noticed before this chapter concludes. (1) It has been argued that the principle of Self-sacrifice cannot be consistently carried out, or taken as the supreme law of ethics; for, if it were universally practised, it would lead to the paradoxical result of a universal sacrifice by each man of his own good to the good of others, while nowhere would any concrete good be realised or enjoyed. Herbert Spencer, who used this argument, accordingly reached the ingenious conclusion that egoism is no less necessary to successful altruism than altruism to successful egoism. Egoism must persist, in order that the self-denying efforts of altruism may not be wasted. ${ }^{1}$ Enjoyment must begin somewhere. To the last statement we may heartily agree, nor is it inconsistent with the theory of Plato, Spinoza, and Green when this is rightly understood. And it is easy to see that here the definition of the good life, as that of "contribution to the Common Good," is superior to the theory of "altruism" strictly understood. For the latter does

1 The Data of Ethics, Chh. XIII., XIV. 
lead to a theoretic contradiction, however far we may be in practice from any grave danger of excessive altruism. But the theory which we have been following out is not that of mere self-sacrifice or self-denial. The will to bring the best possible contribution to the public weal leads to self-development as well as to self-denial; and for many men it must involve such self-culture in a high degree. Hence the emphasis on the education of the Guardians in the Republic; they were to be made the best men, in order that they might perform the highest service. Such a training and exercise of the powers of body and mind as Plato there describes brings with it its own reward; while in a community in which the ruling spirit was that of service, the general level of wellbeing would be so high, the diffused capacities of happiness so great, that even those whose toil was hardest, and in itself least remunerative, would gain a sufficient share in the fruits of the common endeavour.

Thus the theory of the Common Good is not open to all the objections that beset the attempt to universalise the principle of mere "self-sacrifice." Its very designation shows that it is wider in its scope; for the idea of common good suggests community of enjoyment as well as of endeavour. What it does deny is, that immediate individual acquisition or enjoyment should ever be set against the good of the wider circle of men. Its advantage over such theories as those of Spencer and Sidgwick, which start from Egoism and Altruism as definitely separated factors in morality, and so can only arrive at a "conciliation" by a process of "trial and compromise," is that it does justice to that vital unity of the Individual and the Community which, even 
though it be "last in the order of nature," is the presupposition of a completed morality.

(2) The other objection is that in our discussion the question has been unduly simplified, inasmuch as we have only considered the possibilities of conflict between Egoism and Altruism, and not between a narrower and a wider Altruism. Yet the latter is also possible. ${ }^{1}$ To speak of the Common Good as a unity set over against the individual good may have been accurate in the days of the Greek city-state, but fails to represent the complexity of the problem as it confronts us now. For the individual of to-day is commonly surrounded not by one, but by four or five circles of varying circumference, whose members have claims on him. He has to consider his relation and duty not only to the state, but to the narrower circles of the family, church, or profession, and to the all-encompassing circle of humanity; and this rise into prominence of the family, the church, and the idea of humanity as a whole, whose heightened claims are all due to different operations of the Christian ideal, has undoubtedly introduced a new complexity into the problems of ethics. While the questions thus raised are too wide for full discussion here, it may be observed that the conflicts which arise in this way are often placed in too absolute a light. The claims of parental and civic duty do in many cases seem divergent; yet it is becoming increasingly clear to all save the more extreme socialists, that the welfare of nations depends primarily on the strength and completeness of the family life within their borders. In the same way it is coming to be more and more gener-

${ }^{1}$ Cf. Taylor, The Problem of Conduct, pp. 205, 274 ; Sidgwick, Lectures on T. H. Green, p. 70. 
ally realised how closely the separate welfare of church and state is bound up with the due performance by each of its own special functions. It is indeed true that exclusive loyalty to the family may be disloyalty to the state, just as a blind patriotism may lead to the betrayal of humanity; yet none the less is the welfare of the state bound up with that of the families within it, and the progress of the world with the progress of the various nations.

Yet it is possible to admit that there are such conflicting claims on the loyalty of individuals without thereby surrendering the doctrine of the Common Good. For, like the complementary doctrine of the Value of the Individual, it is rather the statement of an ideal than of a fully realised fact. Thus Green says, "The idea of the good, like all practical ideas, is primarily a demand. It is not derived from observation of what exists but from an inward requirement that something should be."1/ Even if we may hold that this statement on its negative side requires qualification, and that there is positive evidence, to be gained "from observation of what exists," of the actual operation of the principle of Common Good, and of tendencies to reconciliation between its divergent applications; yet we may emphatically agree that it must be used and judged as an ideal.

This principle is not indeed removed from all possibility of verification in experience, for in the fact of the selfpropagating character of goodness and the elevation of ethical influences above the limitations which affect ordinary material goods, we see its continuity with the facts of life as we know them; and in every instance in which personal advantage, and even life itself, is surrendered

\section{Prolegomena to Ethics, $\$ 230$.}


for the sake of a wider good than that of the individual himself, it appears as actually operative in the world. Yet its complete realisation lies beyond present experience; and when its ideal character is thus understood, the actual conflict of claims between a wider and a narrower altruism no longer proves a final objection to its validity. Such conflicts must be recognised in present experience, but they will not appear final if it is held that their solution is part of the ethical task which runs through all the history of man. It is no doubt a temptation for the idealist to represent the progress by which the Common Good is established as simpler and more direct than experience shows it to be. But if the recognition that it is often indirect and circuitous removes the possibility of a full realisation of the ideal further from us, yet this is not wholly a loss. For the growing complexity of the conception of a truly common good, which shows itself in the emergence of these new problems, is in itself a sign of the enrichment of the ideal and the widening of its scope.

In thus treating the principle of the Community of the Good as an ideal, whose working may be traced in experience but which points beyond any fact of present experience, we are in agreement with the view of Kant. ${ }^{1}$ The validity which he claims for it is of this order. If the old claim that ethics is a "normative science" is to be maintained, there must clearly be room within it for such guiding principles or standards; and if any such are to be admitted as valid, it can hardly be denied that this must be of their number. For, widely as moral philosophers have differed in their pictures of the ideal

1 Critique of Pure Reason, "The Canon of Pure Reason," $\$ 2$ (2nd ed., pp. 836 ff.). 
polity, two statements regarding its nature must command wide, if not complete, agreement-first, that every member of it should contribute according to his ability (but willingly and not of constraint) to the good of the whole, and, second, that no man should be debarred from sharing in the good which he helps to create. But these two statements are the positive and negative conditions of the existence of a Common Good; and on this foundation we may rest its claim to be one of the great regulative ideas of the moral life.

Thus there remain two aspects of the idea which we have traced. That from which we started represented it as an inward possession, that which we have finally reached, as the principle of an objective order. But the principle, as it passes from the subjective to the objective stage, from the implicit to the explicit, is still essentially the same. For that inward inalienable character of the Good as the life of Spirit, by its freedom from the clash of contending interests and its power of passing undiminished from man to man, points the way to an outward and visible manifestation of the same idea. It provides a goal for human effort by showing that the highest goods are not to be reached through competition but through co-operation, and that it is possible to imagine and work for a state of society in which every individual would have some adequate sense of the significance of the whole, and some worthy share in its activities. $^{1}$

1 Cf. Note K, p. 400, "Dante on the Community of the Good." 


\section{CHAPTER V.}

THE COMMON GOOD AND THE INWARD AND OUTWARD ASPECTS OF VIRTUE IN THE NEW TESTAMENT.

The same tendencies, which in the last chapter were considered in a philosophical connection, meet us also in the ethical teaching of the New Testament. Indeed, they are there displayed with even sharper outlines, for nowhere do we find more strongly maintained both the view of the inwardness of virtue, and that of the Good as realised through outward agencies and even through the things of the material world. Thus the problem of the real relation of these two ideas is no less important for Christian Ethics than for Moral Philosophy.

\section{I.}

On the former aspect of the ethical end-its independence and inwardness-the teaching of the New Testament is so clear, that at first sight it might seem possible to rest the whole structure of Christian morality upon this foundation; and this has indeed been done, not only by the early Christian ascetics, but by St Francis, to a great extent by Tolstoi, and by all who have taught that the secret of Christianity lies in a holy poverty, and in the effort to gain perfection by renouncing rather than 
by using aright the benefits of the material world. And although this view is incomplete, it can be defended by an appeal to many of the most familiar passages in the New Testament. There is much in the teaching of Jesus to suggest that He looked on the roots of character as lying too far beneath the surface of human nature to be readily affected by the rain or sunshine of outward events. ${ }^{1}$ It is needless to repeat what has been said above regarding this side of His message ${ }^{2}-$ His recognition of goodness in unsuspected places, His proclamation that the blessings of His Kingdom lay nearer to the poor than to the rich, and His assertion of the absolute worthlessness of worldly possessions in comparison with the value of the soul.

In this respect the Beatitudes are rightly taken as the centre of His teaching, and there are many incidents and sayings in His life which show how firmly $\mathrm{He}$ asserted the superiority and independence of spiritual interests, when material needs come into conflict with them. Among these is the reference to Deuteronomy in the narrative of the Temptation, "Man shall not live by bread alone, but by every word that proceedeth out of the mouth of God." 3 Such also is the exhorta-

1 "Was hilfts den Seelen, dass der Leib ungefangen, frisch und gesund ist, isst, trinkt, lebt wie er will ? Wiederum was schadet das der Seele, dass der Leib gefangen, krank und matt ist, hungert, durstet und leidet, wie er nicht gerne wollt? Dieser Dinge reichet keines bis an die Seele, sie zu befreien oder fahen fromm oder böse zu machen. . . . So müssen wir nun gewiss seyn, dass die Seele kann alles Dinges entbehren, ohne das Wort Gottes, und ohne das Wort Gottes ist ihr mit keinem Ding beholfen."-Luther, Von der Preiheit eines Christenmenschen.

2 Pp. 91-94.

3 Matt. iv. 4. Here as elsewhere Jesus taught even more by His example than by His commands. Compare the warning to a would-be disciple that "the Son of man hath not where to lay His head" (Matt. viii. 20 ; Luke ix. 58). 
tion to the disciples, "Be not afraid of them which kill the body, but are not able to kill the soul." 1 Again, Jesus laid great stress on the necessity of concentrating on one supreme object those faculties which are too often dispersed over many trivial objects. "One thing thou lackest"; "Thou art anxious and troubled about many things: but one thing is needful" 2-in such words as these Jesus lays supreme emphasis on a single and simple act. But if this be all, if His whole teaching can be summed up in the single exhortation to take up the cross and follow $\mathrm{Him}^{3}$ and the whole lesson of discipleship be that of the need for the spirit of the little child, may it not be said that no man, whatever his intellectual attainments or worldly position, can plead inability to hear and answer so clear a summons, and that the highest good is directly brought within the grasp of all? Does not Christianity do away with all need for the alteration of material conditions and for "the gifts of civilisation" by teaching that faith is the one thing needful, and that it may be exercised by all, ignorant as well as learned, Gentile as well as Jew? And if the highest ethical and spiritual gifts are thus placed within the reach of all men, do we not find in the teaching of the New Testament a direct proof of the doctrine that the true Good is common to all, and that there can be no possible conflict of claims to share it?

The same sense of spiritual good as being something simple, secure, and inalienable, pervades much of the thought of Paul. $\mathrm{He}$ is ready to lay aside all the weapons of learning or of intellect to proclaim the simple message of the Cross; he "counts all things but loss,"

\footnotetext{
1 Matt. x. 28.

3 Mark viii. 34.
}

2 Mark x. 21 ; Luke x. 41 f. 
and is eager to divest himself of all merely human and individual powers in order to be known as the instrument of a divine power $;^{1}$ while in the Quis separabit? which concludes the eighth chapter of Romans, his faith rises to a height at which all material aids or hindrances to goodness seem alike negligible in face of an all-controlling spiritual experience. Such a faith as there finds expression in the free working of the Spirit sees in it a power able to bring all things into subjection to itself; and to one living at such a level of thought and experience it seems the merest irrelevance to speak of goodness as in any sense dependent upon the possession of those material things, in regard to which the interests of men conflict, and the success of one man involves the failure of another.

This sense of the benefits of Christianity as open to all, and as independent of mediation through any external agency, was strengthened by the apostolic belief in the presence and activity of the Risen Master, now set free from all the physical conditions which had limited the scope of His earthly ministry. Whatever critical view be taken of the evidence for the Resurrection, there can be no doubt of the central position which it held in the belief of the primitive Church, nor of the effect of this belief in enabling the smallest and most isolated body of Christians to feel themselves in contact with the source of all spiritual power. During the ministry of Jesus in Palestine, His words had been heard by comparatively few men and women, and His influence travelled by the uncertain means of ordinary human communication. But in the Epistles, the Fourth Gospel, and at least twice in the Gospel of Matthew, there appears the assur11 Cor. ii. 2 ; Phil. iii. 8 ; 2 Cor. iv. 7 ; cf. xii. 10. 
ance that these limitations were only for a time, and that the forces which Jesus wielded for the redemption of man were no longer confined to a few favoured disciples, but had become universal in operation and independent of the restrictions of space and time. ${ }^{1}$ To the primitive Church the conclusion of the earthly life of Jesus, so far from limiting His power, made it possible for Him to bestow the highest gifts on all men without distinction of rank or place or time. ${ }^{2}$

It is thus apparent by what path Paul reached the conviction that spiritual wealth was independent of outward conditions, and that one who was outwardly destitute might yet have the power to enjoy and to bestow the greatest of all benefits. He expressed this belief in one of the most striking of New Testament paradoxes, when he described himself and his fellow-workers "as sorrowful, yet alway rejoicing; as poor, yet making many rich; as having nothing, and yet possessing all things"; and he was persuaded that the message which they carried could make its way in all conditions, "by glory and dishonour, by evil report and good report." ${ }^{3}$ Here we find the Christian analogue of the conception of

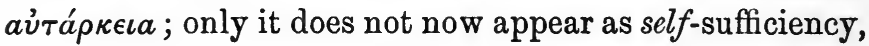
for this Paul denies-" Not that we are sufficient of ourselves, to account anything as from ourselves; but our

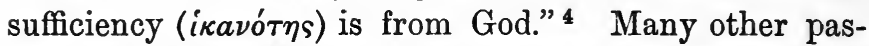
sages might be referred to; but enough has been said to indicate the presence in the New Testament of the

1 Matt. xviii. 20 ; xxviii. 20 ; John xii. 32.

${ }^{2}$ Eph. iv. $7 \mathrm{ff}$; John xvi. 7 ; and cf. Somerville, St Paul's Conception of Christ, pp. $55 \mathrm{f}$.

32 Cor. vi. 8, 10.

42 Cor. iii. 5. In Phil. iv. 11, where the word aủrápкns does occur, it is to be read in the light of v. 13 . 
thought that external things are indifferent when compared with spiritual good, and that the attainment of the latter is directly and immediately possible in any outward state.

II.

But this side of the Christian religion-on which it approaches the Stoic insistence on the inward and inalienable nature of virtue, though with a warmth and persuasiveness to which Stoicism never attained-is not the only one, nor may Christianity be identified with an ascetic indifference to outward conditions or to physical suffering. This is shown by the fact that Jesus gave so large a portion of His short ministry to relieving physical suffering. "The healing ministry was a tacit but effective protest against asceticism and the dualism on which it rests, and a proof that Jesus had no sympathy with the hard antithesis between spirit and flesh." ${ }^{1}$ It is true that, as Dr Bruce from whom these words are taken says elsewhere, preaching was always first with Jesus ; and that more and more as His ministry proceeded He sought to limit His work as a physician of the body, in order that $\mathrm{He}$ might concentrate His effort on the spiritual training of those who were to carry on His mission. ${ }^{2}$ Yet none the less do the care of Jesus for the bodily wants of men and His sympathy with all forms of suffering stand out as among the clearest features of the gospel narrative. The importance which $\mathrm{He}$ attached to this side of His work appears in His answer to the question of John the Baptist regarding His Messianic

I A. B. Bruce, Expositor's Greek Testament, vol. i., Introd., p. 24.

${ }^{2}$ Cf. Note L, p. 401, "The place of Healing in Jesus' Ministry." 
claims; and He clearly dwelt with especial delight on those passages in Isaiah which describe such works of mercy as among the chief glories of the Messianic Kingdom. ${ }^{1}$ Even in comparison with the question of political freedom which filled the minds of so many of His fellowcountrymen, or with the directly moral reformation on which the hopes of John were set, Jesus would not allow that this labour was unimportant; nor did His sense of the burden of the nation's moral destiny prevent Him from seeking to lighten the burden of physical pain which oppressed even its feeblest member.

The work of healing was in Jesus' view so urgent that in pursuit of it $\mathrm{He}$ was ready to break through the Jewish restrictions regarding the Sabbath, and so to call forth the criticism and opposition of those whose religious reputation stood highest in the eyes of His countrymen. The words, "Is it lawful on the sabbath day to do good, or to do harm? to save a life, or to kill ?" 2 show that He looked on this as an essentially religious duty, appropriate to the sacred day and place; and the hardness of the Pharisees in refusing to admit this moved Him both to grief and anger. ${ }^{3}$ Again, it is clear that this side of Jesus' ministry was no merely external process, but that it depended for its efficacy on the same inward conditions and religious attitude as His preaching. To the author of the First Gospel it showed that bearing of the sufferings of others of which Isaiah liii. speaks $;^{4}$ while Jesus Himself taught that faith on

${ }^{1}$ Cf. Matt. xi. 5 (Luke vii. 21 ff.) with Is. xxix. 18 ; xxxv. 5 f. ; and Luke iv. 18 with Is. $1 x i .1$.

${ }^{2}$ Mark iii. 4. Cf. Matt. xii. 11 f.; Luke xiii. 16 ; xiv. 3 ff.

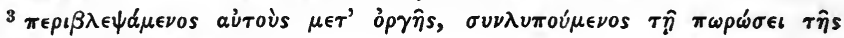

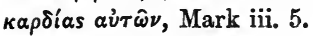

${ }^{4}$ Matt. viii. 17. 
the part of the sufferer is no less essential a condition of healing than is prayerfulness, in which faith is implied, on the part of him who would exercise healing power. ${ }^{1}$

To this direct evidence of the extent to which Jesus rejected the ascetic ideal of self-sufficiency and independence of all outward means of encompassing the good, there may be added one or two less immediately obvious considerations. We have seen how, in the thought of Aristotle, a sufficiency of worldly goods, friendship, and leisure, are all looked on as needful to the good life. ${ }^{2}$ Now, Christianity has certainly modified the Greek idea of what constitutes a "sufficiency" of material "goods" for the good life, and has shown how the noblest character and the truest happiness may be found in the midst of outward poverty; yet Jesus did not deny the need for the ordinary supports of life. " While He earnestly deprecated carefulness about such things as food and clothing, He nevertheless recognised these as things which all have need of." 3 More than this, He gave a religious sanction to their enjoyment when He said "Your heavenly Father knoweth that ye have need of all these things"; and when He commanded His followers to offer the petition, "Give us this day our daily bread." 4

With regard to the other two requisites of the truly virtuous life as Aristotle conceived it-friendship and leisure,-it is clearer still that they cannot be dispensed with without detriment to the growth of character. Under normal conditions, the Christian life is not solitary but social, and can only reach its perfection in the

1 Mark v. 34 ; ix. 29 (R.V. om. " and fasting "). Cf. vv. 23 f.

${ }^{2}$ Supra, pp. 117-119. $\quad{ }^{3}$ Stalker, The Ethic of Jesus, p. 138.

- Matt. vi. 11, 32. 
presence of friends and in the community of love and service. In the same way, although it does not by any means demand for its development the ample leisure of the philosopher or the Athenian gentleman, yet a certain detachment from the pressing interests of the world, and some opportunity for quiet thought, is in most cases, if not in all, essential for the Christian. Jesus recognised this by setting the seal of His approval upon the institution of the Sabbath rest; ${ }^{1}$ and when He saw that the excitement and the crowds which attended on His Galilean ministry were becoming a danger to the spiritual development of His disciples, and that a season of leisure was needful for them, He called them to come apart by themselves "into a desert place, and rest awhile." 2 Again, He enjoined times of solitary thought and prayer in the words, "Enter into thine inner chamber, and having shut thy door, pray to thy Father which is in secret." 3 Now, sayings such as this point to real conditions of spiritual progress; and we cannot separate these conditions from external things. The opportunity for solitary thought and devotion, which the passage last quoted assumes as essential for the normal Christian life, is not in fact possessed by tens of thousands of the inhabitants of the vast blocks of two-roomed and even one-roomed houses in the crowded quarters of our cities; and we can by no means assume that the difficulties which such conditions throw in the way of the life of goodness would have appeared indifferent to Christ.

Again, His teaching was thrown into a form which presupposed knowledge in His hearers of the quiet life of the country. He drew lessons from the birds and

1 Mark ii. 27 f.

${ }^{2}$ Mark vi. 31.

${ }^{3}$ Matt. vi. 6. 
the flowers, and the patient comradeship of the oxen beneath the yoke provided one of His most memorable illustrations of the nature of the new life to which $\mathrm{He}$ called men. ${ }^{1}$ But it has been truly observed that those who pass their lives amid the gloom and the ceaseless rush and noise of a great city have often no opportunity of becoming familiar with these things, and hence for them one way of access into the heart of Jesus' message, simple as it is, is entirely closed.

From such facts as these it clearly follows that the principle, which underlay the healing work recorded in the Gospels, leads directly to the consequence that it is not less important to prevent disease by the creation of a healthy and spacious environment than to relieve the suffering that actually exists. This principle may be defined as that of the unity of human nature. Strongly as Jesus asserted the power of the spirit and the supremacy of spiritual forces over those of the material world, yet His teaching cannot be appealed to in support of the ascetic method of simplifying moral problems by neglecting their material elements. Body and spirit form one man; and this unity explains the fact that Jesus approached men, now by a direct moral appeal, and now by the silent persuasion of deeds of mercy. He knew the various entrances to the secret places of man's nature, and He did not neglect even indirect means of compassing spiritual good.

This union of carelessness and care for the body, of contempt for and sympathy with suffering, which marked the ministry of Jesus descended also to His followers in the early Church. It has been characterised by Seeley in a striking passage, in which he describes the appear-

${ }^{1}$ Matt. vi. 26, 28 ; xi. 29, \&c. 
ance in the Roman Empire of a sect "which distinguished itself by the assiduous attention which it bestowed upon the bodily wants of mankind," and the appearance at the same time of "a sect which was remarkable for the contempt in which it held human suffering." "These two sects," he continues, "appeared to run into contrary extremes. The one seemed to carry their regard for the body to the borders of effeminacy, the other pushed Stoical apathy almost to madness. Yet these two sects were one and the same-the Christian Church." 1

This point has special importance in relation to the beginnings of the higher life ; and it may help to explain the contrasted emphasis on the inner and on the outer aspects of life, both of which are strongly insisted on in the New Testament, if we observe that their relative importance differs at different stages of religious development. From a mature disciple a degree of spiritual independence and of contempt for outward obstacles may be expected, which could not be asked of one to whom the whole spiritual region was an unexplored country. The ultimate end of Christianity, the supreme gift, may be raised above material conditions; yet, as has been well said, "sometimes this gift can only be apprehended through lowlier gifts. ... And when life is sunless, and all its relations are debased, and fortune is unfriendly, how is a man to begin to believe in the love of God? When he has learned to know Him, he can walk with God even in the dark, but how shall he know Him first?" 2 At the outset, before the source of strength has been found within, it is necessary that moral and religious impressions should come to men in such a

${ }^{1}$ Ecce Homo, Ch. X. Cf. Ch. XVIII.

${ }^{2}$ W. M. Macgregor, Jesus Christ, the Son of God, pp. $216 \mathrm{f}$. 
concrete form as will appeal to their actual powers of apprehension, and so gradually awaken their higher nature into life.

The same distinction between the beginning and the full development of the spiritual life in respect of independence may be illustrated from the writings of Paul. He speaks of his power to meet good and evil fortune with the same calm and gladness as the ripe result of his whole religious experience and development. "For I have learned, in whatsoever state $I$ am, therein to be content. I know how to be abased, and I know also how to abound : in everything and in all things have I learned the secret both to be filled and to be hungry, both to abound and to be in want. I can do all things in him that strengtheneth me." 1 Here the word

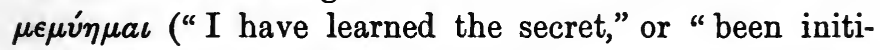
ated into") represents the faculty of gaining good from all circumstances as one that has been acquired by slow degrees and by the long lessons of experience.

Again we may observe that, in spite of Paul's belief that "the word of God is not bound," 2 and can make its own way even if the ordinary means of carrying it are removed, he does not deny the use and even the necessity of these ordinary means, especially in relation to the beginnings of the spiritual life. For in the same passage in which he quotes the saying, "The word is nigh thee," and says that "the same Lord is rich unto all that call upon him," he proceeds, "How then shall they call on him in whom they have not believed? and how shall they believe in him whom they have not heard? and how shall they hear without a preacher? and how shall they preach, except they be sent?" 3 Here it is implied

\footnotetext{
1 Phil. iv. 12 f. $\quad 22$ Tin. ii. 9.
}

3 Rom. x. 8 12-15. 
that in the manifold and complex order of the world of experience one element cannot be completely isolated from the rest, nor can the idea be consistently carried out that spiritual and material agencies are wholly independent. Roman roads and posts and Phœnician merchantmen played a definite part in making possible the spread of the Christian faith; nor did the spirituality of that faith, and its character as something directly given to the receptive mind and heart of man, release those who had felt its power from the obligation to extend its sway by the use of ordinary material agencies. Thus we return to the description of Christianity given in the first chapter; for in so far as it is looked on as an inward and irresistible spiritual power, the fitting attitude of the believer is that of expectation and of quiet trust; but in so far as it is mediated through outward events and advanced by human effort, there is a call for the greatest earnestness in using every method of human activity to further its progress.

\section{III.}

We are thus led to recognise a twofold character in Christianity. On the one side it is a direct inspiration, an immediate gift; but on the other it depends, especially in its origin, on human influences and even on outward events and circumstances. From the philosophical point of view this contrast may be expressed in the antithetic statements that Spirit is all, and that Spirit apart from its material embodiment and expression is nothing. In the Gospels it takes the form of an apparent opposition between those passages in which inward disposition 
is represented as all-important, and those in which a large importance is clearly attributed to physical conditions and means of operation; while in the Epistles the contrast is that between Faith and Works. But just as we saw that the philosophical antinomy loses its absoluteness when it is recognised that the inner and outer aspects of morality are not in fact separable, but must be treated in their concrete unity, so the apparent dualism of New Testament teaching is only a dualism of contrasted aspects, and not of contradictory facts, of experience. In the nature of man the unity of spirit and body is deeper than their difference, and his nature, normally at least, functions as a whole. ${ }^{1}$

It has already been pointed out that this fundamental unity of human nature explains the sympathy of Jesus with suffering, and $\mathrm{His}$ readiness to reach the hearts of men by acts of kindness in the outward and visible order ; but it is also clearly present in His thoughts when he says that "out of the abundance of the heart the mouth speaketh," and that "the tree is known by its fruit." ${ }^{2}$ Just as on the passive or receptive side of man's nature, his heart can be reached through his outward faculties, so on the active side the bent of his inmost thoughts and of his will must manifest itself in word and action. Hence in the teaching of Jesus, the test of the spiritual

1 For Paul the body had an essential part in the spiritual life. See 1 Cor. vi. 13 b, 19 f., 1 Thess. v. 23, Rom. xii. 1, with Dr Denney's penetrating note on the last passage in the Expositor's Greek Testament-" "The body is in view here as the instrument by which all human service is rendered to God, and the service which it does render, in the manner supposed, is not a bodily but a spiritual service."

2 Matt. xii. 33-35. Cf. James iii. 11 f.; and Hegel's remarks on the unity of human nature in his smaller Logic, $\$ 140$ and note, where he quotes the similar saying in Matt. vii. 20. 
life, or the criterion of goodness, is now that of purity of thought and inward intention, or more simply faith; ${ }^{1}$ elsewhere it is the nature of the spoken word $;^{2}$ and yet again it is the actual performance of deeds of obedience and kindness. ${ }^{3}$ Yet there is no real inconsistency; for the evil heart is bound to bring forth evil of every kind, in word as well as in deed, as Jesus made clear in enumerating those evil things which "come forth out of the heart and defile the man." 4 The same principle applies in the life of goodness. "The good man out of his good treasure bringeth forth good things." 5

In the same way Paul teaches that the Christian is not changed in one faculty or division of his nature alone: he is "a new creation," living a new life by which all his powers are given a new direction. This phrase, "a new creation," ${ }^{6}$ is twice used by Paul. In the Epistle to the Galatians it appears in the text, "neither is circumcision anything, nor uncircumcision, but a new creation." But in the previous chapter the words occur, "neither circumcision availeth anything, nor uncircumcision; but faith working through love " $;^{7}$ and from this we may gather that Paul thought of that change by which human nature is created anew as effected by an inner principle, that of Faith, which yet necessarily works itself out in the activity of Love. So

1 E.g. Matt. v. 3, 8, 22, 28 ; viii. 10 ff. Cf. xxiii. 27 f.; Mark xii. 43 f.

2 Matt. xii. 37. Cf. James iii. 2.

3 Matt. vii. 16-27; xxi. 30 f.; xxv. 31-46. Cf. Mark iv. 8; Luke x. 36 f. ; xi. 28 ; John $x \nabla .8$.

4 Matt. xv. 18 (Mark vii. 18-23).

5 Matt. xii. 35.

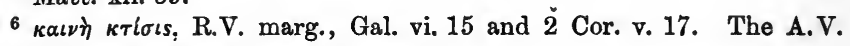
and R.V. rendering is "a new creature."

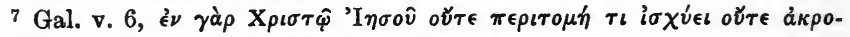

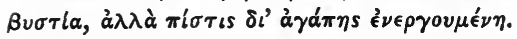


in the Sermon on the Mount the disciples of Jesus are urged not to conceal the light that has been kindled in their own hearts, but to let it go forth to illuminate the surrounding world. ${ }^{1}$ And just as we cannot think of the Good Will as remaining self-centred and making no endeavour to conquer the stubborn facts of its physical and social environment, so it is, but even more emphatically, with the principle of inwardness as Christianity expresses it. For this is no other than Love, which, while it originates as an inward experience and change of disposition, necessarily tends to go forth into the world around, and to express itself in actual deeds. Nothing can be more entirely inward and personal, and yet nothing so inevitably passes beyond itself, and seeks its sphere of action among the material things of the objective world.

This fact that the spirit of Love cannot remain subjective or merely spiritual is strongly enforced in the apostolic injunction. "Whoso hath this world's goods, and beholdeth his brother in need, and shutteth up his compassion from him, how doth the love of God abide in him? My little children, let us not love in word, neither with the tongue; but in deed and truth." 2 Thus, if Love be the principle of the Christian life, it finds its expression and indeed its realisation in Service. Now this is only the more direct and simple expression given by Christian Ethics to the principle of contribution to the Common Good, in which the philosopher seeks to find a solution of the double antithesis of the inward and outward, and the individual and social, aspects of the Good.

No elaborate proof is needed to show that this assign-

1 Matt. v. 15 f.

${ }^{2} 1$ John iii. 17 f. Cf. James ii. 15 f. 
ment to the idea of Service of a central and determining position in Christian Ethics is in accord with the teaching of the New Testament. The whole narrative of the Gospels is its proof and justification. But in one passage it appears most clearly that Jesus proclaimed this as the grand distinction between His Kingdom and the kingdoms of history - that in the former Service, and not power or splendour, was both the universal law and the insignia of greatness. "Ye know that they which are accounted to rule over the Gentiles lord it over them; and their great ones exercise authority over them. But it is not so among you: but whosoever would become great among you shall be your minister; and whosoever would be first among you, shall be servant of all. For verily the Son of man came not to be ministered unto, but to minister, and to give his life a ransom for many." 1 This thought of the reversal in the Christian community of all the ordinary standards of leadership aud greatness, is enforced and illustrated by the story of the washing of the disciples' feet in the Gospel of John, with the solemn words that follow, "Know ye what I have done to you? Ye call me Master, and Lord: and ye say well ; for so I am. If $I$ then, the Lord and the Master, have washed your feet, ye also ought to wash one another's feet." ${ }^{2}$ The same principle, that in the Christian economy greatness is reached and maintained by service instead of by coercive power, and that contribution takes the place of acquisition as the ruling motive of the Christian life, finds expression in the saying of Jesus preserved in the Book of Acts, "It is more blessed to

1 Mark x. 43-45. Cf. ix. 35 ; Matt. xxiii. 11.

2 John xiii. 12-14. Cf. 1 Peter v. 5, "All of you, gird yourselves with humility, to serve one another." 
give than to receive." 1 And Paul in his own writings enforces the double duty of humility and service by appealing to the example of his Master, who "took the form of a servant" and "became obedient unto death." 2

The practical side of Paul's teaching centres round the exhortation to a constant and deliberate practice of this principle of Service. No support can be gained from his teaching for the idea that enlightened self-love is sufficient to bring men into a relation of harmony and mutual helpfulness, or that by some alchemy unrestricted self-regarding competition can lead to universal happiness. The effects of such a rule of life are indicated by a single warning- "If ye bite and devour one another, take heed that ye be not consumed one of another"; and the true way is pointed out in the words, "through love be servants one to another." 3 But even if a natural harmony of interests had been possible in the sphere of material wants and possessions, Paul, like Plato, would have rejected this as an unworthy ideal of life, in comparison with the conception of a community of individual men, bound together not by the external and accidental ties of self-interest, but by the vital bond which unites the members of a single living body. 4 The metaphor of the body and its members was a favourite one in antiquity, but it was never applied more forcibly and thoroughly than in the epistles of Paul. To the use which he makes of it to illustrate the diversity of function in the Christian community we shall shortly

1 Acts xx. 35.

2 Phil. ii. 3, 7 f. Cf. 2 Cor. viii. 9. 1 John iii. 16.

3 Gal. v. 13, 15.

4 Cf. Rep. 372 D with 462 CD. The latter passage may have influenced 1 Cor. zii. 26, to which it is closely parallel. 
return: what is of importance at this point is its significance as enforcing the fact of function, that is, of service, as the great condition of the Christian life.

It is indeed true that love has a still higher importance, as the animating and inspiring spirit of true service ${ }^{1}$ but the love which Paul commends cannot be interpreted as a self-contained love, isolated from the material world or indifferent to the ordinary needs of man. The spirit of the giver, for Paul as for Jesus, is the chief thing,-for "if the readiness is there, it is acceptable according as a man hath, not according as he hath not" ${ }^{2}$ and the highest praise bestowed upon the generous Macedonians is that "first they gave their own selves to the Lord." 3 Yet at the same time the gift is in itself not to be despised. It is a duty to obtain by labour the material of generous action, and the opportunity of giving liberally is itself a good gift of God.4 In the same way the First Epistle of Peter shows the nature of love as expressing itself in service in the sphere of material things, "Above all things being fervent in your love among yourselves; . . . according as each hath received a gift, ministering it among yourselves, as good stewards of the manifold grace of God." 5

Now it is doubtless true that this characteristic of Christianity has not always been recognised as essential

11 Cor. xiii. 3.

22 Cor. viii. 12. This principle is recognised by Aristotle when he says that "liberality lies not in the actual amount given but in the moral state of the giver," and that one who gives less may be more liberal than another if his means are smaller.-Eth. Nic., IV. 1120 b $7 \mathrm{ff}$.

32 Cor. viii. 5.

4 Eph. iv. 28 ; 2 Cor. ix. 8-13.

5.1 Peter iv. 8, 10. See Note M, p. 402, "Christianity and Material Goods." 
and central. There have been periods in which the Christian life has been thrown back upon itself and ceased to go forth into the world around, in which it has been thought that the inward and the upward view were sufficient; whereas in truth, apart from the outward view and the forthgoing activity, they lose even their own proper clearness and strength. Such have been the periods of Christian asceticism; and it was one great achievement of the Reformation to break with this subjective conception, and to restore the life of the world and the affairs of men to their true place in relation to the spiritual life, as the field both of its discipline and of its efficient working. Hence the place of work, that is, of practical service, in the Christian scheme.

This lesson of the Reformation has at times been obscured; and the charge of excessive subjectivity has been brought, not without reason, against some forms and tendencies of Protestant teaching. This charge cannot indeed be justified if it is advanced in criticism of the doctrine that the Christian life must be founded upon an inner change, a personal and incommunicable experience, by which the whole outlook upon life is altered, it may be suddenly, or it may be gradually and almost unconsciously. This moment of the Christian life, this "transaction" (to use the old term), is essentially inward. But the error creeps in if the same subjective character is attributed to its progress and development. Where "sanctification" was treated by the oider theology as no less private and personal than "justification," there was ground for the charge of overemphasis on the purely individual, and neglect of the social, aspects of Christian virtue. Not that inward and secret discipline is without a place in the further 
development of Christian character. But, if the previous argument is in any degree valid, its full unfolding is possible only in the intercourse of social life and in the effort to serve others and to promote the Common Good. If the doctrine of the Brotherhood of Man and the metaphor of the body and its members have any real meaning, then the idea of isolated development is a contradictory one, and the calling of the individual can be realised only in union with a community bound together by mutual service. The full growth of the Christian character which is implied in the idea of sanctification must, normally and in the main, be a social process.

We have now reached a point from which the teaching of Christian Ethics regarding the Common Good can be briefly summed up. The two aspects of the Good as inward and as outward, as independent of outward circumstances and as making them instruments in its own development and expression, which from the first we distinguished, still remain as distinguishable elements in the Christian view. But though still distinguishable they are not rigidly separate, still less at war. In the former aspect the Good transcends the limitation which clings to all divisible and material goods; if a material illustration of its nature be sought, it may be found in the flame which increases instead of diminishing as it passes from torch to torch, or, as Dante found it, in the light which gains brightness as it is reflected from mirror to mirror. ${ }^{1}$ On this side the immediacy and the social nature of the Christian Good place it beyond the sphere of competition; while history has confirmed its claim to

1 Purgatorio, XV. 75 (quoted p. 401, below), and cf. the quotation from Mr M'Taggart, p. 87 above. 
give strength to bear the most crushing misfortune, and to bring peace into the midst of extreme suffering.

But while this is much it is not all. The distinction of Christianity from the nobler among preceding religions and rules of life, lies not so much in the power which it has given to rise above outward circumstances and to maintain freedom of spirit in the midst of pain. It has indeed never been surpassed in this sphere; but its greatest glory is that it has provided for the ordinary needs of human nature as well as for its supreme emergencies, and has not hesitated to claim as a means of furthering man's true good even the ordinary objects and occupations of daily life. For its inner principle is not Fortitude alone, but also Love, which seeks a sphere of activity beyond the mere individual soul and aims at an embodiment in space and time of its spiritual purpose. In the Christian view, "the change which piety effects must not remain concealed in the recesses of the heart, but must become an actual, present world."1 In the idea of Service as the highest law, there is not only a guarantee that all may share in the activities of the Christian community, and a recognition of human effort as bearing a higher value than that of its actual and measurable result: there is also the promise of a concrete realisation of the ideal of the Common Good, in a polity in which the most richly endowed shall hold their powers and gifts for the interest of all, and in which none shall be excluded from sharing in the outward, as well as the inward, benefits of life.

1 Hegel, Philosophy of History, Part III., Sect. III., ch. ii. (tr. Sibree, p. 347). 


\section{CHAPTER VI.}

THE NATURE OF CHRISTIAN UNIVERSALISM.

IT is now possible to define certain broad aspects of the Universality which is claimed for the Christian religion and ethics, and to state more clearly in what sense the claim is to be understood. The material for this definition and statement has already been examined in the last four chapters, but it may not be without advantage to devote this chapter to a review and restatement of the positions that have already been reached, rather than to the breaking of wholly new ground.

\section{I.}

First, then, we have seen that the Christian view of man penetrates behind all his superficial qualities, setting aside every pre-eminence of race or education, and finding in his inner nature that which alone has supreme value. But this does not imply that the value of the individual man, as Christianity finds him, is an actual, accomplished, developed fact. Rather it is in the language of philosophy a "potential" value, which needs to be actualised. Thus the strongest bond by 
which men of every race are held together is that of a common need; for the common potentiality for good, which Christianity recognises and claims to be able to develop, is first witnessed by a sense of need, that is, of dissatisfaction and shortcoming.

In this need Jew and Gentile alike shared; or, as Jesus and Paul both taught, the Jewish nation were even at a disadvantage, in so far as their trust in a legal righteousness prevented them from feeling that "hunger and thirst after righteousness" which is ever the first condition of spiritual progress. ${ }^{1}$ When the sense of need was thus emphasised as the only, but also the sufficient, preparation for the reception of the Gospel, the barriers of nationality and social distinction inevitably fell away, and the universality of its message became fully evident. When Jesus found this openness of heart and readiness to believe in His power outside the Jewish nation, in the case of the Roman centurion, He welcomed it with the words, "I have not found so great faith, no, not in Israel. And I say unto you, that many shall come from the east and the west, and shall sit down with Abraham, and Isaac, and Jacob, in the kingdom of heaven." 2

The same emphatic assertion that the benefits of the Gospel transcend all national limitations is found in several of Christ's later parables, spoken when it had become apparent that the leaders of the Jewish

Cf. Matt. v. 6 ; ix. 13 (Mark ii. 17) with Rom. i. -iii. and x. 3. In Rom. ii. $28 \mathrm{f}$. there is one of the most striking assertions of the independence of true goodness of external distinctions, " $\mathrm{He}$ is not a Jew, which is one outwardly ; . . but he is a Jew, which is one inwardly ; and circumcision is that of the heart, in the spirit, not in the letter." Cf. 1 Cor. vii. 19.

2 Matt. viii. $10 \mathrm{f}$. 
people were too deeply entangled in their own narrow religious prejudices to appreciate or respond to His message. Thus the parable of the Good Samaritan teaches that a despised stranger might give a high example of that love and helpfulness which the Priest and the Levite wholly failed to show $;^{1}$ while the parables of the Two Sons and the Wicked Husbandmen proclaim the truth that ethical performance, and not profession or privilege, is the real mark of membership in the Kingdom of God. ${ }^{2}$ Finally in the parable of the Marriage Feast, which follows them in the Gospel of Matthew, the lesson is once more enforced that men are hindered from accepting the benefits which Jesus was ready to bestow, only by that preoccupation with outward things which does away with all sense of need for a higher good; and that consequently those who have been regarded as social outcasts may enter the Kingdom before many whose reputation for piety has stood high with the world. ${ }^{3}$

Thus Christian Universalism implies a recognition of the solidarity of the human race in respect of its needs, whether these needs are consciously felt or not; but it goes further-and herein lies its originality-by teaching that, wherever the need is consciously recognised, there is already present in the recognition an earnest of its satisfaction. We have already seen that it is in the assurance of the possibilities of human nature at its weakest that the teaching and ministry of Jesus are most of all unique, and that thus the Christian assertion of the value of the individual points less to a present fact than to a task-but a task which is not to be

1 Luke x. 30-37.

2 Matt. xxi. 28-46.

${ }^{3}$ Matt. xxii. 1-10. Cf. Rev. iii. 16-19. 
looked on as hopeless. Nor is the realisation of that hardly suspected potentiality for good which Christianity detects a work for the individual alone; for the development of character depends on education, and education - the "drawing out" of immature powers-is essentially a social process, while its end is to be sought in the fitting of the individual to take his place as a member of a wider whole.

It is not in the mystical teaching of the Gospel of John or the Pauline epistles alone that the value of the individual is treated as dependent on his relation to the whole body of believers and to their Head. The same thought can be clearly traced in those words in which Jesus, as reported by the Synoptists, speaks of the value of single souls and of their claim on the service of others, as conditioned by their relation to Himself. "Whosoever shall receive one of such little children in my name, receiveth me." "Inasmuch as ye did it unto one of these my brethren, even these least, ye did it unto me." 2 And conversely, Jesus teaches that all truly ethical service necessarily brings men and women into the closest relationship with Himself: "Whosoever shall do the will of God, the same is my brother, and sister, and mother." 3

Thus the author of Ecce Homo gives a true account

1 Mark ix. 37 ; cf. 41 f. : "Whosoever shall give you a cup of water to drink because ye are Christ's, verily I say unto you, he shall in no wise lose his reward. And whosoever shall cause one of these little ones that believe on me to stumble, it were better for him, \&c." The phrase translated "because ye are Christ's" in the R.V. runs in the

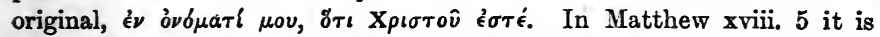

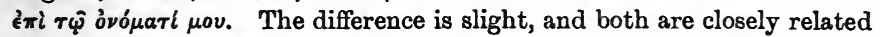

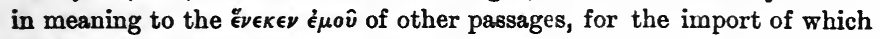
see Denney, Jesus and the Gospel, pp. 224, 234. Cf. John xv. 5.

2 Matt. xxv. 40.

3 Mark iii. 35. 
of the teaching of Jesus as to the condition on which human lives become truly valuable, and also as to the ground of brotherhood and helpfulness in the Christian community, in saying that "Christ believed it possible to bind men to their kind, but on one condition-that they were first bound fast to himself. He stood forth as the representative of men, he identified himself with the cause and with the interests of all human beings, he was destined, as he began before long obscurely to intimate, to lay down his life for them." And thus all men, "as the brothers of Christ, as belonging to his sacred and consecrated kind, as the objects of his love in life and death, must be dear to all to whom he is dear." 1 Thus it is that the scattered sheep are to be gathered into one flock, and so to find out themselves and display to others the hidden meaning and value of their lives. So, in truth, that value is to become actual and real, not in isolation but in the life of a community. For the ideal of the Value of the Individual carries with it in Christian Ethics the ideal of the Common Good, and the process by which both ideals come by degrees to penetrate and control the life of the world is one and the same.

\section{II.}

If this is the first characteristic of Christian Universalism-that it describes an ideal rather than an accomplished fact, and belongs less to the statical than to the dynamical order of truths-the second point of importance is that, for Christian Ethics, universality is

1 Ecce Homo, Ch. XIV. 
not identical with uniformity. Christian universalism is of a kind that does fullest justice to the differences of individuals, and comprises within itself the widest diversity. This holds true both of the development of the Christian life and of its matured activity, and it appears as a diversity both of discipline and of function.

One of the most striking things in the gospel narrative is the way in which Jesus adapted His teaching to the needs of individuals. He never addressed Himself to a merely abstract or typical man, but always to the particular man or woman with whom He was in contact at the moment; and He dealt with each according to his special circumstances and limitations. In harmony with this fact, the whole Christian conception of Providence suggests that the moral government of the world is not a mere uniformity, but that individual differences, so far from being of little consequence, are of real significance for the whole, and that the circumstances of life are tempered and attuned to individual needs. Such a doctrine is indeed a difficult one for certain minds and from some points of view. The philosopher in his effort to gain a "synoptic" view of the world, tends to overlook details and to see only the greater correspondences and adjustments between the outer and the inner world. Or he falls back on the Stoic view that the former is of moment only as the Negative, the opposing force against which Spirit has to make good its own character and destiny; and thus he comes to look on external circumstance as important and yet indifferent-important in so far as it draws out the power of the will and strengthens it through conflict, but indifferent in that the virtue of the good man can prevail against any 
obstacle, and find means of realisation in any outward condition. ${ }^{1}$

But this view, noble as it is in itself, and dignified by the association of great names, does not fully represent the point of view of Christian Ethics. The writers of the New Testament asserted triumphantly the power of faith to rise above circumstances of pain and danger; yet they did not look on the form of these circumstances as indifferent, or think of the course of outward events as a mere negative to be overcome. It had always some positive meaning, and the form of the conflict was an essential factor in shaping the final victory. The greatest instance of this belief is the assurance which runs through the New Testament, that the whole course of Christ's ministry, and most of all the seemingly hopeless tragedy and failure of its close, showed that the darkest events and the utmost forces of evil are made to contribute in the Divine Order to the achievement of a supreme moral and spiritual end.

But the same principle that outward events, and even misfortunes and hindrances, are not a mere negative background but have a definite meaning for the Christian life, is applied in the New Testament to the smaller things as well as to the greatest of all. Thus Paul speaks of his imprisonment as "having fallen out rather unto the progress of the gospel "; ${ }^{2}$ and in the same spirit he can say that " to them that love God all things" -not the directly spiritual forces of life alone, but its outward events as well - "work together for good." 3 Browning truly interprets this Christian attitude to the

1 Cf. supra, pp. 109-11.

2 Phil. i. 12.

${ }^{3}$ Rom, viii. 28. 
chances and changes of the world, the "dance of plastic circumstance," when he describes it as :

"Machinery just meant

To give thy soul its bent,

Try thee, and turn thee forth, sufficiently impressed." 1

Not less suggestive, although less familiar, are the words of Keats, "Do you not see how necessary a World of Pains and troubles is to school an Intelligence and make it a soul? A Place where the heart must feel and suffer in a thousand diverse ways. . . . As various as the Lives of Men are-so various become their souls, and thus does God make individual beings, Souls, Identical Souls of the sparks of his own essence." 2 Thus the varied experiences of different lives are seen to have a positive import, as disciplining them for varying tasks, and as giving a rich content to the idea of human value which it would lack in a world of uniform circumstances and characters. It is not enough that men should be good, but there must be originality in their goodness, and this originality is drawn out by the varying forms in which the discipline of life, even in small things, comes to each.

It was pointed out above that the philosopher naturally tends to dwell on the great features of human life and history, and so to miss the importance of the less conspicuous influences which help to mould and direct them. This attitude is exemplified in Plato's description in the Republic of the lover of wisdom, as one whose thoughts are so filled with "the vision of all time and all existence," that he sets little store upon this life and its trivial interests. ${ }^{3}$ But at the end of his life, when
1 Rabbi Ben Ezra.
2 Letters of John Keats (Eversley ed.), p. 256. 3486 A. 
he wrote the Laws, Plato had come to see the inadequacy of this ideal, and the weakness even from the philosophic point of view of a theory which neglects small things for the sake of great. He then argued that if the idea of divine government be applied to the course of the world at all, it must be carried out consistently and thoroughly; for great issues cannot be wisely directed if small details are overlooked or despised. "Let us not, then," he concludes, "deem God inferior to human workmen, who, in proportion to their skill, finish and perfect their works, small as well as great, by one and the same art." Rather, "let us say, "The ruler of the universe has ordered all things with a view to the preservation and perfection of the whole, and each part has an appointed state of action and passion. ... And one of these portions is thine own, which, however little, has the whole in view." "1

Since, then, care for the whole involves care for the several minute parts, "Providence," if it exists at all, cannot be other than "particular"; and the infinitely varied circumstances of human life, in which the conflict takes a different shape for each man, cannot be indifferent or meaningless. Nor are they simply the hard and intractable material-the virgin forest $\left(v^{*} \lambda \eta\right)$, through which he must hew his way to the attainment of truth and goodness. They are in some sort the necessary presupposition of the existence of a virtue as varied and many-coloured as the "many-coloured grace of God." 2 They provide the training necessary for service in a world where every kind of service is called for.

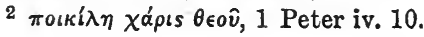


Thus the thought of the New Testament, like that of the ancient philosopher and the modern poet, naturally passes from the idea of the influence of variety of circumstance in helping to produce variety of character, to its effect in calling for and providing a sphere for variety of gifts. In other words, the thought of diversity of discipline passes over into that of diversity of function, and this, as we have seen, is a cardinal element in the full and concrete conception of the Common Good. In the parable of the Talents ${ }^{1}$ the greatest emphasis is laid both on the absolute value of faithfulness in service, even in the smallest sphere, and on the complementary truth that the actual and measurable results of service must differ according to the endowments and opportunities granted to different men. Thus the parable teaches a double lesson-that of the diversity of gifts, and that of the worth of every gift when applied in and increased by service; and it may be taken as an illustration and enforcement of the principle that " to whomsoever much is given, of him shall much be required." 2 In the conclusion of the parable of the Sower the same emphasis is laid on variety of attainment. Not only does the good soil differ from the stony, or the hard, or the thorny ground; but of the seed which "fell upon the good ground and yielded fruit," some brought forth " a hundred fold, some sixty, some thirty." 3

The same thoughts underlie the metaphor of the body and its members as it is used by St Paul. Functions and capacities vary, but all may work harmoniously for the good of the whole, so long as they are obedient to

1 Matt. xxv. $14 \mathrm{ff}$.

2 Luke xii. 48.

3 Matt. xuii. 8, 23 (Mark iv. 8, 20). 
the direction of the Spirit which permeates and co-ordinates them all. "There are gifts, each from each distinct, but the same Spirit; modes of service, each from each distinct, and the Master served the same; manifestations of energy, each from each distinct, and the same God, sole source of all energy whatsoever, in whomsoever manifested. None but has the opportunity offered him of revealing the Spirit for a beneficent end." "God has attempered the body, part to part, assigning to that which ranks the lower a greater dignity, that the sundry members may all be concerned alike for the wellbeing of the rest, and may work together without jarring." "Just as in our one body we have many members, and these members have not all the same function, so we form one body in Christ, and severally are members of the rest. Possessed of gifts, differing according to the grace that has been given to us, let us exercise these gifts aright." 1

In these passages there is the fullest recognition of the fact that the unity of the Christian life is not a dead uniformity of similar objects cast in the same mould, but a living and organic unity of dissimilar persons, each maintaining his own individuality, but subordinating it to the needs of the whole, and enabled to do so by the living principle which controls every will and harmonises all effort. In the First Epistle to the Corinthians Paul worked out this idea by enumerating the various functions and duties of members within the unity of the Spirit in the Church; and the order in which they are named suggests the relative importance which he attached to these different offices

11 Cor. xii. 4-7, 24 f.; Rom. xii. 4-6. I quote from the late Dr W. G. Rutherford's translation. Cf. Eph. iv. 11-16. 
of service. ${ }^{1}$ The highest rank belongs to the most directly inspired and the most distinctively spiritual gifts-"First apostles, secondly prophets"; then teachers of the truth; next, those occupied with less purely inward things, healing and administration; and, finally, those possessed of the gift of "tongues." In this order there is a distinct gradation, the more external forms of service being subordinated to those most directly bearing on the inner life; yet the need for the former no less than for the latter is recognised. This is in fact a reassertion of the double principle of Christianity, that, while the external is ever to be treated as subordinate to the spiritual, there is no impassable gulf between them, but that material things can and must be used in the service of the spiritual, stamped with its image, and made the medium of its manifestation.

This Pauline conception of a hierarchy, not of power, but of service, has the advantage of bringing out the continuity of different kinds of service, and of showing that those which we consider external are separated from the inward by a series of steps, or even a continuous gradation, rather than by a single sharp break. And yet for many purposes it remains needful for the sake of clearness to draw a more definite line between the two. At a very early stage of Church History this line was drawn when "the Seven" were ordained, in order that they might "serve tables," and so set the Apostles themselves free to "continue stedfastly in prayer, and in the ministry of the word." 2 Thus early it was acknowledged that even within the Church there is a twofold need to be met, and that the care of its external affairs calls for a distinct class of office-

11 Cor. xii. 28.

2 Acts vi. 2-4. 
bearers. In this position matters remained for three centuries; for, while this side of the Church's work increased with its growing extension and power, yet as long as it remained a persecuted or merely tolerated minority under the autocratic power of the Empire, the external, objective side of Christian activity was confined to works such as almsgiving, the care of the sick, and Church administration. But when Christianity gained the opportunity of influencing directly the course of secular history, the great problem emerged -a problem that has exercised all the ages sincehow the principles of Christianity may best be worked out in the political and social life of man.

Attempts have indeed been made to evade this problem by treating the Christian religion as purely spiritual, and as separable from the course of history and political life. But if our previous analysis has been in any degree accurate, this attempt to confine religion to the inner world alone fails to do justice to the comprehensiveness of Christianity. And if it be admitted that such objects as the relief of suffering and want by an external organisation fall within the Church's duty, the right of the State to prevent these evils by its own proper means of action must also be recognised. If the end of the Christian religion can be attained only in the upbuilding of an organised society constituted on Christian principles, then questions of outward organisation cannot be dismissed as irrelevant, nor can it be denied that it is of importance to regulate wisely the external circumstances of life. Thus the State has a place beside the Church in forwarding the one great end-the perfecting of the human race.

This conception ruled the thought of Dante, who 
held that the Empire as well as the Church existed by direct divine authority, and that each was charged with a definite share in the redemption and education of mankind. "For as man alone of all beings participates both in the corruptible and the incorruptible, so he alone of all beings is ordained to gain two ends, ... . and has need of two guides for his life, . . . whereof one is the Supreme Pontiff, to lead mankind to eternal life, according to the things revealed to us; and the other is the Emperor, to guide mankind to happiness in this world." 1 This conception of a fundamental duality in the divine education of mankind, and of the incompleteness of either the spiritual or temporal rule in isolation, is the more striking in that Dante possessed to the full the mediæval longing for unity. His De Monarchia is in great part occupied with the defence and exaltation of the principle of unity; but at its close he recognises that the "fountain of authority, one in its unity, flows through many channels out of the abundance of the goodness of God." 2 And in particular, he condemns any attempt either to merge the temporal rule in the spiritual, or to confuse their separate spheres and methods.

In the light of this idea, and of the recognition by Christianity of the influence of outward circumstance in helping or hindering the good life, especially when it is still immature, it is necessary to modify and add to our previous statement of the relation of political action to the Christian estimate of man. ${ }^{3}$

1 De Mon., III. xv. (tr. Church). Cf. Purg. xvi. 107 ff., where occurs the warning against "grafting the sword upon the crook."

2 Ibid.

3 Pp. $70 \mathrm{f}$. 
That statement emphasised the negative side of this relation, and the fact that both law and its administration, "by reason of their generality," tend to cast a shadow on the individual, and to treat men in masses to the neglect of their different needs and the disparagement of their separate value. But, when once the central Christian assertion of the ultimate value of the single soul has been received-when it has been acknowledged that in the deepest sense the individual man is the true ethical unit-it is possible to reinstate the methods of action peculiar to political rule, and to look on the statesmen as not less really, although less directly, than the preacher an exponent of the Christian principle of service. In his special sphere, it is true, he is in the main removed from contact with individuals, and cannot minister, as Jesus and His immediate followers did, to individual needs. But if outward circumstances count for much in life, then it is necessary to deal with men in classes as well as with men singly. As has been well said, "a man here and there may be raised in spite of his circumstances, but a class of men can only be raised in and with their circumstances." Now, the alteration of the circumstances of a class of men demands something other and wider than the method of individual alleviation. The claims of the individual as such must be for the time ignored by the statesman, in order that he may seek to reach the individual by raising the circumstances of the whole class to which he belongs. Nor is this a lapse from the Christian standpoint-unless it be held that the statesman's methods are in themselves sufficient, or that his point of view is the ultimate one. At the last, we are always thrown 
back on that inward reformation, that experience in which each man is most entirely alone; but if this be given the central place, then the objective work of the statesman or reformer, whatever its precise form, has an inexpugnable place in the Christian scheme.

But the variety of service which is required in the realisation of the Christian ideal of life is not exhausted by the division into political and directly spiritual work. "The objective work of Spirit," to borrow Hegel's phrase, includes art and literature as well as political activity. The Christian spirit of love towards Nature as well as Man is bound to seek and to find expression along these lines also; and its embodiment in a renewed society would not only bring in juster social relations, it would transform the outward conditions of life into new and more fair and worthy forms. It is impossible here to enter on a full discussion of the connection between the spirit of Ghristianity and the expression of its inner content in the sphere of art. Enough has been said if it has been made clear that the Christian ideal is not that of mere uniformity, but that the most widely varying forms of human genius and effort may take part in the work of bringing every province of life beneath its sway. Our conception of its richness and scope has been largely built up by the life-work of the great thinkers, artists, and poets, who have not only enlarged the intellectual horizon of mankind, but have shown that every part of it may be illumined by the spirit of religious devotion. Such lives as those of Michael Angelo, of Milton, or of Newton, stand out as noble embodiments of the Christian spirit both of devoutness and of service. 
Yet, high as is the rank of the great statesman or thinker or creative artist in the Christian hierarchy of service, no supreme or exclusive merit can be claimed even for these. There are other forms of service as essentially Christian; for the truest followers of the Carpenter of Nazareth have often, like their Master, been found in the humbler walks of life. Of the spirit which has animated such men we may find an example in the saying of Brother Lawrence, that he was able to enjoy the highest religious serenity and peace amid the bustle of his monastery kitchen, and that "he was always finding pleasure in every condition in doing little things for the love of God." 1

We have thus defined two great aspects of Christian Universalism. In the first place, it asserts an ideal rather than a fact, points to a potentiality rather than an actuality, and sets before the believer not a dogma but a task-the task of realising in himself and others through the agencies of social life that value which Jesus taught his followers to see-undeveloped, it might be, but still indubitably present-in even the meanest of human lives. And again, it stands for no dead level of uniformity. For the unity of the body into which Christians are called, and in whose service their true life consists, is not attained through mere sameness, nor is the form of personality in which the value of the individual is realised alike for all. The Christian ideal is not the uniformity of objects cast in the same mould, but the unity of men inspired by the same spirit. Thus it is consistent with the widest diversity, reached through the infinitely varied dis-

1 Brother Lawrence, The Practice of the Presence of God. 
cipline of life, exercised in and demanded by the infinitely varied tasks of life. For in the whole range of duties, and in all forms of service from the most commonplace to the most exalted, there is none that fails to find its place and its recognition in the Christian life. 
CHAPTER VII.

THE KINGDOM OF GOD AS PRESENT AND AS FUTURE.

I.

OUR argument up to this point has led to the conclusion that no one term is sufficient to exhaust the principle of Christian Ethics. Any exposition of it as purely inward, or purely outward, as concerning the individual alone, or as entirely social in its bearing, is fatally one-sided; for it is in reality a synthesis of all these elements. The principle is one, but it has a necessary duality of aspect; for it appears first as an inward state of love and trust, but afterwards as the expression of this in the world of material things and social action, love thus passing into service and seeking to build up an actual polity in which its own genius shall become fully visible and objectively real. Thus on one side the inner attitude of the soul is all-important, and is complete from the first moment in which it consciously turns from the old to the new life; but on the other, this is a mere potentiality, which must be actualised through selfdiscipline, but more especially through the effort to extend the sway of the Christian principle in the world. Hence the Christian life is both something given once 
for all, and something to be wrought out hour by hour and year by year. "The imperative mood is used as well as the indicative. We are personally to become what in Christ we already are." 1

So far, however, the terms used have been largely philosophical and abstract. We have dealt with the antitheses of outward and inward, potential and actual, the individual and the community. It is now time to test the results reached by comparing them more closely with the concrete teaching of the New Testament, in which we read, not of the Community of the Good, but of the Kingdom of Heaven, or the Kingdom of God. And we at once find that the conclusion of the last paragraph meets us again here; for it has become almost a commonplace of modern ethical theology, especially in Germany, that the Kingdom of God is at once present and future, both a Gift and a Task. This German distinction between Gabe and Aufgabe had a philosophical origin in the writings of Kant and his successors. Hegel made use of it in his criticism of Fichte, where he asserted that the realisation of the end of progress was not to be looked on as a task whose fulfilment depended on the strength or weakness of human wills; but while philosophical in origin, it has readily become acclimatised in theological ethics, and writers like Harnack, Holtzmann, and Haering have joined in asserting that the Kingdom is both a gift and a task. ${ }^{2}$

But although the definition of the Kingdom as possessing this double character is very widely adopted, it is not accepted universally. As against the view that

1 Somerville, St Paul's Conception of Christ, p. 103.

2 See Note N, p. 403, "The Contrast between Gabe and Aufgabe." 
Jesus' teaching regarding the Kingdom referred both to the present and the future, it has been maintained that it can be sufficiently explained by one or other point of view taken alone. The ethical and eschatological aspects of His teaching have not only been distinguished: they have been separated, and either by itself has been taken as the key to the whole. At present attention is largely directed to the eschatological element in the Gospels; indeed it may be said that the storm-centre of controversy in regard to the New Testament has rapidly passed from the question of miracle to that of eschatology. Nor is it difficult to see why this is the case. For long it had been usual to treat the Gospels from a point of view which tended to neglect their historical setting, and to pass lightly over those portions of them which were most deeply coloured by the special ideas of their age. Against this tendency the "religious-historical" school of interpretation has raised a vigorous protest, and its adherents are now seeking to avoid all modernising of the Gospels, and to show them in intimate relation to the conditions amid which Jesus and His earliest followers lived and thought. Hence there arises a new and opposite tendency-to minimise those points in which the Gospels come nearest to the familiar thoughts of our own day, and to emphasise rather their affinities with Judaism and especially with Jewish apocalyptic literature.

The fact that this forrn of thought is so alien to our own ways of thinking, that these eschatological utterances come to us with so remote and unfamiliar a sound, and that their spiritual significance and value are often so far from clear, is an adequate explana- 
tion of their comparative neglect in the past. But a continuance of this neglect is no longer possible, for their importance for a complete understanding of the New Testament has been made too abundantly clear, and the problems that they raise have become too insistent to be dismissed as of minor importance. Thus for the present, and it may well be for long to come, New Testament criticism and theology must find their most urgent and probably their most difficult problem in this question of eschatology; for the problem is twofold, first to determine the significance of these apocalyptic sayings and their relation to the more directly ethical and spiritual parts of New Testament teaching, and then to show how far the discounting of those parts of the teaching, which were born entirely of the conditions of that age and have lost their meaning for the modern world, must alter its general character and aspect. Nor is it hard to see that the first step in the solution of this problem must be the full recognition of the place which the thought of a glorious future Kingdom held in the minds of Jesus and His first followers.

But while this demands recognition, we are not thereby compelled to admit that eschatology is necessarily the determining element in the Gospels, nor that its categories provide the master-key for the interpretation of Jesus' teaching. This was the side on which the thought of the Gospels was in all probability most closely related to, and even conditioned by, the forms of Jewish Messianic belief; and thus it was the least original and distinctive part of early Christian thought. It would therefore be something of a historic paradox to interpret the religion of the New Testament from this standpoint, to the relative exclusion of those directly ethical and 
spiritual principles, in which its originality chiefly appeared, and on which its permanence depends. If Christianity had been at the centre an eschatological faith, it would have passed away with the passing of those conditions which gave rise to Jewish eschatology. Just because there was a deeper and more original form of spiritual vision underlying the diverse teaching of the Synoptists, of the Fourth Gospel, and of Paul, men of every subsequent age have found in them words which speak to the universal conscience and need of mankind. The new apocalyptic interpretation of the Gospels doubtless has a relative justification, in that it corrects the tendency to express their teaching in too exclusively modern terms, which marked the era inaugurated for English thought by Ecce Homo. Yet if it were needful to adopt one view to the exclusion of the other, it would surely be our wisdom to emphasise, as Ecce Homo so persuasively does, those characteristics in the life and teaching of Jesus which bring Him near to ages so different from His own. Fortunately we are not shut up to this rigid alternative, and we can say with a recent writer, that either interpretation by itself is one-sided and incomplete; and that this one-sided outlook in the case of both the purely ethical and the purely apocalyptic interpreters, rests upon "a failure to apprehend the spiritual greatness of the Personality with which they are dealing." 1

On these general grounds we may argue that neither interpretation can be wholly set aside. But, while both are legitimate and necessary, the ethical must be treated

1 Cairns, Christianity in the Modern World, p. 173. For a forcible, if extreme, statement of the opposite view, see Schweitzer, The Quest of the Historical Jesus (Von Reimarus zu Wrede), p. 237. 
as in the last resort dominant and determining. This general position may be confirmed by considering the relation of Jesus and the Pharisees. On purely eschatological grounds, He might have found little reason to attack their system. But the gravamen of His charge against them was simply that they had separated this side of religion from the ethical side, and that they had lost the moral insight and fervour which thrills through the great passages of Old Testament prophecy. The bitterness of Jesus' denunciations of Pharisaic religion shows that $\mathrm{He}$ considered that, in ceasing to be ethical, it had lost all its value, and thus shows also how central and how distinctive a place the ethical element held in His own mind. It is a familiar truth that one of the great aims of His life was to introduce a new ethical and spiritual content into the Messianic idea; and no less remarkable was the way in which $\mathrm{He}$ gave a new moral significance to the apocalyptic ideas which $\mathrm{He}$ adopted from the thought of His time.

To this point we may return shortly. But before we proceed further it is necessary to draw a more accurate distinction. So far only two aspects of the Kingdom of God as it appears in the New Testament have been mentioned, and these have been referred to indifferently as present and future, as ethical and eschatological, or as representing the blessings of the Kingdom as a task and a gift. But closer reflection shows that this is not a sufficiently precise or adequate division. For the last antithesis has within it elements requiring a further distinction. Both the gift and the task have present and future aspects. Under the former the Kingdom may be considered either as a direct, spiritual endow- 
ment conferred on the individual believer, or as a glorious revelation and consummation of the divine purpose in the future. Similarly the Task necessarily begins in the present, but stretches forth into the far future. But in the latter case the continuity is not broken, for the ethical process is one and the same. So there are three terms to be taken into account; and the Kingdom must be contemplated under three aspects, (1) as immanent-as a present, spiritual gift; (2) as an ethical task linking the present with the future; and (3) as a completely realised and divinely instituted Kingdom, to be established at "the end of the age." These three aspects might be distinguished as the spiritual, the ethical, and the eschatological. But if we would give an adequate account of the ideas of early Christianity on this subject, we must add a fourth aspect - the Kingdom as actually existing in a transcendent and superhuman sphere. The authority in the Synoptic Gospels for this fourfold characterisation of the Kingdom may now be briefly reviewed.

II.

(1) The view of the Kingdom which may be distinguished as pre-eminently spiritual is that in which it appears as a direct gift to the hearts of men, enabling them to enter into a new life of confidence and peace, which does indeed open a prospect of effort and attainment reaching into the future, but is in the deepest sense complete and satisfying from the first. It is this element which is denied in the assertion that Jesus thought of the Kingdom as belonging entirely to the 
future. The passage by reference to which that denial may be most readily answered is the saying recorded in Luke xvii. 21, "The Kingdom of God is within you." The decisiveness of this saying has, however, been disputed; for it has been argued that the word évтós, which in both the English versions is translated "within," may also mean "among." This would give the rendering, "The Kingdom of God is in the midst of you." 1 The traditional interpretation seems more in harmony with the spiritual character and the originality of Christ's teaching, and it also seems to meet more effectively the question of the Pharisees regarding the time at which the Kingdom of God should come. On the other hand it is argued that the verse should be taken in connection with the passage which follows, in which the coming of the Son of Man is described as like " the lightning," flashing from one side of heaven to the other, for suddenness and brightness; and in this case the words, "the Kingdom of God cometh not with observation," would mean that it will come so suddenly as to baffle observation and be present in a moment "in the midst." But, even although the traditional interpretation of this saying be surrendered, the idea of a present Kingdom by no means falls with it. There are other points of vantage for its defence.

In the first place it seems clear that Jesus claimed that His ministry of beneficence marked the real appearance of the Kingdom of God in power among men. This is shown by the discussion between Jesus and the Pharisees regarding the power by which He expelled evil spirits, which $\mathrm{He}$ concludes with the words, "If I by the Spirit of God cast out devils, then is the

${ }^{1}$ Luke xvii. 21, R.V. margin. 
Kingdom of God come upon you." 1 The same conclusion may be drawn from 'Jesus' answer to the question of John, which claims that whereas John had been "the last and greatest herald of Heaven's King," Jesus was actually exercising the kingly power and carrying out the tasks of the Messiah in His work of mercy, humble though that work might appear. ${ }^{2}$ And if this were true even of His activity as a Healer of the body, much more did it apply to the aspect of His ministry which Jesus named at the close of His reply, "the poor have good tidings preached to them." For this cannot be taken as referring merely to the proclamation that a better era was about to dawn, although the "good tidings" doubtless bore such a forecast of good: it must be taken also as referring to the spiritual benefits which Jesus held out for immediate acceptance, and especially to the sense of forgiveness.

At this point, if our interpretation is a sound one, we have the strongest proof that the view of the Kingdom . as a present reality is not a mere modern misconception, but is warranted by the thought and the words of Jesus. "It is by his healing," Harnack has said, "above all by his forgiving sin, that the kingdom of God comes. This is the first complete transition to the conception of the

1 Matt. xii. 28. The importance of this saying is very generally admitted, even by writers of the eschatological school. It is suggestively treated by Prof. E. F. Scott in The Kingdom and the Messiah (pp. 114 ff.), a book which was not published till after the completion of this chapter. Such passages as Mark i. 27, Matt. ix. 8, have an indirect bearing on this question as showing the immediate impression made on the people by Jesus' work ; and the sense it conveyed of a definite and decisive new departure. Cf. also Luke iv. 21 ("To-day hath this scripture been fulfilled in your ears"), and 36-44.

2 Matt. xi. 2-5; in vv. $11 \mathrm{f}$. it seems to be clearly implied that the Kingdom could be entered or "taken by storm" at that very time. 
kingdom of God as the power that works inwardly. As he calls the sick and poor to him, so he calls sinners also, and it is this call which is all-important." ${ }^{1}$ Here at least it would seem certain that Jesus did not act merely as the herald of a future benefit. And yet there are two possible objections which may be made here. On the one hand it may be said that this doctrine of forgiveness, concerning as it does the individual soul in its inmost experience, belongs to another order of thought than that in which the preaching of the Kingdom moves. But the weakness of this objection is felt as soon as we reflect that the preaching of the Kingdom, in the case of Jesus, not less than of John the Baptist, was at the outset a preaching of repentance, and that at a later stage "he upbraided the cities wherein most of his mighty works were done, because they repented not." ? But if the preaching of the Kingdom and the mighty works which evidenced its presence were both designed to lead to repentance, and through repentance to forgiveness, the connection of the latter with the Kingdom is established.

But is not this connection, we may now be asked from the other side, so firmly established that forgiveness can no longer be understood as a separate and substantive element in the teaching of Jesus? Is not participation in the blessings of a future kingdom the ratio essendi of both repentance and forgiveness? Are they not the keys by which its portals may be opened? and do they not gain their value and importance solely from their relation to it? Now the answer to this objection must depend upon a general impression of the character and teach-

1 What is Christianity? p. 60.

2 Mark i. 15 ; Matt. xi. 20. 
ing of Jesus rather than upon the interpretation of isolated sayings. Nor will it always prove possible to convince those who regard the idea of forgiveness as a benefit immediately conferred as a later modification or idealisation of Jesus' teaching. They have their own canons by which to interpret or reject those passages in the Gospels, which bring the benefits of the kingdom nearest to the deep and timeless needs of human nature. But the greater number of those who seek to gain a true conception of the general tenor and atmosphere of the Gospels, will probably always feel that there is an element in them which refuses to adapt itself to the eschatological scheme, and that the change of heart which is implied in forgiveness - the new attitude of love to God and man - was held up by Jesus as needful and possible in the immediate present. They were more than passports valid at some future time: they did indeed give access to immediate blessedness. It was when a certain scribe showed his appreciation of the supreme importance of this twofold, ever-present duty of love, that Jesus addressed him in words of high recognition and approval, "Thou art not far from the kingdom of God." 1 Surely this shows that Jesus thought of the Kingdom not only as lying in the future, but as constituted by the moral attitude of the seeker after goodness.

This impression is borne out by such sayings as "Thy faith hath made thee whole: go in [or into] peace." ${ }^{2}$ In the great invitation in the eleventh chapter of Matthew, the words, "I will give you rest," ... "ye shall find

1 Mark xii. 34.

2 Mark v. 34 ; cf. Luke vii. 50. 
rest unto your souls," speak of no distant future, but of an opportunity that is near at hand; and the same timelessness runs through many of Jesus' sayings. Especially is this true of the Beatitudes; for while they undoubtedly refer to a future time, at which the mourners shall receive a more complete consolation, and the meek shall more fully and evidently than at present "inherit the earth," yet there is a present reference as well. The first Beatitude in particular"Blessed are the poor in spirit, for theirs is the kingdom of heaven"- -seems clearly to make the possession of the kingdom dependent on an inner state of mind, and so to bring it from the apocalyptic to the spiritual and universal order of truth.

Only two more passages need be cited in this connection, but these two are among the most decisive of all. The first is the saying, "Blessed are your eyes, for they see; and your ears, for they hear. For verily I say unto you, that many prophets and righteous men desired to see the things which ye see, and saw them not; and to hear the things which ye hear, and heard them not." 1 The second is the saying of Jesus in regard to the children who were brought to him, that "of such is the kingdom of heaven." Nothing could more clearly show His anxiety that the timeless and spiritual aspect of His kingdom, of which He chose childhood as the fittest type, should never be forgotten or eclipsed. Eschatology has a great place in the Gospels, but it is far from having the central place-if indeed it is present at all - in this central passage. Nor is it possible to connect with a merely eschatological conception of the kingdom the words, "Whosoever shall not receive

1 Matt. xiii. 16 f. 
the kingdom of God as a little child, he shall in nowise enter therein," for the ideas of sonship and fatherhood carry our thoughts into a far different region. ${ }^{1}$

It would be possible to trace the same line of thought through the writings of St Paul, but one or two references must suffice. And indeed a full treatment of the Pauline side of the New Testament teaching on this subject is the less necessary, because Professor Anderson Scott has recently given an admirable analysis of the parallel between Jesus' teaching concerning the kingdom and St Paul's view of the new life in Christ, showing how the same antitheses are found in both and the same union of apparently diverse aspects. $^{2}$ The Pauline conception of the Spirit clearly carries with it the conclusion that the central benefit of Christianity is both immediate and a gift. It does indeed look to a more glorious future, of which it is "an earnest," 3 but it is not less true for the apostle that "the love of God hath been shed abroad in our hearts through the Holy Spirit which was given unto us." 4 In the one place in the Epistle to the Romans in which he uses the phrase "the kingdom of God," he defines

1 Mark x. 14 f.; cf. Matt. xviii. 3. "It is also clear that another train of thought of purely religious nature and undisturbed by apocalyptic speculation (the idea of sonship) existed concurrently. But it is impossible to reduce these two sides of Jesus' thought to complete harmony" (Johannes Weiss, Paul and Jesus, tr. Chaytor, p. 107. The italics are mine).

2 Cambridge Biblical Essays, pp. 362-366: "The Kingdom of Heaven is at once the most comprehensive and the most elusive of religious conceptions. But it is elusive only because it is employed successively to describe every aspect of the highest good at every stage of its apprehension by man."

${ }^{3} 2$ Cor. v. 5. Cf. Rom. viii. 18 ff.; Eph. i. 13 f.

4 Rom. v. 5 (R.V. marg.) ; 2 Cor. iv. 6. Cf. 1 Peter i. 8 f. 
it as consisting in "righteousness and peace and joy in the Holy Spirit." 1 And the idea that its blessings must be accepted as a gift, and not treated as cause for pride or self-praise, is more than once strongly affirmed. ${ }^{2}$

(2) But throughout the New Testament the complementary view of the kingdom as ethical and progressive in its development balances this first aspect. Or rather, it is not so much an addition to it as its necessary result and fruit, as I have already tried to show. The implicit must become explicit, the inward gift by its very presence institutes an outward task. It is also needful to remember that the word $\beta a \sigma \iota \lambda e^{\prime} a$ originally had the sense of "rule" hardly less than that of "kingdom"; 3 and so, when the phrase $\dot{\eta} \beta a \sigma \iota \lambda \epsilon^{\prime} a$ rov $\theta \epsilon o \hat{v}$ is rendered the "Rule of God," it is impossible to miss its significance as a power commanding the hearts of men, but also depending for its realisation upon their response. Thus there is a constant call on Christians to make good their profession.

This can, indeed, hardly escape recognition; but it may be reconciled with the purely eschatological view of the Kingdom by the argument that the call to moral effort, as it came to the first Christians, did not summon them to the attempt to transform the present world or "age" into the likeness of the Kingdom, but only to prepare themselves for the destiny that awaited

1 Rom. xiv. 17 (R.V. marg.).

${ }^{2}$ Rom. iii. 27 ff.; Eph. ii. 8 ; 1 Cor. iv. 7. The last passage is rendered as follows by Dr Rutherford: "What hast thou which has not been given thee? If given it was, then why applaud thyself for it, as though it were a feat and not a gift?"

3 Cf. E. F. Scott, op. cit., pp. 95 ff. 
them in the "coming age," when the rule of God would be made evident in a perfect state revealed from above. In other words, their task was less to reclaim the world than to reclaim themselves from the world, that they might be ready to welcome and enter the Kingdom of their Master at His return. Now this was undoubtedly a note of great importance in the New Testament idea of duty and "calling." Watchfulness and patience and preparedness were among the great concerns of the early Church. To be "accounted worthy to attain to that world" 1 did in a sense sum up all aspirations, and constancy in watching for the Parousia was the measure both of duty and of hope. "In your endurance ye shall win your souls," "If we endure, we shall also reign with him." 2 Nor is this motive only appealed to in support of such individual duties as personal watchfulness and purity; it is also used to emphasise the condemnation of those who fail in the duty of justice and consideration to others. $^{3}$

But while all this is true, there is another side to Jesus' teaching. He did not look on this world as an altogether hopeless place; and it is hard to believe that He meant His followers to look on work done in it by Himself or by them as having a merely indirect and disciplinary value without real, immediate significance. If we examine the parables of the Kingdom in Matthew xiii., and the additional parable of the Seed growing

1 Luke xx. 35 ("that age," R.V. marg.). Cf. xxi. 36.

2 Luke xxi. 19; 2 Tim. ii. 12. My justification for the use of "endurance" in the former quotation is the desire to bring out the identity

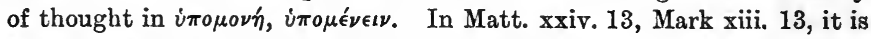
so translated-" He that endureth to the end."

3 Matt. xxiv. $48 \mathrm{ff}$. 
secretly recorded in Mark iv. 26-29, we shall find support in these eight parables for all three views. The aspect of the Kingdom as an immediate inward gift or discovery, which we considered first, is the most prominent in the parables of the Hid Treasure and the Pearl. The eschatological reference is foremost in that of the Dragnet. But in the parables of the Tares and the Seed growing secretly there is a double reference-to a future consummation and judgment ("the harvest"), but also to a period of present growth, although the relative emphasis is different. In the remaining three parablesthe Sower, the Leaven, and the Mustard-seed - the principal thought is that of the growth of the seed to maturity and perfection under the quietly fostering influences of nature; and this is taken as the type of the growing influence of Jesus' message in the hearts of His followers. ${ }^{1}$ In the parable of the Sower it is made very clear that abundant fruit can only be brought forth when receptiveness and constancy are shown on the human side; nor does there seem any need to interpret it as limiting the ethical results of the Kingdom to the period beyond the Parousia. Rather one must believe that Jesus thought of the fruit of His teaching as in an important sense immediately present, and so transforming the existing order of the world. This is the ruling idea in the metaphor of the leaven, which slowly penetrates the

1 Professor Shailer Mathews says that " in the case of the parable of Mark iv. 26-29, the teaching as to a present evolving kingdom is wholly dependent upon a disregard of v. 29" (The Messianic Hope in the New Testament, p. 70). This seems too sweeping a statement, although the parable has perhaps at times been applied in too exclusively modern a sense. In the same way it must be observed that the parable of the Mustard-seed may be interpreted in an eschatological sense, as intended to emphasise the sudden and quasi-miraculous development of a great result from insignificant sources (Cf. Schweitzer, op. cit., p. 354). 
whole mass in which it was hid, as it is in the similar description of the Christian community as "the salt of the earth." 1 Such is the power of the Christian life to permeate its whole surroundings, preserving what is good from decay and purging away what is evil or corrupt.

Another interpretation which perhaps calls for mention is that in which a dominantly or exclusively eschatological meaning is attached to the idea of the Kingdom, while the ethical element in Christ's teaching is thereafter introduced under some other category. So Professor Shailer Mathews says that "in the teaching of Jesus the most fundamental thing was not the kingdom itself, but that quality of life which assured a participation in its blessings." 2 Here the essential point is granted. But why in the interests of a dominantly eschatological view of the Kingdom should it be thought needful to make this rigid distinction between the Kingdom itself and the character of its citizens? Is not the former category as used in the Gospels wide enough to include the latter, which in truth supplies its essential content? How closely the two thoughts, or better the two aspects of the one thought, are intertwined is shown in the command to "seek first the kingdom of God and his righteousness "; ${ }^{3}$ where the idea of the Kingdom may perhaps lie chiefly in the future, ${ }^{4}$ but where Jesus makes

1 Matt. v. 13.

2 Op. cit., p. 112.

3 Matt. vi. 33 (A.V.). The fact that Juke's version of this saying is immediately followed by the words, "Fear not, little flock ; for it is your Father's good pleasure to give you the kingdom " (xii. $31 \mathrm{f}$.), shows how closely the different aspects of the Kingdom were interwoven in the minds of the early Christian community.

4 This is suggested by comparison with vv. 19-21 ("Lay not up for yourselves treasure upon the earth," \&c.). 
it absolutely clear that it is inseparable from goodness and the desire for goodness on the part of those who are to share it. In the same way it is perhaps not without significance that, in the First Gospel, the description of Jesus' compassion for the helpless and unshepherded multitude immediately precedes the sending out of the disciples to preach and heal, and the saying, "The harvest truly is plenteous, but the labourers are few. Pray ye therefore the Lord of the harvest, that he send forth labourers into his harvest." 1 The narrative shows clearly how His sense of the people's need urged Him to send them immediate succour, multiplying His own power through the hands of His disciples, and making them givers of present help as well as heralds of a coming Kingdom.

But the strongest proof that this element of effort and progress has a place in the Gospels is to be sought for, not in any isolated passage, but in their general ethical character. He who "came to fulfil the law and the prophets," refused as sternly as the prophets had done to allow the hope of a glorious release and restitution of all things in the future to excuse blindness to the actual needs and claims of others in the present. He agreed with the Pharisees against the Zealots in holding that the Kingdom was not to be advanced by the violent methods of political revolution; but He turned on the former with more than the indignation of an Old Testament prophet when the question was that of their extortion and oppression of the weak. ${ }^{2}$ Such actual wrongdoing could not be covered by professed faithfulness to the Messianic hope.

Again, in Jesus' teaching the duty of mercy and kind-

${ }^{1}$ Matt. ix. 36 ; x. 1.

${ }^{2}$ E.g., Matt: xxiii. 23 ; Mark xii. 40. 
ness is not only reaffirmed but set in a hundred new lights. Forgiveness, courtesy, love towards enemies, pity for the suffering, are all enjoined in the Sermon on the Mount and in many other passages. And is all this teaching of a new, more intimate, more searching morality, with its respect for the small and immediate opportunities of life as well as for the great possibilities of the future, to be looked on simply as setting forth a moral discipline and probation, directed to the changed conditions of a new era still to be revealed? However fully this aspect of New Testament ethics may be recognised, it is impossible to rest content with this as a complete account of its meaning. For it is acknowledged by all that the carrying out of this morality would in fact transform the world, and create a new and better order of society; and we can hardly suppose that this gradual introduction of a better order through the efforts of men inspired by His spirit formed no part of Jesus' plan, when we remember His warnings that the present age might be prolonged, and that for a long time His servants might be required to employ their talents under the ordinary conditions of its life. ${ }^{1}$

The attempt to view the whole of Christian morality as a great probation for a future life has indeed been made, but at a heavy cost. For if virtuous action be directed not to bringing about an immediate result in the improvement of this world, but only to securing the fitness of the good man for entrance into another, it loses all the naturalness and spontaneity which shone out in the life of Jesus. His pity was real pity, unfeigned and unforced, which led directly to the effort to bring relief; and so must it be with His followers. Efforts for others

1 Mark xiii. 32; Matt. xxv. 5, 13, 19. 
must be made with no arriere pensie, for the sake of others, and not for the sake of exercising the virtue of the benefactor. Otherwise, in place of the ready sympathy of Jesus, with all the beneficent power which it gave, there arises an unnatural form of piety, which considers that misery is necessary as the corpus vile on which benevolence may be exercised, and which encourages pauperism in order to stimulate the charity of the faithful. Against this state of mind the polemic of Nietzsche is in large measure justified. But it is surely clear that this is a perversion of the spirit of the Gospels. Yet, if the efforts of good men are not to be directed to the advancement of a Kingdom of God, actual, present, and progressive, we are shut up to some such view as this.

(3) Yet, notwithstanding all this, the element of hope is also present throughout the New Testament, and looks onward to a consummation which does not in the last resort depend on human effort. Regarding this eschatological side of the Kingdom nothing need be added here; unless we pause for a moment to emphasise the remark already made regarding the way in which the eschatology of the Gospels is ever closely linked with their morality. The former element Jesus adopted from the thought of His time; but it provided only the form of His message, and into this form He introduced the content of His essentially original ethical teaching.

In the first place, Jesus carried His doctrine of the worth of the individual man and the supreme importance of personal goodness into the sphere of eschatology. This of itself changed the whole aspect of the teaching concerning the Last Things. For the Jewish picture of the Judgment had been that of a 
separation of the Jews from the Gentiles, or of the pious as a class from the irreligious and outcast. But the principle of judgment as Jesus declared it cut through all class distinctions, and emphasised the final separation of those who were most nearly bound together by ties of external fellowship. "Then shall two men be in the field; one is taken, and one is left: two women shall be grinding at the mill; one is taken, and one is left." 1

So also it has been said that the Jewish apocalyptist saw " the advent of the Kingdom, but not the Kingdom itself." ${ }^{2}$ This content, which was deficient in Jewish apocalyptic, Jesus supplied by His whole teaching regarding the nature of the Kingdom's growth and the character of its citizens. In particular is this true of Matthew xxv., where, with an unparalleled boldness, $\mathrm{He}$ reaffirmed all that $\mathrm{He}$ had taught regarding the worth of humble individuals and the value of small and inconspicuous acts of love, and set it in relation to the grandest possible portrayal of the future judgment. In this passage the most opposite elements of humility and majesty in the whole range of the Gospels are combined into one scene; and, as has well been said, "the audience feels that, whoever the "Son of Man' may be, He will not judge otherwise than Jesus of Nazareth." 3 Thus the ultimate value of moral effort and the ethical character of the Kingdom are confirmed by the greatest apocalyptic utterance in the Gospels. So also in the reply to the sons of Zebedee, Jesus refused to countenance ideas of the future

1 Matt. xxiv. 40 f. Cf. Bousset's Jesus (Eng. trans.), pp. $124 \mathrm{ff}$.

2 Muirhead, The Eschatology of Jesus, p. 85.

3 Muirhead, op. cit., p. 202. 
Kingdom which were still tainted with personal ambition, and recalled the thoughts of His disciples from the individual advantages which it might bring them to the certain and immediate duties of service and constancy under trial. ${ }^{1}$ Thus while the idea of a Kingdom to be hereafter revealed had an important place in His thought and teaching, it was so stated by Him as to reinforce, and not to annul, the moral ideals which $\mathrm{He}$ proclaimed, and especially the allcomprehending duty of love.

(4) It is worth while to devote a few words to unfolding the implications of this description of the Kingdom as something "to be hereafter revealed." It was looked on as the subject of revelation in the future, not of creation; and hence it must already exist elsewhere. It was to come down from Heaven, "made ready," or "prepared": it was to be manifested by God, to appear for the first time on earth $;^{2}$ but it was not to come into existence only when it should first appear to the eyes of men. Thus Jewish piety tended to depict the Kingdom as having a present, transcendent existence, upon which its future manifestation depended, and to imagine some higher order of life, in which the rule of God was unassailed and undisputed-not an ideal, but a fact.

This conception was closely connected with the belief in angels, as the spiritual beings who perfectly and continually fulfilled the will of God, the "army of heaven" who never failed to respond to His commands. ${ }^{3}$ Their lineage could be traced back to those

1 Mark x. $35 \mathrm{ff}$. 2 Rev. xxi. 2 ; cf. Matt. xxr. 34.

3 Ps. ciii. 19-21 ; Dan. iv. 35. 
unfallen angels who appeared in the story of the Creation and Fall which was elaborated from the opening chapters of Genesis; just as the "prince of this world" and the spirits of evil who owned his sway were the angels who fell at the beginning, and who were still responsible for the disease and disorder of the world. To the latter side of this belief, which was intimately related to the demonology of gospel times, we need not now refer; but it is important to notice the significance of the belief in angels, for it pointed to the realisation and supremacy of the will and purpose of God in a transcendent region, and so gave support to those who were seeking to do His will, and were awaiting the fulfilment of His purpose, amid the discouragements and the frequent conflicts of earth. This thought continued to exert its influence for centuries; and, when Augustine wrote his City of God, he described the heavenly state, which was opposed to the earthly empire of Rome, as consisting of two parts. There was not only the part on earth, whose progress could be traced through the history of the Jewish nation and the Christian Church. There was also that angelic community which had ever remained constant in its original vocation and obedience. Thus in treating of "the origin of the holy city," he first mentions "the holy angels, who constitute a large part of this city, and, indeed, the more blessed part, since they have never been expatriated." 1

This view seems also to have been accepted by Jesus, who thought of the angels as representing an order of life in which the characteristics of the Kingdom, which $\mathrm{He}$ had come to inaugurate on earth, were con-

1 Book XI. 9 (tr. Dods). Cf. 28 ff., and Book X. 7 ff. 
stantly and perfectly realised. Thus $\mathrm{He}$ could appeal to that higher order as exemplifying His conception of the Kingdom, and as ready to support $\mathrm{Him}$ in $\mathrm{His}$ mission. This appears from such sayings as, "There is joy in the presence of the angels of God over one sinner that repenteth"; "In heaven their angels do always behold the face of my Father"; "In the resurrection they . . . are as angels in heaven." 1 It is not necessary to determine how far Jesus used these words in a. consciously metaphorical sense. The essential point to which they bear witness is that $\mathrm{He}$ did not think of the Kingdom merely as an ideal, but that, in all its earthly aspects, whether spiritually present, progressive or apocalyptic, He claimed for it the sanction and support of the highest order of life and power in the universe. At once the simplest and the most memorable expression of this attitude is to be found in the petition, "Thy will be done, as in heaven, so on earth." 2

But behind the thought of the Kingdom in all its forms lay the belief that it represented the Will of God, and so was founded on the deepest reality which could be conceived. The phrase "the Will of God" is not among those most frequently used in the Synoptic Gospels. But it can hardly be doubted that the idea of the Divine Will formed an undercurrent in all Jesus' teaching, and that it was no occasional or random thought which finds utterance in the saying that the truest kinship to Himself belongs to those who do the will of His Father; or in the words, "It is not the will

1 Luke xv. 10 ; Matt. xviii. 10 ; xxii. 30 (Mark xii. 25). Cf. Matt. xxvi. 53.

2 Matt. vi. 10. 
of your Father which is in heaven, that one of these little ones should perish." 1 No less characteristic is the saying recorded in the Fourth Gospel, "My meat is to do the will of him that sent me, and to accomplish his work." ${ }^{2}$ The same consciousness that the progress of His work depended on contact with a power above the earth is evidenced by the place taken by prayer in the life and teaching of Jesus. Quotations might be multiplied to illustrate this; but it is indeed implied in the first point from which we set out on this survey, the idea of the Kingdom as a gift. For if it has this character there must be some great reserve of spiritual power from which such gifts come $;^{3}$ and the Spiritual Order, of which the belief in angels is an imaginative expression, must actually exist. Jesus did in truth most directly teach that those who followed His precepts were not building on sand, but on the bed-rock of that Order which, however deeply it is hidden from common observation by the course of outward events, yet stands to religious faith as the most secure and final truth. ${ }^{4}$

\section{III.}

We may conclude this chapter with a comparison between these phases of the Christian idea of the Kingdom and those of the corresponding Greek conception of the perfect polity, which obtained its first and greatest expression in Plato's Republic. The last of the four aspects, the Kingdom as a transcendent realisation of the Divine Will, has its analogue in the Platonic

1 Mark iii. 35 ; Matt. xviii. 14.

3 Luke xi. 13 (Matt. vii. 11); James i. 17.

2 John iv. 34. Cf. vi. 38.

4 Matt. vii. $24 \mathrm{f}$. 
conception of the ideal world, the abode of real Being and the object of true knowledge, existing in dependence on the supreme reality, the Idea of the Good. Thus too the inward aspect of the Kingdom, as it exists in the heart of the individual man who has caught sight of the ideal and seeks to transform his life into its image, has a corresponding place in the thought of the Republic and of the New Testament.

But regarding the second and third aspects-the progressive and final realisation of the ideal polity on earth -Plato's thought shows more hesitation. Regarding the "theoretic construction of the pattern of a perfect state" 1 he spoke with assured voice; for his deepest certainty was that of its transcendent and absolute reality, and of its reflection in the souls of those who had "turned to the light." But his hope of its realisation under the conditions of human life was less firm than his faith in its ultimate truth. Not by a manifestation from above could it come, as the Jew and the early Christian expected the Kingdom of God to appear; for the statical "Ideas" of the Republic had no dynamic energy by which to transform the world of change and corruption. Nor did Plato hope for its realisation through the accumulated labour and devotion of successive generations of humble workers inspired by a single great purpose. If it were to be built up on earth at all, it could only be through the insight and devotion of an elect few-the philosophers who should gain sufficient political power to give the ideal an expression in an actual state. ${ }^{2}$ But this fortunate chance might never

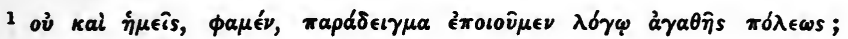
สdvv $\gamma \epsilon, 472 \mathrm{E}$.

2 Ibid., 473. 
occur; and thus in many cases the highest wisdom of the good man was to find shelter for himself from the driving storm of lawlessness and passion, and so to keep his own life clear of stain and to depart at the end with unsullied character and bright hope. ${ }^{1}$ This indeed was not the highest destiny-which was that the good man should not only save himself, but also become the saviour of his fellows, - but often he was forced to give up the effort to influence the world about him and to live the life of virtue in solitude and apart.

There are circumstances in every life when this appears to be the highest possibility for the Christian also; when, in face of the seeming impossibility that goodness will ever become regnant or the Kingdom of Heaven be realised on earth, he falls back on the thought of personal duty, and on the hope that the values won in the present struggle may perchance be conserved in another sphere where the rule of good is less sorely hindered than here; when he is content to trust that the failures of this world may have significance for some other. In this mood he will "look away to the pattern city which is laid up in heaven, treating as of little account the question whether it is or will ever become visible on earth, content to live as a citizen in it and to practise its laws alone." 2 But such an attitude is not finally possible; for the Christian faith cannot be attained or kept in solitude by the meditation of the thinker or the absorption of the mystic. Such a faith is inevitably

1496 C-497 A. Cf. Thecet., 176, "Evils can never pass away. . . . Having no place among the gods in heaven, of necessity they hover around the earthly nature, and this mortal sphere. Wherefore we ought to fly away from earth to heaven as quickly as we can; and to fly away is to become like God, as far as this is possible" (Jowett).

2 Rep., 592 B. 
THE KINGDOM OF GOD, PRESENT AND FUTURE. 207

shattered by the rude impact of the world's evil. It can only be securely held in so far as it is experienced and practised as a regenerating power, ${ }^{1}$ strong enough to enforce its own right against all that opposes it, whether in the inner life or the life of the world. Thus the characteristic aspiration of the Christian life, Fiat Voluntas Tua, ceases to be "understood only as an act of resignation," and comes to "point out the duty of working with all our strength for the triumph of Divine Law in the field of human liberty." 2

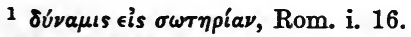

2 A. Fogazzaro, The Saint (Eng. trans.), p. 94. 


\section{CHAPTER VIII.}

THE PLACE OF REWARD IN MORAL PHILOSOPHY.

WIтH the survey in the preceding chapter of the idea of the Kingdom of God in its many aspects, the first part of our inquiry may be taken as having reached its close. For we have in some measure seen how the various conceptions which we have dwelt on hitherto-the worth of the individual life, the inward and outward aspects of man's good, and the relation of individual wills to the welfare of the community-find their synthesis and completion in the comprehensive idea of the Kingdom. Yet from that idea, as it is partially and imperfectly defined in the preceding pages, other problems take their rise; and we are led on to inquire into the nature of the authority by which its citizens are controlled, the motives to goodness which are dominant within it, and above all the form which is given to the great conceptions of Law and Freedom. For until this last question is answered the nature of the Kingdom can at best be very inadequately understood. But since this question of Law and Freedom is perhaps the deepest of all, it may best be treated when our discussion is approaching its close; and in this and the following chapter we may ask what are the Christian motives to virtue, and what is the dynamic of the Christian life. 
Thus our next task is to define the conception of Recompense and to show its place in Christian Ethics. Of its two aspects, those of reward and punishment, the former is of special importance, for the character of an ethical system is determined to no small extent by the form which the conception of reward assumes within it. And this question is closely related to the subject of the last chapter; for the Christian idea of morality, as it is expressed in the doctrine of the Kingdom, has been criticised on the ground that the recompense of virtue is set forth in too close connection with virtue itself, and that the thought of future rewards and punishments is placed too much in the forefront. But before we turn once more to the teaching of the New Testament to determine how far this criticism is a just one, we may gain some preliminary insight into the problem by examining the forms which it has taken in the history of Moral Philosophy.

\section{I.}

This is indeed one of the regions in which the path of religious thought runs closely parallel to that of ethical speculation. For when a certain advance has been made along either line, the thinker becomes aware of a double demand of the moral or religious consciousness. On the one side the necessity comes to be felt that virtue must be before all things disinterested, and that on this quality its very existence depends. For any form of good action which is prompted by the hope or fear of recompense sinks at once from the level of true virtue to that of prudence; and the one type of conduct which fulfils all the conditions of moral goodness, is that 
in which the spirit of man ventures all upon the intrinsic rightness of an action, or seeks an end which is felt to be noble in and for itself, laying aside every consideration of future 'pain or profit. But over against this demand there stands another which is hardly less universal or insistent-the demand that virtue shall in the end be recognised and rewarded, that the struggle shall not be fruitless, nor the effort of the good will be rendered unavailing by the resistance of a hostile or an apathetic world. Any system of ethics which disregards the force of this demand for some ultimate harmony of goodness and happiness, must fail to give a satisfying answer to the moral problem in one of its essential aspects.

It is hardly needful to labour the first of these points, for it is clear that, with the possibility of disinterested action, and of the determination of the will towards the Good independent of its rewards or advantages, the whole idealistic conception of virtue stands or falls. Perhaps the most memorable and picturesque statement of this truth is the story, told in Joinville's life of St Louis, of a Saracen woman who was seen walking down a street of Damascus with a pan of fire in one hand and a pitcher of water in the other; and who, when asked by a monk what she intended to do with these things, replied, "Burn up Paradise and put out the fires of hell, so that men may do good for the love of God alone." 1 The same thought is carried to a further point in that form of Indian philosophy, which insists that not only the hope of personal reward, but even the desire to achieve any result or "fruit of action," other than the good action itself, must be dismissed from the mind of the

1 Quoted by Höffding, Philosophy of Religion (Eng. trans.), p. 337. 
truly good man. Extreme as this doctrine is, one cannot but feel how infinitely it surpasses the Christianity of an early Father who used this form of appeal :- " $D a$ pauperi ut des tibi: da micam ut accipias totum panem: da tectum, accipe calum"; or that of Paley, when he defined the purpose of religion as, "to influence the conduct of human life by establishing the proof of a future state of rewards and punishments." 1

In this connection we may also recall the noble words of the Theologia Germanica, "He who hath put on the life of Christ with the intent to win or deserve ought thereby, hath taken it up as an hireling and not for love, and is altogether without it. . . . But true Love is taught and guided by the true Light and Reason, and this true, eternal and divine Light teacheth Love to love nothing but the One true and Perfect Good, and that simply for its own sake, and not for the sake of a reward, or in the hope of obtaining anything, but simply for the Love of Goodness, because it is good and hath a right to be loved." 2 Again, "where men are enlightened with the true light, they ... are in a state of freedom, because they have lost the fear of pain or hell, and the hope of reward or heaven, but are living in pure submission to the Eternal Goodness, in the perfect freedom of fervent love." 3

This teaching is clearly echoed by two thinkers so great and so different as Luther and Spinoza. Luther names it as a mark of true Christians, "that even if they knew that there were no heaven, no hell, and no reward, even still would they seek to serve God for his

1 Quoted in Studies in Theology by Estlin Carpenter and Wicksteed, p. 315. The comparison of the two attitudes brings Dante's words forcibly into the mind-Tai Cristian dannerd l' Etiope.

${ }^{2}$ Chh. xxxviii. and xlii. (tr. Winkworth). ${ }^{3}$ Ibid., ch. x. 
own sake." 1 Spinoza also repeatedly defines the good life as a life inspired only by the love of God and of virtue, and not by the hope of reward; but of many passages to this effect it will suffice to quote one: "Our highest happiness or blessedness is... solely in the knowledge of God, whereby we are led to act only as love and piety shall bid us. We niay thus clearly understand how far astray from a true estimate of virtue are those who expect to be decorated by God with high rewards for their virtue, and their best actions, as for having endured the direst slavery; as if virtue and the service of God were not in itself happiness and perfect freedom." 2 Not long after, Fénelon brought on himself the censure of the Church of Rome by his strong proclamation of the same doctrine of "the disinterested love of God."

Many passages might also be quoted from Kant in support of this view of virtue as essentially disinterested, and independent of all hope of reward. Indeed the greater part of his ethical theory may be taken as an enlargement and defence of the position that all motives springing from desire, hope or fear are "pathological" in character, and that virtue consists in dismissing them all, and acting out of pure respect for the Moral Law alone. Indeed it is just in man's power to take his stand against all these natural impulses and to hold to his course of action in their despite, that he proves his freedom and his greatness as a moral being. But the interest of Kant's philosophy for the present inquiry does not only lie in his strong and impressive, even un-

1 Quoted by Herrmann, The Communion of the Christian with God, 1st Eng. ed., p. 151 ; 2nd do., p. 196.

${ }^{2}$ Ethics, note to Part II. (tr. Elwes). 
compromising, statement of this demand of the moral consciousness; it lies rather in the fact that he proceeds to set the other demand-that virtue shall find its due reward-in close juxtaposition to it. The vigour with which he maintains both sides of the antithesis makes his treatment of the problem of the place of reward in the ethical scheme in the highest degree suggestive, although at the same time it has led to his being charged with radical inconsistency.

The transition from one position to the other is made at the beginning of the second portion of the Critique of Practical Reason, in the "Dialectic." Here virtue, whose independence of every foreign assistance or motive Kant has dwelt on throughout the "Analytic," is by an unexpected turn of thought defined as "worthiness to be to be happy (glïcklich)"; and the idea of the summum bonum, with which he is dealing, is divided by one of his numberless subtle distinctions into the "supreme," and the "perfect good." 1 The former consists in virtue alone, and its attainment is thus within the power of man's will; while the latter combines with virtue a happiness justly proportioned to it. But as such a union cannot be guaranteed by the ordinary laws of the empirical world, we are forced to assume that it is achieved by a higher Power; and so we reach the idea of God, the all-knowing Ruler of the Universe, who assigns to virtue its due meed of happiness. Neither idea can be reached from the consideration of the other; for Kant holds that the Stoics were wrong in teaching that virtue included happiness, though their error was less serious than that of the Epicureans, who reversed the relation

\footnotetext{
206).

1 Bonum supremum-bonum consummatum, V. 110 (tr. Abbott, p.
} 
and taught that happiness included virtue. Now if neither of these ideas can be inferred from the other by analysis, their relation in the summum bonum must be a synthetic one, and the synthesis can be effected by God alone. ${ }^{1}$

Such in brief outline is Kant's famous argument for the existence of God. It does not indeed fall within our present purpose to consider its theological adequacy; but it is to the point to note how forcibly it testifies to the feeling that virtue can be thought of as the complete and perfect Good, only when it is met and recognised by some cosmic power outside the individual human will. Deep in the common consciousness of mankind is the thought that the life of the good man demands some completion, some token that his efforts have not been cast away, or proved useless to himself and others. Yet it is striking to find this demand, that virtue should be in some sense rewarded, so pointedly expressed by the great exponent of Stoicism and rigorism in modern ethical thought. It may, however, be shown that this sudden turn of the ethical argument is no mere private eccentricity or inconsistency of Kant's, if we compare with his treatment the course of the argument in Plato's Republic, taking for the purpose two passages, one near the beginning and another at the end of the dialogue.

The central inquiry of the Republic begins in the Second Book, with the contention of Glaucon that the real nature of justice can only be understood and its inalienable superiority over injustice placed beyond doubt, when both qualities are examined as they are in themselves, and when all extraneous considerations of reward or punishment are strictly excluded. But if

1 Op. cit., pp. 111 ff. (tr. Abbott, pp. 207 ff.). 
this is to be done, and if it is to be shown that justice is worthy to be chosen entirely for itself and not at all for its consequences, then we must imagine that all the common sanctions and inducements to justice are done away, and that the whole weight of worldly interest and advantage is thrown into the scale of injustice. We must suppose the unjust man to be uniformly successful, and to gain all the rewards which in a normal society fall to the lot of the just; while "we must strip the just man bare of everything but justice, and make his whole case the reverse of the former. Without being guilty of one unjust act, let him have the worst reputation for injustice, so that his virtue may be thoroughly tested, and shewn to be proof against infamy and all its consequences; and let him go on till the day of his death, steadfast in his justice, but with a lifelong reputation for injustice, in order that, having brought both the men to the utmost limit of justice and of injustice respectively, we may then give judgment as to which of the two is the happier." But even this is not all ; for the advocates of the unjust life will go further. "They will say that in such a situation the just man will be scourged, racked, fettered, will have his eyes burnt out, and at last, after suffering every kind of torture, will be crucified; and thus learn that it is best to resolve not to be, but to seem, just." I

${ }^{1}$ Rep., 358 D, 361 C-362 A (tr. Davies and Vaughan). One can hardly miss the parallel between this passage and the picture of the Suffering Servant in Isaiah liii. There is, however, a characteristic difference, in that Plato has here an end in view which is predominantly theoretic-the manifestation of the nature of goodness in and for itself ; while the object of the Hebrew prophet is wholly practical-to show how the entire self-surrender of one man is the only path to the redemption of the many. But both are alike in the final conclusion that righteousness will be vindicated, and that in this vindication the good man will find his reward. 
It is next pointed out by Adeimantus how much support the mercenary conception of justice and virtue, as deserving to be followed for the sake of the rewards they bring, receives from popular religious teaching; and finally the brothers join in appealing to Socrates to show them what influence justice and injustice exert on their respective possessors, "by which, whether gods and men see it or not, the one is in itself a blessing, and the other a bane." 1 Socrates accepts the challenge, and the argument of all the following books is a sustained attempt to show that in itself justice is good and worthy of choice. But in the Tenth Book, when this argument has reached its close, Socrates demands that what had been borrowed at the outset-the admission that the rewards of conduct go to the man whose life is unjust -should now be returned to him. "Now that judgment has been passed upon them, I, in my turn, demand on behalf of justice, that we should admit the estimation in which she is held, to be what it really is, both among gods and among men, in order that she may receive the prizes of victory. . . Hence, in the case of the just man, we must assume that, whether poverty be his lot, or sickness, or any other reputed evil, all will work for his final advantage, either in this life, or in the next. For, unquestionably, the gods can never neglect a man who determines to strive earnestly to become just, and by the practice of virtue to grow as much like God as man is permitted to do." 2

Still another parallel may be found in the closing pages of Spinoza's Ethics. Through several propositions he has developed his doctrine of immortality, which forms, as in Kant and in Plato, the culmination of his ethical argument; and then he adds these words: "Now,

1 Rep., 367 E。

${ }^{2}$ Rep., 612 B-613 A (tr. Davies and Vaughan). 
while we determined what reason prescribes as useful, we took no account of the mind's eternity, which has only become known to us in this Fifth Part. Although we were ignorant at that time that the mind is eternal, we nevertheless stated that the qualities attributable to courage and high-mindedness are of primary importance. Therefore, even if we were still ignorant of this doctrine, we should yet put the aforesaid precepts of reason in the first place." 1

Now, it is remarkable that in three systems so different as those of Plato, Spinoza and Kant, we should find this similarity of philosophical procedure, this identical articulation in the structure of the whole of ethical thought. All three thinkers are equally in earnest in their determination to show that morality depends neither on the belief in immortality nor on the expectation of reward, but that the Good has an indestructible right to the allegiance of man, quite apart from the advantages that it may bring. The supremacy of justice over injustice, and the duty of following virtue apart from any hope of reward, and of avoiding vice not from fear of punishment but because it is in itself unworthy-these basal facts must first be given a firm and independent foundation. But when in this way the possibility of a true morality (which begins where the fear of punishment ends) has been established, the hope of a future life and of the reward of virtue may rightly be introduced. The good man would indeed be under the obligation to follow the guidance of conscience, even if the universe were wholly indifferent to his virtue; but neither Plato nor Kant is finally willing to believe in such an indifference. Both begin with the demand for a completely disinterested virtue, but both end by giving 
expression to the other demand that such virtue shall not fail of its reward.

Thus the first and most fundamental "interest" of morality is that of the purity of virtue in respect to its motive: the first task of Moral Philosophy is to show that every man owes allegiance to the imperative of duty and the idea of the Good, apart from the thought of any reward which this allegiance may bring to him as an individual. But when this task has been performed, this "interest" secured, it is laid upon the philosopher to take a wider view, to pass beyond the isolated virtue of the individual conscience to consider the effect of the good life on the world beyond. And if he can show that goodness awakens an unfailing response, then he may go on to state and to justify the belief that the good man is not in the end unrewarded, but that, as Plato affirms in the closing words of the Republic, he receives the prize of virtue and can "never cease to prosper." Thus while the idea of reward must be rejected as a presupposition of the good life, it finds a fitting place in its consummation. ${ }^{1}$

\section{II.}

There are some considerations which may now be briefly referred to, in order to illustrate further the connection of these two aspects of ethical theory.

(1) We may first suppose for the time that, when the first of these aspects had been placed beyond dispute, morality were considered as a closed system requiring no further explication or defence. If the independence

1 Cf. Note O, p. 404, "Kant on the Place of Happiness in Moral Philosophy." 
of the Good Will were all, if the virtue which scorns reward and pain alike were held to constitute the whole content of ethics, what then? Might it not be said that such a virtue, placed in the midst of a hostile universe, or even in an entirely indifferent and non-moral universe which opposed to the good will the dead-weight of an infinite inertia, would be baffled, overborne, and finally crushed? Is it conceivable that any man could persevere in the path of virtue if his utmost efforts achieved nothing and awakened no response? Or if it were conceivable, would not such a picture of the moral life be hopelessly irrational? Can we suppose that, if the moral imperative is in line with the ultimate truth of things-as a "categorical imperative" surely must be - the man who obeys it will be left wholly and finally to himself, and that no power greater than his own will meet and second his efforts? On such a supposition morality would be impossible, for it would be a heroic but futile endeavour to realise a purely subjective ideal. But if, as the great idealistic moralists teach, the Good is the central category of all our experience and thought, then the life of goodness is truly objective : it carries a man beyond his own narrow individuality, and in it he may gain the assurance that his will is met and supported by a cosmic Will that makes for the success and the reward of goodness. As Kant teaches, the question, "What should I do?" leads inevitably to the further question, "What may I hope?" I

1 Kritik der reinen Vernunft, 2nd ed., pp. 833 f. Throughout this argument I am greatly indebted to a lecture on the "Dialectic," by Mr Henry Barker, of Edinburgh University, which I heard several years ago. 
The answer to this question must at least give some support to the belief that the end striven after is not a matter of indifference to the universe, that the task set is not a radically impossible one. The end set up by Reason must be a real and valid end, "for it would be practically impossible to strive after the object of a conception which at bottom was empty, and had no object." 1 Thus perseverance in the pursuit of the moral ideal implies the hope of some measure of success, and of the reward which lies in the attainment of the object striven for.

(2) But it also implies the possibility of continued striving. Thus it comes to be a moral postulate that the life which is devoted to the endeavour after moral progress shall not be cut short by the intervention of an alien and non-moral fate. Hence the reward of virtue now appears less as something to be acquired at a definite point, or as an external addition to the good life, and more as the assurance of the possibility of further progress, as the belief that what has been won in the past will not be scattered to the winds by some power indifferent to the claims of morality, but that all past advance will provide the starting - point for yet further advance in the future. And so it has been said of Virtue :-

"She desires no isles of the blest, no quiet seats of the just,

To rest in a golden grove, or to bask in a summer sky :

Give her the wages of going on, and not to die." 2

From this point of view it is possible to appreciate the close connection between the ideas of immortality and of the reward of virtue which has so constantly appeared

${ }^{1}$ Kritik der Praktischen Vernunft, V., 143 (tr. Abbott, p. 241).

2 Tennyson, Wages. 
in ethical thought, but at the same time to recognise that the conception of reward so held need not be in any sense external or mechanical. The reward sought for is nothing foreign to the nature of virtue itself. It is rather the opportunity for the necessary development and completion of goodness that forms the content of the ethical and religious hope. Religion has been defined as concerned with the relation of Value to Reality, and religious faith as the assurance of the Conservation of Values. ${ }^{1}$ But-if the values won in the moral life are to be held as of essential and ultimate importance, if they are of moment in the wider life of the universe, then this assurance that they will not finally be dissipated and destroyed is in itself a true reward; nay, it is the one form of reward which is indispensable if man is to continue to believe in and to practise virtue. But this faith that goodness is not at the mercy of forces subject to no spiritual control, is of a kind wholly different from any outward reward or any single pleasure, or even from that self-satisfaction of the mens conscia recti which is sometimes treated as the true recompense of virtue. It is both higher and more durable, for it rests upon the experience of ethical values, and on the conviction that they will be conserved in the wider stream of effort into which all individual strivings after goodness must finally flow.

This view of reward as the opportunity for continuance in virtue may be illustrated by a parallel theory of

1 Höffding, op. cit., pp. $6 \mathrm{ff}$., $223 \mathrm{ff}$. This position is essentially that of Kant, who held that the theoretical question, "What can I know ?" and the practical question, "What should I do?" led up to the third question, "What may I hope?" which deals with the union of theory and practice, and thus has a religious character. (Kr. der reinen Vern., loc. cit.). 
punishment. There is in the Gorgias a famous passage in which Plato argues that it is better for the wrongdoer to undergo the due punishment of his fault than to escape it. For if he be allowed to evade all retribution for his crime, he will plunge ever deeper into injustice and wrong; whereas punishment may draw him towards what is good. Thus Plato upholds the paradox that if we would inflict the direst penalty upon any man who has injured us, we need only leave him unpunished, and so encourage him to " become immortal in his wickedness," going on in that path of injustice which finally leads away from all true wellbeing. ${ }^{1}$ Thus, if the heaviest of all punishments be the opportunity to continue unchecked in the career of crime, it is natural to see in the opportunity of perseverance in goodness the one sufficient and appropriate recompense of virtue. If the worst penalty of sin be that it always tends to reproduce itself in further sin, this analogy points to a conception of reward which is not outward and accidental, but inward and dynamical-the free development and reproduction of goodness itself.

(3) So far we have considered this demand as related in the main to the moral life of him who makes it. But this is neither its strongest nor its most characteristic form. It is made not less earnestly on behalf of others. This altruistic interest constantly lies at the root of the desire for the reward of virtue; and it is not hard to see that in this case virtue and happiness may be thought of as united by a closer bond. For there is no difficulty in conceiving a demand for the happiness of others as being entirely consistent with the personal disinterestedness of him who makes

1 Gorg., 479-481 A. 
it. It is indeed almost a commonplace that their happiness has an ideal character for the individual who takes it as his end. So, while a man may rightly hesitate in his own case to equate the two ideas of virtue and worthiness to be happy, he may instinctively treat them as identical when he is thinking of his fellows.

From this point of view Kant's transition from one idea to the other, while it may seem inconsistent with certain of his own ethical doctrines, harmonises with the moral sense of the mass of mankind. We need not adopt in its full rigidity the distinction which he draws elsewhere between the two aspects of the ethical end, as "My own Perfection" and "The Happiness of Others"; ${ }^{1}$ but we must acknowledge that there is a real difference underlying it. It may be the mark of a noble nature to desire perfection-even the perfection that is won through suffering-rather than immediate happiness, for those who are most loved; and yet it remains true that it is the duty of every man to guard the happiness of others more directly and constantly than he guards his own. Thus the good man will inevitably make the demand for the reward of goodness with greater intensity when he thinks of others than when he thinks of himself; because he is most keenly conscious of the apparent indifference and injustice of the universe, when he sees their efforts frustrated, or their devotion followed only by suffering. Here he judges impartially, and, as he has no concern for the disinterestedness of virtue in any save himself, he is the more free to consider whether

1 Pref. to the Metaph. Aufangsgründe der Tugendlehre, IV., V., XI. (tr. Abbott, pp. 296 ff., 309). 
the faith that duty and goodness are ultimate facts, that the Moral Law has final authority, does not carry with it in the end the further belief that a reward must follow obedience, and that he who sacrifices his own happiness for the sake of noble ends must at last find some joy higher than that which he resigns.

That this second demand of the moral consciousness gains its validity largely from the disinterestedness with which it is made, and hence acquires added force when it is prompted by the concern for others, is suggested by more than one phrase of Kant's. He holds that the perfect good "requires happiness also, and that not merely in the partial eyes of the person who makes himself an end, but even in the judgment of an impartial reason, which regards persons in general as ends in themselves." And again, "The same law must lead us to affirm the possibility of the second element in the summum bonum, viz., Happiness proportioned to that morality, and this on grounds as disinterested as before, and solely from impartial reason." 1 Hence this requirement is not based on "pathological" desire. Its motives are the concern for the welfare of others rather than for selfish wellbeing and the desire for the upbuilding of a complete and harmonious moral polity.

The results of our discussion may now be summed up in a few words. The first concern of ethical thought should be for the purity of moral motive, and for the exhibition of disinterested loyalty to the Good. But when the consequences of moral action in the world-order are taken into account, as they must

1 V., 110, 124 (tr. Abbott, pp. 206, 220). Cf. Kr. der reinen Vern., quoted in Note 0 , infra, p. 405. 
be, it becomes clear that such action can only gain its end if it is supported by broader and deeper forces than that of the isolated human will; and that virtue can only come to its perfect development in a universe whose highest Power favours and fosters its growth. And while the good man asks for himself no other reward than that "of going on, and still to be," he naturally and rightly seeks that the virtue of others shall lead to happiness. But neither for himself nor for them is the-happiness the same as that which was condemned at the outset. For it is a happiness which cannot be severed from virtue, and its nature is raised and purified by the whole discipline of the moral life.

Thus we need not fear that there will prove to be any ultimate discord between the two demands of the moral nature of man; for the second, rightly understood, is disinterested as well as the first, and the happiness which is bound up with the recognition of the Moral Law, and the thought of progress towards the moral ideal, has a new ethical character and content. Indeed the two demands which we have considered, and which at first appear contrary and incompatible, are seen in their true relation and harmony in the precept, "Die to live." The beginning of morality consists in the entire complete surrender of immediate pleasure and personal gain without thought or hope of reward; but its completion is not experienced until this surrender is found to lead forth into a larger and more abiding life. 


\section{CHAPTER IX.}

THE PLACE OF REWARD IN THE NEW TESTAMENT.

I.

WITH the results reached in the last chapter in view, we may now pass on to consider the teaching of the New Testament on this subject in its broad features, and to inquire in what form the antithesis of reward and the disinterestedness of virtue there finds expression, and how the two ideas are brought into harmony. For a full treatment of the question an examination of its statement in Old Testament thought would be essential; but this would prove no small undertaking, and as the ground is not unfamiliar, a very brief sketch may suffice. The religious thought of the Jewish nation set out from a point at which the thought of reward was prominent, definite, and, in the main, material. It was a central point of faith that obedience to the divine commandments would bring prosperity and happiness to the individual as its immediate fruit; and exhortations to obedience were enforced by the appeal to such prosperity as the sufficient sanction of righteous conduct. But gradually this direct and simple view became untenable, and a more spiritual conception was sought for in its place. 
Several influences helped to bring about this change. In the first place the deeper thinkers of Israel came to see that material prosperity could not in itself be the end of the moral life, since when attained it often proved the occasion of forgetfulness and moral decline; and so there grew up beside the idea of reward that of a divine discipline, by which the nation was brought to feel that there were more essential things than outward comfort and happiness. So the lesson was taught " that man doth not-live by bread only, but by every thing that proceedeth out of the mouth of the Lord doth man live." 1 Another line of thought, leading to the same result, was suggested by the opposite experience. It was found that, if prosperity led away from virtue, virtue in many cases led away from prosperity. More and more the thought and imagination of the noblest men in the Jewish nation came to be stamped by the fact, slowly and reluctantly recognised, that the righteous not only suffered, but suffered more than others, and suffered because of their righteousness. All this, and the corresponding fact of the frequent prosperity of the wicked, worked a deep change in the conception of the recompense of good and evil in the present life.

The inward conflict, which accompanied this change in beliefs at first so fundamental to Jewish religion, finds its most notable expression in the Book of Job, where all the elements of the problem are fused in a white heat of poetic imagination and religious fervour. This book indeed possesses its unique and lasting value, rather as a record of the struggle after a firmer and wider idea of the Moral Order of the world, than as providing any dogmatic answer to the deep questions

1 Deut. viii. 3 ff. Cf. xxxii. 6-18. 
with which it deals. Indeed the conclusion seems at first sight to fall below the height of the "great argument" by which the poet, like his English successor, seeks to "justify the ways of God to men." But there are two points of view which must be emphasised in his attitude to the problem. First, the suffering of Job is in some sense vicarious, since interests far wider than his own are represented as involved in his trial. It is directed to no less grand an object than the vindication of the purity and constancy of a good man's virtue against the suggestion, which " the spirit that denies" is ready to make in every age, that this virtue is but an affair of selfinterest after all-"Doth Job fear God for nought?"1 The patience of Job under unmerited suffering serves to vindicate the disinterestedness of true virtue; and the author's faith in Divine Government was sufficently strong to assure him that one who had suffered for this high end would in turn himself be finally vindicated. ${ }^{2}$ This final vindication he expressed in the terms natural to his age.

But there is another feature of the Book of Job which is even more significant-the emergence beside the idea of recompense of the idea of discipline- "When he hath tried me, I shall come forth as gold." 3 This thought shed a new light on the suffering of the righteous, and on the frequent failure of happiness to follow virtue. By this path more than any other, men were led to treat the thought of discipline as higher and more central than that of reward. Or if the latter idea still found expression, it was in a form from which the external

1 Job i. 9 ff., ii. 3 ff.

${ }^{2}$ One need hardly point out how clearly this illustrates the argument of the last chapter.

3 Job xxiii. 10. 
element had been refined away, and the religious experience in itself was the one thing sought after. This was the attitude of those among the psalmists whose one ambition was to enjoy the shelter and the inspiration of God's House, without regard for earthly wealth or rank, to whom the sense of communion with the Highest was the supreme reward of the good man. ${ }^{1}$

But the experience of the divorce between righteousness and worldly success did not always lead to this religious quietism. Other thinkers, or the same thinkers in another mood, sought to preserve the idea of reward by holding that the due recompense of good and evil was only delayed in its coming, not wholly cut off. Thus they counselled the good man to look away from the suffering and triumphant injustice of the present, to a future in which his righteousness would be vindicated and his happiness made secure. In proportion as the idea of a speedy reward proved impossible to maintain, the interval before its expected coming was lengthened, and the expectant look of hope was directed ever further into the future. In the Wisdom literature, we can clearly trace three phases of this belief in the Books of Proverbs, Ecclesiasticus and Wisdom; while a fourth phase (that of almost complete scepticism) finds expression in the Book of Ecclesiastes.

In the Book of Proverbs we find the first stage. In the main the writer still holds to the doctrine which may be described as that of Jewish orthodoxy, untroubled by the more searching doubts, that the reward of justice and the punishment of evil-doing will come clearly and finally in the present. ${ }^{2}$ Ben Sira, who

1 Ps. xxvii. 4, lxxxiv. 10, and especially lxxiii. 25.

2 E.g., xiii. 13, 21. Cf. Ps. xxxvii. $2,10 \mathrm{ff}$. 
represents a transitional stage, is troubled by the discrepancy between this doctrine and the facts of life; yet he still holds to the idea of reward in the present world, teaching that it will come at the end of a long and severe course of moral discipline-that it will come at the very end of life, if not before, or to the children of the good man, if not to himself. ${ }^{1}$ The last phase is to be found in the Book of Wisdom, where the idea of reward is taken up into a triumphant faith in immortality, and is thus made secure from all attacks based on a purely earthly experience. "The righteous live for evermore ; their reward also is with the Lord, and the care of them with the most High. Therefore shall they receive a glorious kingdom, and a beautiful crown from the Lord's hand." 2 Thus in the progress of Jewish thought, the idea of reward lost its immediate and material character, and was elevated into a transcendent sphere. Nor was this the case only among the Platonising thinkers of Alexandria, among whom was the author of Wisdom. It was so not less emphatically in the popular and largely apocalyptic religion of Palestine in whose midst Jesus was nurtured.

\section{II.}

Thus the idea of reward, which ran through so large a part of Jewish religion, still held an important place in the time of Jesus, and had then become closely

1 Ecclus. iv. 15-18, xi. 21-28. "It is an easy thing unto the Lord in the day of death to reward a man according to his ways. The affliction of an hour maketh a man forget pleasure ; and in the end his deeds shall be discovered. Judge none blessed before his death : for a man shall be known in his children." It is interesting to find the aphorism of Solon in this thoroughly Jewish work.

2 Wisdom, v. 15 f. Cf. ii. 23 -iii. 8. 
connected with the Messianic Hope and with the eschatological idea of a future Kingdom. It was therefore natural that Jesus should state His own teaching in the light of these conceptions. We saw how $\mathrm{He}$ adopted the idea of the Kingdom of God, but in doing so refashioned it and read into it a more spiritual content than it had held before; and in this restatement the interwoven idea of the reward of righteousness also received a new interpretation.

In our consideration of the various aspects of Jesus' doctrine of the Kingdom, the first point that demanded recognition was His representation of it as a gift bestowed on individual men, and as thus inward and spiritual; and the Beatitudes were referred to as illustrating this aspect of His idea of the Kingdom. Now the form of these sayings is that of promise, or even, it may be said, of the promise of reward. But if the idea of reward is here prominent, it does not bear its first or ordinary sense, but rather that spiritualised meaning in which it was used by the greater psalmists. The reward is conceived as belonging to the same order of spiritual experience as the state of mind and heart which ensures its bestowal. It has been said of the First Beatitude that "Christ speaks of the kingdom here not as a known quantity, but as a thing whose nature $\mathrm{He}$ is in the act of defining by the aphorisms He utters"; and the same mode of interpretation applies to the sayings throughout. ${ }^{1}$ The nature

1 A. B. Bruce in Exp. Greck Test., Matt. v. 3. These remarks perhaps apply less directly to the Third Beatitude than to the others; but it inevitably makes a different impression in this passage from that of its original context (Ps. xxxvii. 11). Cf. "The Place of Rewards in the Teaching of Christ," by G. Wauchope Stewart-Expositor, Sept. 1910, pp. $230 \mathrm{ff}$. 
of the reward is determined by, nay is continuous with, the quality of spirit that is commended: it is of such a kind as can only be prized by those who have entered into the spirit of the words, "Thou art my Lord; I have no good beyond thee." 1 The two blessings pronounced upon the merciful and upon those who hunger and thirst after righteousness are of especial significance, since they so clearly illustrate the truth that the right attitude of heart and will is rewarded in kind, and not by any accidental or external recompense-that by a spiritual law goodness, or even the aspiration after goodness, returns and multiplies itself upon the man of good will. ${ }^{2}$

There is also a later passage in the Sermon on the Mount which clearly shows the direction of Christ's teaching regarding reward. In it $\mathrm{He}$ warns His disciples against that ostentatious form of piety which was chiefly designed to impress the multitude; and then says regarding those who practise it-"Verily I say unto you they have received their reward. But when thou doest thine alms, let not thy left hand know what thy right hand doeth; that thine alms may be in secret: and thy Father which seeth in secret shall recompense thee." In the following sentences the same counsel is given in regard to prayer and to fasting. ${ }^{3}$ In each case the main emphasis lies on the thought "They have received their reward," or rather have received it

1 Ps. xvi. 2.

2 Matt. v. 6 f. The saying in Luke vi. 38 ("Give and it shall be given unto you," \&c.) might be taken as a statement of the same principle in the outward sphere of social relationships, where a man's deeds and temper commonly determine his treatment by other men. Cf. Stalker, The Ethic of Jesus, p. 318.

3 Matt. vi. 1-6, 16-18. 


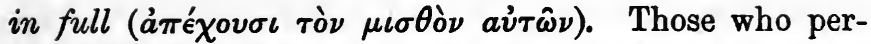
form religious duties in the spirit of the "actor"

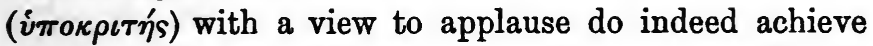
their end. They make the impression on the multitude and gain the reputation for sanctity which they seek; but with that the profit of their action ends. In the present, they gain the full enjoyment of that poor and mean reward to which their desires are directed, and no spiritual fruit can be theirs in the future: the immediate recompense is all, the nobler and remoter religious recompense can never come to them. The idea at the heart of this passage is thus exactly the same as that of the saying given in the Third Gospel, "Woe unto you that are rich! for ye have received your consolation." 1

It may, however, be said that the effect of this warning against doing good deeds with a view to reward is qualified or discounted by the promise of a recompense from above which closes each of these passages. But in the first place it must be observed that the promise of a reward to be given openly is due to an addition to the

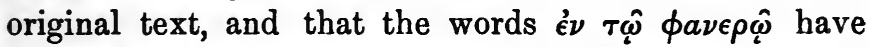
been omitted by the revisers. In the sentence as it stands without them no definite character is assigned to the reward, and certainly nothing is promised which could attract the imagination of those whose minds are set on immediate or material gains. All that is here assured is that actions which are good in themselves, and are done in simplicity and directness "in an honest and good heart," will "bring forth fruit," not for others only, but also for him who performs them. ${ }^{2}$ What form the reward may take is left undetermined, for that is not

1 I luke vi. 24. Cf. James v. 3, 5.

${ }^{2}$ Luke viii. 15. 
the concern of the good man himself; but from the whole tenor of the Sermon on the Mount we may gather that it is not to be looked for in any external gift, but rather in the sense of sonship to the Most High; since this is the reward promised to those who take part in the work of peacemaking, and who show the character of love-a work and a character which Jesus regarded as in a special sense divine. ${ }^{1}$

Further light is thrown on this point by the passage in the Gospel of Luke in which Jesus is recorded to have condemned that form of hospitality which is but a disguised self-seeking. "When thou makest a dinner or a supper call not thy friends, nor thy brethren, nor thy kinsmen, nor rich neighbours; lest haply they also bid thee again, and a recompense be made thee. But when thou makest a feast, bid the poor, the maimed, the lame, the blind and thou shalt be blessed; because they have not wherewith to recompense thee: for thou shalt be recompensed in the resurrection of the just." $2-$ Here the point of view is essentially the same as in the passage on alms-giving in the Sermon on the Mount. Benevolence is worthless when its motive is the hope of a reward, either in kind or in popularity, to follow in the near future; and it is well to avoid every action that may even resemble such counterfeit goodness. But it does not follow from this that deeds of true and sincere kindness will fail to bring forth fruit or to win an ultimate recompense; and the promise of the latter is here made in a more definite form than in the other passages which we have considered. On this account it

1 Matt. v. 9, 45 ; Luke vi. 33-35. In the version of Luke the connection of these ideas is very clearly brought out.

2 Luke xiv. 12-14. 
might be objected to by a moralist of rigorist tendency; but we may rightly point out to such an objector how much is gained when the hope of a near and speedy return is wholly banished from among the motives to morality, and when the recompense of the just is placed in a region to which only faith can penetrate, and which Jesus himself described in terms of the spiritual life alone.

There are indeed not a few indications that Jesus refused to encourage, nay that $\mathrm{He}$ sternly suppressed, all those hopes of advantage which appeal to men at the ordinary level of thought and desire. He gave no countenance to the hope of material advantage in an earthly Messianic kingdom. When "one out of the multitude" asked Him to lend His powerful aid toward the recovery of an inheritance, $\mathrm{He}$ not only disclaimed the office of " a judge or a divider," but at once added, "Take heed, and keep yourselves from all covetousness," and went on to describe the folly of him who "layeth up treasure for himself, and is not rich toward God." 1 To the same purpose was His counsel to lay up imperishable treasure in heaven, rather than treasures subject to corruption on earth-" "for where thy treasure is, there will thy heart be also." 2

These words show how great emphasis Jesus laid on the introduction of a new scale of values, and on the guidance of His hearers' desires to those objects which could give the best and most permanent satisfaction. Like other preachers, $\mathrm{He}$ was faced by the might of sheer worldliness (for a false other-worldliness was by no means the only error of that age); and like

1 Luke xii. 13-21.

2 Matt. vi. 19-21. Cf. Luke xii. 33 f. 
them $\mathrm{He}$ made it one of the first objects of His endeavour to lead men to a truer sense of proportion, to teach them to distinguish the higher from the lower ends of life. It is at best a half-truth to say that all desire for happiness and all pursuit of reward is at the same level of ethical worthlessness. Rather we must admit that it does make a difference whether the happiness is worthily or unworthily conceived, whether the thought of reward is held in a material or a spiritual sense. And so Jesus sought to raise men from the pursuit of the lower, immediate gain, by setting before them the image of a more exalted and more enduring reward.

\section{III.}

After thus considering the general character of Jesus' use of the idea of reward, it will be well to ask what position it occupies in His teaching. For in the philosophic sphere we saw that one of the most important considerations is the point at which the thought of recompense is introduced; and that Plato and Kant, who bring it in at the end of their ethical argument, stand in a very different position from that of those moralists who make it their starting-point, and appeal to it as a main motive of action. So the question whether the Ethic of Jesus sets out from the thought of reward, or only introduces it as ancillary to other and more urgent motives to goodness, is not unimportant. Nay, it is perhaps the central question of our whole discussion; and it can best be answered by considering His attitude to those who had thoughts of following Him, or whom $\mathrm{He}$ wished to number among His followers. 
When $\mathrm{He}$ thus faced a man or a group of men at the crucial point of decision, which was to determine their relation to His mission and to Himself throughout the future, He does not seem to have said much regarding reward. At such times $\mathrm{He}$ laid far greater stress on the difficulties that surely lay before His disciples. The path which Jesus called men to tread did indeed "lead unto life"; but it was a "straitened way" and the entrance to it was through a "narrow gate." 1 Of the whole body of His sayings, a much larger part is taken up with the cost of service than with its reward; and this is especially true of the words addressed to those who were at the beginning of their discipleship. In the group of sayings at the close of the ninth chapter of Luke, it is possible to trace a fear in the mind of Jesus that some might begin to follow Him without sufficiently realising what was involved in so doing, and so, growing weary, might fall away. Indeed before these sayings were uttered $\mathrm{He}$ must have had experience of men who put their hands to the plough and then looked back, whose enthusiasm was not deeply enough rooted to stand the test of time and of adversity; and so he resolved to set the full cost before the minds of those who came to Him. ${ }^{2}$ Again, if we accept the account of the Gospel of Mark, we see that the great saying, "If any. man would come after me, let him deny himself, and take up his cross, and follow me," was addressed to the multitude as well as to the disciples, and thus was intended as an admonition to those who might yet become His

1 Matt. vii. 13 f.

2 Luke ix. 57-62. (Matt. viii. 19-22). Luke xiv. 28-33. Cf. Mark iv. $5 \mathrm{f}$. 
followers, not less than to those who were followers already. ${ }^{1}$

But even at the earlier period of the call of the original disciples, Jesus abstained from emphasising the reward of discipleship; although at that time $\mathrm{He}$ may not have felt it needful to lay as great stress as $\mathrm{He}$ did at a later time, on the positive suffering which was in store for those who threw in their lot with Him. We do not read that $\mathrm{He}$ ever held out the hope of a share in the glories of the Messianic Kingdom, conceived after the fashion of popular Jewish thought, as an inducement to draw men to His discipleship. His call was of a different nature. First of all it was a call to personal loyalty and obedience"Follow me"; then, as we have seen, it was a call to self-sacrifice; and the only reward which $\mathrm{He}$ associated with this call was that of a share in His own work, "I will make you to become fishers of men." 2 It was on the attraction of His own character, on the sense of the world's need and of His power to meet it, that Jesus relied to bring men first into the circle of His followers. Nor did He promise them any exemption from the sufferings which He foresaw for Himself : it was enough that they should share all with Him, that "the disciple" should be "as his master, and the servant as his lord." 3

1 Matthew in both instances records this saying as addressed to the Twelve (x. 5, 38 ; xvi. 24), Luke, also in both instances, as spoken to

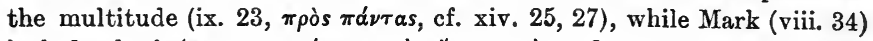

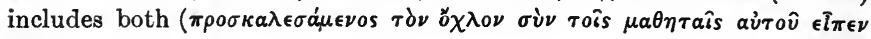

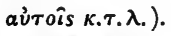

2 Mark i. 17, ii. 14.

3 Matt. x. 24 f. ; John xv. 20. While we are considering the call of Jesus as one to sacrifice and disinterested service, we may well recall the words in which Carlyle speaks of this as the call which always wins the greatest response. "They wrong man greatly who say he is to be 
But the application of this truth was not limited to the prospect of trial. If on the one hand it conveyed a warning, on the other it bore a promise. So when certain of His followers had been tested and when their faithfulness had been proved, Jesus was ready to encourage them with the hope that their faithfulness would find its recompense. Thus His promises of reward to His disciples belong for the most part to a later phase of His relation to them, when it was before all things needful that they should be sustained under the disappointment caused by unexpected difficulties and opposition. The demand of Jesus was stern at the outset; but $\mathrm{He}$ was not a harsh Master or a Stoical theorist : if $\mathrm{He}$ had been such, if $\mathrm{He}$ had failed to show an appreciation of His followers' devotion and the reality of the hardships which they were called to face, His example could not have gained its universal moral authority. Rather $\mathrm{He}$ believed in the ultimate success of His mission, and $\mathrm{He}$ held forth the hope that His followers would share in it. But the reward, not less than the call, was vitally connected with His own work. "Ye are they which have continued with me in my temptations; and I appoint unto you a kingdom, even as my Father appointed unto me." 1

With this saying as it is thus given in the Third Gospel, we may compare the similar promise recorded by all the Synoptists, but most fully in the Gospel of Mark:"Peter began to say unto him, Lo, we have left all, and seduced by ease. Difficulty, abnegation, martyrdom, death, are the allurements that act on the heart of man. . . . Not by flattering our appetites; no, by awakening the Heroic that slumbers in every heart, can any Religion gain followers." (On Heroes and Hero-Worship, Lect. II.).

1 Luke xxii. $28 \mathrm{f}$. 
have followed thee. Jesus said, Verily, I say unto you, There is no man that hath left house, or brethren, or sisters, or mother, or father, or children, or lands for my sake, and for the gospel's sake, but he shall receive a hundredfold now in this time, houses, and brethren, and sisters, and mothers, and children, and lands, with persecutions; and in the world to come eternal life. But many that are first shall be last; and the last first." ${ }^{1}$ This is indeed a promise of great wealth and sweep, but it is accompanied by more than one remarkable qualification. The first is contained in the words, "with persecutions." The reward promised can only be accepted along with experiences which to the ordinary man are not attractive, but deterrent. Only those who are strongly enough drawn to the Good as Christianity presents it to be willing to undergo pain and loss in its pursuit, can enter into the reward which it brings.

Further, the very boldness of the promise, "now in this time," suggests that it cannot be taken in its literal or surface meaning. It may perhaps be interpreted in the following way. Jesus was determined to show how fully $\mathrm{He}$ recognised the real loss which His disciples had undergone, but $\mathrm{He}$ went on to promise that this loss would lead out into a larger gain. Just as $\mathrm{He}$ was able to look upon all who shared His own devotion to the service of God as His mother and His brethren, ${ }^{2}$ so $\mathrm{He}$ told His disciples that they would find that they had given up certain dear relationships of common life, but in so doing had entered into the wider brotherhood of all who gave their lives to Him; and this promise was abundantly fulfilled in the wide-spreading ministry and

1 Mark x. 28-31. Cf. Matt. xix. 27-30.

2 Mark iii. 35. 
affection of the community which gathered as a single family after His death. ${ }^{1}$

In giving this assurance Jesus stated a far-reaching law of the spiritual life. For it often happens that the sacrifice of a single affection or interest, so far from narrowing life, proves to be the entrance into a wider and richer experience. The single channel through which a man had drawn refreshment and power is suddenly closed, and at first it seems that his whole life must become dry and barren; but he who has borne the loss soon finds that, for the one source of happiness that has failed, a hundred fresh channels have been opened, each in itself contributing a lesser stream, but all forming together a more plentiful and more secure supply. But this reward is not one which of itself will attract the thoughtless. It is rather "one whose sweetness is scarcely realisable till it is attained; it is the love of kindred souls, . . . the intimate comradeship of spirits that strive towards the same goal." ${ }^{2}$

Another proof of the essentially social character which Jesus attributed to the rewards which $\mathrm{He}$ promised in the future is to be found in the reply to the sons of Zebedee. Their request was an attempt to secure in advance a special privilege and private advantage for themselves in the coming Kingdom. But this attempt Jesus firmly checked. He not only recalled their thoughts to the immediate sacrifice which they had to face, but rebuked their eagerness for a position of honour apart from their fellows, thus making it clear that motives of selfish ambition were wholly out of place in this sphere, and that the right attitude was the

1 Acts ii. 44-47.

2 F. W. H. Myers, Classical Essays, pp. 221 f. 
faithful performance of present duty, and calm trust in regard to the future. ${ }^{1}$ A state in which, as Jesus taught at another time, there was neither marrying nor giving in marriage, was not one which would attract the desires of those who wished to gain individual rewards; those only would be drawn towards it whose lives were already in some measure lost, and found, in the common life. ${ }^{2}$

There is another aspect of the teaching of Jesus in regard to reward, which brings us back to the doctrine which we have already noticed in the philosophical sphere, that the truest reward is the opportunity to continue and to advance in virtue. This appears in the words of approval addressed to the good servant in the Parable of the Talents, "Thou hast been faithful over a few things, I will set thee over many things." 3 As Jesus had called His disciples to share His own mission of "fishing for men," so He represents those servants who had discharged a small trust faithfully and well, as being rewarded by receiving at their master's hand a larger share in his own responsibility and his own work of government. Here, then, we find the thought of the "wages of going on," and of reward, as consisting chiefly in the development of powers for service. The recompense of work well done is to be looked for first of all in the advance to positions of higher trust and wider responsibility; "for unto everyone that hath shall be given, and he shall have abundance." But this truth must be balanced by its complement, and the expectation of continuance in virtue must never be allowed to lead to over-confidence; and so we

1 Mark x. 35, 43. 2 Mark xii. 25.

3 Matt. xxv. 21, 23. Cf. Luke xix. 17. 
find at the close of the promise of reward which we considered a short time ago the words, "But many that are first shall be last, and the last first." 1

IV.

From what has been said it is now possible to draw certain broad conclusions regarding the place of reward in Jesus' teaching. He did not seek to disown this idea or to banish it wholly from the thoughts of His followers. Just as we found at a previous point that the Stoicism which regards physical pain with complete indifference was alien to the spirit of His work, so here we find the idea of reward taken up into the Christian scheme. The rigorism which refuses to allow that external conditions can have any influence on the truly moral life, and dismisses all thought of the results of action as they return from the world outside upon the agent himself, may have the advantage of theoretical simplicity and logical consistency; but it leaves out of account not a few of the facts with which morality has to deal, and it can afford no satisfaction to a side of human nature which refuses to be disregarded or disowned. In both cases Christianity rejects the Stoical view as an unreal, because an incomplete, solution of the moral problem, and seeks to find a solution which will do justice alike to the external conditions and the external consequences of good or evil conduct.

Nor, indeed, need it appear strange that Jesus should have made use of the idea of reward; for $\mathrm{He}$ set out

1 Matt. xxv. 29 ; Mark x. 31 . We shall return to consider this antithesis in the next chapter. 
from the ordinary moral thought of mankind, using and transforming those ideas with which His hearers were familiar. Further, because His great aim was not to promulgate a complete and consistent ethical theory, but to awaken the desire after goodness in the hearts of men and to reveal to them the path of its attainment, because His method was that of the preacher who seeks to set moral truths in bold relief rather than in formal harmony, it is a mistake to seek in His teaching for any abstract statement of the relation between the two aspects of moral thought which we are considering. The question is rather one of emphasis - Which did Jesus treat as the fundamental motive and principle of right conduct, disinterested love of goodness, or the hope of reward? We have already seen that the former was the keynote of His teaching; and when we remember how central a position $\mathrm{He}$ assigned to the spiritual duty of love even to the unthankful, it at once becomes clear that this inward disposition could never be produced by any motive so external as the hope of reward, but only by an inward and spiritual power. ${ }^{1}$

This view may also be confirmed by two of the central sayings of the Gospel, "Seek ye first the kingdom of God and his righteousness; and all these things shall be added unto you"; "Whosoever would save his life shall lose it; and whosoever shall lose his life for my sake and the gospel's shall save it." 2 The first of these sayings clearly shows where, in Jesus' view, the heart of morality lay. It was to be sought in the effort after goodness, the thought of the outward fortune of the good man being treated, not indeed as indifferent, but rather

1 Cf. Ecce Homo, Ch. XI.

2 Matt. vi. 33 (A.V.); Mark viii. 35. 
as the concern of a higher Power. The second saying is not less significant; for in the first place it absolutely condemns all reliance upon the material rewards of the present, thus emphasising the warning against laying up treasure upon earth; while in the second and positive clause the true principle is announced, the principle of sacrifice. And while it is given the form of a promise, it seems clear that the thought of the return which this sacrifice brings, the renewal upon a higher level of the life surrendered, is not so much the motive as the consequence of the surrender. The motive is to be found in the disinterested attachment of the heart to Jesus and the willingness to share His work-" for my sake and the gospel's." But when this proof of loyalty has been given, when a man has willingly surrendered the present good for a good of a higher and more unselfish order, then he may rightly cherish the hope that his action will not be vain and fruitless.

In harmony with this passage is the view which has already been stated, that Jesus introduced the thought of reward sparingly or not at all as an inducement to those who had not yet cast in their lot with Him, but that $\mathrm{He}$ often used it to encourage His followers to persevere in the loyalty which they had already shown. In His exhortations to courage in the face of persecution, it was natural that He should seek to communicate to His disciples His own faith in the final victory of His cause; natural also that $\mathrm{He}$ should encourage them by the hope of sharing in that triumph, which He foresaw awaiting Himself and them beyond the suffering and ignominy of the present. ${ }^{1}$ And while $\mathrm{He}$ sometimes pictured this triumph in vivid metaphors drawn from the

1 Matt. v. 10-12, x. 28-33. 
banquet or the judgment-hall, there were other times at which $\mathrm{He}$ definitely severed the thought of it from the associations of earthly success or splendour. The reward was inseparably connected with the Kingdom, and the Kingdom was characterised by the spirit of humility and meekness which ruled among its citizens. All emulation was banished from it, save the emulation of virtue, and an essential element in the reward of virtue was the opportunity for wider responsibility and service. In all these ways we may see how Jesus gave a higher meaning to the moral ideas of His time. For there is in His teaching a response to both the great demands of the human spirit; to the aspiration after a virtue which lays aside all thought of personal advantage, but also to the longing for a secure ground of belief that virtue will in the end triumph over the opposing forces of the world, and that the good man will at last enter into the reward of his labour and see its perfect fruit.

But there is still one other passage in the Gospel of Matthew which must be considered before our final conclusion can be drawn. It is the Parable of the Labourers in the Vineyard. ${ }^{1}$ The object of this parable is clearly to distinguish the principle of reward as it exists in the spiritual sphere from its familiar legal and economic form. In the latter, the end aimed at is the exact equivalence of recompense to work performed; and it is this conception of reward which has been adopted by more than one philosopher, and notably by Kant, who lays much stress on the assignment of a happiness exactly proportioned to the virtue of each man. But Jesus here disowns this idea of a reward precisely determined by merit or work accomplished; for in

1 Matt. xx. 1-16. 
neither respect were the servants who had worked but one hour equal to "those who had borne the burden and heat of the day," and yet they received the same reward. To this they had no legal claim, and they owed it entirely to the free generosity and goodness of the master of the vineyard. Thus the whole lesson of the story is that the idea of recompense, as legally exigible and strictly proportioned to merit, is out of place in the spiritual sphere; and that those servants are.wise who do their work earnestly, confident that a recompense transcending their effort will be granted freely at the day's end, and never seeking to limit that assigned to any fellow-labourer. But this recompense is clearly a gift rather than a reward; hence if the latter conception is still retained in Christian Ethics it is transmuted into a form, in which exact equivalence to the amount of service rendered characterises it no longer.

$$
\text { V. }
$$

In the writings of St Paul, a conclusion which is essentially the same is reached by a somewhat different path. It is true that he uses the idea of reward at times in a quite definite and simple sense, especially in the exhortation addressed to those members of the Ephesian Church who were still in the position of slaves, urging them to perform their service faithfully "with good will, as unto the Lord, and not unto men: knowing that whatsoever good thing each one doeth, the same shall he receive again from the Lord, whether he be bond or free." 1 In this whole passage, the union of

1 Eph. vi. 5-8. 
warnings against " eye-service" and "men-pleasing," and of exhortations to "singleness of heart," with the promise of ultimate reward, is strongly suggestive of the similar union in the Sermon on the Mount; and it is clear that the promise must be read in the light of the precept. Disinterestedness is insisted on at the same time that hope is aroused, and the hope is closely connected with the assertion of the equality and worth of all men in the religious sphere. ${ }^{1}$ Another passage in which the thought of reward is definitely appealed to is that in which Paul compares the Christian life to the work of builders, careful and careless. Of the former he says, "If any man's work shall abide, . . . he shall receive a reward." 2 There can be little doubt that the reward here referred to is primarily that which we have already described as inevitably sought for by the earnest worker - the knowledge that his labour is fitted to endure.

Thus this conception still holds a place in the thought of Paul, but the main tendency of his teaching is to make that place a subordinate one. For his thought is deeply stamped by the antithesis between the ideas of reward, strictly understood, and of a gift freely bestowed; while it is the latter idea which is the determining and characteristic one. The contrast finds pointed expression in the words, "The wages of sin is death; but the free gift of God is eternal life in Christ Jesus our Lord." 3 Here a sharp distinction is drawn between $\dot{o} \psi \omega \dot{\omega} \iota a$ and $\chi a ́ p \iota \sigma \mu a$, as between a recompense or retribution legally due, and a gift resting upon the bounty of the giver.

1 Eph. vi. 9.

21 Cor. iii. 14.

3 Rom. vi. 23. "Tertullian, with his usual picturesque boldness, translates $\chi \alpha \dot{\rho} \iota \sigma \mu \alpha$ by donativum (De Res. Carn., c. 47, Stipendia enim delinquentice mors, donativum autem dei vita aterna),". Sanday and Headlam, ad. loc. 
The former conception is that of the Law; and the Law in Paul's view had proved hopelessly unable to give those placed under it the power to live the good life. On the platform of merit and reward, no man had any valid claim to a recompense; but the Christian stood on this platform no longer. Knowing that he had no claim, he was content to receive the new life that came to him as a free gift. Since this was the apostle's view, it is clear that the great benefit, which he thought of as coming at the beginning of the Christian life, had no longer for him the character of a reward.

But, it may be asked, did not Paul, like the other teachers of the early Church, speak much of the glory of the future? Did he not constantly exhort his brethren to cultivate the grace of hope, and treat hope as one of the central parts of Christian character and as an essential support in present trial ? ${ }^{1}$ In this respect Paul did indeed follow the example of Jesus, and the description of the Christian as "rejoicing in hope, patient in tribulation" is thoroughly characteristic of his thought. ${ }^{2}$ But with him the Christian hope is not in any strict sense the hope of reward. It is indeed true that it is to be reached through faithful endurance, and so might be spoken of as the result of such endurance, as in the words "Our light affliction, which is for the moment, worketh for us more and more exceedingly

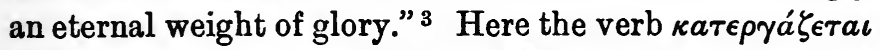
might at first suggest that the future glory is the reward of present service; but, as the context shows, it rather emphasises the fact that faithfulness gives the power more and more to enter into the fulness of that

1 Cf. especially Rom. viii. 24.

2 Rom. xii. 12.

32 Cor. iv. 17. 
new life, which has already begun to work in the Christian. So also Paul exhorts the Roman Christians to rejoice not only in hope, but also in their tribulations, "knowing that tribulation worketh patience"; for a character moulded by trial into approved goodness was the ground of hope, but not of a hope which belonged merely to the future. It was a hope founded upon an actual and present experience, and the confidence which it gave was that this experience would be confirmed and enlarged in the future, when present hindrances and imperfections had been done away. ${ }^{1}$

Thus the ground of hope for Paul was no longer desert or merit; and, in so far as the idea of reward is bound up with these conceptions, it had been banished from his thought for ever. It was an experience not gained by his own merit which supplied this ground, and the content of hope was the fuller unfolding of this experience in the future. But this transference of the greatest gift from the goal to the starting-point of the new life, clearly involved a complete change in the moral dynamic. At the primitive level of morality from which the Jewish religion set out, the hope of happiness as the reward of good action, or the fear of punishment, formed the chief incentive to goodness. But at the level of Pauline thought, fear and the hope of reward had given place to gratitude as the central motive. He was conscious of the release of the higher powers of his nature which had formerly been checked and baffled by the rule of sin; and these powers, together with the new religious insight which he had gained, formed a trust which he could not disregard. "For if I do this of mine own will, I have a reward; but if not of mine

1 Rom. v. 2-5. Cf. viii. 16 ff. 
own will, I have a stewardship entrusted to me." So he sought to disown all positive merit for his labour"necessity is laid upon me"; and the only recompense which he desired was that the work entrusted to him should prosper and that the whole charge and burden of it should rest upon him. "What then," he asks, "is my reward?" and the answer is, "That, when I preach the gospel, I may make the gospel without charge." 1

Thus we return once more to the definition of the Christian life as a gift which is also a task, an endowment which becomes a trust, an access of power which brings with it a new responsibility. "Necessity" - a moral necessity - "is laid upon" the Christian; for the gifts which he has received, and the freedom into which he has entered, are not given him for himself alone. Rather they are his only as long as he uses them in the common service. Thus, while hope retains its place in the Christian life, it is no longer the hope of a reward to be earned by merit and service; it is the hope of the workman to whom a task has been committed and who desires to bring it to completion, of the servant who has been entrusted with a stewardship which he hopes faithfully to discharge, of the runner who has entered on a race and seeks for nothing save to persevere to the end and to reach the goal set before him. ${ }^{2}$ And so the hope of continuance and progress in the good life is freely recognised as a powerful aid to virtue; but the mainspring of virtue in the Christian scheme lies rather in the sense of responsibility and of gratitude, and in the moral necessity of using for unselfish ends a benefit and a life unearned by personal merit. Nor is this conception confined to one part of the New Testa-

11 Cor. ix. 16-18. Cf. iv. 2.

2 Phil. iii. 12-14. 
ment-though the special character of Paul's experience led him to reject most decidedly all thought of reward as the due of individual goodness-for it receives its most memorable expression in the words of Jesus, "Freely ye have received, freely give." 1

It only remains to add that, if the analysis which we have carried out of the Christian view of reward be accurate in its main outlines, we have proved that the charge brought against Christianity, of resting morality on an appeal to selfish interests and hopes, depends on a superficial view of its teaching, and falls to the ground as soon as a closer study brings out the relative importance of its different aspects. The criticism which called for consideration was that Christian Ethics failed to satisfy one of the three great criteria of morality suggested by Kant-that of purity of motive. ${ }^{2}$ But our whole argument has gone to disprove this criticism, and to vindicate the purity of the Christian appeal. It is indeed true that the motives recognised in Christian Ethics are not pure in the strictest Kantian sense; but, as has often been pointed out, the Kantian idea of purity comes perilously near to vacuity. Now the Christian motives to goodness make no claim to the "purity" which springs of abstractness. They are assuredly concrete; and they include a definite hope for the futurethe hope for the individual of a growing approach to the ideal of Christian character, and for the world of the coming of the Kingdom of God, in whose triumph the individual will share, and in which he will find his highest satisfaction. But if loyalty and gratitude-if

1 Matt. x. 8.

2 The two other criteria, universality and autonomy, will be considered in Chapters XI. and XII. 
the longing for progress in virtue and for the advance towards a Common and Universal Good - are pure motives, then the motives to which Christianity appeals and which it awakens are in the highest degree pure. For its supreme principle is the love which "seeketh not its own," but ever gives its first thought to the needs and the good of others. ${ }^{1}$

11 Cor. xiii. 5 ; Phil. ii. 4. 
CHAPTER X.

MORAL CONTINUITY AND THE POSSIBILITY OF NEW BEGINNINGS.

I.

THE discussion in the previous chapter of the question of reward led us inevitably on to consider the idea of moral continuity. In the earlier and simpler forms of society and law, the relation between conduct and its recompense was already clear and definite; and this principle of continuity appeared in the effort to secure an exact equivalence between the degree of good or evil in an action and the magnitude of the reward or punishment which followed it. Thus the necessary connection between conduct and recompense was realised, even though the latter was thought of as attached to the former by an external authority rather than as growing inevitably out of the nature of the deed. From this simple view, we traced the process by which the idea of recompense was refined and spiritualised; and at first sight it might seem that, as this process advanced, the lessening emphasis on the exactness of the return of merit or demerit involved some weakening of the bond between actions and consequences, and thus 
some infringement of the principle of continuity. But this is not so; since, in proportion as the emphasis on the quantitative equivalence was relaxed, that on qualitative continuity grew stronger.

In other words, reward and punishment have gradually come to be thought of as consisting in the free and inevitable development of the inner nature of good or evil action, rather than as added to it from without. The primitive conception of reward is that of a benefit attached to virtue, to which it must be equivalent in amount, but which it need not resemble in nature: the higher idea is that of a consequence growing out of the action itself. Thus while the quantitative aspect of the relation of conduct and recompense falls, as we have seen, into the background, the inner connection of character between the two comes to be all-important. ${ }^{1}$ This view of recompense, as in the last resort immanent, teaches that $\sin$ is punished chiefly by further sin, and that the greatest reward of virtuous endeavour is to be looked for in progress in the good life and a share in the victories of righteousness. Thus the more spiritual our rendering of this idea, the greater is the place that the conception of Moral Continuity must occupy in our thought.

But it is apparent on very brief reflection that this form of doctrine cannot be taken as representing the whole circle of Christian teaching. Beside the doctrine of continuity Christianity places the assertion that continuity may be broken, nay, brings forward the promise

1 This thought has a great place in Indian philosophy. Karma itself means "action"; and it is observed in a modern Hindu text-book that this word "should remind us that what is called the consequence of an action is really not a separate thing, but is a part of the action, and cannot be divided from it." Sanatana Dharma, quoted by A. G. Hogg, Karma and Redemption, p. 48. 
of a new life, essentially distinct from the old, as its greatest gift and its greatest challenge to the life of the world. If the Gospels emphasise the principle that virtue begets virtue and that goodness leads on to ever higher degrees of goodness, they also speak of a reversal of all moral estimates based on mere continuity, of a Kingdom into which the sinful shall be received while those of the greatest reputed piety are shut out. ${ }^{1}$ In no other way, as we saw at the close of our discussion on the value of the individual, can that value which Christianity so emphatically asserts be transformed from an ideal into a present reality. Thus we have to find a place on the one hand for the doctrine of Moral Continuity, towards which the argument of the preceding chapter pointed, and on the other for the possibility of new beginnings in the moral life, of an escape from bondage to the past-in a word, of Redemption.

But, before we examine the specifically Christian view of these related questions, there are certain more general considerations which may be brought to bear upon them. And first of all it must be remarked that, even more than the other problems of Christian Ethics, this regarding new beginnings in life demands study in the concrete, and in the light of actual experience. If within this region Christianity not only sets up a standard but creates a new order of facts, then the historical and experimental appeal to these facts must be more important than any abstract discussion. If new beginnings have taken place and do constantly take place, then to record and analyse what is known as an actuality is more essential than to discuss its mere possibility. To this task much time and ability have been given

${ }^{1}$ Matt. viii. 11 f., xxi. 31 f. 
during recent years by the late Professor James and others working from the side of religious psychology; and their labours have placed the doctrine of Conversion in particular in a new position of prominence and security. Within the Church its importance has always been recognised, but it is now coming to receive scientific recognition without. More than forty years ago the words were used by Seeley and endorsed by the cautious and critical Sidgwick, that "this Article of Conversion is the true Articulus stantis aut cadentis Ecclesioe"; ${ }^{1}$ and if the statement was valid at that time, much subsequent study and thought have helped to establish its validity on an unassailable basis. Nor are new moral beginnings to be looked for only in those signal instances to which the word "conversion" is applied: the same principle receives a more silent but not less real support from that power of moral recovery and initiative, which marks the normal progress and maturity of the Christian life, even where no sudden and conscious crisis has marked. its inception.

But while this concrete study is the more essential portion of the defence of the Christian doctrine, it falls somewhat outside the purpose of our present inquiry, which is directed chiefly to the presuppositions of Christian Ethics, and hence is less concerned to establish the fact of new beginnings than to show its implications and its place in ethical theory. Not that the study of the fact is of less importance. We may give it the first place, and yet find room for the more abstract and formal treatment which harmonises with the purpose of these chapters. We must also welcome all that has of late

1 Vide Sidgwick's review of Ecce Homo, reprinted in Miscellaneous Essays and Addresses, p. 32. 
been done by students of the psychology of religion to set the fact of moral and spiritual initiative on a firm basis. For in their success there is an encouragement to hope that, where Psychology has led the way, Moral Philosophy may not find it impossible to follow.

But, apart from these special developments of modern thought, it is matter of common observation that the moral life does not pursue an absolutely even course, whether upward or downward. Sudden impacts or impulses often deflect it, and the prevailing tendency is only a tendency, not an iron necessity. Hence springs a great part of the interest of human life, and of its tragedy and hope. The diverse feelings which are aroused by the uneven course of human life and character in its two directions are finely expressed in Dante's lines:-

" Let not the people be too swift to judge, As one who reckons on the blades in field, Or e'er the crop be ripe. For I have seen The thorn frown rudely all the winter long And after bear the rose upon its top ; And bark, that all the way across the sea Ran straight and speedy, perish at the last, E'en in the haven's mouth." 1

Thus in treating of the possibility of new beginnings we are not seeking to establish that which is unknown or problematic, but only in some measure to unfold what is involved in an experience which cannot be denied, and which is essential to the truth of Christian Ethics. As Dante's twofold image suggests, there is a double aspect of this experience to consider, for there are sudden declensions as well as sudden risings in the life

1 Paradiso, Canto xiii. 126 ff. (tr. Cary). 
of the spirit, new beginnings in evil as well as in good. But it is on the latter that our attention must chiefly be concentrated, for it is to the power of escape from the tyranny of past failure that Christianity bears its strongest witness.

\section{II.}

When we consider the Christian doctrine in this positive sense it must be at once apparent that it answers a practical demand. The bearing of this fact may best be understood by comparing it with the other demand which must be harmonised with it. On the one side is the ideal of continuity, or (more concretely) of justice, which is jealous for the regular sequence of the moral life; while over against it is that of mercy, which asks less what a man has deserved, than what he may yet make of his life if he is raised to a higher level and given a new opportunity. The latter demand, or interest, to use Kant's term, is definitely practical, the former is to some extent at least theoretic. It is indeed true that it also has a practical aspect. This is suggested by the argument of the preceding chapter, and still more by the moral passion which has often inspired the proclamation that from the consequences of wrong-doing there is no escape, and by the essential part which this proclamation has played in the moral education of the race. The truth that they who "sow the wind shall reap the whirlwind," 1 has been driven home by men whose dominating aim was the practical one of the prophet of righteousness; nor

${ }^{1}$ Hos. viii. 7. Cf. v. 11, "Because Ephraim hath multiplied altars to sin, altars have been made unto him to sin"; and x. 13, "Ye have ploughed wickedness, ye have reaped iniquity"; also Rom. i. 28. 
was it a small achievement to attain to the idea of an unbending law by which the doom of sin follows sin itself. $^{1}$ Yet this achievement is not the highest, for lofty as is this belief in the full working-out of justice, it is only a partial ideal. In isolation, its sternness may lead to despair, and so it may cease to help forward the actual progress of goodness among men.

Thus the interest in the working-out of justice at first sight seems to be a thoroughly and exclusively practical one; and yet, paradoxical as the assertion may appear, it shows a certain abstractness and detachment from actual facts and needs. In one aspect, it is part of the demand of reason for continuity and intelligibility. The theoretic reason seeks at all times to trace sequences, to establish invariable connections, to reduce the manifold of the universe to order and distinctness of outline; and when the subject of this attempt is human nature, the postulate of continuity becomes that of the constant connection between conduct and its results, near or remote, for character, and also between character and conduct. The aim of the theoretic student of human nature, both in psychology and ethics, is to see each man's life in all its elements and at all its stages as a single whole; and thus he naturally gives a cold welcome to the suggestion that there may be unforeseen developments and sudden risings to a higher level of life, with no clear antecedent cause or preparation in the character of the man himself. The effort to understand the inner life of man as a unified whole may lead to a denial of the

1 "Lo! sin by sin, and sorrow dogged by sorrow-

And who the end can know?

The slayer of to-day shall die to-morrow-

The wage of wrong is woe."

- Eschylus, Agamennon (tr. Morshead). 
possibility of any escape from bondage to the past, or of any entrance upon a new range of experience or power. The interest in theoretic completeness, not less than the desire for practical justice, may cause the doctrine of Moral Continuity to be carried to a rigid and unsparing extreme.

When this extreme has been reached, the doctrine does in truth tend to defeat itself, as we may shortly see. But, for the moment, let it be assumed that the purely theoretic interest in Ethics does tell wholly on the side of continuity, and against the possibility of new moral beginnings. Even in this case the latter doctrine, as Christianity expresses it, would not be finally crushed. For in its essence it is not a theoretical but a practical postulate, and from its practical character it draws its inner validity and strength. It is thus to be tested less by theoretic reasoning than by experience of its actual working in the world's life and conflict.

It is a familiar truth that the understanding deals with universals; and the attempt to classify and arrange the facts of the moral life can only be made by separating its broad and general aspects from the particular features of individual lives. Thus the method of the theoretic reason is to grasp what is true on the whole. But for Christianity it is the individual who has ultimate value and interest; and, as we saw at the close of Chapter III., the Christian doctrine of the value of the individual inevitably leads up to the idea of his recovery or redempcion. Thus, while the theoretic demand of the ethical reason is that justice shall be done, and the final consequences of good or bad conduct be wrought out in reward or punishment, the practical demand of Christianity is that the lives of individual men shall be rescued 
from the power of evil and raised to a nobler level. The former seeks to see the world as intelligible and morally just, the latter to bring it into closer conformity with the ideal of good.

While surveying life at leisure and from a distance, the student of morality may rest content with the belief in continuity and the confidence that good and evil actions will in the end work out their appropriate results; but he who gains his experience not as a detached spectator but as a participant in the conflict of life, will hold rather to the practical faith in the progressive triumph of good in the individuals among whom and for whom he labours. His great question will be, not what they have deserved, or whither their present disposition and actions tend. It will rather be whether there is no power which can give them a fresh start on the upward path, and enable them to throw off the burden of past failure. His main concern will be for those individual men and women whose needs he feels and with whose struggles he has learned to sympathise; and he will be willing to let the theoretic demand for consistency and continuity fall into the background, if only he can find an answer to this practical demand and a ground for the practical hope of seeing the faltering lives about him reanimated and renewed.

There are thus two possible views of moral advance or failure; and the specifically Christian view is assuredly the second, with its high claim of value for common men and women, and its belief in a possible reversal of the direction of those lives which seem to tend inevitably downward. In the other attitude there may be a lofty dignity, as in the Stoic 
ideal of the Sage who steadily pursues his path of conscious virtue; or again, there may be serenity and sweetness, as in the Epicurean conception of the good life as a companionship in the pursuit of an even and secure calm of spirit. But in both ideals there is something remote and cold, when they are contrasted with the Christian ideal, with its intense sense of the moral issues of life and its intense hopefulness where there is least apparent ground for hope. This attitude of detachment is clearly seen in Lucretius' famous description of the bliss of the Wise Man, who looks forth on life as one who watches a scene of storm and shipwreck from the security of the shore, or one who from the peaceful summit of a mountain surveys the mist and confusion of the valleys below. ${ }^{1}$ This attitude, favourable as it may be to a calm and wide contemplation of human affairs, has a remoteness which we instinctively feel to be foreign to the highest moral ideal; and so

"Our world, which for its Babels wants a scourge, And for its wilds a husbandman, acclaims The crucifix that came of Nazareth." 2

But it is now necessary to revise the assumption which we provisionally accepted - that the theoretic interest is wholly on the side of strict continuity and opposed to the Christian standpoint. When we do so, we find that detachment is not the only philosophic virtue, nor is the type of thought which emphasises continuity and similarity at the expense of individuality and divergence the only path to real know-

1 II., 1-13.

2 George Meredith, The Garden of Epicurus. 
ledge. There may even be an essential form of knowledge, inaccessible to such investigation, but lying open to those who are in intimate relation to the facts which they seek to understand. Participation in the moral conflict may be the only condition on which, in certain of its aspects, it can be truly known. The Lucretian Sage on his mountain crest gains a clear, a wide, and an untroubled view of what passes in the valley below him. He may trace far-reaching tendencies or draw wide conclusions which lie beyond the vision of those in the midst of the dust and confusion below. Yet their knowledge of the conditions of the conflict in which they are engaged must be more intimate than his who only watches it from afar; and their understanding of its issues may be more real than his.

When from this point of view we examine the doctrine of Moral Continuity in its more rigid form, we find that in its extreme issue it tends to overreach and to defeat itself. For it then negates those very facts which it is the chief object of ethical theory to explain. The attempt to discover the nature and significance of moral phenomena by tracing their relations to preceding phenomena may finally deprive them of their specifically moral content. For if there be no free reaction of the personality as a whole upon these conditions of conduct, the conception of personality is driven further and further into the background, and the roots of action are finally found in a region into which morality proper has not yet entered. To connect every stage of the inner life with similar though less developed stages in the past, to see in every state of will and feeling the 
resultant of forces which have been present from the first-what is this but to deny the possibility of any initiative, and hence of any true freedom or personal activity?

So, here as elsewhere, the effort merely to understand leads to a complete determinism. The theorist who stands outside the life-process, seeking only to trace connections and to prove the solidarity of the inner life throughout its whole course, may end by denying not only all sudden and unawaited deviations in that course, but any real distinction between the activity of the human spirit and that of the cosmic process from which it originally emerged. Moral continuity is in the last analysis only a halftruth, and it must find its complement in the recognition of the possibility of new beginnings, and of the real character of moral initiative as implied in all truly moral action. For, as Lotze argued, it is possible that new factors may enter into the stream of causal sequence, and thus that man's activity may be really originative and free. ${ }^{1}$

This, then, is the attitude natural to the thinker who tries to understand morality from within, by setting himself in the current of effort rather than by surveying it from a fixed standpoint beyond its bounds. Nor is it impossible to combine with this assertion of moral spontaneity a due recognition of the extent to which the moral life is indeed determined, or rather conditioned, by the past. For at every point the content of a man's consciousness is affected by the whole course of his past conscious

1 Cf. Note P, p. 406, "Lotze and Bergson on Spontaneous or Creative Action." 
life, and the form in which any question involving a moral decision arises is conditioned in the same way. The different possibilities of action, both in their intellectual aspect and in the feeling-tone which they assume, are determined by the past. These constitute the terms in which the problem of conduct presents itself at every moment of decision. Not only do the effects of past action persist in so far as they have passed out into the world beyond their author's reach and control: they persist in his own nature, physical and mental. They determine at every moment the task which lies before him and the measure of his difficulty. But as he faces this problem and deals with this material of action, the power is his to discriminate between varying motives, and to throw the active energy of his will into the scale on the side of the motive which he makes his own.

Thus, by the attitude which we take to the past, by the way in which we appropriate afresh, and so give new life to, certain elements in the complex formed by the interaction of past experience and present circumstance, and above all by the energy of will which presses ever forward, we are in a real sense able to bend what comes to us from the past to the use of the present, and to fit it to the ends of the future. The past is not wholly dead so long as the living action of the mind and the will can vivify and inform it anew, and so long as we can regard it as the material out of which present needs are to be met and future destiny hewn. To the detached spectator, the intellectualist who views the process from without, the past does appear as wholly rigid and dead, and therefore as determining the present and the future 
without the power of modification or appeal. But when the standpoint is changed and the view taken is from within, the whole life of the spirit is seen as one stream of endeavour in which the past is eonstantly taken up anew in the creative activity of the living will. "From this point of view, it is only a shallow insight into the past which pronounces that it cannot be undone. The effective appropriation of the past, its transformation into realised experience, is a perpetual undoing of the past. It is this living adoption of the past into the spiritual present, as an inspiration or as a warning, that first enables us to realise philosophically the possibility of its forgiveness and redemption." 1

Now, our argument up to this point has been directed to making clear the existence of spontaneity, and of a real, if limited, power of initiative in all moral effort. ${ }^{2}$ But the Christian doctrine of new beginnings is far more daring than this. It goes so far beyond the experience of freedom in dealing with the past which belongs to the ordinary moral life, that the difference comes to be one of kind rather than merely of degree. Yet the words just quoted show how natural the transition to the second position becomes when the first has been securely established. And at the least our recognition of the free and creative element in all moral action has the effect of loosening the chain by which the doctrine of rigid continuity seeks to bind the future to the attainments of the past. The way is

1 Boyce Gibson, Rudolf Eucken's Philosophy of Life, pp. 27 f.

2 So far we have considered freedom and spontaneity as they are presupposed in all morality. The higher form in which they belong to the good life alone-"the Freedom of the Spirit," in Pauline phrase-will call for consideration later (Chapter XII.) 
so far open to the possibility of new beginnings of the higher and more radical order, when it has once become clear that in all ethical endeavour there is that which breaks through the categories of strict determinism, and that all moral values must first appear as values newly created or achieved. An absolutely thorough application of the idea of continuity would be fatal even to the ordinary moral life, for we instinctively think of it as one in which an increase of real value does indeed take place; and in this sense the two doctrines stand or fall together.

What then, it may be asked, is the true place of the idea of Moral Continuity? Or is it to have no fixed place, but simply to fill in gaps in which we do not desire to insert that of Moral Initiative? An answer may be found in Lotze's argument regarding causality in the sphere of the inner life. He holds that its function is to secure that each cause, or each fresh impetus, once introduced into the stream of moral tendency shall continue to act within it, rather than to negate the possibility of the entrance of such new factors. ${ }^{1}$ In other words, it looks forward, not backward. Its effect is not to tie the present immovably to the past, but to safeguard the future effects of present action. The values won in the struggle will indeed be conserved; but the principle of their conservation does not imply that no new values can ever be created. And it was on this side that we approached the principle in our last chapter. It appeared as a positive demand for the opportunity of progress in virtue, not as a negation of the possibility of real initiative. 
This point may be illustrated by M. Bergson's view of the abstract intellect as essentially retrospective in its working. All determinism springs from its tendency ever to measure the future by the conceptualised experience of the past. "It is of the essence of reasoning to shut us up in the circle of the given. But action breaks the circle." 1 Thus we may reach the conclusion that, for a philosophy which seeks to think forward rather than backward, and to express something of that sense. of originative effort which is experienced in moments of strenuous endeavour, new beginnings are not only possible but are inwoven in the very warp of the moral life; and yet that continuity does hold sway, inasmuch as the past persists in the present, not indeed as an irresistibly determining power, but as providing the material and the conditions of vital and originative action.

\section{III.}

In the New Testament the thought which we have tried to work out, that new beginnings are involved in all moral action, holds no prominent place. It might be said that it is presupposed; but the attention of the authors of the New Testament is bent on a greater and more striking transformation than that furnished by the slow development of the ordinary moral life. It is of a radical change that they think, a change whose possibility and necessity Jesus Himself proclaimed.

In the religious life of the time $\mathrm{He}$ found embedded the principle of continuity in its most negative and unsympathetic form. For, when that principle in its

1 Creative Evolution (Eng. tr.), p. 202. Cf. pp. 250 ff. 
full rigidity is transferred from philosophy to the religious life, it assumes the form familiar to us as Pharisaism. When it is felt that religious duty is sufficiently fulfilled by carrying on the traditions and maintaining the standard of the past, and that those who have once wandered beyond the limits of virtue can never re-enter the circle of goodness, Pharisaism is present in its full development. Here continuity is the sole standard applied: the virtuous are sceptical as to the need of new beginnings in their own case and as to their possibility in the case of others; nay, they may even spend more effort on shutting out those who have shown themselves unworthy in the past from the upward path, than on advancing in it themselves. ${ }^{1}$ In this case the use of the idea of continuity is that which we have already seen reason to criticise. It is rightly used in a positive sense for the encouragement of those who are striving after what is good; but wrongly in the negative interest, when it is made the reason for the condemnation to perpetual failure of those who are judged to have failed at the outset. It then expresses the attitude of those who are indifferent to the fate of the world at large, so long as they themselves are secure. It was the self-satisfied theory of "certain which trusted in themselves that they were righteous, and set all others at nought"; or of the Elder Son in the parable who made his own fidelity a ground for the denial of his brother's right to a joyful return to their common home. ${ }^{2}$

To this exclusive theory of virtue, which denied any worth or any future hope to those whose past it condemned as sinful, Jesus set Himself steadily and firmly

Matt. xxiii. 13 ; Mark ii. 16 f.

${ }^{2}$ Luke xviii. 9 ; xv. 29 f. 
in opposition. He met this most narrow and heartless application of the principle of ethical continuity by the strongest statement of its contrary as of supreme importance. So far was $\mathrm{He}$ from admitting that no reversal of current moral judgments was possible, that He identified His message and His life-work with just such a reversal, and proclaimed in the words which conclude the story of the Pharisee and the Publican that " every one that exalteth himself shall be humbled; but he that humbleth himself shall be exalted." 1 Nor was this proclamation of the possibility of a radical change in life a mere proclamation or an empty call. Coming from Jesus, it carried with it its own confirmation. As His love towards and hope for men shone forth even on those who had failed most grievously, the might of His personality gave the needed power to break the spell of the past and to rise to a new level of life.

This experience of a new start in life, so definite and so complete that it could not be adequately described as anything less than a new birth or "regeneration," became the typical experience of early Christianity. "The power of the new spiritual life within the Church showed itself in transformations that were not gradual but sudden, altering the whole bent of habit and of thought. Nor need we feel that this access of power to enter on a new and transfigured life, which was experienced by the early Christians both during and after the ministry of Jesus, so far surpassed all ordinary experience as to be wholly incomprehensible. Unique in degree, it may yet be illustrated from the experience of other ages, which teaches that, while the course of

1 Luke xviii. 14.

2 Cf. John iii. 3 ; 1 Pet. i. 23. 
life is at most times an even one both in its ascending and descending reaches, yet there may come sudden breaks and turning-points which affect the whole direction of the future. When a man or woman comes into the circle of a new and powerful influence the effect may be not less than revolutionary. A new ideal of action, a new vision of truth, but, most of all, the impression produced by a strong and lofty personality, may effect such a change-the change which Plato described as "a soul's revolution," and as the turning of the eye of the soul from darkness to light. ${ }^{1}$

But in such a revolution the whole outlook upon life of him who has experienced it is necessarily changed. His idea of relative values is altered from the foundation. As in Plato's allegory, he recognises that the objects for which he had spent his life, were in reality only shadows : "what things were gain" unto him he now "counts loss" for the sake of the higher good which he has come to know. ${ }^{2}$ And when a change so radical and complete takes place, it is impossible that the outlook on the past should not share in the transformation which has altered the whole aspect of the present and the future. As we have already seen, the past is ever in some measure refashioned and recreated in the present, and in the experience with which we are dealing this remoulding of the past is found at its highest power. Thus, when a life that has been marked by failure or by lowness of aim and insensibility to the higher claims of goodness is carried into the orbit of some

1 Rep. 518 C, $521 \mathrm{C}$. The outward occasion of the change may be much less conspicuous, as in the case of Brother Lawrence, whose whole life was altered by the thoughts suggested by the sight of a leafless tree in winter.

${ }^{2}$ Rep. 516 f. Cf. Phil. iii. 7. 
great spiritual force, a break with the past does become possible. It remains indeed impossible to break with the past in the sense of wholly escaping from it or treating it as if it had not been; but it may receive a new interpretation, and it may be considered from a new spiritual elevation. The new objects of life may show that the old were utterly inadequate or unworthy, the old freedom may now be seen to have been enslavement; but, just in so far as the change is complete and a new standard is whole-heartedly accepted, the binding effect of the past will be relaxed and it will become a contributory force in the new activity of the spirit.

For Christian Ethics, the supreme instance of this change is found in the case of those who have identified themselves with the work and the aims of Christ, who have in some degree come to judge the world by His standard, and who have experienced something of the power that was manifest in His life. As His life was unique, and as a unique "virtue" went forth from Him to all who approached in need, whether bodily or spiritual, so an unparalleled transformation has ever been wrought upon those who have come from the dim ideals and poor achievements of common life into the searching light of His character. Of such Paul could say that for them "the old things were passed away" and that they were indeed created anew. ${ }^{1}$

But their escape from what lay behind was not so complete as to amount to a total obliteration of the past. In this respect the example of Paul himself is typical, and in his later life the memory of the earlier still lived on, not only as a cause for humility and for regret, but as an ever-present spur to greater effort. Because he had

12 Cor. v. 17. 
once persecuted the Church he was content to rank as "the least of the apostles," or even as one who was "not meet to be called an apostle"; but at the same time and for the same reason he could say, "I laboured more abundantly than they all." 1 So also the prophetic warning, which the Third Gospel records as addressed to Peter, ends with the words, "Do thou, when once thou hast turned again, stablish thy brethren." 2 The thought is clearly present that Peter's fall and recovery, as he looked back on them in after days, would do more than awaken his own remorse-would, in truth, enable him to bring a special measure of strength and encouragement to those among his brethren whose need was greatest.

But this brings us to another point in which the Christian doctrine has an essential advantage over the theory of strict continuity. It provides an additional stimulus and dynamic of the highest ethical value. For the life of steady virtue, especially when it is a life of conscious and conventional virtue, is apt to become set in certain grooves, to become a thing of routine rather than of inspiration. I have referred to the charge which Jesus brought against those who so lived, of having lost all sense for the real needs of their fellows in their devotion to a rigid system of outward conduct. But $\mathrm{He}$ had a further ground of complaint-that the very regularity and precision of their lives had dried up within them the freshest springs of religious enthusiasm. "To whom little is forgiven, the same loveth little." ${ }^{3}$ And so $\mathrm{He}$ commended the warm love of the woman whose gratitude showed that she had been forgiven much,

11 Cor. xv. 9 f.

2 Luke xxii. 32. Cf. John xxi. 15 ff. ${ }^{3}$ Luke vii. 47. 
rather than the chilly uniformity of the lives of those who sat in judgment upon her.

This is perhaps the greatest achievement that can be claimed for any ethical or religious force-that it is strong enough to take the most grievous failures of the past and use them as a spur to future efforts after goodness. To annul the past were much; but to transform it, so that all its impressions and memories contribute to produce a higher degree of effort and devotion, is a greater thing still. And this power has appeared in the highest degree in Christianity. To the ordinary motives of patient and consistent morality it has added that incentive to personal purity and to service, which is felt by those who find themselves set free from the fetters of past weakness, and who are thus enabled to attempt and achieve what had long seemed impossible. They have not only learned to look on the world and its needs from a new standpoint, but at the same time they find that it has become possible to shake off those defects which had crippled their efforts after good, and so they are enabled to meet the needs around them with a new confidence. To those who have shared this experience, as we saw at the close of our last chapter, the hope of reward is no longer necessary as a motive to goodness; for it has been replaced by one which is not less constant, and far more disinterested and intense. This new motive is the desire worthily to use the new freedom into which they have been enabled to enter, and faithfully to discharge a trust freely bestowed on them.

Nor is this true only of virtue as a whole; for we must also take into account the influence of this belief in making possible that single virtue which the Christian 
law so steadily insists on as of vital importance-the readiness to forgive. Perhaps no disposition is so strongly condemned by the New Testament as that which cherishes the memory of injuries, although in other systems of morality to do so has at times been looked on more as a virtue than as a fault. And if continuance in virtue be the only standard of ethical judgment, it is perhaps natural that the readiness to forgive and forget should be regarded as a doubtful good. "The just persons who need no repentance" will tend to judge other men by the limited but rigid standard of their own consistency, and, feeling no urgent pressure of need for new beginnings in their own lives, will be prepared to deny that in other, and outwardly less virtuous lives, such new beginnings are possible. But when a truer vision of the ideal of character makes a man feel that his own moral life must be built up anew from the foundation, he will judge the shortcomings of others more gently. And even when these shortcomings touch him nearly, taking the form of injuries done to himself, he will be the more ready to forgive them in the measure in which he feels that the highest good which he himself has known has come to him as undeserved. Thus the New Testament often links the duty of forgiving others with the experience of him who feels that his own debts have been remitted $;^{1}$ and the sense that the Christian ideal can only be attained by those who are themselves prepared to start afresh becomes the ground of interest in and hope for the spiritual development of others.

1 Mark xi. 25; Matt. vi. 12, 14 f., xviii. 21-35; Eph. iv. 32 ; Col. iii. 12 f. Cf. Matt. vii. 1 f. (Luke vi. 37), James ii. 13. 
IV.

But all this may be granted, and it may be fully acknowledged that a strong motive is thus brought in to further the moral life as a whole and to promote the special virtue of forgiveness; and yet it may be asked whether, in describing this experience as of central importance for Christian Ethics, we do not approach the conclusion that conversion in the sense of a sudden, even a catastrophic, change is a normative experience, and therefore an essential moment in the Christian life. ${ }^{1}$ Or, in the absence of such a decisive crisis sharply separating the new from the old, will it not lose that vigorous spring of effort which accompanies the glad escape from long-standing bondage into freedom? Now, it must be admitted that a special freshness and glow of enthusiasm is possible for those to whom the change comes most swiftly and decisively; but good though this may be, it falls short of completeness. Christian Ethics, not less than other systems of moral philosophy, has as its aim the production of more than a sudden glow; its end is to kindle a steady and enduring flame. But it does not seem essential to the attainment of this end that the rise of the spiritual life into brightness should be a sudden one. There are indeed not a few cases in which the memory of a swift

1 Related to this there is the slightly different question whether the greatest saints are not those who have risen from the greatest depth. Might we not add to the familiar saying, Corruptio optimi pessina, its converse, Redemptio pessimi optima? There is doubtless an element of truth here; but it is only a half-truth, which needs to be corrected and complemented by the Christian view of moral continuity, on which we have seen that stress must also be laid. 
passage from the old to the new acts as a lasting stimulus to virtue; but there are others in which no sudden transition can be seen, and yet the sense of having escaped from an unworthy life and entered upon a higher life is a real and potent factor in the effort after goodness. And even where the spiritual life originates in a drastic change, it is needful that the original experience should be again and again renewed, in its essence if not in its full intensity, in order that the first impulse drawn from it may not be dissipated or grow faint.

So it seems that the really essential point in the Christian experience of new beginnings is not that the break with the past should be sudden or violent. But, whether it be sudden or not, it is needful to feel that the bonds of past habit have been loosed, and that moral and spiritual powers which once were captive have been set free. The central fact is the knowledge that opportunities of advance have been granted when, on grounds of strict desert, they would have been withheld, or that they have been renewed although the claim to them had been forfeited by indifference or misuse; that new moral and spiritual beginnings have in fact been made possible for one who, by the strict rule of continuity and of justice, would have been held down on the lower levels of the past. Nor is it the case that only great sinners can hope to become great saints. The reaction from a life of crime or sensuality may, it is true, when once its baseness has been seen, carry a man many stages onward towards the good. But this extreme instance cannot be taken as normative, nor does Christian Ethics, rightly understood, countenance that particular form of autinomianism which treats evil as a 
stepping-stone to the highest spiritual good. The experience which is set up as normative is the recognition of the height of the Christian ideal, which makes the life of conventional morality look poor and feeble, causing those who behold it to condemn even what has been outwardly virtuous in their past lives and thus to seek for some means of rising above the past. ${ }^{1}$ And in ceasing to be satisfied with former attainments of their own, they also learn to look with greater pity and with readier forgiveness on the failures of others; just as the desire for and the belief in the possibility of new beginnings for themselves lead to the spirit which "hopeth all things" for other men also.

But if the fact of new beginnings has so central a place in Christian thought, have we left any room for that of continuity? Has not the argument of this chapter undermined the validity of our previous conclusion that there is an essential coherence in the moral life, and that virtue and the fruits of virtue are indissolubly knit together? The question is both difficult and important; yet a partial answer must be given if these two threads of ethical thought are not to fall hopelessly apart. Both, as we have seen, are present in the Gospels; for if the redemptive aspect, by which the possibility of new beginnings is affirmed, appears in the saying, "Many that are first shall be last, and the last first," the aspect of continuity is not less prominent in the saying, "Whosoever hath, to him shall be given." On the one side the spiritual life is represented as showing a reversal of the results of ordinary moral judgment: on the other it is described as being ruled by the principle of continuous and ever-accelerating advance.

1 Cf. Phil. iii. 4-7. 
It will be well to note the contexts in which each of these sayings appears, in order that we may gain some clue as to their true application.

The principle which finds expression in the words "Whosoever hath, to him shall be given," and which might be described as that of geometrical progression in the moral life, is applied in two different connections. It appears in all three Synoptic Gospels as having been used by Jesus to enforce the need for careful and thoughtful attention to His teaching, and especially to the parables in which $\mathrm{He}$ embodied His message. ${ }^{1}$ It also comes at the close of the Parable of the Talents or the Pounds as the direct statement of the spiritual truth which the parable expresses in similitude. ${ }^{2}$ It is thus applied both to religious thought and practice, both to the understanding of the "mysteries of the Kingdom," and also to the use which its citizens are required to make of their active powers; but by both its uses the same lesson is conveyed, that progress is only possible for those who at every moment apply faithfully the powers of understanding and of will which they possess, and that such faithful use will bring its reward in the increase of spiritual knowledge and capacity.

The other saying, "Many that are first shall be last, and the last first," occurs four times in the Gospels, and in three different connections. Matthew and Mark both introduce it at the close of the promise of reward with which Jesus met Peter's half-questioning words, "Lo, we have left all, and have followed thee"; Matthew brings it in again at the close of the Parable of the Labourers in the Vineyard; while in the Gospel

1 Mark iv. 25 ; Matt. xiii. 12 ; Luke viii. 18.

2 Matt. xxv. 29 ; Luke xix. 26. 
of Luke it concludes the group of sayings which begins with the words, "Strive to enter in by the narrow door," and continues with the prophecy that many who have been in close contact with Christ will be rejected, while others " come from the east and west, and from the north and south, and sit down in the kingdom of God." 1 Now, in these passages there is clearly a double application of the principle. In the first and last cases, it is used to indicate the danger of reliance upon past achievement or special privilege, and to emphasise the fact that neither can take the place of constant effort and watchfulness. Here it is equivalent to the Pauline warning, "Let him that thinketh he standeth take heed lest he fall." ${ }^{2}$ But there is another application which is uppermost in the Parable of the Labourers in the Vineyard, where the lesson is that no supposed personal merit or pre-eminence in service can give any right to treat other men as having less interest in Christ's Kingdom. If the first effect of the realisation that many who are first shall be last and the last first, is to remove all false feeling of security for the future based upon privilege or desert, its second and even more important effect is to show that such privilege or desert can give its possessors no title to bear themselves proudly or exclusively towards others. There is no vested interest in goodness.

There is the same union of complementary truths in the Parable of the Prodigal Son. Here, as in the two parables which precede it in the Third Gospel, the em-

1 Mark x. 31 ; Matt. xix. 30, xx. 16 ; Luke xiii. 30.

I 1 Cor. x. 12. Paul, like Jesus, had a strong sense of the especial danger of this false and exclusive application of the idea of continuity in the religious life of the Jews. Cf, Rom. xi. 20-23. . 
phasis lies on the aspect of redemption, on the possibility of return for those who have wandered, and on the peculiar value in the spiritual order of their recovery. Yet, while this is the central idea of the parable, the opposite truth is not denied. The patient dutifulness of the Elder Son is not disparaged: it is only his exclusiveness that is condemned. He himself possesses his enduring reward, for the words are addressed to him, "Son, thou art ever with me, and all that is mine is thine." ${ }^{1}$ The fact that the way of return was open to the Younger Son could not obliterate the fact that he had spent long years in the far country while his brother remained in his father's house; and while the greater part of the parable is occupied with the thought that new beginnings are indeed possible, these words suggest the other lesson that continuance in virtue brings its own especial and unvarying reward.

There is still another passage which we may consider, as showing how strongly and even vehemently the truth of continuity was at times asserted by the teachers of the early church. It is that in which Paul addresses a solemn warning to the Galatian Christians:- " Be not deceived; God is not mocked: for whatsoever a man soweth, that shall he also reap. For he that soweth unto his own flesh shall of the flesh reap corruption; but he that soweth unto the Spirit shall of the Spirit reap eternal life. And let us not be weary in well-doing: for in due season we shall reap, if we faint not." 2 In these words the truth of moral continuity is stated both as a warning and as an encouragement-stated in terms so sweeping that it might well be thought that no place is

1 Luke xv. 31.

2 Gal. vi. 7-9. Cf. Heb. xii. 17 ; Rev. xxii. 11. 
left for any complementary or modifying view. Yet it is clear from the whole tenor of Paul's teaching that he could not mean this emphatic assertion to contradict the belief in forgiveness or to cast doubt upon the opportunities given to rise above the past.

How then can we explain the unqualified nature of his statement of this other truth? The explanation may perhaps lie in the very form of the statement itself. For when we ask what is meant by the metaphor of "sowing to the flesh," the answer suggests itself that it refers to a life continually directed to material and bodily satisfactions, and signifies the refusal to recognise the claims of the higher life and to strive after its attainment; while on the other hand, " sowing to the Spirit" can hardly have any other meaning than the repeated rejection of the lower and choice of the higher. Because Paul represents both possibilities as really open to men, he clearly implies that there must be some bridge from the one to the other, some way of passing from the old to the new. It is only when the lower is persistently chosen that the law of continuity places an impassable gulf between them. And that "sowing to the Spirit" which brings its own sure harvest of good, consists in the effort again and again renewed to escape from bondage to the flesh, and to live in the spiritual sphere in which new beginnings are constantly possible.

Thus while the two truths are stated with varying degrees of emphasis in different parts of the New Testament, and while in some passages one may be so strongly enforced that there appears to be no place left for the other, this exclusion is rather apparent than real. The two conceptions do not so much negate as correct and supplement one another, nor can either 
stand wholly by itself. Thus the belief in Moral Continuity makes it possible for the good man to trust that the result of his efforts will not be lost, and that every advance in understanding or power of service will prove the starting-point for further progress. But he is not therefore justified in relaxing his watchfulness or diligence, for his former progress is only secure so long as he continues to press forward. Still less is he justified in applying his own hope in a negative way by seeking to condemn those who have once been below him to a perpetual inferiority. Rather, because he feels that he must himself strive to mount to ever new heights, he will welcome the thought that other men also may gain strength to rise above the past.

Thus continuity and order are necessary in the life of the spirit, but no less needful are spontaneity and the belief that the future holds within its concealing veil experiences which will transcend those of the past. If the former principle teaches the need for watchfulness, the latter calls to charity and hope. And if there remains some degree of paradox in their simultaneous assertion, this is but one of the practical paradoxes by which life is ruled; nor could we readily find a truer expression of its significance than the old saying in which the two thoughts are linked in one - "The perseverance of the saints is made up of ever new beginnings."

\section{V.}

There still remains another stand-point from which the subject of this chapter may be illustrated. We have seen that the Christian assertion of the possibility of 
new beginnings answers a practical demand, while it comes into at least apparent conflict with the theoretic demand for continuity. But at the same time it is in closer touch with the actual needs of men, and so meets these needs in a way which no merely theoretic morality, however consistent, could possibly do. Its concern is less that life should be governed by a strict and undeviating law, than that men should by every means be drawn towards what is good. And in so doing it fulfils the higher purposes for which all Law exists. It is true that Law in the hands of the legalist constantly tends to be thought of as itself the supreme end of morality, rather than as the instrument and means by which the good life is fostered and upheld. But just because this tendency is so strong and persistent, there is the more need to recall and emphasise the fact that the true ends of life are higher than even the maintenance of a system of unvarying law, and that the uniformity of the legal order must be transcended, whenever it fails to lead men to the good.

In other words, the controlling principle of ethics must in the last resort be teleological rather than legal, and must look beyond mere legal observance to the positive moral development of human nature. Even in the State, which at first appears as the embodiment of uniformly executed law, this teleological principle rightly has the supreme place. The State exists, as Aristotle said long ago, to promote the good life, and where law fails to attain this end "because of its generality," clemency must come in to correct and supplement its defects. ${ }^{1}$ To the uniformity of external law there must be added an inner principle of allegiance to

1 Pol., 1252 b30; Eth. Nic., 1137b26, quoted p. 70 above. 
the Good, and in order to foster this principle it may be needful to suppress the claims of strict justice in order that a higher Law may come into operation. This truth is clearly stated by Ritschl in the words, "Legal right is not itself the highest good, but in all cases only a means to secure the moral goods which further the true life of the people." This teleological criterion having been stated, he proceeds to show how it applies in the religious sphere,- " The moral legislation of God is, under all circumstances, the means toward the moral commonwealth, the Kingdom of God. The attribute of God as Founder and Ruler of His Kingdom is therefore absolutely superior to His attribute as Lawgiver. It follows then that pardon, or the forgiveness of sins, is connected, not with God's special attribute as Lawgiver, but with His general attribute as King and Lord of His Kingdom among men." 1

But even this does not provide the basis on which we can finally rest the argument of this chapter. For the analogies of political life are in themselves insufficient to afford adequate expression for the Christian view of the Good, and so we are forced to advance from the thought of the State to that of the Family in our attempt to find expression for it. Thus Ritschl goes on to point out that, even at the best, the analogy of state action breaks down, because the exercise of pardon or clemency never loses the character of an exceptional measure breaking in upon the administration of uniform law; whereas in the case of the Family it becomes, through the peculiar intimacy of the moral relation there existing, a regular means of moral action and discipline. "This train of thoughts carries us beyond the limits of

${ }^{1}$ Justification and Reconciliation (Eng. tr.), pp. $91 \mathrm{f}$. 
the conceptions derived from the analogy of the human judge. But the forgiveness extended by a father to his child combines in one act the judgment that a fault committed by the child ought to bring about no alienation between father and child, and the expression of the purpose to admit the child, as a right and gracious action, to the unfettered intercourse of love." And again, "The difference between the two is seen in this, that" in the political sphere "the right of pardon is only exercised in individual instances of legal condemnation, which . . . always form exceptions to the recognised legal order, while the forgiveness of sins by God the Father is a universal, though not unconditioned, fundamental law, established in the interest of the community of the Kingdom of God." 1

In support of this interpretation, Ritschl appeals to the close connection which appears in the New Testament between the ideas of Fatherhood and forgiveness. And the same appeal might be carried further back to certain of the deepest passages of the Old Testament; for it can hardly be an accident that the verse, "As far as the east is from the west, so far hath he removed our transgressions from us," is immediately followed by the words, "Like as a father pitieth his children, so the Lord pitieth them that fear him." 2 More than once the two ideas are found in close association in the writings of the later prophets, and their most urgent moral appeal is often founded rather on the idea of the divine long-

1 Op. cit., pp. 94 f. We have already seen that in this thought of the Family and the relations within it there is a more perfect type than exists in the political sphere of the individualising character of Christian morality. (Supra, p. 96). $8 \mathrm{f}$.

${ }^{2}$ Ps. ciii. 12 f. Cf. Is. Ixiii. 8 f., 16 : Jer. xxxi. 20 : Hos. xi. 1, 
suffering than on that of the divine vengeance. This estimate of the relative importance of the two forms of appeal comes out clearly in a remarkable passage in the Book of Ezekiel, in which both are emphatically used. For the words "The soul that sinneth it shall die : . . the righteousness of the righteous shall be upon him, and the wickedness of the wicked shall be upon him," which answer to the demand for continuity and strict justice, are followed by the still more impressive words, "Have I any pleasure in the death of the wicked? saith the Lord God: and not rather that he should return from his way, and live?" 1 It is in this last thought that the prophet finds the final and controlling end of the Divine Government. Both ends have their place; but above and beyond the judicial purpose there is ever the supreme end of moral uplift and redemption.

Thus it comes to pass that in Christian Ethics, as in the loftiest passages of the Old Testament, the present experience of mercy takes the place of the fear of future judgment as the great moral dynamic. And it is just because of the superior power of the former motive to goodness, as it exists in the relations of Fatherhood and Sonship, that these supply the terms in which the ultimate truths of sin and redemption find their most adequate expression. In the state, in so far as it exists for the maintenance of justice and ethical continuityin so far as its order is a purely judicial order-there must remain a certain externality ; for it appeals largely to hope and fear, and so falls short of that inwardness of moral appeal which is possible in the closer relations of the family or of intimate friendship.

${ }^{1}$ Ezek. xviii. 20, 23. 
For it is only when men are connected by some essentially spiritual bond, such as that between parent and child, that it is possible to secure respect for the law and loyalty to goodness, not less when the strict penalties of the law are remitted than when they are enforced. When confronted by wrong-doing, the State as such has no resource but punishment, and if punishment fails to influence the will of the wrong-doer for good, it has to confess its failure. But in the personal relation of man with man, there is another resource. The harm and pain caused by the wrong done may be brought home to him who has caused it through his affections, when he sees the suffering which it brings on those whom he is bound to trust and to revere; and if the outward penalty be then remitted, his conscience may be more deeply touched by forgiveness than it could ever have been by punishment. Just because the punishment is not inflicted, his sense of honour may be awakened and stirred to the resolve to prove himself worthy for the future of this unmerited trust. In this case the strict course of the law is interfered with, but only that the ends of the law may be reached by a different path, which is in a peculiar sense the Christian path. For, transcending the judicial and retributive order, is the higher moral order which Christianity reveals. In the Christian view, "the divine purpose in creation is the 'Kingdom' and not the Judgmentseat"; and the greatest means through which the Kingdom is advanced is to be found in undeserved suffering willingly borne for the sake of others. ${ }^{1}$ But unmerited suffering is inexplicable in the merely retributive system: it marks the breakdown and the failure

${ }^{1}$ A. G. Hogg, Karma and Redemption, p. 56 . Cf. pp. 60 ff., 96 ff. 
of that system, while in the higher order it becomes the powerful means of awakening the impulse after a higher life.

It is in the light of these ideas that the assertion of the possibility of new beginnings may best be understood; and we may for a moment return to consider the place of the idea of Fatherhood in this connection. It has been said that at the present time we are apt to apply that idea in too facile a way, as if it stood for mere placability and good nature. In this sense, certainly, it has not strength or dignity enough to bear the weight which rests upon it in Christian thought; for there must always be present an element of stringency and of moral discipline even in the idea of forgiveness. In the words of Thomas Erskine of Linlathen, "Forgiveness in its deepest sense does not mean deliverance from a penalty or the reversal of a sentence, it means the continuance of a fatherly purpose of final good even through the infliction of the penalty and the execution of the sentence. . . . In the truest theology forgiveness (taken in the sense of remission of penalty) is never considered as an ultimate blessing, but only as means to an end. That end is righteousness." 1

Thus forgiveness, like punishment, although at a higher level, is essentially an instrument for the promotion of goodness; and it can be rightly exercised only by one who has moral authority enough to win respect for the law even while he modifies its action, one who, by remitting the penalty of wrong-doing, can place a stronger compulsion towards good on the heart of the wrong-doer than would have been caused by the

1 The Spiritual Order and other Papers, pp. 140 f. Cf. Heb. xii. 5-11; and Note Q, p. 409, "The Conception of Punishment as Reformatory." 
MORAL CONTINOITY AND NEW BEGINNINGS. 291

full exaction of the penalty. It is in such a way, and by such a conception of Fatherhood, that we may truly interpret the Christian view that the final aim of Lawthe development of goodness-may best be reached when the strict system of legal retribution gives place to that bigher system, which depends on the free working of forgiveness and trust. 


\section{CHAPTER XI.}

THE CHRISTIAN IDEA OF LAW AS PERSONAL.

WE now approach the last, and in some ways the most profound and difficult, part of our subject, the conception of Law and its place in Christian Ethics. In the preceding pages it has indeed already confronted us, for we have observed the contrast between the strictly legal order and that higher order in which new beginnings, moral and spiritual, find a necessary place. Thus the idea of Law has emerged in a form which suggests its inadequacy to express the higher truths of Christianity. It has appeared as the type of a rigid and external order, whereas the Christian ideal is marked by spontaneity and inwardness, and by the stress laid on the free personality. Thus it may be held that Law necessarily falls short of this character, that the conception of it must be left behind by those who would mount from the lower region to which it belongs into the free atmosphere above, and that some higher conception must be found to take its place. Yet this idea of Law has actually occupied so great a place in the ethical thought of mankind, and expresses so much that remains essential for even the highest and most spiritual ethic, that one cannot lightly abandon it. It would, therefore, seem wiser to ask 
whether it may not be reinterpreted in such a way as to harmonise with the thought suggested at the close of the last chapter; and the next two chapters will be devoted to this attempt.

\section{I.}

A few moments may first be spent in a statement of the claims of the idea of Law to persist (although in an altered form), after those of legality and the legal order have been definitely transcended. For these two terms point decidedly to the element in law which is external and incapable of development. But there are other elements which it is possible to develop, and it is the presence of these which gives the conception its value at every stage of ethical thought. As long as the conception of "the Kingdom" continues to be used as Jesus used it, the question suggests itself by what manner of law this Kingdom is ruled and how the activities of its citizens are directed; and this of itself suggests that the category of Law must retain its place in Christian Ethics. ${ }^{1}$

If we seek to express its function in the most general terms, we may say that it stands for the element of universality and stability in morality and religion, as in

1 The transition from the conception of "the Kingdom "to that of the Christian "Law" was historically the work of Paul. There will always be those who regret the passage of the free and natural thought of the Synoptic Gospels into the more formal rendering of Paulinism. Yet, from the point of view of the preservation and progress of Christianity, it was needful that some thinker should grapple with the problem of relating the teaching of Jesus to preceding ethical thought, and in particular to the great thought of Law; and this indispensable service was performed by Paul. 
other spheres. If the Christian commonwealth is to be an ordered unity and not an anarchy, if the lives of its members are to be ruled by principles which, however flexible, are firm and constant, then there must be an inner law to which they always respond. Thus that character of the universal and inevitable at which Law in all its forms and stages aims, continues here. The object of a natural law, or generalisation, is to state an invariable sequence in nature; that of a moral law, or commandment, is to enforce an invariable or categorical duty in the moral sphere. And, however high we rise, there will still be room for the attempt to express the principles of conduct in the form of laws, or of one supreme Law. If the latter could be apprehended in its fulness, it would indeed be in the highest degree authoritative and universal. But how may we actually obtain the least inadequate idea of this universality? How does Christianity seek to reach it? These are the questions to which we must now address ourselves; and it would be hard to find a better way of doing so than by comparing the Christian conception with that of Kant. For both positively and negatively, by affinity and by contrast, his great formulation of the ideas of the Moral Law and the categorical imperative of Duty is in a high degree suggestive; and so we may find in a brief criticism of the Kantian position a way of approach to the Christian idea of Law, which will show wherein its originality and strength especially lie.

Kant may be taken as typical of those who look for the secret of universality in abstractness, and in the exclusion of all that is variable or merely individual, especially of feeling. For Kant as for Plato, reason is the universal element in human nature, feeling the 
particular. The former is the constant, the latter the variable factor. So he argues that the Moral Law must speak through reason alone, for only thus can its imperative have the inevitable, impartial, universally compelling character which makes every man accountable before it. Its only true relation to the emotional side of man's nature is that it awakens the feeling of Respect, which has affinities with both pain and pleasure. But the feeling of pleasure in conformity to the Law, or of love for it, must remain the posterior element in virtue, for to treat even this feeling as the motive to obedience would involve a departure from the strict purity and disinterestedness of the Good Will. For Kant, "moral sense" is at best a dangerous principle in ethics. Its action is uncertain, its presence liable to disturb the even balance of the virtuous will; and thus the only true guide is to be found in "pure practical Reason," or Conscience in its response to the imperative of the Moral Law. ${ }^{1}$

Thus if feeling is essentially individual and particular, it follows that even the highest form of feeling-admiration for what is noble in character and action-is insufficient as the foundation of morality; and that an absolutely secure foundation must be sought for in that which is common to all rational beings, Hence arises Kant's suspicion of any personification of the Moral Law, or any attempt to rest its observance on feelings of admiration for or delight in what is beautiful in a.ctual human character. In his view not only do

1 The objection of Kant to the doctrine of "moral sense" is summed up in his statement that " feelings which differ infinitely in degree cannot form a uniform standard of good and evil."-Grundlegung (IV. 442). Cf. Kritik der Prakt. Vern., V. 38 f., 63 f., 117. (Abbott, pp. 61, 129, 154 f., 213.) 
such feelings vary from time to time and from man to man, but their presence or absence cannot be made the ground of praise or blame, ${ }^{1}$ since their origin is in the main independent of the will. Hence it is not by their means that all men alike can be made accountable to the Law.

Now before criticising this conception, it is worth while to remark that it is not confined to Kant alone or to philosophy alone. One of the great aims of the Jewish religion was to preserve the purity and majesty of the Law by severing it from every visible expression or personification. The Law was thought of as standing above those to whom it was given, in a majesty which suffered no attempt at visible embodiment, and which drew forth the reverence and the awe of its hearers, but did not appeal to their sense of beauty or arouse their love. "The mountain burned with fire unto the heart of heaven, with darkness, cloud, and thick darkness. And the Lord spake unto you out of the midst of the fire: ye heard the voice of words, but ye saw no form; only ye heard a voice." 2 The idea of the Moral Law in its austere remoteness and generality, which these words express in the language of poetry, may be compared with the similar idea which finds expression in the abstract terms of the Critical Philosophy. In the latter also the Moral Law is thought of as a voice; only it is no longer a voice from without, but one coming from the inmost nature of man as a rational being. But the author of Deuteronomy and Kant are at one in this, that both think it essential

1 Cf. infra, pp. $329 \mathrm{ff}$.

2 Deut. iv. $11 \mathrm{f}$. By passing from this passage to the opening words of the First Epistle of John, we may measure the interval that separates Christian thought in this respect from the Judaism out of which it sprang. 
to the universality of the Law that men should "see no form" and "hear a voice only." 1

This conception of universality led Kant to conceive moral truth largely on the analogy of mathematics, where universality is undoubtedly attained by way of abstractness, and where he found principles that are inevitably accepted because they make their appeal to the reason which is the same in all men. But before we accept the analogy as conclusive, it will be well to ask in what sense mathematical principles represent the most universal form of truth. For it may be that the moral appeal is of a different nature from the purely intellectual, and if so moral universality must be sought for along a different path.

If we look at the matter for a moment from the standpoint of ordinary experience, we cannot fail to notice that the highly generalised truths of mathematics or of any other abstract science appeal chiefly to minds of a certain type. Nor does the mathematical mind represent the whole range of human intellect, not to say of human capacity. There are many men who show a remarkable want of appreciation of, and even imperviousness to, truths of that order, who yet in other directions possess high intellectual or artistic gifts; nay, the latter at least seem to be definitely antipathetic to the exercise of the formal and generalising reason. It is true not only of the majority of ordinary men but of many of the highest minds of the race, that they respond readily and eagerly to truth, whether intellectual or moral,

\footnotetext{
- 1 This whole argument applies chiefly to the ethical writings of Kant. For the modification of his position in the later treatise on Religion within the Bounds of Mere Reason, cf. the first paragraph of Note R, pp. $410 \mathrm{ff}$., "Kant's Final Theory of Law and Personality."
} 
only when it is clothed with a certain concrete warmth and colour. But such a ready response is of the essence of morality, and when we reflect that in only a minority of cases is it made to abstract truth, logically universal and certain though that form of truth is, it becomes clear that this form of universality is not adequate to the demands of the moral life. The demonstrations of an abstract science do indeed possess a complete and final certainty for every one who follows the steps by which they are reached; and it may also be true that every man of normal intellect may with sufficient time and pains be brought to see their validity. But this slow and painful process, by which these universal truths come to be actually understood by ordinary men, clearly gives no idea of the swift, decisive, authoritative appeal with which the Moral Law must strike home to the conscience and win its assent. If an analogy be sought for in this direction, it can only be found in the case of those rare intellects to which abstract truth appeals with an intuitive immediacy.

Even in this case, however, the analogy is imperfect. For the Moral Law claims to control the whole man, and thus cannot gain entrance through the intellect alone, even in its swiftest and clearest intuitions. To come with full authority, it must be addressed to feeling and will as well as to intellect. It must awaken some glow of emotion, and must point to an end which arouses the will by inspiring the imagination. Hence it must lay aside its abstractness if it is to be universal. ${ }^{1}$ There

1 This progress to the concrete is exemplified in the Kantian Ethics, as the analogies of the first Critique are gradually departed from, and the idea of a Kingdom of Ends comes into greater prominence as the embodiment of the Good. 
is thus a difference between the two orders of truth. Logical or mathematical truth attains universality by a sacrifice of the concrete; while moral truth gains universal assent-the assent of will above all-only in as far as it appeals to the imagination and rouses the slumbering ideals in the hearts of all. Further, since it is directed to action, it is most cogent when it appears, not as a formula which still needs translation into terms of practice, but as a living example showing what goodness is in reality and deed.

Thus while logical universality involves the sacrifice of content to the greatest possible extension and generality, the universality of the Moral Law is best exemplified, not by the attenuation but by the intensification of its content. Its appeal to all is secured, not when all particular forms of goodness are refined away into a thin abstraction, but when goodness is manifested at so high a power that it pierces through all conventions and prejudices to that faculty of moral perception and response which is the most fundamental thing in human nature. For the power of aisthesis is as widely distributed as, and is far more direct and potent than, that of reflective thought. There is a Universal in this sphere not less than in the sphere of mathematics or logic; and to make this power operative is the end of the Moral Law.

So far our argument has been in some measure a priori; but it is amply confirmed by the appeal to experience. For we there find that the response of human nature, in all its varying forms and at every level of culture, to a noble example may as surely be counted on, and hence may form as firm a foundation for morality, as its response to "the truths of reason." 
We must even go a step further, and acknowledge that the former appeal produces by far the stronger ethical impulse. It is when the appeal, spoken or silent, of a personality is added to the silent promptings of conscience that the moral temperature rises most surely; and if the personality be great enough, the moral influence so exercised will be wider, more universal, more secure, than that of any formal code of law. It is this fact that explains the tendency of the great ethical movements of history to group themselves around a great man and take his character as their law. M. Sabatier has said that in the early days of the Franciscan movement the true rule of the order was Francis himself $;^{1}$ and this is no solitary instance, but the expression of a universal tendency which appears most clearly in the Ethics of the New Testament.

It is indeed the greatest strength of Christian morality that it is based upon this very fact. Nowhere else has the power of a personal attraction been so fully exemplified; and by that power the desire for goodness has been kindled in the hearts of men the most widely different in all other ways-men who could not have been drawn together by any formula of belief or any abstract demonstration of duty. The "common good" of Christianity rests upon a common appeal to the capacity

1 Vie de Saint François, p. 86. It has been well said that "as an educational implement a bare theory of morals is sadly ineffective. Men require a living example, they need to see Goodness moving and speaking before their eyes, before they will believe and be saved. It is the Founder of Christianity, rather than the system, who 'draws all men after him '; nor was it in blindness that the Cynics, for the edification of their disciples, whitewashed Heracles into a saint." (R. G. Bury, in the International Journal of Ethics, April 1910, pp. 279 f.) 
for loyalty and admiration which is assuredly not less deep-seated or universal than the purely rational powers of man. Nay, even before the days of Christianity there were those who knew that men are most surely drawn to goodness "with cords of a man, with bands of love." 1

But in the New Testament itself this truth shines out with a clearness which makes any elaborate proof needless; for it is at once apparent how closely the teaching of Jesus was related to His life and example. His most searching criticisms of Jewish legalism were not supported by abstract reasoning, but were based on His own inherent authority. He constantly made a direct appeal to the loyalty of His hearers as well as to their consciousness of right and wrong. He gave the impression of one who claimed obedience for Himself even more than for His mere teaching; or rather teaching and example were inseparably united in a Personality which made its single and undivided appeal to the hearts of men. Or we may borrow Thomas Erskine's phrase and say that the secret of that appeal lay "in what He was, interpreted by what He taught." 2 If the blessing pronounced upon the hearers and doers of His word was characteristic of Jesus, still more characteristic was the call to follow Him and to find in His example the rule of life and the secret of blessedness. ${ }^{3}$

In the Epistles also, the Law for Christians is set forth as a Personal Law. The standard of right action, not less than of right belief, is the truth as it "is in

1 Hos. xi. 4.

2 The Spiritual Order, p. 2. Cf. Hort, The Way, the Truth, the Life, pp. 205-207.

3 Matt. vii. 24; Mark i. 17, viii. 34, x. 21, 39 ff. ; Matt. xi. 29. Cf. John xiii. 1534. 
Jesus," and His " mind" is to persist as the ruling motive of His followers. ${ }^{1}$ The informing and liberating principle of their lives is "the law of the Spirit of life in Christ Jesus." 2 When Paul exhorts his Corinthian converts to be imitators of him, he gives the ground and sanction of this exhortation in the words, "even as I also am of Christ." ${ }^{3}$ Essentially the same thought underlies the call in the Epistles of Peter and John to "follow in the steps" of Christ, and to walk as $\mathrm{He}$ walked; and in the same spirit the writer of Hebrews reminds his readers that they can only find strength for the race set before them by "looking unto Jesus, the author and perfecter" of their faith. ${ }^{4}$ In respect both of His perfect fulfilment of the requirements of the earlier law, ${ }^{5}$ and of His self-sacrificing love for His brethren, the example of Jesus is held up as the supreme standard for all men. It is so very clearly in Paul's exhortation, "Bear ye one another's burdens, and so fulfil the law of Christ." 6 The writers of the New Testament were able to gather up all the many rules of the old morality into the one, positive, comprehensive Law of Love, only because they had first seen its

1 Eph. iv. 20 f.; Phil. ii. 5.

2 Rom. viii. 2.

31 Cor. xi. 1 ; cf. iv. 16 f._-" my ways which be in Christ."

41 Pet. ii. 21 ; 1 John ii. 6 ; Heb. xii. 2.

5 Rom. v. 19. Another passage which naturally occurs to the mind in this connection is Rom. x. 4- "Christ is the end of the law unto righteousness unto every one that believeth." It may be objected that to attribute the sense of "perfection" or "consummation" to $\tau$ ć $\lambda$ os here is to read Paul too much in the light of Aristotle. But even if this is so, does not the meaning of $\tau$ é $\lambda$ os as " annulment" or "superseding " presuppose the former sense? Only those who hold that the Law was completed in Christ can hold that it was annulled by Him. Cf. Jülicher, Paulus und Jesus, p. 17.

6 Gal. vi. 2. Cf. Rom. xv. 3. 
perfect embodiment and manifestation in the life from which they had learned the full meaning and power of love. Thus it is in full accord with their teaching to say that "Christ is the Christian Law." 1

II.

But there are still certain objections to this personal view of Law which must be considered. It may be said that, even if we admit the objective value of a personal manifestation of the ideal, and the subjective value of the faculty of moral perception and response to which it appeals, it is still the latter rather than the former that is the real universal. Must not the true and unfailing standard of right and wrong be found in Conscience (provided that "conscience" is understood in a wide enough sense as including emotion as well as intellectual insight) and not in any external law, whether the latter is given in a code or in a life? There is of course a sense in which this objection holds, for no code of conduct and no actual example has ever come within the ken of more than a minority of the human race. In one sense the $\mathrm{Law}$ of Conscience is at once the most fundamental and the most universal fact in the moral life of humanity. This is clearly recognised by Paul when he says that, "when Gentiles which have no law do by nature the things of the law, these, having no law, are a law unto themselves; in that they show the works of the law written in their hearts, their conscience bear-

1 Ecce Homo, Ch. X.; cf. Ch. IX., and Dean Church's sermon on "TChrist's Example" (The Gifts of Civilisation, Serm. III.); also note S, p. 303, "The Character of Jesus as the Universal Ideal." 
ing witness therewith." 1 Without this inner law, or power to respond to the claim of goodness, no outer law would be of any avail; and while the appeal of goodness comes to men in numberless different forms, while there are many expressions both abstract and personal of the outer law, Conscience must be thought of as common to all men.

But while this is certainly true, there are two possible interpretations of the relation of the inner to the outer law, especially when the character of Jesus is acknowledged as the final expression of the latter. We may see in His character and teaching the full-orbed truth which was known but in fragments to men who had not been taught of Him. We may see in Him the final end to which the moral strivings of the ages had been unconsciously tending, and in His message the most urgent call to repentance and the new life. This was the view of $\mathrm{Paul}^{2}$ as it is essentially the view taken by Christian Ethics, which looks on Christ as standing above the Law of Conscience as its truth and its fulfilment.

But if this view is to be established, the criticism of those who dissent from it must be met. $\backslash$ Judged from their standpoint, the example of Jesus only makes clearer, and brings more rapidly to full consciousness, those moral principles which lie in the heart of each man, and which are the ultimate standard by which every character, even the loftiest, must be estimated. In this case the inward law remains the essential factor, the ultimate authority in the moral life, while all else is relatively accidental. This view is strongly expressed by Kant when he says, "Every example of morality that
${ }^{1}$ Rom. ii. 14 f.
${ }^{2}$ Cf. Acts, xvii. 27, 30 ; Rom. ii, 16. 
is set before me must be first itself tested by principles of morality, whether it is worthy to serve as an original example, i.e., as a pattern, but by no means can it authoritatively furnish the conception of morality. Even the Holy One of the Gospels must first be compared with our ideal of moral perfection before we can recognise Him as such; and so He says of Himself, ' Why call ye Me (whom you see) good; none is good (the model of good) but God only (whom ye do not see)?' But whence have we the conception of God as the supreme good? Simply from the idea of moral perfection which reason frames a priori." 1

The first observation that may well be made on this passage is that it supposes a far more clear and developed standard of moral judgment than is to be found in the ordinary conscience. The critical philosophy is (perhaps inevitably) unsuccessful in describing the genesis and advance of the moral life. At this point Plato shows the truer insight, for while he shares Kant's distrust of feeling as compared with the rational powers of man, he speaks, not of a fully developed capacity, but of a faculty or potentiality in the soul of each man, enabling him to learn. ${ }^{2}$ This power he represents as only coming into due exercise when it is drawn out by contact with intellectual or spiritual truth, just as the light of the sun shining on the world around draws out the power of bodily vision. Thus, while he regards the Good as general and impersonal, he certainly teaches in the allegory of the Cave and its application that it exists without as well as within the individual, and that

1 Grundlegung, IV. 408 f. (tr. Abbott, p. 25).

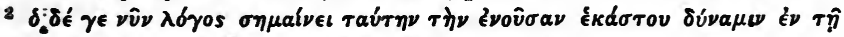

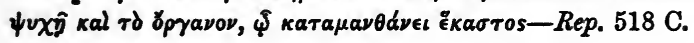


its brightness must shine upon him from above in order that his power of inner vision may be stimulated to its full exercise.

In this whole question of the relation of the objective Good to the inner faculty, by which it is recognised and appreciated, we are largely dependent on spatial metaphor. The use of metaphor is unavoidable, but it is needful to see that the metaphor adopted does not disguise the nature of the spiritual fact which it is used to describe. Kant, in his anxiety to establish the autonomy of the Moral Law as expressed in conscience, represents the latter as judging every example of good and noble character as it were from above, and by comparison with clear and infallible moral principles. Plato rather thinks of man's nature as containing the capacity for the recognition of all truth and response to all goodness, but in a latent form, which needs to be drawn out by education. His Doctrine of Reminiscence enables him to hold quite as firmly as Kant that neither knowledge nor goodness can be imposed on the soul from without, and that it can acknowledge no alien dictatorship in either; but at the same time he gives full value, especially in the Republic, to the part played by the objective truth and goodness in the world in drawing forth the response of the soul.

We may state the antithesis in terms of the two possible uses of the word "appeal." There is the appeal to a higher authority, or to an absolute judgethe appeal from below. But there is also the appeal from above, of a leader to his followers, and the latter is the sense in which the Christian Law appeals to the hearts of men. It is true that Christ submitted Himself to the judgment of the men of His day, but He did not in so doing place them above Himself. The author 
of the Fourth Gospel, in saying, "He came unto his own, and they that were his own received him not," 1 does not for a moment suggest that they were higher than He. The appeal of Jesus was the appeal from above; and thus the faculty to which it was addressed is better described as that of moral recognition, appreciation, response, than as that of moral judgment. For while the latter suggests a pronouncement from a higher authority, the former describes the acknowledgment of a rightful superiority by men whose loyalty is justly claimed.

Thus far our argument has been directed towards the establishment of two related positions-first, that the universality of the Moral Law only becomes a real, as opposed to a formal, truth, when its appeal is in some sense personal, and is directed more to the power of appreciation and admiration than to the power of acknowledging abstract truth; secondly, that this appeal is from above, from the higher to the lower and less developed, and yet that it is not the imposition of an alien authority or force, but that it arouses and gives both energy and clearness of form to those aspirations after good which, even when they are still dim and confused, are the deepest element in human nature. Both these thoughts are finely expressed in Tennyson's words,-

"Tho' truths in manhood darkly join,

Deep-seated in our mystic frame,

We yield all blessing to the name Of Him that made them current coin ; For Wisdom dealt with mortal powers,

Where truth in closest words shall fail,

When truth embodied in a tale Shall enter in at lowly doors." 2

1 John i. 11.

2 In Memoriam, xxxvi. 
But all this may be admitted, and a further difficulty still remain. Even when it is recognised that the strongest moral appeal is not that of abstract truth, but that of "truth embodied in a tale," that the Law is most urgent when it comes as precept wedded to example rather than as precept alone, and that in this case it cannot be described as subordinate to the conscience to which it speaks, it may still be questioned whether the Moral Law for all humanity can be found gathered and summed up in any one personality. The moral needs of men are infinitely various. The qualities which call for repression in one are just those which need to be stimulated and fostered in another; nor can all these varying needs be met by the exhibition in a great example of any one virtue or group of virtues at however high a power. If the idealised Heracles sufficed as an embodiment of virtue for the Cynic preacher, ${ }^{1}$ that was only because the Cynic's conception of virtue was radically one-sided; for such an example of fortitude as the character of Heracles supplied gave him just the text which he needed in his attack on the special evils of his day, and the vision of a complete and harmonious virtue never rose above his mental horizon. But when the question is that of an authority not limited to any single class or period or country, but extending over all, it is clear that such a vigorous but incomplete personification of virtue cannot make so high a claim. That morality alone can be universal in which all the diverse elements of goodness appear in their due place, so that in contemplating it each man may hear a call to follow after the virtue of

1 Vide supra, p. 300, n. 
which, whether he knows it or not, he stands most in need.

Now our first chapter was an attempt to show in outline that the Christian ideal fulfils this condition by welding into one the many forms of virtue which are generally isolated, and are sometimes even opposed to one another. If that attempt was wellfounded, the claim of Christian thought, that the Moral Law for all times and circumstances is to be found in the life and teaching of Jesus, could be established by adding detail to the outline, showing that $\mathrm{He}$ displayed no one-sided development of any single virtue, but a character complete on every side. Thus it might be shown that there is here a law for all, and that no man can fail to find in the character and words of Jesus, if he be honest in his study of them, the very reproof or stimulus which is needed for the perfecting of his own character. Not only do the harsh and unfeeling recognise a call to mercy, gentleness, and kindness, but the timid are called to be courageous, the desponding to hope, the impatient to endure, the envious to rejoice in the good of others, the careless and the indolent to work strenuously and constantly. Thus the claim that the Christian Law is both personal and universal is founded both on the unique moral intensity of the character of Jesus, and also on the way in which men in the most various circumstances, and of the most widely differing characters, find in His example the completeness of which they themselves fall short.

But more impressive than any general or theoretic proof, is the way in which the Christian ideal has in fact met the changing demands of the countries 
and centuries through which it has come down to us, displaying new aspects as the needs of one age have given place to those of another. For the finer spirits in each have found in it the corrective of the special evils of their time, and the summons to pursue that form of good in which the society in which they lived was notably deficient. In the corruption and despair of the decline of ancient civilisation, it pointed to purity and hope; amid the disorders and violence of the Dark Ages it stood alike for order and for pity; and in our own age we are beginning to hear in the Gospels a condemnation of the modern sin of commercial greed and a call to the establishment of a happier social order. And what is true of the different ages is no less true of the different nations of the world to-day. The traditional theology of the West often fails to satisfy the men of other climes to which the Christian message is taken; but the ideal of goodness, as it is presented in the life of Jesus, never fails to win an answering admiration or worship. ${ }^{1}$ Thus the logical universality which is achieved by exact definition breaks down on all sides, for our carefully constructed systems often carry as little conviction to the Eastern mind of to-day as those of mediæval Europe carry to our modern mind. But where the universality of abstractness fails, as intellectual formulas vary from century to century and from country to country, that of the concrete realisation of goodness in the life of Jesus receives an ever new endorsement from the varying races and individuals who

1 See especially the Report of Commission IV. of the World Missionary Conference, 1910, The Missionary Message in Relation to NonChristian Religions, pp. 59, 109, 147, 188, 301, 305, et al. 
agree, as they agree in nothing else, in the respect and love which they freely accord to His character.

Nor do we in any way endanger the claim of the absoluteness of Christianity by thus appealing to actual experience. For the theoretic proof of that position, however perfect it may be made, still requires the support of the a posteriori argument; nor can the title of Christianity to be absolute and final both as a religion and an ethic, be established once for all. It demands a continual and progressive confirmation; and this is found in the experience of its wonderful adaptability to widely varying situations and needs, and in the fact that the Christian ideal makes, not only an ever new, but the most necessary and definite, appeal to the consciences of nations and of men. In one sense no subsequent age could add anything to the confidence in the universality of their faith and rule of life which was felt by the early Christians, but in another sense the claim of Christianity has been confirmed by every new condition in which men have felt the moral constraint of the character and message of Jesus.

Further, it is of no small consequence to note that the Christian Law is especially fitted to keep alive the sense of moral obligation in our own day. The authority of the more abstract systems of law has been to a great extent undermined by the evolutionary character of modern thought. Or, if their validity as expressions of the ideal is still acknowledged, they fail to bring home to the individual the same sense of absolute obligation as in former times. We have become increasingly impatient of the view 
which involves the individual with the race in the bondage of "original sin"; yet at the same time our sense of the power both of heredity and of environment makes us slow to cast on him full responsibility for his faults. We instinctively qualify the absoluteness of the moral demands of the Law, by asking how far the inherited disposition or the often degrading surroundings of the individual have made it impossible for him to fulfil these demands. In the same way we feel grotesque unreality in the passage in which Augustine speaks of the sins of infancy; ${ }^{1}$ and Kant's doctrine of an original timeless act of free choice on the part of the individual, preceding and conditioning all his temporal decisions for right or wrong, seems no less forced and unnatural than Paul's attribution of all the subsequent misery of the race to participation in the guilt of Adam's sin. ${ }^{2}$ More than this, we find it difficult to understand the intense and tremulous sense of obligation to perform the minutest requirements of the Law which marked the life of Paul before his conversion, or that of many of the most earnest followers of the monastic ideal; while our common-sense instinctively sides with the advice given to Luther in the monastery at Erfurt by the good Staupitz, that he should cease confessing until he had some real sin to confess.

Now this tendency to consider the circumstances of an act before assigning blame, and to regard the obligatoriness of the Moral Law as in some sense qualified by the ability of the individual to respond to it, is a

1 Confessions, I. vii.

2 Religion within the Bounds of Mere Reason, I. iii., iv. (tr. Abbott, pp. 339 ff.) ; Rom. v. 12 ff. 
good thing in so far as it forms a protest against formal and unreal theories of obligation. It seeks to bring the ideal to the test of the actual, and thus undoubtedly is favourable to the exercise of charity in judging the faults of others. But at the same time there is present the danger that the Law may lose its ideal character when judged by too empirical a standard, and that charity in judging others may be made an excuse for over-leniency in self-judgment. The effort to understand and allow for all the conditions of moral action may readily pass into a quest of excuses for moral weakness. And so the ideal is lowered to the facile level of the possible, while the Moral Law loses its dignity and high obligation, and comes to be thought of as accommodating itself to the feebleness of man.

This result is wellnigh inevitable so long as it is viewed in a purely abstract light; for then its authority cannot but seem vague and shadowy in comparison with the very real difficulties and hindrances to good in daily life. But when it is seen to be personal, when it is bodied forth in the character of One whose message was conveyed not in words alone but in a life of the most complete devotion to the service of others, the sluggish conscience is quickened and the sense of obligation revives. Even at a time when men have many questions to ask before they will admit that they are "debtors to do the whole law," 1 and when their sense of obligation is cut down to the measure of what may reasonably be expected of them as individuals, they have not lost the power of responding to an example, and of seeking to imitate a life lived among the same temptations as their own. It is a familiar saying that

1 Gal. v. 3. 
Socrates brought philosophy from the study and lectureroom to the market-place and the haunts of men; and not less truly may it be said that Jesus brought the Law down from the Mount to the fields and the lake-side and the carpenter's workshop. And even an age which has wellnigh ceased to tremble at the terrors of Sinai can feel the pressing claim of the Law of Goodness as it was manifested in Galilee and at Jerusalem. It is in presence of that life, that the readiness to take refuge in excuses most surely gives place to an acknowledgment of the right of all that is true and noble and self-sacrificing to the allegiance of man, and that an easy acquiescence in a low level of moral attainment most certainly passes over into self-condemnation and the desire to rise to better things. And so the wavering authority of the Law is once more established on a sure foundation.

\section{III.}

The nature of the Christian Law may also be set in another light, by considering somewhat more closely what is involved in the obligation to its fulfilment. It has been said that in the conception of the Moral Law, or of the ethical end, there is a radical antinomy. "The thesis of this antinomy may be briefly given as 'my ethical end must at least be capable of attainment,' and the antithesis as 'my end, just because it

1 "The proposed conviction of sin is not here by the law, or by any computation of sins and deserved penalties, but it is to be by the gospel rather, not as being bolted in by the legal majesty of Sinai, but as being melted in by the suffering goodness of Christ." (Bushnell, Forgiveness and Law, p. 254 ; cf. Ritschl, Justification and Reconciliation, Eng. tr., pp. 328 f.) 
is an ethical end, must be incapable of attainment." " 1 Now, this is not an unreal or merely verbal difficulty; for both points of view may be defended as essential to an adequate conception of the standard or end of action. On the one hand, as we have just seen, there is a fatal unreality in attributing to any man an obligation to perform an action which does not lie within his power, or in blaming him if he fails to perform it. Before I acknowledge the claim of the law to my full and perfect obedience, I must be satisfied that it demands no impossibilities; otherwise the feeling of inner obligation, which is the essence of the moral life, passes over into revolt and the denial of the rights of the Law. But on the other hand, it is not less essential that the demands of the Law should not be reckoned according to the scanty measure of individual performance. It must stand above man in a greatness undiminished by his failure to rise to it. "A man's reach should exceed his grasp," and the Law must ever summon him on to yet higher attainment. Thus its character as imposing an absolute obligation to full performance seems to stand opposed to its ideal perfection; yet both these aspects are equally necessary to an adequate conception of it.

This antithesis is clearly traceable in the thought of Kant, but in his ethical writings at least he does little to show how it may be transcended. ${ }^{2}$ On the one side we find the line of argument which is summed up in the words "I can because I ought." If our knowledge of the fact of freedom depends on our consciousness of the categorical imperative, and on the experience that in obeying it we escape from the sphere of natural causa-

1 A. E. Taylor, The Problem of Conduct, p. 393.

2 Cf. Note R (2), p. 412. 
tion, then it seems clear that the duty set forth in this imperative must be possible of accomplishment, and that the experience of obedience must be real. Kant indeed says clearly that "the moral law commands the most punctual obedience from every one," and that "it is always in every one's power to satisfy the categorical command of morality." 1 But against these statements we must set those other passages in which Kant emphasises the complete disparity of reason and feeling, and estimates the purity and authority of the former by its radical opposition to the latter, thus making a perfect performance of its behests impossible for a still sentient being. ${ }^{2}$

But if the full force of this difficulty in formulating an adequate definition of the Moral Law often fails to be recognised, an opposite criticism must be passed upon the ethic of the Roman Catholic church, which has not only recognised the antinomy, but has allowed it to harden into a systematic dualism. Rather than sacrifice either aspect of the Law, it has divided it into two laws, a lower and a higher, assigning a completely and universally binding character to the one, and reserving the attribute of ideal perfection for the other. This division is expressed in the contrast between binding commands and "counsels of perfection." 3 The former (duties of strict obligation) are measured according to the assumed moral capacity of the ordinary man, and so regarded as obligatory always and on all. The latter ("counsels of perfection ") are addressed to those ardent spirits who are not

1 Kritik der Praktischen Vernunft, V. 30, 36 (Abbott, pp. 119, 126).

${ }^{2}$ E.g., Grundlegung, IV. 407 f., Kr. der Prakt. Vern., V. 32, 83 f. (Abbott, pp. 24 f. 121, 176 f.).

3 Or "duties of perfect and imperfect obligation," a distinction which Kant accepts, Grundlegung, IV. 424 (Abbott, p. 42). 
content to comply with the requirements of the ordinary law, but seek for a higher virtue, and have courage to explore the further regions of morality and of devotion. Thus the possibility of moral attainment and the infinite character of the moral ideal are both provided for; but the unity of the Law and of the good life are shattered in the process. And, when the unity of the Law is gone, its dignity can hardly remain. For, in its narrow sense, it is made to appear as a rule that can be fulfilled, in common phrase, with something to spare, and as though there lay beyond it a territory in which additional merit could be obtained. This solution has been defended by an appeal to the letter of certain passages in the New Testament, but it seems clearly out of accord with its pervading spirit and the general trend of its teaching. ${ }^{1}$ But if we reject it, how is the dualism in the nature of the Moral Law to be transcended?

We must first ask how it is stated in the Gospels; and here the student is first of all impressed by the heightening of the demands of the Law and the deepening of its spiritual content. The most searching words of the psalmists and prophets never penetrated so far into the hidden impulses and motives of the heart as did the words of Jesus; while His example, held up before His followers as the rule of their life, formed a more exacting standard, and called for a more entire forgetfulness of self, than any previous seer or lawgiver had dared to demand. He came to liberate men from the heavy burdens which the Jewish legalists had laid upon their shoulders, and yet the righteousness which $\mathrm{He}$ demanded was not less but more thorough and exigent than theirs. "For I say unto you, that ${ }^{1}$ Cf. Haering, The Ethics of the Christian Life (Eng. tr.), pp. 231-239. 
except your righteousness shall exceed the righteousness of the scribes and Pharisees, ye shall in no wise enter into the kingdom of heaven." 1 This sentence from the Sermon on the Mount expresses the same truth as Paul worked out in his own intense experience-that true righteousness is something deeper and more penetrating than the fulfilment of the most arduous round of legal or ceremonial observance, that it requires an altogether different attitude of the will and a change in the whole method of the moral life. ${ }^{2}$

Thus the demand of Jesus was not for outward conformity to a precisely defined and limited standard, but for a thorough inward cleansing of a man's whole nature, and the sacrifice of all merely personal aims, in order that he might be able to share the aims and the work of Jesus Himself. ${ }^{3}$ Nor did $\mathrm{He}$ disguise the exacting character of that work. He gave those who were disposed to obey His call full warning of this, and in a memorable passage $\mathrm{He}$ is represented as telling them that the task was not one which they could hope ever to complete or lay aside for a fully earned repose"Even so ye also, when ye shall have done all the things that are commanded you, say, we are unprofitable servants; we have done that which it was our duty to do." 4 The Christian's duty is not to be measured in the set terms of a legal code, but shares the infinitude of the world's need and the opportunities for service which spring from it.

But the other and more immediate aspect of the Law

1 Matt. v. 20 ; cf. xxiii. 4.

2 Phil. iii. 5-7. Cf. Rom. iii. 20 ; Gal. i. 14, iii. 10 ff.

3 Matt. x. 24, 37 f., xxiii. 25 ; Mark viii. 34.

Luke xvii. 10. 
is insisted on in the Gospels with equal emphasis and originality. If the path of service reaches out beyond all present vision, yet the light thrown upon the first step to be taken is none the less clear; nor is any point of daily life too small to escape the notice of Jesus. Sincerity and simplicity of speech and the avoidance of words that might show contempt or give pain to another are the subject of earnest exhortation; and the early Christian exaltation of pity and courtesy in the ordinary relations of life is in entire harmony with the teaching of Jesus Himself. ${ }^{1}$ Patience with children, kindness to the unfortunate, the granting of a cup of cold water to a disciple ${ }^{2}$-these duties are treated as of central importance; and they may be taken as typical of a whole class of actions, which are neither impossible nor negligible, but which are often unperformed because of a lack of thought for small things or of imagination to understand their worth. Here above all it may be said that, in thus underlining the lesser duties of life, "Wisdom dealt with mortal powers."

It is also significant that Jesus did not shrink from expressing praise or appreciation of work well done amid ordinary human limitations. In the Parable of the Talents, the servant who administered his small trust faithfully is rewarded with the words, "Well done, good and faithful servant"; and the story of the anointing of Jesus' feet ends not only with the words, "She hath done what she could," but with the promise that this good deed would be recorded wherever the Gospel was preached. ${ }^{3}$ These are not the words of a

1 Matt. v. 22, 37, 47 ; 1 Pet. iii. 8.

2 Mark ix. 41, x. 14 ; Matt. xxv. 34 ff.; Luke x. 33-37.

3 Matt. xxv. 23 ; Mark xiv. 8 f. 
teacher so possessed by the idea of the infinity of duty and the imperfection of all human attainment, as to be unwilling to recognise the degree in which men and women do actually fulfil the law of goodness.

Are we then simply to observe these facts, and to consider them as showing once more the many-sided, synthetic character of the ethic of the Gospels, an ethic which represents the Law as at once so searching and so simple, so infinite in its demands and yet so answerable to the powers of ordinary men when they act under the impulse of love? Must the two sides be stated in contrast only, or may they be brought into relation? It seems to me that they can be seen in their true relation when they are considered in the light of the saying regarding the reception of the Kingdom in the spirit of a little child. ${ }^{1}$ Christian obedience is to be filial-better, it is to be childlike-in character; and a child's obedience like all its other doings is marked by an entire absorption in the thing immediately in hand. The immediate duty is only one of an infinite series, but it is the mark of the child not to think of the series, still less of its infinity, but only of the interest or demand of the moment. It is on the present task, not on its remote consequences, that a child's attention is bent. This is in full harmony with the passages in which Jesus commands concentration on the immediate duty, and promises a sure response to those who are willing in the first instance to seek and to strive, while trusting the further results of their action to a higher power. ${ }^{2}$

The same spirit breathes in the Pauline exhortation, "Be ye therefore imitators of God as beloved children,"

1 Mark x. 15 ; Matt. xviii. 3.

2 Matt. vi. 33, vii. 7 f., 13. 
and in other passages in the Epistles in which the spirit of Sonship is held forth as being of the essence of Christian obedience. ${ }^{1}$ Indeed in this respect the teaching of Jesus and that of Paul approach much more closely than is commonly realised. "For both," it has been said, "the one end is the creation in man of the filial spirit." 2 Even when Paul speaks in the terms of the court of justice rather than in those of the family, we may recognise in his doctrine of Justification by Faith only a more formal and scholastic expression of the principle of trust which underlay the whole teaching of Jesus. Moreover, the very fact that the presentation of Christianity in judicial terms involves a certain straining of the simpler teaching of the Gospels, suggests that its spirit finds a more fit expression in metaphors drawn from the home. It requires some forcing to bring a personal law within the rigid framework of a legal system; but the difficulty is avoided where the more natural metaphor is retained. For obligation may also be expressed in terms of the relation between persons. Nay, that is its most essential sphere, as the type of all moral authority is that of a wise and good parent, whose authority is exercised for the good of all, and is supported not by fear but by affection and respect. $^{3}$

In the life of obedience to an authority such as this, the dual aspects of law which we have been considering no longer prove final and irreducible. For the child, the parent's will is binding at every moment jet it stretches far into the future and rises high above

1 Eph. v. 1 ; Gal. iv. 5 ff. ; Rom. viii. 14 ff. Cf. 1 John iii. 1 ff.

2 Forrest, The Christ of History and of Bxperience, p. 273.

3 Cf. Note R (3), p. 413. 
him, thus representing an ideal which can never be completely or finally attained. But because the bond uniting the lower to the higher will is a personal one, reverence being answered by sympathy and understanding, the antinomies and limitations of a purely legal obligation disappear, and the service of constraint gives place to the free service of friendship and of sonship. ${ }^{1}$

As we found at the close of the last chapter, so we find here that this is at once the simplest and the most adequate expression of the central principle of Christian Ethics; yet it is also possible to develop that principle by the help of a political analogy. It is indeed true that the lawgiver is limited by the capacity of those for whom he legislates : he must make obedience possible for the ordinary man, so that citizens may be divided, according to their observance of the law, into the two classes of law-abiding and law-breaking. But this division is not exhaustive, for if a state is to live and prosper there must be within it a third class made up of those-the patriots and heroes-whose love of their country will not let them remain satisfied with a bare observance of the laws, but urges them forward to a willing service and self-sacrifice. It is this political classification of duties as illegal, legal, and super-legal, that Roman Catholicism has borrowed and stereotyped, demanding the third type of virtue only from a few favoured or heroic souls. But the true demand of Christian Ethics is that every Christian should take as his example the patriot who hears in his country's call one that goes beyond his highest power of service, but who knows that his service, incomplete as it must be, will not fail to win acceptance and gratitude. The

1 Cf. John xv. 14 f. 
deepest political thought is at one with Christianity in teaching that loyalty, and not legality, is the motive and mark of true citizenship.

But the distinctive mark of the action that springs from loyalty is that it transcends the limits of prescription. It is measured by the desire to do the utmost service, and not by the constraint of a prescribed task. Nor does it, even in its noblest manifestations, lay claim to any outstanding merit. The epitaph placed over the graves of the Spartan Three Hundred at Thermopylæ did not celebrate their courage as unparalleled or transcendent: it was felt to be the highest praise to record that they had obeyed their country's behests. ${ }^{1}$ Thus there is an element of infinity present here; and it springs from the fact that the end of Law, the highest good of the community which transcends all precise computation, has here become also the freely chosen end and desire of the individual. Thus his service is essentially a free service; and his keeping of the law assumes a new character. In Horace Bushnell's striking words, it is " a keeping as the mother keeps her child, or a patriot his country. How very different is that grudging, slavish way of keeping the commandments that is contriving always how to pass the test by being exactly up and even with them. The true keeping is different, that of a bodyguard; that which is free as love is, not that which is in bonds looking after the jot and tittle because it must. It is the noble form of duty, which thinks not of what is to be feared, but of what is treasure to be lovingly guarded." 2

These considerations have brought us very near to

${ }^{1}$ Herodotus, VII. 228 ; cf. 104.

2 Forgiveness and Law, p. 105. 
the subject of our next chapter-the reconciliation of the ideas of Law and Freedom; but this chapter may be closed with a remark on the form which this conception especially assumed in Greek thought. It was that of the Fair or Good ( $\dot{0} \kappa a \lambda o ́ \nu$ ) as the motive of virtue. The good citizen acted for its sake ( $\tau o \hat{v} \kappa a \lambda o \hat{v}$

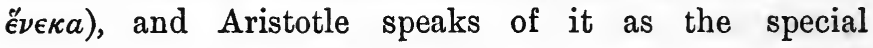
province or object of kingship as opposed to tyranny. ${ }^{1}$ Thus, for those who see in Jesus the supreme embodiment of what is noble in the moral life, of the qualities of the truest kingship, it is natural that the Greek motive, "for the sake of the Good," should pass

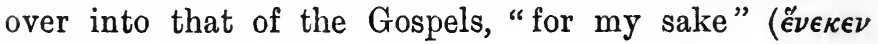
$\dot{\epsilon} \mu o \hat{v})$.

And so we return to the idea of the Christian Law as personal; and because it is personal, appealing to the sense of loyalty, and not rigid and legal, it is absolutely binding while it yet transcends attainment and remains an ideal. That it does transcend attainment is proved by the testimony of the noblest of those who have made it their guide. Yet it enjoins very simple duties, and because its motive is not fear - even in its highest form, the fear of disgrace-but trust and the "love that casteth out fear," 2 it gives rise to a great confidence even while it drives home the sense of the imperfection of all actual service. The Law of the New Testament is at once uniform and varied-uniform in that it sets the same ideal before all, but varied in that the different degrees of knowledge and capacity in different men are recognised

1 Pol., VIII. (V.) 1311 a 5 (tr. Welldon, p. 382).

21 John iv. 18. 
and taken into account. ${ }^{1}$ But those who have heard and answered its appeal are alike in this-that they say they are led onward

"By no dim influence of a law, But by a Figure that we saw And bands of brotherhood that draw."

${ }^{1}$ Luke sii. 48 ; 2 Cor. viii. 12. 


\section{CHAPTER XII.}

THE CHRISTIAN IDEA OF LAW AS POSITIVE-

LAW AND FREEDOM.

\section{I.}

THE second aspect of the Christian Law-its positive nature-has been already touched on more than once, and so needs the less introduction. If, as was argued in the first chapter, the ideal of virtue in Christian Ethics is essentially positive, it is natural to look on the Law of Goodness as positive also. It has indeed become a familiar saying that the moral originality of Jesus consisted largely in this, that $\mathrm{He}$ substituted commands for prohibitions - a morality whose watchword was Thou shalt for one which was based on the negative Thou shalt not. An illustration of this difference might be drawn from the two forms of the "golden rule." That found in Jewish morality, as in the morality of more than one other nation, is negative -a warning against inflicting any treatment on others from which one would shrink in one's own person; but Jesus gave the rule a wider interpretation, bringing within its scope all those offices of kindness which each man would wish to receive in his own time of 
need; and $\mathrm{He}$ added that in this single maxim, so stated, the pith and marrow of all the ethical teaching of Judaism was comprised. ${ }^{1}$ Again, He denounced the preoccupation of the Pharisees with the minute prohibitions and ritual injunctions of the traditional law, as having caused them to forget the broad issues of conduct, the positive content of goodness and of religion - those "weightier matters of the law"judgment, mercy, faith, the love of God. ${ }^{2}$

We have already noticed the significance of the saying, "Except your righteousness exceed the righteousness of the scribes and Pharisees," as setting forth the need of a goodness deep enough to penetrate all the recesses of man's nature and bring his secret thoughts and impulses into harmony with the Divine Will. In the verses which follow, this principle is carried out in its application to anger, revengefulness, and impurity; and the whole passage culminates in the precept of universal love, "Love your enemies, and pray for them that persecute you." 3 This final injunction is in truth at once the summary of what has gone before and the key to its meaning; for such an entire and thorough exercise of the pure and forgiving spirit, and of courtesy and simplicity in speech, is only possible when the heart is ruled, and its inmost motions controlled, by the power of love. Thus this division of the Sermon on the Mount, taken as a whole, may be regarded as the counterpart of Jesus' saying regarding the greatest of the commandments, on which the whole teaching of the law and the prophets depends, and also of

1 Matt. vii. 12; and see Note T, p. 416, "Positive and Negative Forms of the 'Golden Rule.'"

2 Matt. xxiii. 23 ; Luke xi. 42.

3 Matt. v. 20-44. 
Paul's proclamation, "Love worketh no ill to his neighbour; love therefore is the fulfilment of the law." 1 In the Johannine writings Love is held forth no less notably as the mark of true Christian discipleship and the compendium of all Christian duty. ${ }^{2}$ Moreover, when this is recognised, it at once becomes clear why the Christian Law is a personal one, and why the example of Jesus is the supreme authority for His followers, since His life was the perfect and consistent manifestation of this positive principle, by which alone the scattered fragments of duty are bound into one.

There is a further sense in which the Christian view of virtue as the many-sided development of the one active principle of Love has a positive character. It enlists the emotional aspect of man's nature and its deepest and most elemental impulses on the side of goodness-nay, it teaches that, when rightly disciplined and exercised, they form the energy of goodness itself. Thus in the Christian ideal they do not appear as powers to be uprooted by reason, or even to be brought into subjection to reason, but rather as constituting in their transmuted form, when "ै $p \omega s$ has

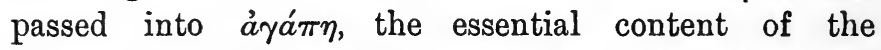
highest morality. ${ }^{3}$ But, it may be asked, have we not here passed beyond the region of moral law? Does not this attempt to represent the nature of goodness as akin to ardent emotion negate the ideas of obligation and of responsibility? May it not be

1 Mark xii. 28 ff. ; Matt. xxii. 40; Rom. xiii. 8-10; Gal. v. 14; 1 Thess. iv. 9 ; James ii. 8 .

2 John xiii. 34 f. ; xv. 12,17 ; 1 John ii. 10 ; iv. 7 ff.

31 Cor. xiii. ; and cf. Note R (4), p. 414. 
argued that the creation of such emotion, however fully its nobility be recognised, is not within the power of the will, and hence that no man can be held responsible for his failure to reproduce that state of feeling which the New Testament represents as embodying the highest and most perfect virtue ? ${ }^{1}$

It is assuredly true that the Christian ideal, viewed simply as an ideal, is necessarily harder to realise than any standard of conduct which involves mere rationality, or which places the whole of virtue in the exercise of self-control. The Christian Law is not only more exacting in its demands, it is also wider in its scope. It lays its behests not only on the will and the reason of man, but also on his powers of sympathy and affection; and thus points to an allround development of human nature, including those elements in it which at first would seem least fit subjects for the ethical command. The morality of the Sermon on the Mount-nay, the character of Jesus itself-so long as they are viewed as constituting an external standard by which men are to be judged, may well lead to a deeper despair than any previous law. If this were the whole result of the transformation of a negative into a positive ethical law, then it would not carry us far towards a solution of the moral problem. It would indeed raise and purify the idea of the Law, but it would in so doing place it further above the reach of human attainment than ever before. ${ }^{2}$

This fact does not fail of recognition in the New

1 Cf. Kant, Kritik der Prakt. Vernunft, V. 83 ; Pref. to the Metaph. Auf. der Tugendlehre, XII. (C) (Abbott, pp. 176, 312).

2 Cf. Strong, Christian Ethics, pp. $21 \mathrm{ff}$. 
Testament, and in the Gospel of John it is stated with great clearness. It was indeed natural for the disciples who had found a new life in their association with Jesus to reflect upon the fact that others had rejected Him, and to hold that the crime of that rejection owed its darkness to the purity and the unselfishness of His character and work. To those who failed to respond to the appeal of His life, knowledge of Him only brought a deeper and less expiable guilt. And so we find such sayings as these:- "This is the judgment, that the light is come into the world, and men loved the darkness rather than the light"; "If I had not come and spoken unto them, they had not had sin : but now they have no excuse for their sin." 1 The entrance of a higher standard of moral knowledge, by itself, intensifies and does not diminish the responsibility of man, so long as his will remains bent on what is unworthy. ${ }^{2}$

This is the truth underlying Paul's sayings, "The law came in beside that the trespass might abound;" "The commandment, which was unto life, this I found to be unto death." 3 If Paul found that the spirituality of the Tenth Commandment and its incisive and searching power were such as to cause his "death" as a natural man-if this precept made it impossible for him longer to carry on the vain attempt to attain righteousness by keeping the law-could the "new commandment" of Jesus have had any other effect than to confirm him in his despair? For it was more spiritual, more searching still. We may indeed see in the story of his experience

1 John iii. 19, xv. 22. Cf. ix. 41, xii. 48, xv. 24, xvi. 8-11; Mark xii. 6 ff., 1 Pet. ii. 6-8; with Dr Inge's remarks in Cambridge Biblical Essays, p. 282.

2 Cf. James iv. 17.

${ }^{3}$ Rom. v. 20, vii. 10. Cf. $\nabla v$. 7-14. 
on the road to Damascus, a testimony to the fact that his first real appreciation of the character of the Man whom he was persecuting came to him with just such a crushing and annihilating force. And yet, in his after life, he thought of the new light which then flashed upon his vision, not as a dazzling or blinding light which no human eye could support (though it was in truth beyond comparison brighter than that which had shone from the face of Moses), but rather as a transfiguring light imparting its own glory to those on whom it fell. ${ }^{1}$

What, then, is the truth which underlies this symbolism? How is this differing effect of the same vision of moral truth and goodness to be explained? There must clearly be two ways in which it may be received and regarded. What these are and how they are related is suggested by the saying of Coleridge, that "the true life of Christians is to eye Christ in every step of His lifenot only as their Rule but as their Strength." 2 In other words, the principle of Christian morality is positive in a double sense. As we have already seen, it enjoins an "active morality": it demands sympathetic action as well as self-restraint. But it is positive in the further sense of supplying an impulse and a motive power, in the sense of being dynamical. Here we see the full value of the Christian appeal to the emotions-admiration, gratitude, and pity - to which more than one reference has been made. Christianity not only gives them a place in the ideal which it holds up for imitation: it is able to bring them into exercise, and to use the driving force that is in them to make goodness the ruling power of the

1 Cf. Acts ix. 3 ff., xxvi. 12 ff. with 2 Cor. iii. 7-18, iv. 4, 6.

2 Aids to Reflection, "Aphorisms on Spiritual Religion," No. XVI. 
world. The Christian ideal is not merely an ideal-if it were, its very loftiness would make the moral life only more hopeless; it is an ideal which, in the case of those who respond to it heartily, draws out those powers which are needed for its own full realisation. It not only demands a fuller and more inclusive morality, in which feeling shall co-operate with reason and will: it awakens this very power of feeling into activity. It is indeed true that, for one who thinks of the ideal simply as a standard or a law, its influence may be wholly disheartening, and only more so the loftier it is; but for him who looks on it as it is in itself, and thus for a time forgets his own weakness, the very enthusiasm which it kindles gives a new power of response, and so it becomes to him not only a rule but also, and more essentially, an inspiring power.

It was this fact that Paul had in view when he gave his great counsel to his Philippian followers, "Finally, brethren, whatsoever things are true, whatsoever things are honourable, whatsoever things are just, whatsoever things are pure, whatsoever things are lovely, whatsoever things are of good report; if there be any virtue, and if there be any praise, think on these things." 1 But the sense which pervades the New Testament of the power of what is noble to transform the character of him who steadily beholds it, comes out in its full force only in those passages in which all the elements of moral strength and beauty are regarded as summed up in the single character of Christ. To behold and to reflect that character was to be "changed into the same image," for the love which $\mathrm{He}$ manifested necessarily aroused an answering love in the hearts of those who saw and felt

1 Phil. iv. 8. 
it. And this transformation was so remarkable and so complete, that Paul could not account for it save as proceeding "from the Lord, the Spirit." 1

II.

But again the question emerges whether this attempt to state the New Testament view of the Law as positive has not carried us beyond the sphere of Law altogether? In the writings of Paul, this question receives two different answers according to the sense in which the term "law" is for the moment used. In the sense of a statutory enactment, imposed on man from without and carrying a promise of recompense to him who should keep it perfectly-the sense in which the Jewish Law was typical of Moral Law in all its forms-it had indeed been transcended. Law so understood could not assist the infirmity of human nature-it was "weak through the flesh," and "worked wrath," not righteousness. Hence it could not meet the supreme need of man, the need for life; and so it was necessary for him to "die to the law," and to rise above it into the realm of freedom. ${ }^{2}$ But elsewhere Paul speaks of a higher law, which is not of works, but of faith, not of death, but of life; and he defines it in a phrase in which the various aspects of his conception of the higher Law are presented in organic union-" the law of the Spirit of life in Christ Jesus." 3 Here, as in the passage from the Second Epistle to the Corinthians already quoted, it is apparent how closely

12 Cor. iii. 18. Cf. 1 John iv. 19.

2 Rom. iv. 15, viii. 3 ; Gal. ii. 19, iii. 12, 21, v. $\mathcal{~}$. Cf. 1 Cor. xv. 56.

3 Rom. iii. 27, viii. 2. 
the Christian Law as Paul conceived it was bound up with his idea of the Spirit; and in both these passages yet another idea is essentially involved with these-the idea of Christian Freedom. It remains therefore to attempt to determine more closely the relation of Law and Freedom in the Christian scheme.

It is an old accusation that this idea of moral freedom is in truth equivalent to lawlessness, that, when a man is set free from the legal obligation supported by the fear of punishment to fulfil a definite rule of action, there is no other effective means of restraint or guidance possible for him. He is left to the sway of impulse; and even if his impulses be noble, even if he have seen and been stirred by a high and generous ideal, yet subjective impulse is no sufficient substitute for Law, in that it cannot produce objective rightness of conduct. Even generous effort may be inconstant or ill-directed, and thus it still calls for the firm grasp and the clear guidance of Law. Thus the charge against the ethics of Freedom may take two forms, both of which must be considered. The accusation may be that of complete antinomianism, the argument being that in such a system all is left to the unrestrained impulse of the individual; or, short of this, it may be said that conduct so directed must be inconstant and uncertain, as feeling itself is judged to be inconstant.

Now, it is common ground that moral action must conform to an objective standard, and must be directed to ends whose validity does not depend on their recognition by this or that individual. But Paul believed that this truth could be safeguarded while the doctrine of Freedom was still maintained; for he claimed that his teaching, so far from nullifying or reversing the 
older law, established it. ${ }^{1}$ Just as Jesus proclaimed that He had come to "fulfil the law," but in so doing implied that, as needing "fulfilment," it had in the past failed of its object and been imperfect; so Paul held that "the ordinance of the law" was fulfilled in those, and those only, who so far identified themselves with the work of Christ and became partakers of His character, as to "walk not after the flesh, but after the spirit." 2

This Pauline doctrine clearly involves a readiness to trust to the free and unforced flow of goodness in the case of all who have experienced the new life; and it does undoubtedly assign an important place to the subjective element in morality, the element of feeling. Thus it may be brought under the criticisms which are commonly advanced against the type of ethical theory which takes feeling, rather than reason or will, as its determining principle. These criticisms may take two forms, according as the "blindness" of feeling (to quote a well-known phrase of Kant's), or its inconstancy, is more insisted on. Now, even if these criticisms were admitted as valid against other forms of Gefühlsmoral, it might still be possible for the defender of Christian Ethics to show that it provides a sufficient supplement and corrective to such deficiencies. First, however, the problem must be more definitely stated.

It is said with considerable force that feeling provides but an insecure foundation for morality, since the action which it inspires is always apt to be ill-directed and "blind." Emotion is often ready to seek for its own

1 Rom. iii. 31.

2 Matt. v. 17 (cf. Denney, art., "Law in the New Testament," in Hastings' Bible Dictionary, iii. 74) ; Rom. viii. 4. 
relief, rather than for the real good of the person towards whom it is directed. Pity and the charity based on pity may, and often do, demoralise instead of helping their object. Thus conduct which is "free" may be directly and simply cruel in the sense of disregarding the feelings and interests of others; or at a higher stage, when some measure of sympathy has been aroused, it may become indirectly cruel through an unwise kindness or a weak emotionalism. This is the discovery which has led all wise social reformers to condemn much that passes under the name of "charity"; and it affords at least a relative justification of Kant's much-criticised paradox that good deeds of kindness and mercy must be done not at the prompting of pity or benevolence, but simply because they are commanded by reason. ${ }^{1}$ The same thought occurs in Spinoza's Ethics, where it perhaps gains force from the more genial character of the thinker. "The good effect which follows" from pity, "namely, our endeavour to free the object of our pity from misery, is an action which we desire to do solely at the dictation of reason; only at the dictation of reason are we able to perform any action which we know for certain to be good; thus in a man who lives under the guidance of reason, pity in itself is useless and bad." 2

Before attempting to indicate the answer to these questions it may be well to state the objection in its other form-that a morality of Freedom, which depends largely on spontaneous impulse, provides no assurance of the persistence and steadiness of the good life. Feeling

${ }^{1}$ Kritik der Praktischen Vernunft, V. 118 ("Inclination is blind and slavish, whether it be of a good sort or not"). Cf. V. 82 ; and Grund. legung, IV. 398 (Abbott, pp. 14, 175, 214).

${ }^{2}$ Ethics, IV. 1. (tr. Elwes). Cf. Note U, p. 418, "Chalmers on the Defects of Mere Feeling as a Moral Dynamic." 
even at its best, it may be said, not only stands in need of direction and wise control, but it is uncertain and sporadic in its action, at one time energetic, at another weak and faltering. While it burns brightly it may indeed be the most powerful moral dynamic; but there are times when its flame flickers and fails, and at these seasons a more enduring and persistent force is required to carry on the tasks enjoined by the Moral Law. In Wordsworth's Ode to Duty there is a singularly beautiful description of the life of glad and spontaneous virtue; and yet the poet teaches that this is in itself not enough, but that a "firm support" is needed when the natural impulse towards goodness fails :-

"'There are who ask not if thine eye

Be on them; who, in love and truth,

Where no misgiving is, rely

Upon the genial sense of youth :

Glad Hearts! without reproach or blot ;

Who do thy work, and know it not :

$\mathrm{Oh} !$ if through confidence misplaced

They fail, thy saving arms, dread Power! around them cast."

We do the thought of Wordsworth an injustice if we neglect the last two lines of this stanza, and consider it simply as a tribute to the grace and beauty of the life of "unchartered freedom" as it is lived by those who have a natural bent towards noble conduct. He rather teaches that even in such a character the impulse to good may fail, and that at such times a sterner law must be invoked than that of gracious and kindly feeling. Feeling in itself is variable and inconstant: the voice of Duty alone never falters. Thus in regard to Christian Ethics, the question comes to be whether the "Law of Liberty" is of such a nature that the permanence of good impulses is made not less sure than their spontaneity. 
The answer to these criticisms is to be looked for in the fact that the liberty of the Christian is determined and conditioned both by the example of Jesus, and by the needs of his fellow-men. Freedom from legal control and spontaneous flow of benevolent impulse are to be regarded as constituting the Christian ideal, only in so far as they bring a man's character into closer conformity to the character of Jesus, and adapt his action to the actual requirements of the social whole. Here there is a twofold safeguard, against unwise and indiscriminate pity, and also against the variableness of mere emotion.

The life of Jesus was marked by the most direct and spontaneous sympathy, but also by a great patience in dealing with men and women according to their individual needs. His compassion was in the highest degree natural and unforced, yet there was nothing headlong or blind in its working; nor does His example give any countenance to that "charity" which is merely emotional or too impatient to find out the wisest path of action. The patience which is willing to pause and reflect, and to study the remoter effects of benevolent action, is essentially akin to His spirit. Again, His life is portrayed as that of one who spent many silent years in thought and preparation before $\mathrm{He}$ began His ministry, but who thereafter went on His way with unswerving stedfastness, bending neither to the mistaken enthusiasm of the crowd nor to the anxious fears of His friends. It is that of one who set His face like a flint in His advance to the inevitable end. ${ }^{1}$ If Christ is the Christian Law, then that Law includes constancy and wisdom as well as generous impulse in its range.

But if it be objected once more that such a union

1 Mark viii. 31 ff. ; Luke ix. 51. Cf. John vi. 15. 
of disparate or even contradictory qualities is not to be looked for in ordinary life, what answer shall be given? Is it not possible that, while feeling at its ordinary levels is uncertain in its operation, there may be a higher type of feeling which moves on steadily and without pause, that the element in human nature which has been decried as varium et mutabile semper may, in its nobler manifestations, be the very type and norm of constancy? If there is such a constant and enduring emotion, then the argument from its existence harmonises with that previously used to prove the universality of the Christian Law. If the element of moral appreciation, of instinctive response to a high example, is in a truer sense than the power of accepting abstract truth the universal in man's moral nature, then it is natural to think of its further operation in the life of spontaneous goodness as the most permanent moral dynamic. This was at least the view of Paul, who spoke with the authority of a rich experience when he said, "Love never faileth." 1

But Christian Freedom is also to be defined in relation to the needs of mankind, that is to say, in relation to the Kingdom of God. This determination cannot conflict with that which has just been referred to ; for the life of Jesus was devoted to the task of founding the Kingdom, and if His work was perfectly fashioned to meet the need of men, then His example and their interest in the advance of the Kingdom are only two different aspects of the same determining principle. Thus the great ends of the Kingdom have a controlling and normative value for all its members, whose freedom is conditioned by, or rather consists in, loyalty to its ideals and the effort to

11 Cor. xiii. 8. 
further its progress. The words, "Where the Spirit of the Lord is, there is liberty," find their necessary complement and expansion in that other saying of Paul's, "The fruit of the Spirit is love, joy, peace, longsuffering, kindness, goodness, faithfulness, meekness, temperance: against such there is no law." 1

Nor is it hard to understand this identification of Freedom with the exercise of the "social virtues" which Paul names. For all external law exists in order to bring men whose natural interests conflict to refrain from mutual injury, and for this end alone is its compulsion applied. But that compulsion becomes unnecessary, just in so far as the object of the law becomes also the object of those who live under its sway and the real goal of their own desires. In this case they no longer need to be constrained to respect the rights of others, for each man sees his own good and the good of his neighbours bound together in a Common Good which claims the unforced allegiance of all. Thus, in so far as the growth of the Christian spirit makes it possible to escape from self and to enter into the lives and interests of others, the sphere of legal compulsion is left behind; and those who live in the life around them and take its higher good for their own are enabled to live as indeed free. For love is of all things the least subject to constraint. It cannot exist unless it exist in liberty, and, where it so exists and rules, the Law is perfectly fulfilled. ${ }^{2}$

This point is one of capital importance in Christian Ethics, and many of the lines of thought which we have followed converge here. For it is the Community of the highest Good, known as an ideal, but also and increasingly known as a fact, which makes it possible for men to take

12 Cor. iii. 17 ; Gal. v. 22 f.

2 Rom, xiii. 10. 
the good of others as in reality their own, and to show in the service of a wider whole the same entire spontaneity which others show in seeking their private advantage. Nor would this union of inward liberty with outward subjection to the wider social needs be possible in the purely legal sphere. It can only be experienced in so far as that sphere is transcended, and the controlling principle of conduct becomes not legal but teleological. ${ }^{1}$ Only in so far as life is governed by an ideal that appeals to the whole man, can he find freedom in the service of ends, which extend far beyond his individual ends, but which he is yet able to make truly his own.

This union of Christian Liberty with a voluntary subjection to the claims of others is strikingly expressed in the opening sentence of Luther's tract on the Freedom of a Christian Man: "A Christian man is a most free lord over all things, and is in subjection to no man : a Christian man is a servant profitable in all things, and is in subjection to every man." This paradoxical statement only expresses in sharper form what is an essential principle in the thought of the New Testament writers. ${ }^{2}$ For them, liberty existed not to give scope to the natural impulses, but only as a means to the more complete and willing service of God, and of all who were within, or might be brought within, the limits of His kingdom. "We preach," said Paul, "ourselves as your servants for Jesus' sake." 3 And again, "Though I was free from all men, I

1 We reached the same result in a slightly different connection at the close of Chapter X.

2 We may compare the paradox stated by Paul in 1 Cor. vii. 22 : "For he that was called in the Lord, being a bondservant, is the Lord's freedman : likewise he that was called, being free, is Christ's bond. servant."

32 Cor. iv. 5. Cf. Gal. v. 13 ; 1 Pet. ii. 16. 
brought myself under bondage to all, that I might gain the more." 1 Nor was there anything facile or ill-considered in the benevolence of Paul. Rather, as appears in this passage, he gave the most unwearied study to the varying needs of his converts, and spent all his great powers of thought and imagination in the attempt to come as close as possible to their ways of thought. In all his counsel to the Roman and Corinthian Christians, he held up the edification and strengthening of the whole body as the determining end constantly set before each individual; nor did he shrink from the sacrifice of the liberty of individuals in external things, if the spiritual upbuilding of the whole church might be furthered thereby. The love which Paul preached was no sporadic benevolence, but a force working slowly and patiently for this building up of the church as a united body. ${ }^{2}$

Here, then, is the true guarantee against the passing of liberty into the lawlessness of uncontrolled emotion. The idea of the Kingdom of God as an order in which the freedom of each man is limited, and yet amplified and realised, by the free development of others, gives a definite and objective, though an ideal, standard by which the altruistic impulses may be both estimated and disciplined; and true service can only be rendered to this ideal by those who have learned to unite wisdom and patience with enthusiasm. Wisdom is necessary to the Christian both because he is called to work for distant ends, and because he can bring lasting help to others only in so far as he gains a true insight into their needs. But patience and constancy are also needed, and they can be gained only in so far as a man's life is

11 Cor. ix. 19.

21 Cor. viii. 1. Cf. vi. 12, viii. 10 ff., x. 23-33; Rom. xiv. 
dominated, not by a passing emotion, but by a sense of the greatness and permanence of the work in which he is called to take part. Thus in the epistle of James, the ideas of liberty and perseverance are connected as the double condition of fruitful effort in the words, "He that looketh into the perfect law, the law of liberty, and so continueth, being not a hearer that forgetteth, but a doer that worketh, this man shall be blessed in his doing." 1

\section{III.}

The first aspect of the New Testament idea of Freedom which naturally arrests the attention is that of emancipation from the bondage of evil habit and desire. The latter-the "freedom" of the natural man-is looked on by the writers of the New Testament as the most entire enslavement, for "every one that committeth sin is the bondservant of $\sin " ;^{2}$ and such a man when his conscience awakens finds that he has been "brought into captivity, under the law of sin" in his members. ${ }^{3}$ It was the message of the early preachers of Christianity that an escape from this enslavement was possible; but the freedom so gained was conditioned by the source from which it came. This source is variously described as "the truth," the action of Christ, the gift of God." But however it is defined, it carries with it a very definite obligation to use the freedom so granted in accordance with the purpose for which it was given. Those who were "made free from sin" had at the same

1 James i. 25. Cf. the collocation of constancy and wisdom in vv. 5-8.

2 John viii. 34. Cf. Rom. vi. 16 ff.

3 Rom. vii. 23.

- John viii. 32, 36 ; Rom. vi. 23 ; Gal. v. 1. 
time "become servants to God." 1 If the old form of legal obligation had been done away, it was only that the new spirit of filial service might take its place. No man gloried more in the sense of freedom than Paul, yet he gloried also in a twofold subjection. On the one hand he confessed himself a debtor to all men, on the other he was "in the law of Christ." 2 In this subjection to a higher law his freedom was realised; and so we may apply to his teaching, as to that of his fellow-apostles, the words Das Gesetz nur kann uns Freiheit geben. But this does not represent his complete view of the relation of Law and Freedom until there is added to it the truth which is its complement and converse; for if there is a place in his teaching for the thought that Law alone can give Freedom, a more central place is taken by the thought that only those who live in Freedom-the Freedom of the Spirit-can perform the works of the Law and fulfil its grandest aim.

Further, while Paul regarded the Spirit in an objective light as independent of the varying moods and achievements of individuals, and thus as able to confirm and direct their fitful impulses after good, he also considered it as an indwelling power assisting and bearing witness with man's imperfect faculty of trust and of obedience. ${ }^{3}$ So complete was this penetration in Paul's view that he considered it as bringing a full and true life for the first time within the reach of men. ${ }^{4}$ In this

1 Rom. vi. 22 . Cf. 1 Cor. vii. 22 f. ; 2 Cor. v. 14 f.

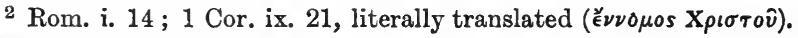

3 Rom. viii. 6-10, 16, 26.

${ }^{4}$ Cf. Gal. ii. 20 ; 1 Cor. xv. 10 . Yet these passages must not be taken as implying that the human will is entirely merged in a higher influence or that all effort on man's part becomes needless. That Paul believed none the less in the continued importance of the human factor in the good life is shown by the passages in which he speaks of himself 
way alone could man realise the true possibilities of his nature, the true meaning of his vocation. And so the thought of Paul brings us very close to the philosophical idea of the Law of Goodness as being no foreign law but the essential truth of man's nature. Both are interpretations of a single experience, the experience which alone enables us to understand how the change from a life controlled by natural impulse to a life in which moral ends exercise a supreme attractive and constraining power should prove a true emancipation. Only if the Christian Law is vitally related to the reality in which our nature is rooted, and hence to the deepest needs of that nature, can subjection to it mean true freedom.

Thus we see how all that is essential in the Kantian doctrine of Autonomy (as in the case of the two criteria, Purity and Universality, already discussed) is conserved and deepened in Christian Ethics. It is true that the Christian view does not meet the exact requirements of Kant's own theory, for his external view of the relation of God and man caused him to include even the divine command under the idea of Heteronomy, and to contend that the Moral Law must issue from man's legislative reason, and from it alone. But, when this external view of the Deity as a mere dispenser of reward or punishment is abandoned for one which, instead of setting a chasm between God and Conscience, teaches that the

as the bondservant of Christ (Rom. i. 1 ; Gal. i. 10), or of the danger of "quenching" or "grieving the Spirit" (Eph. iv. 30; 1 Thess. v. 19). So Ritschl says that "to think of the Holy Spirit, in this connection, as a resistless natural force is absolutely forbidden; for freedom over the world, under all circumstances, must be learned, acquired, fought for." (Justification and Reconciliation, tr. Mackintosh and Macaulay, p. 534.) 
divine voice is to be recognised most of all in the prompting to what is good, it at once becomes clear that the two essential elements in the idea of Autonomy are most fully safeguarded in the Christian view. For, as we have seen, the purity of moral motive is conserved, nor does the hope of reward detract from the complete disinterestedness of Christian virtue; and at the same time the higher Law comes to man, not as a statute imposed from without, but as the constraining power of a supreme example and supreme moral ends, which are indeed objective in that they extend above and beyond his finite efforts, but which claim his free allegiance and appeal to his own deepest aspirations. ${ }^{1}$

Such then is the Christian doctrine of Autonomy, through which the externality, and hence the limited power, of statutory law is overcome; while the sway of the higher Law, which is also Freedom, is extended over the whole man. This, along with the twin principle of Universality, is the full expression of the ideal which Jeremiah held up in one of the noblest and most penetrating utterances in all ancient religious thought. "This is the covenant that I will make with the house of Israel after those days, saith the Lord; I will put my law in their inward parts, and in their heart will I write it; and I will be their God, and they shall be my people: and they shall teach no more every man his neighbour, and every man his brother, saying, Know the Lord: for they shall all know me, from the least of them unto the greatest of them, saith the Lord." 2 This is the state of

${ }^{1}$ Cf. Ritschl, op. cit., pp. 510, 516, 526. "Even Divine authority does not imply the heteronomous character of the Christian moral law, for it lacks the statutory quality on which that character depends, and excludes all egoistical regard for purely individual pleasure or reward."

${ }^{2}$ Jer. xxxi. $33 \mathrm{f}$. 
liberty which Dante represented as being attained at the summit of the Mount of Purification, by those who had ascended through all its circles. Before Vergil bids farewell to Dante, he addresses him in these words, "Await no more my word or my sign; free, right, and sound is thine own judgment, and it were a fault not to act according to its thought; wherefore thee over thyself I crown and mitre." 1

This perfect Freedom, which springs from the entire accord of the individual will with the supreme and universal Law, stands as the ideal; but the approach to it can only be made by continued endeavour. Luther's teaching that true goodness is the effortless and inevitable fruit of true faith, is a right and beautiful characterisation of the ideal; but while it is still afar off, while lower desires and impulses still remain in part unsubdued, the strain and effort which accompany the active exercise of will must continue. ${ }^{2}$ Thus in regard to Freedom, as in regard to other aspects of the Christian Good, we must finally recognise a certain dualitythe familiar duality of gift and task. That which is in one sense given at first in all its completeness, has in another sense to be taken possession of in increasing measure, and to be followed out step by step. The Christian Law has a dynamical as opposed to a merely statutory character, and yet it remains an ideal. For Christian Ethics, morality no longer appears as the attempt to fulfil the letter of a strictly

1 Purg. xxvii. fin. (tr. Butler). The line, "Libero, dritto e sano è tuo arbitrio," is especially noteworthy. In an earlier Canto (xvi. 71) the same phrase "libero arbitrio" is also used, but in the other sense, that of "freewill," which I referred to in Chap. X. (Cf. p. 267 n.)

2 Cf. Herrmann's criticism of Luther's view in The Communion of the Christian with God (2nd Eng. ed.), pp. 312, 323. 
defined law; but the obligation remains and must remain, to use every human power in the effort to approach the ideal, and to extend the sway of the Christian Law.

We have thus considered the Christian conception of Law as personal, as universal in that it makes an individual appeal to every man according to his capacity and need, and as positive or dynamical; and these are the marks which Jowett once attributed to the Moral Law in its perfect and ideal expression. "The philosopher or theologian who could realise to mankind that a person is a law, that the higher rule has no exception, that goodness, like knowledge, is also power, would breathe a new religious life into the world." 1 But was not this lesson taught and learned more than eighteen centuries ago? And has it not, as often as it has been learned afresh, breathed a new religious life into the world?

\section{IV.}

Before this chapter concludes, it may be well to pass in brief review the results of the last five chapters. They have dealt with different categories and different aspects of the moral problem; but they have had this in common, that in all of them we have seen a transformation or sublimation of the familiar thoughts of ordinary ethical reflection, as morality is driven by an inner necessity to seek completion, and turns in this search more and more in the direction of religion. We have seen the clearly defined and articulated ideas which belong to the legal type of ethical thought one after

I Introduction to Plato's Politicus. 
another subjected to an immanent criticism, by which they are not indeed annihilated, but are certainly changed into less sharp and definite forms. Thus the idea of an external recompense as the motive of virtue has passed into that of a reward essentially akin to the action by which it is gained-the opportunity to press on to higher levels of character and service, and to share in the progress of a Kingdom whose very essence lies in the activity of goodness. So also the idea of an order, in which continuity is the ruling principle and legal retribution the great ethical instrument, an order whose end is attained when every act is followed by its fitting reward or punishment, no longer claims to be dominant or final. It is not rejected; but it is given a subordinate place, and above it there is seen a higher order, in which the failures of life are made the occasion of new beginnings, and the failures of retributive justice become the means through which redemption is achieved. Again, the idea of duty, as connoting a strict but limited obligation, has been enlarged into the call to pursue an infinite ideal. Finally, the idea of merit, which is based upon that of duty, has more and more fallen into the background; both because the exaltation of the final goal makes self-complacency impossible, and because the free and spontaneous character of the higher goodness transcends the old absolute antithesis between duty and inclination.

Thus the whole system in which the ideas of legal obligation, merit, and recompense naturally fall into place has been radically modified. But we have seen other ideas and other analogies take their place. The determining relation in Christian Ethics is not to be typified as that of judge and defendant, but rather as 
that of king and free citizen, or, better still, as that of father and child. Now it cannot be denied that this modification of old categories-this transition from a legal to a teleological mode of thought-penetrates very deep; and it may be argued that in its progress much of the precision of the familiar ethics of duty and merit has been lost. The conceptions of free service entered upon for the love of goodness itself, and of a moral ideal which is dynamical as well as statutory, may be grander and more far-reaching; but it may be questioned whether they adequately take the place of the more exact conceptions which they have superseded? Is not the old distinction between right and wrong, on whose inviolateness the whole fabric of moral thought depends, in danger of dissolution in the exalted but misty region of religious feeling, in which enthusiasm replaces conscience? Have we not passed out of the ethical sphere into another sphere-perhaps higher, but no longer the home of the clear distinctions of the moral life? If these be the categories appropriate to Christian Ethics, does not this familiar name, Christian Ethics, conceal something of a contradiction in terms?

The question is an old one. It is indeed our previous question, whether there is any longer a Christian Law in the true sense, expressed in more general terms. And as an answer has already been attempted in this chapter to the latter question, a further reply may perhaps seem needless. Yet it may be possible to throw some light on the wider question from a somewhat different point of view. Now, we have already seen that the Christian life is indeed free from the old constraints, but that it is sulject to a new guidance, 
not less effective that it is teleological rather than legal; that it looks to an end to be attained rather than to a code to be observed. The question whether the Christian life has therefore transcended the ethical or moral sphere depends for its answer largely on how that sphere is delimited. But though it thus resolves itself into a question of definition, and of the precise use of the terms "ethical" and "moral," it cannot be dismissed as unimportant. For if these terms be defined in a strictly limited way, the inference may be drawn that the Christian ideal of conduct is "superior to" ordinary moral distinctions; and, in popular thought at least, this inference may lead to serious misconception. ${ }^{1}$

If, then, the standpoint of ethics be defined as that of legal obligation, merit, retribution, and the ideas which harmonise with and naturally accompany these, it is indeed true that Christian virtue refuses to be confined within these terms, and requires an ampler and freer expression. The specifically ethical or moral standpoint has in fact been so defined, and the more rigid statements of Kant may be quoted as an authority for so doing. ${ }^{2}$ But when we consider this definition closely, we find that it is almost wholly a formal one. It elucidates the form of the moral life, and that not in its whole course but at a particular level of experience. But if the content of the moral

1 Nietzsche puts the point with his usual crude effectiveness in one of his aphorisms : "Jesus said to his Jews, "The law was for servants ;-love God as I love him, as his Son! What have we Sons of God to do with morals !" (Beyond Good and Evil, tr. H. Zimmern, p. 99).

2 As when he speaks of the perfect will of the Divine Being as holy, but not moral (Kritik der Prakt. Vernunft, V. 82). Cf. Grundlegung, IV. 439 (tr. Abbott, pp. 174 f., 58). 
life be made the basis of our definition, then the result is wholly different. We then ask what type of character and what order of society the whole legal order was designed to produce, and our answer must be given in the very terms which are the natural expression of Christian thought in its highest reaches. If we apply the adjectives "ethical" and "moral" primarily to the character of the good man and the structure of the good society, rather than to the discipline by which they are led towards goodness, then the Christian conception of both is moral and ethical through and through. Estimated by the legal or formal criterion, Christian Ethics may be held to have transcended "morality," 1 but in the light of the teleological criterion-the test of aim and content -it remains ethical and moral in its very highest development.

There are two ways in which an opposition may be overcome in thought as in life. The opposing elements may be taken up into a higher unity to which each brings its own contribution, and which is determined to an approximately equal extent by both its constituents. Or the opposition may be resolved when one of these becomes dominant, and vanquishes and negates the other; and in this case it is the element which persists and overcomes that determines the character of the final result. Now the transcending of the opposition of good and evil in the religious, and particularly in the Christian, experience may be interpreted in either of these ways. It may be under-

1 It is unfortunate that in English we have no terms rendering concisely the distinction expressed in German by Moralität and Sittlichkeit. 
stood either as the sublation of both into a higher unity, in which the opposition is overcome, but both must be thought of as in some sense persisting. Or it may be understood as the overcoming of the opposition through the destruction of the element of evil and the victory of the good. In the first case, the religious synthesis would indeed be supra-moral or non-moral in its character; but unless our argument has wholly missed the mark, this is an entire misunderstanding, and the only true interpretation is the latter, in which the moral character of the final result most clearly appears.

Nor, when we pass from the region of legal morality into that of fully developed Christian virtue, do we find that moral distinctions have lost their meaning, or that the claims of the Good are less urgent or paramount than before. The new life of freedom is not one in which the desires of the morally good man and the morally bad are alike transformed and satisfied. It is reached by the conquest of the lower self through the new access of power that comes to the higher. The form of the Moral Law may be modified or even abolished, but this is in order that its content may be realised. The method is altered, but the end aimed at, and now for the first time attained, remains the same. ${ }^{1}$

This is essentially the Pauline reply to the charge of antinomianism. "The Law" as known to earlier ages, the law of definite commandments, and even the deeper Law speaking from the conscience of Jew and Gentile alike, had failed to achieve its purpose. Its end was the production of goodness or righteousness.

${ }^{1}$ Cf. Forrest, The Christ of History and of Experience, pp. $444 \mathrm{f}$. 
But the end was not discredited by the failure of the means, nor was the sanctity of the Law itself impaired; it had proved ineffective, and so was ready to be superseded and "to vanish away," and another method was already taking its place. ${ }^{1}$ Still the end was the same, and it could now be reached by a sure and straight path. For the great discovery of Paul was that the inmost principle of the Law might enter into man's heart and rule his life, no longer as a condemning but as an inspiring principle; and that that inward disposition, which the Law had tried and failed to produce, might be attained in a new and more effective way by the kindling of an ardent emotion. And in this result the whole long discipline of the moral history of the world found its justification. The rule of $\mathrm{Law}$ as a preparatory training, and its final supersession, were alike seen to have been needful and right, when "the requirement of the law" was really and visibly fulfilled in the freedom and love in which Christians lived.2 But they were able so to live only in as far as they were controlled and inspired, not by "the law of a carnal commandment," but by "the power of an endless life." 3 In this change the form of morality had indeed been transmuted, but not its essence or its truth; for the legal order had been left behind only that its unattained promise might be brought to fruition in the freedom of the Spiritual Order.

1 Rom. vii. 12-16. Cf. the Pauline passages in Heb. vii. 18 f. : "For there is a disannulling of a foregoing commandment because of its weakness and unprofitableness (for the law made nothing perfect), and a bringing in thereupon of a better hope, through which we draw nigh unto God."

2 Rom. viii. 4 (R.V. marg.) Cf. Gal. iii. 24 f. 3 Heb. vii. 16. 


\section{CHAPTER XIII.}

THE NATURAL AND THE SPIRITUAL ORDER.

I.

Ar the close of the last chapter we reached the idea of a Spiritual Order, which is ethical in the fullest sense in that it takes up into itself and consummates those ends to which the long struggle and labour of the Moral Order were directed; but which transcends the merely ethical, because in it the legal categories of obligation, merit and recompense, fall into the background, and the higher categories of freedom and spontaneous service take their place. There are thus three distinguishable stages in the moral life - the natural, the ethical (in the narrow sense), and the spiritual. They do not, it is true, exist in hard isolation in actual experience, whether in history or in the individual life. In the concrete development of mankind they are not marked off from one another by definite lines which, once crossed, are never recrossed. Rather the lower passes into the higher by many fine shadings and hardly perceptible gradations. But for the purposes of moral philosophy it is none the less useful to draw certain broad distinctions between them, 
so that the specific character of each may be more clearly seen.

In the last five chapters the distinction between the two higher stages in the life and thought of mankind has been treated from several points of view. But it may help to define and emphasise the conception of a Spiritual Order which we have now reached, if we consider the broader contrast between the extreme terms of the series, the spheres which Paul more than once contrasted as natural ( $\Psi v \chi \iota \kappa o ́ v)$ and spiritual $(\pi \nu \epsilon v \mu a \tau \iota \kappa o ́ \nu) ;{ }^{1}$ and we may reasonably do so, because in his view the merely ethical (the dispensation of "law") was but a transitional stage, incomplete in itself, but pointing towards and preparing the way for a higher order of life and liberty. This wider comparison will also enable us to gather up and bring into focus the results of our whole discussion of the ideas on which the structure of Christian morality is founded.

For the concept of a Spiritual Order is that under which these various aspects may best be included and summarised, as it is also the best fitted to bring out the parallelism between them and certain of the deeper ideas of moral philosophy. It is true that other ideas might be taken which would give the contrast a different form. Thus the Pauline antithesis between " the law of the spirit of life" and "the law of sin and death" 2 might be taken as fundamental; or we might return to the idea of the Kingdom of God, and set over against it, with Schleiermacher and Ritschl, the opposing idea of a "Kingdom of Sin." 3 But both these conceptions, of two

11 Cor. ii. 14 f., xv. $44 \mathrm{ff}$.

2 Rom. viii. 2.

3 This antithesis is not, it need hardly be pointed out, modern in its origin, but is native to the apocalyptic form of thought. (E.g., Rev. 
laws and two kingdoms, fall naturally under the conception of two orders within which man may find his place and exercise his activity. For if there is a double law in life, then it is natural to consider both the higher and the lower law as the law of a kingdom or an order of life; and the close relationship in which all three ideas are linked together is suggested by the words of Hort which Dr Sanday takes as the best definition known to him of the "Kingdom of God"- "the world of invisible laws by which God is ruling and blessing His creatures." 1 This description applies more aptly and naturally to a Spiritual Order, underlying, supporting, and finally permeating, the Natural Order, than even to the Kingdom of God. But the two conceptions are in the last analysis but a more and a less personal way of embodying the same truth; and whichever we adopt, we must consider it in a double aspect, as the deepest and most permanent Reality, and yet as gradually and painfully realised through the travail of history and the long contest of good with evil in the arena of our human experience. This idea of a higher and a lower order, to both of

xi. 15, xvii. $9 \mathrm{ff}$.) Nor is the idea of the Kingdom of God as opposed to

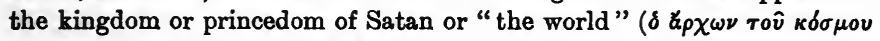
тoúrov, John xii. 31 . Cf. Mark iii. 22 ff. ; Luke iv. 6 ; John xiv. 30 ; Eph. ii. 2, vi. 12 ; Col. i. 13 ; 1 John iv. 4) confined to the definitely eschatological parts of the New Testament.

1 Art. "Jesus Christ" in Hastings' Dict. of the Bible, ii. 619. This definition is curiously like the answer in the Shorter Catechism, which defines the "works of providence" as "God's most holy, wise, and powerful preserving and governing all his creatures and all their actions." Considered as a definition of the Kingdom, it might be criticised as emphasising the element of continuous divine action too much at the expense of that of conflict, and of the opposition between good and evil. 
which man belongs and which dispute the controlling place in his life, has had a large place in the history of philosophy. Philosophers, no less than religious teachers, may be divided into two great classes according as they lay greater emphasis on the continuity or on the difference between the two. Those who follow the genetic method and give a leading place to the idea of evolution, naturally fall into the first class. Hence, though we may find the contrast between the two orders expressed with considerable emphasis by Aristotle and Hegel, it is rather in the thought of Plato and Kant that it appears most strikingly and clearly. We may perhaps express the most salient forms of the contrast if we consider the higher or Spiritual Order from three different points of view, as-

(1) The Real or True, as opposed to the Apparent;

(2) The Permanent, as opposed to the Transient;

(3) The Order of Concord and Unselfishness, as opposed to that of Discord and Self-seeking.

At different stages in the history of thought, these aspects appear in various degrees of prominence. In Plato all three are present. In the period of his philosophy represented by the Republic and the Phoedo, the two former ideas stand in the forefront, and are stated in the closest connection. The world of Forms or Ideas is both the Real (the object of true knowledge) and the Eternal; nay, its reality is proved by its eternal character and its complete elevation above the changing world of appearance which presses in on man through his sense-experience. But, as we have seen, Plato also defines its ethical manifestation-the perfect 
city of the Republic - as the form of society in which self-interest is forgotten, and the perfect harmony of those who live in and for a Common Good is realised. ${ }^{1}$ In Spinoza the same ideas meet us again, although their statement and interrelation are different. He teaches that the most real object of thought (the unica substantia) is also the eternal; and that when we advance to "the third kind of knowledge"-that of direct intuition and the "intellectual love of God"-we may boldly claim an assured experience of eternal lifescimus et experimur nos ceternos esse. ${ }^{2}$ But once more this life is the life of harmony, from which selfish desires have disappeared, and which all who attain to it enjoy in common as the highest good. In the thought of Kant the opposition appears as that of the "noumenal" and "phenomenal" worlds. He too identifies the intelligible world with the permanent reality behind the flux of sense-experience, and teaches that, in so far as man acts as a member of that world, he gains an assurance of God, Freedom, and Immortality, and finds himself associated with all good men in the service of the "Kingdom of Ends" in which all private and selfish interests are for ever abolished.

Thus these three great thinkers, amid all other differences, unite in teaching that in the upward progress of the human soul it passes from the apparent to the Real, and comes more and more closely into touch with the deeper truth of the universe which does not change or pass away. In Plato's words, "having

1 For the third element in Plato, Spinoza, and Kant, vide supra, pp, $112 \mathrm{f} ., 130 \mathrm{f}$.

2 Ethics, V. xxiii., Schol. xxv. ff. ; and compare the definition of the three kinds of knowledge, II. xl., Schol. II. (or four kinds in the Tract. de Int. Emend.) with Plato's fourfold division, Rep., $509 \mathrm{ff}$. 
communion with the unchanging, it is itself unchanging." 1 Further they agree in representing this higher life, the true life of the human spirit, as overcoming the differences and the conflicting interests of the lower sphere, and thus consisting in a common activity in the service and enjoyment of the Good.

Other phases of thought might be referred to, in which the idea of a higher and a lower order is prominent, but in which one or two only of these three characteristics are attributed to it; but it will be enough to cite one example, the evolutionary ethics of the Nineteenth Century. Here the idea of an ultimate and unchanging truth in the knowledge of which man may find eternal life has completely vanished. But while the positivist or agnostic philosopher can find no place for the first two criteria he still lays stress on the third. Thus in the ethics of evolution the opposition of Egoism and Altruism continues to be emphasised, and thus a kinship of ethical interest is found between evolutionary and Christian Ethics. One at least of the leaders of this school seemed to cling more tenaciously than ever to the third criterion of the higher life, because he could no longer hold by the two former; and the opposition between the lower life of self-seeking and the higher life of self-sacrifice has never received a sharper, and seldom a more stirring, expression than in that passage in his Romanes Lecture in which Huxley contrasts the "cosmic" and the "ethical" processes. ${ }^{2}$

Now we are not called upon to decide whether the thinkers who thus emphasise the disparateness of the lower and the higher life, or those who lay stress on

1 Phodo, $79 \mathrm{D}$.

2 Evolution and Ethics, ad fin. 
their continuity, have the larger share of truth on their side. We may admit that in the systems we have referred to-certainly in that of Kant-the opposition is stated in too rigorous a form; and that, if the two spheres were indeed so strictly separated, there could be little hope of passing from the lower to the higher, nor could man's experience embrace them both as it actually does. And yet, although both elements, the animal and the spiritual, the permanent and the changing, the selfish and the unselfish-name and distinguish them how we will-mingle so strangely in our complex human nature, none the less, but rather the more, are we forced to distinguish between them and give our final allegiance to one or the other. It is the very involution, and at the same time the incompatibility, of these rival principles that give human life its character of conflict and often of tragedy. Thus while we are forced to admit, with those thinkers who lay the chief stress on continuity, that the higher and lower aspects of our being are intimately related and interwoven, we are none the less forced by the very conflict and division of human life to recognise the presence of two opposing orders, according to one or other of which man must guide his life. It is not needful that we should accept the Platonic or the Kantian statement of this contrast in a literal way : it is enough that we have this testimony from the great thinkers of very different ages to the fact that it does indeed run through our life, and that they show a notable agreement regarding the chief forms in which it becomes apparent. So we may once more turn to the teaching of the New Testament, to inquire how far the same contrasted aspects are to be found there. 


\section{II.}

It is natural that in the circle of thought, practical rather than philosophic, within which the writers of the New Testament move, the first form of the opposition, that of the Real and the Apparent, should find less full expression than the other two; $;^{1}$ and so we may leave the discussion of this question to the close of this chapter. But some further discussion is needful regarding the second form, and its relation to the third. Here the contrast between the Permanent and the Transient appears as that between the eternal life and the changeful character of our present temporal experience.

Now, at the two points at which we have been brought into contact with the idea of immortality, it has appeared chiefly as a postulate of the moral life. If completeness of character is ever to be attained and the Christian ideal of virtue to be realised in its many-sided development; if the moral gains of this life are to be conserved and the moral processes begun here are to be carried forward to the fashioning of a perfect humanity, - then the moral and spiritual life must go forward into the unknown, and its consummation must be reached beyond the grave. Thus the belief in immortality may

1 Of certain parts of the New Testament, the later epistles of Paul and the Johannine writings, this statement could only be made with some qualification. Cf. Col. i. $15 \mathrm{ff}$. John i. 1-9; 1 John v. 20 . In John xvii. 3, the thoughts of the True and the Eternal (the two first of our predicates) are linked as closely as by any philosopher- "This is life eternal, that they should know thee the only true God." Nor was the contrast between Jahveh as the True and Abiding, and the passing world with its transient and hollow deities, unfamiliar in the Old Testamente.g., Ps. xcri. 5, cii. 25 ff. ; Is. xl. 18 ff. ; Jer. x. 10 ff. 
originate in a demand or postulate, apart from which the ethical experience of life would remain unsatisfying and incomplete. And in this form the thought appears even in the Old Testament, especially in the words of the Sixteenth Psalm, "Thou wilt not leave my soul to Sheol; neither wilt thou suffer thine holy one to see corruption." 1

But there is another and more characteristic aspect of the Biblical conception of immortality. If it is a demand of the good man (or in our modern language, a postulate of the moral consciousness), it is never a mere demand; for it rises out of, and is supported by, the sense that his present ethical and religious experience has an aspect that transcends time, that it already shows a certain eternal quality. If the thought of the psalm just quoted be considered closely, it will be seen how directly the confidence of the closing verses is connected with the psalmist's experience of the divine goodness in his present life. So it is in the New Testament also, as in the words which occur in the First Epistle of John, "We know that we have passed out of death into life, because we love the brethren. He that loveth not abideth in death." 2 The first of these sentences expresses clearly the Johannine idea that "life"-the "æonian life" of the Christianis not only to be looked for in the future or argued towards from present experience, but that it is to be experienced and recoguised here and now. Nay more, the sign by which it is to be recognised is the third criterion of the Spiritual Order, the enlarged and harmonious life of brotherhood and service.

1 Ps. xvi. 10.

2 iii. 14. Cf. ii. 17 ; 1 Peter i. 22 ff. 
But a further step remains. For this saying, if it stood alone, might be interpreted as a vivid metaphorical statement of the idea of "corporate immortality." It might be taken in the sense of George Eliot's lines-

" $O$ may $I$ join the choir invisible

Of those immortal dead who live again

In minds made better by their presence." 1

There is a true greatness in this thought, that every man who breaks the bonds of his own narrow life, and merges his effort in the upward striving of mankind, is enabled to escape in a very real sense from the limitations of his own mortality. He feels that his influence will not die, and that, when his personal share in the strife is over, others will inherit his spirit and carry on his work; so that in faith and imagination he can share the joy of the attainment of those ends for which he is working, but whose consummation he as an individual will never see. ${ }^{2}$ But while this sense of united struggle and corporate victory is present in the New Testament, it is not all. There is also a more personal note, nor is the workman separated from his work. ${ }^{3}$ The belief in immortality is based on that fact that even the individual life, when lived in the Spiritual Order, is increasingly felt to rise above the fatal correlation of dissolution with develop-

1 Cf. Swinburne's splendid stanzas in Super Flumina Babylonis (Songs before Sunrise), beginning :-

"Whoso bears the whole heaviness of the wronged world's weight And puts it by,

It is well with him suffering, though he face man's fate; How should he die?"

2 This might be described as a nobler form of the idea of "the immortality of Fame," and to it we might apply Horace's ringing words, "Non omnis moriar, multaque pars mei vitabit Libitinam" (Odes, III. $\mathbf{x x x}$.).

${ }^{3}$ Cf. 1 Cor. iii. 10.14 with Rev. xiv. 13. 
ment, of decay with growth. So Paul finds in the present experience of Christian freedom, incomplete and rudimentary though it is, the ground for the sure hope of a complete and final escape from "the bondage of the corruption," and the "subjection to vanity" which casts a shadow over the life of earth. ${ }^{1}$

It may help to make this clear, if we return to the thought that the experience of new beginnings and of the escape from thraldom to the past is one characteristic of the Spiritual Order. The great Prophet of the Exile in one of his grandest passages joined these two ideas very closely; for he took the fact that pardon and a new beginning in the life of goodness are open to every man who will "forsake his way" of unrighteousness and "return unto the Lord," as witnessing the truth of the great declaration: "As the heavens are higher than the earth, so are my ways higher than your ways, and my thoughts than your thoughts." The prophet goes on to speak of the fertilising office of the rain from heaven, and concludes, "So shall my word be that goeth forth out of my mouth: it shall not return unto me void, but it shall accomplish that which I please, and it shall prosper in the thing whereto I sent it." 2 Here the analogy used by the prophet, like Paul's metaphor of the resurrection of the dead seed, ${ }^{3}$ breaks down when tested in the dry light of modern knowledge; for we know that the "rain and the snow from heaven" do "return thither again," and that they are involved in that very movement of cyclical and unprogressive change which the prophet was concerned to deny in regard to the spiritual life. But, if we do not try to press the metaphor too

1 Rom. viii. 19-23. 2 Is. lv. 6-11. Cf. Ps. ciii. 8-12. 31 Cor. xv. 36. 
stringently, it remains a true and memorable illustration of his meaning. The earth has drawn from the rain and sunshine a fertilising influence, renewed with every returning season, which is not less now than in those dim ages when man first gathered in her fruits; and by this experience man has been led on to the belief that the working of God in his own heart witnesses to an exhaustless source of spiritual energy, through which he may rise above the universal decay of Nature and escape the growing degradation which the stern law of justice ordains for the sinner, and so may enter upon a life whose strength fails not because it is ever reinforced by a power from above. Thus the aphorism of Heraclitus, "The way up and the way down are one and the same," which holds true of all the processes of Nature, is seen to have no validity in this higher sphere.

In a fine passage the late Dr Hort expressed the same thought:- "The spontaneous uncultured joy of spring or of youth is short lived. It dies out with the mere lapse of time. In men it is liable to be prematurely choked with labours and cares. But he whose heart has learned to make answer to the Lord comes to find that the power of life and joy lives on with him while outward things are taking their course of obstruction or decay. He has a life exempt from being dried up, for it flows not from within himself or from any part of the perishable creation but from an ever living fountain in the heavens." 1 This is essentially the experience described by the psalmist

1 The Way, the Truth, the Life, p. 99. (On "With Thee is the fountain of life," Ps. xxxvi. 9.) Cf. Ps. xcii. 14, and the contrast in John iv. $13 \mathrm{f}$. To the same effect is Hegel's saying, "The Old Age of Nature is weakness; but that of Spirit is its perfect maturity and strength." (Phil. of Hist., tr. Sibree, p. 114.) 
in the words, "Who redeemeth thy life from destruction; Who satisfieth thy mouth with good things; so that thy youth is renewed like the eagle." 1 Here also this experience is very clearly based upon that of the divine forgiveness and healing mentioned in the previous verse; for it is only through the latter that this constant renewal of the energy of the spirit becomes possible. Finally, before leaving the thought of the Old Testament on this subject, the conclusion of Isaiah xl. must also be cited: "Even the youths shall faint and be weary and the young men shall utterly fall: but they that wait upon the Lord shall renew their strength; they shall mount up with wings as eagles; they shall run, and not be weary; they shall walk, and not faint." 2

Now, in all these passages we find clearly the idea of two orders of life. In the lower the law prevails without exception that growth is followed by decay, and toil by exhaustion; but in the higher a continuous energy is to be found, and a progress which does not halt or return upon its path. And when it is seen that character does not share in the pause and the decline which come to the physical, and even in a measure to the intellectual, powers of man as he passes the prime of life and approaches its close, then that fact gives a basis in actual experience to the faith in immortality which otherwise might remain an aspiration or a postulate only. When we come to the New Testament, we find a very striking expression of this thought in the words of Paul, "Wherefore we faint not; but though our outward man is decaying, yet our inward man is renewed day by day . . .; while we look not at the things which are seen, but at the things which are not seen: for the things which are

1 Ps. ciii. 4 f.

2 Is. $x 1.30 \mathrm{f}$. 
seen are temporal; but the things which are not seen are eternal." 1 In this passage Paul, like the great philosophical idealists, divides the objects of our experience into two classes, of which one has the character of decay and instability, but the other is abiding and most real, although unseen. But there is a difference; for while Plato might have written the concluding words of this passage, he could hardly have written the earlier. His idea of the eternal world, in the contemplation of which man may find his highest good, was a statical one, whereas Paul found in the thought of it a most powerful dynamic, giving a constantly renewed and ever-growing energy for the conflict of the present life.

Thus the two realms are closely related, and the eternal life is thought of, not as standing apart and unmoved in its timeless perfection, but as providing a present source of power, and as evidenced by the exemption of the Christian life from that slackening of interest and failure of vitality which in the end overtake the natural life in all its forms. This power is traced, in the Epistles both of Paul and of John, to the fact that in it the individual is lifted out of his solitary and self-centred existence into a wider life of boundless richness and energy. For love is the one thing which endures through all shocks of time, and survives all the corrosive and wearing influences of earthly change. ${ }^{2}$ Thus the idea of immortality as it is found in the New Testament is neither statical in nature, nor confined wholly to the future; nor is it purely individual or contemplative. It is rather claimed that in the Christian experience there is manifested the first working of a limitless energy, "the power of an

12 Cor. iv. 16-18. Cf. 8-11.

21 Cor. xiii. 8. 
endless life." 1 And hence springs the sense of security which marks this experience; for it is intimately connected with the belief that in the goods of the spiritual life, and most of all in character, there is a permanence to which the terms of ordinary experience can give at best but a negative expression, since its positive character belongs essentially to the Spiritual Order. "Make for yourselves purses which wax not old, a treasure in the heavens that faileth not, where no thief draweth near, neither moth destroyeth." 2

\section{III.}

From the permanence of life in the Spiritual Order we pass readily to a consideration of its third characteristic; for we have already seen that it is enduring largely because it is unselfish, or rather because it belongs to a level of experience at which the distinction between selfishness and self-sacrifice disappears for those who follow a Common Good. We have already discussed this conception so fully in Chapters IV. and V. that it is needless to repeat what was there said; and we may assume the main results of that discussion. These results were that, as man advances from lower to higher levels of life, the clash of interests

1 Heb. vii. 16. Cf. John xiv. 19 ; Rom. vi. 4 ff. Modern thought naturally distinguishes two forms of the lower law-a natural law of desay and an ethical law of retribution. But for the writers of the New Testament there was but one lower law or power, opposed to, and finally to be conquered by, the Christian power of life and righteousness. This point of view especially conditions Paul's thought in Rom. จ. (e.g., v. 21).

${ }^{2}$ Luke xii. 33. (Matt. vi. 19-21.) Cf. Col. iii. 2 ; 2 Tim. i. 12. 
gives way more and more to a community of interest, and the effort to gain the material good things of the world at the expense of others who also seek them, is transformed into the pursuit of a Good which can only be won and enjoyed in common. Thus if the lower order is that of rivalry and competition, the higher is that of harmony and the subordination of private desires to the wellbeing of the whole; and if the latter condition is but seldom perfectly realised in our present experience, none the less it has an unshakeable validity as an ideal, as the Law of the Spiritual Order.

But it still remains to consider the active character of the unselfish life, as the means by which its sway is extended in the actual world. In other words, we may ask what are the weapons of the Kingdom; and an answer on the negative side is at once found in the words of Paul, "Though we walk in the flesh, we do not war according to the flesh (for the weapons of our warfare are not of the flesh, but mighty before God to the casting down of strongholds)." 1 Paul thus thinks of the Christian as still living his outward life amid all the circumstances and impediments of the natural worldorder, and as engaged in a conflict which may be described in terms borrowed from the conflicts of the world. Yet the conflict is essentially different, for it is fought with other weapons than those of "the flesh." The nature of these other weapons may be gathered from the preceding appeal to the "meekness and gentleness of Christ," ${ }^{2}$ or from the words used by Paul at an earlier time, "Being reviled, we bless; being persecuted, we endure; being defamed, we intreat"; or from his counsel to the Roman Christians to meet injury by kindness and 
forgiveness, with its final exhortation, "Be not overcome of evil, but overcome evil with good." 1 The whole armoury of the natural man was to be set aside, and the methods of strife and personal rivalry, whether the strife of the sword or the tongue, were to be entirely discarded and never resumed; while the Christian was to fight his battles apparently undefended, but armed in reality with those weapons which Paul believed to be the most powerful of all-faith, patient endurance, forgiveness, and the readiness to spend and be spent in the service of others. ${ }^{2}$

Now all this is simply a reassertion of the great lesson of the life of Jesus - the lesson not only of His teaching, but of those qualities in His character to which Paul makes his moving appeal. The story of the Temptation, which stands in the foreground of the picture of Jesus' life in the First and Third Gospels, gives a key to the interpretation of His whole career; for it expresses in figurative form His entire and consistent rejection of those outward means of success, those material roads to a spiritual goal, which all save the greatest souls are often tempted to use or to follow. ${ }^{3}$ Thus also the passages in the Sermon on the Mount which laid down forgiveness of injuries and the love of enemies as the basal principles of Christian conduct, and those words in which Jesus spoke of service and not self-assertion as its supreme standard, ${ }^{4}$ implied the very belief afterwards

11 Cor. iv. 12 f. ; Rom. xii. 19-21. Cf. 1 Thess. v. 15.

${ }^{2}$ Cf. Eph. vi. $10 \mathrm{ff}$.

3 Matt. iv. 4-10. Cf. Ecce Homo, Ch. II. ; and, for the subject of the following paragraphs, Sanday's art. "Jesus Christ," in Hastings' Dictionary of the Bible, II. $621 \mathrm{f}$.

4 Matt. v. $38-48$; vi. 14 ; xviii. 21 f. ; Mark x. 42-45. 
developed by Paul that these were the true and effective weapons of warfare in the Spiritual Order. But for Paul, as for his fellow-apostles, the example of Jesus was a stronger foundation for this belief than even His sayings, and their faith in the power of sacrifice to overcome all the imposing forces of the world rested finally upon their knowledge of Him. ${ }^{1}$ Thus the whole teaching of the New Testament centres round the idea that life can be found only when it is willingly lost, and that the final victory lies with those forces which men commonly consider as of no account. ${ }^{2}$

But this at once suggests the question whether, if this doctrine is adopted at all, it must not be applied without exception or modification. The life-work of Tolstoi has driven home this question to the conscience of our own day; but it belongs not to one age alone, for it is one which every candid student of the New Testament must ask. If such be the methods of the Kingdom, is it at any time or for any purpose allowable for any member or members of it to call in the aid of force? Are not all its members in every age sent forth by the deliberate intention of their Master "as sheep in the midst of wolves," 3 and will they not inevitably fail of success if they attempt to combine the natural weapons of force with the spiritual weapons of forbearance? A full discussion of this great and pressing question cannot be attempted here; for it belongs rather to the application of Christian Ethics than to those ground

11 Peter ii. 15, 19 ff.; iii. $14 \mathrm{ff}$.

2 Mark viii. 35. Cf. 1 Cor. i. 27-29.

3 Matt. x. 16. 
principles with which we have been concerned, rather to its practical than to its speculative side. But one or two general considerations may be advanced.

First, as we saw in our introductory survey, Christian virtue is not wholly summed up in forgiveness and forbearance: there is in it a strain of moral rigour and stringency as well. And as our argument proceeded we also saw that Christian thought does not deny the claims of the outward life of man, but recognises its bearing on his spiritual welfare. Further, if the Christian ideal is to find its perfect expression in a fully formed society, then a material framework is needed within which that edifice may be built up. For the very existence of certain types of virtue-and especially of those which we know as the "social virtues"- requires a state of society in some degree ordered and settled. This is true both of internal and external affairs. So, in reference to the guarding of the internal order of the State, Paul commends the office of the magistrate, and argues that "he beareth not the sword in vain." 1 But this is still more true of external policy. For it is possible to imagine a community so thoroughly disciplined in the virtues of citizenship, and so penetrated by the Christian sense of the Common Good, that the need for penal law and its maintenance by force would no longer exist within it; but the need might still remain for external defence against an enemy who refused to recognise these standards or to respect the virtue with which they were applied, since otherwise the very existence of the non-resisting community

1 Rom. xiii. 4. 
would be endangered. ${ }^{1}$ It is hard to deny that more than once in the first ten centuries - particularly during the invasions of the Huns and the Saracensthe preservation of organised Christianity was won by the sword.

The answer to this problem-how the necessary use of force for the protection of the community within which the Church lives and works may be reconciled with the teaching and example of Jesus - may perhaps be found in the consideration that the deepest distinction lies not between the methods of force and of persuasion, but rather between the spirit of selfassertion and that which postpones all selfish considerations to the good of the whole. Nor is this a merely academic distinction. For it needs no argument to prove that a soldier, using the weapons of his special calling, may dismiss all thought of his own inclination and safety as completely as the noblest of martyrs; while, on the other hand, methods outwardly peaceful or even sacred may, in the rivalry of commerce or of ecclesiastical policy, be used with all the ruthlessness of the sword. And in this case it is surely the weapons of peace that must be described as "weapons of the flesh," because they are used in the spirit of bitterness and in the service of greed or faction. Thus the final test is inward. Not outward force, but

1 Tolstoi's answer to this difficulty-an impressive answer, if not a wholly convincing one-may be found in sect. xi. of Ivan the Fool. Plato, in the Gorgias (511 ff.), represents Callicles as pressing the same difficulty on Socrates as regards the individual, and arguing that the just man will finally be slain by the unjust; but Socrates, less optimistic than Tolstoi, falls back on the ultimate argument that, even if this be so, death is not the worst of evils, and that in the future life the wrongs of this world will be set right. 
inward malice, is the unfailing mark of the natural order in its contest with the Spiritual. "Whereas there is among you jealousy and strife, are ye not carnal, and walk after the manner of men?" 1

But while this is the ultimate distinction, to which all others must in the last resort be subordinated, yet it is also clear that reliance on material weapons tends very strongly to develop the spirit which uses force for its own sake and subordinates ideal to material ends. Seldom can the aggression which leads to war be justified by the canon of Aristotle, "We make war in order to have peace "; ${ }^{2}$ more seldom still by the teaching of the New Testament. In the other application of force also for the maintenance of the internal order of the State, it becomes more and more clear that there is inherent a grave defect. For, necessary as our systems of police and prison are, we are beginning to see that they fail in the most essential point as long as they fail to touch the heart and conscience of the wrong-doer, but rather harden him in crime. Thus, as they exist at present, they are not Christian in the full and positive sense-they do not show the distinguishing characteristics of the Spiritual Order. For in that distinctive activity both methods and results relate in the first instance to the inner nature of man; and its full fruit is only found where enmity and rivalry are overcome by the might of forbearing love. Perhaps no philosopher has so fully entered into this side of Christian thought as Spinoza, whose beautiful words may fitly be added here: "He

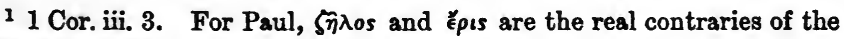

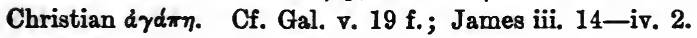

2 Eth. Nic., X. 1177 b 5. 
who chooses to avenge wrongs with hatred is assuredly wretched. But he who strives to conquer hatred with love, fights his battle in joy and confidence; he withstands many as easily as one, and has very little need of fortune's aid. Those whom he vanquishes yield joyfully, not through failure, but through increase in their powers." 1

Such a conquest, in which victor and vanquished are brought together into the true concord of moral unity, is the great aim of Christianity. Nay, it is the open secret of the teaching of Jesus. And even if the strong arm of force is at times needed to preserve that wider polity in which Christianity finds its sphere of action, yet in its own proper work the Church can never afford to fall back on a reliance upon force or fear or the power of wealth. All the deepest and most lasting ethical and religious work must be done by the means sanctioned and used by Jesus Himself. Thus even in the period of confusion and the rule of force, to which reference has already been made, the most real triumphs were won for Christianity, not by Leo the Emperor or Leo the Pope or Charles Martel, as they thrust back the tide of invasion from the walls of Constantinople or Rome or the plains of Touraine, but by those obscure missionaries of the Cross, who carried their message into the dim North, and won for the faith of Christ the races with whom lay the hope and promise of the future. And as often as the original impulse which came from Galilee has been renewed, men have been found brave enough to

1 Ethics, IV. slvi. Schol. (tr. Elwes). A little later (li. Schol.) he distinguishes the case in which force may rightly be used "by the sovereign power for the sake of preserving peace." 
lay aside the weapons of the world, and to rely on the power of service and of suffering freely borne for the sake of others. In such lives as these the nature and the potency of the Spiritual Order become fully manifest; and the love, which "suffereth long" and "beareth all things," is seen to have the right also to "hope all things." 1

IV.

But a further consideration is suggested by the subject of the last paragraphs. If love and forbearance are strong enough to overcome all the forces of the world which oppose them, then they must be in close harmony with the inner nature of the universe. If they are the all-conquering powers that the New Testament represents them to be, their strength must be drawn from sources deeper than those of our ordinary experience. Thus we return to the conclusion that has met us twice beforethat Christian Ethics is not only a theory of conduct detached and complete in itself, but that this practical theory leads up to conclusions regarding the Reality which underlies all knowledge and all experience. We saw that the idea of the Kingdom of God on earth implied for the writers of the New Testament the correlative idea of a transcendent Kingdom; and our discussion of the doctrine of Reward led to the conclusion that the efforts of the good man must be met and seconded by powers greater than his own, if his life is not to end in failure. ${ }^{2}$

So it is also in regard to the present subject; for the

11 Cor. xiii. 4, 7.

2 Supra, Chh. VII. and VIII. 
duty of meekness and forgiveness is based both by Jesus and Paul on a definite belief that the exercise of these virtues brings men into a fundamental harmony with the Divine Nature and Action. Paul explicitly connects his exhortation to abstain from acts of vengeance with the thought that vengeance is the prerogative of God; ${ }^{1}$ and Jesus in an even loftier argument appeals to the character of the Father in Heaven as the supreme sanction of that love for enemies which shines out in the perfect Christian character. ${ }^{2}$ Thus we cannot but conclude that in the Christian view ethics leads on to philosophy, or rather to theology, ${ }^{3}$ and that the Good which man is called upon to follow is indeed related to the deepest Reality, nay, that it is itself that Reality. Therefore we were justified in defining the Spiritual Order not only on its purely ethical side as that of unselfishness and harmony, but also as that of ultimate and abiding truth.

Thus it has become apparent that the New Testament doctrine of the Kingdom has a closer affinity to some theories of the universe than to others. Attempts have been made in recent times to separate Christian Ethics from any belief regarding ultimate questions, and to represent Christian morality as self-contained, requiring no other support than is provided by those human needs which all thoughtful men cannot but see, and that sympathy which all good men cannot but feel. It has thus been held that an ethic of sympathy and service may be founded on, or rather exist alongside of, the associationist empiricism of Mill or even of Hume; and that the Kingdom of which Christianity tells may

1 Rom. xii. $19 . \quad 2$ Matt. $\nabla .48$; cf. 45.

3 The $\pi \rho \omega ́ \tau \eta \phi \iota \lambda о \sigma o \phi i ́ a$ of Aristotle's Metaphysics. 
be sought after and found by those who look no further for its significance than to the presently experienced life of mankind.

To the service of the Kingdom, thus understood as the instrument of the highest human progress, much noble thought and effort have been given. A high ideal of the future of the race may be seen and followed on these lines; only it cannot be taken as representing the Christian ideal in its completeness, for the Christian ideal is that of a "Kingdom of Heaven," arising and growing strong in the life of the world, but answering to and supported by a hidden reality in a sphere above that of ordinary experience. Now this belief is closely akin to the Platonic doctrine that the Good, which in our ideals we dimly apprehend and which in our moral life we strive to realise, is indeed the deepest Truth and the central Reality of the universe.

In other words, Christian Ethics implies an idealistic view of the world; but at the same time it is clear that most of the actual systems of idealistic thought have been too narrow to express its full range of meaning. At some point they prove defective. Thus intellectual idealism, which looks on man chiefly as a spectator of the slow unfolding of the Divine Purpose in Nature and History, fails to recognise that Christianity has a moral significance in the strict sense of the word-that it teaches man to look on the Kingdom as a task entrusted to his care, and in some sense depending for its fulfilment on his faithfulness. The mystical and emotional form of idealism is for the same reason incomplete; while, on the other hand, a purely ethical and voluntaristic philosophy, which lays the whole emphasis on the exercise of the will, fails to do justice 
to the Christian view of the Good as a revelation and an endowment.

In the same way the Spiritual Order cannot be described from the Christian standpoint as either purely immanent or purely transcendent, for it unites both characteristics. The Good is immanent, because it appears more clearly in the sphere of History than in that of Nature, and most clearly of all in the hearts of men. It is " not afar off, but very nigh" $;{ }^{1}$ not imposed from without, but speaking from the depths of man's own nature in man's response to the divine appeal. But it is also, or rather it is on that very account, transcendent, because it never appears to the Christian as anything that has been realised either in his own life, or in the life of the Christian society. His apprehension of it is always a witness to the ideal, which has found but one adequate expression in the long course of history - a witness and a call to follow. Thus the deepest Reality is immanent, for it is known only through the experience of heart and conscience, but it is transcendent in that it is never thought of as finally attained or realised, but always as an ideal to which man must press forward. ${ }^{2}$

Further, in this thought of the moral ideal, as the revelation within of a great Reality which exists above, it is clearly implied that goodness of character and the deepest knowledge are not finally separate. Truth may be, as the Pragmatists urge, that which works, and the

1 Deut. xxx. 11-14. Cf. Luke xvi. 31, "If they hear not Moses and the prophets, neither will they be persuaded, if one rise from the dead."

2 Cf. Phil. iii. 12-14. This view of the union of immanence and transcendence has recently received so admirable a statement from Professor J. H. Muirhead (International Journal of Ethics, January 1910, pp. 132 137) that I feel the less need to enlarge upon it. 
abstract rightness of a course of action or an ideal of character may be demonstrated by its ultimate effectiveness. But if so, the reason must be that the universe is at bottom a moral one; and so the good man pursues no wandering light in his effort after perfection for himself and others. In the measure of his attainment he feels himself brought into harmony with the being of the Whole, and his own frail craft carried onto the great current which sets through all the ages towards the one divine end of life and history. Thus the Spiritual Order is not strictly created by the efforts of man; he must indeed realise and actualise it in his own life and in the society in which he lives. But none the less it has an abiding reality, from which he gains strength for the contest through the faith which apprehends it as true. ${ }^{1}$

That the revelation of spiritual truth is one great function of religion, and that the faith of which $I$ have just spoken is the correlative of revelation-the human response to and appropriation of that which is revealedthese are familiar theological positions. But theologians have often forgotten that neither revelation nor faith is primarily a thing of the intellect. It is not mere neutral truth, the same for all rational beings, that is revealed. Revelation is addressed to feeling and will as well as to reason, and if there is any primacy here, it is a primacy

1 In this respect Eucken seems to come nearer than the Pragmatists to the typically Christian Weltanschauung; for he lays equal emphasis on the thought of the spiritual life as a task and a problem, and on the other thought which I have tried to express, that its progress in face of seemingly overwhelming obstacles and its final validity depend on its being a true expression of the deepest Reality. (Vide Boyce Gibson, Rudolf Eucken's Philosophy of Life, 2nd ed., pp. $176 \mathrm{ff}$. , and The Life of the Spirit, Eng. tr., pp. 172 f., 271; and cf. pp. 21, 304.) 
of will. It is reported in the Third Gospel that Jesus replied to a question regarding the composition of His Kingdom with the imperative, "Strive to enter," and the most mystical of the evangelists records the great saying, "If any man willeth to do his will, he shall know of the teaching, whether it be of God." 1 Revelation, both in the Old and New Testaments, is always a revelation to conscience in the first instance, a revelation of duty based on the idea of God as Holy. But it also becomes a revelation of the power of the Good, and thus, as we have already seen, has a dynamical as well as purely ideal aspect.

This is in full accord with our argument regarding the personal character of the highest law; for in the light of it the theological statement that Jesus is the supreme revelation of God is seen to be, in its first and most direct meaning, identical with the statement that $\mathrm{He}$ is the Christian Law. But whether we remain satisfied with this thought, or advance to the thought that $\mathrm{He}$ is the strength of Christians as well as their rule, ${ }^{2}$ it is equally true that the Christian revelation and the faith which apprehends it are very closely connected with the active side of man's nature. In the wider sense already defined they are moral through and through. Only those who seek to direct their lives according to the Christian Law can gain a firm grasp of Christian truth. Only those who strive to live in the Spiritual Order and to make its precepts real in their practical activities, can gain an abiding certainty or a true understanding of it. It cannot be known from without by inquiry, but only from within by practice.

1 Luke xiii. $23 \mathrm{f}$. ; John vii. 17.

2 See the quotation from Coleridge above, p. 331. 
But not less important is the converse truth-that such practice is only possible in the full degree to those who have learned to rest in the inner harmony and peace of the Spiritual Order. If there is essential truth in the thought of a "Will to Believe," not less is there in that of a "Faith to Will." 1 The highest energy is the privilege of those who themselves "have entered into the beginning of peace."

Thus the Christian consciousness has two aspects, that of repose in the thought of a harmony above the stress and toil of life, and that of ceaseless endeavour to impress the stamp of the higher order upon the life of the world around. It has indeed been held that this duality of aspect amounts to a radical dualism, that it destroys the unity of the religious life, breaking it up into a quietism which looks on the Good as already fully realised, and an ethical voluntarism which regards it as an ideal to be realised wholly through human instrumentality and the efforts of man. Religion, we are told by Mr Bradley, "exists by a kind of perpetual oscillation and compromise. . . . The whole is at once actually to be good, and, at the same time, is actually to make itself good." 2

The first point to be urged in reply is that this duality exists in the world, and that any adequate philosophy or theology must unreservedly recognise both these aspects. Man does live in two worlds, which are only very partially in harmony. But a second and more vital point is that this frank recognition of the two factors is essential for the most effective life. The mystic, who lives wholly in the contemplation of the ideal and of

1 Cf. pp. 40 f. abore, and Höffing, Philosophy of Religion (Eng.tr.), pp. 119, 163.

${ }^{2}$ Appearance and Reality, pp. 440, 442. 
timeless truth, falls as far short of the highest spiritual achievement, as he does who sees nothing beyond the present struggle and has no hidden support or source of strength in the conflict. It is he who from a higher sphere draws energy and inspiration for the tasks that meet him in the actual world, and who is able to bring something of the calm of the Spiritual Order into the confusion of the natural, who shows the truest mastery over the world. Because his deepest life and citizenship is elsewhere, he is not less but more effective as a citizen of the visible polity to which he belongs. And this practical test is of essential importance; for the object of Christianity has always been less the intellectual object of finding a single formula to comprehend the whole of experience, than the practical aim of bringing life in all its parts into complete conformity to the moral ideal.

With this practical answer we might perhaps rest content; but one further step may be taken. The chasm between the two orders cannot be an impassable one even from the intellectual point of view, when mastery over the lower is so directly drawn from contact with the higher. But the intimacy of their interconnection becomes fully evident only when we consider the inner principle of the Spiritual Order. For the whole teaching of Christianity is directed to prove that this principle is no other than Love. But while Love on the one side stands for repose, for tranquillity, for the satisfaction of the most restless yearnings of human nature, it is none the less essentially active. It cannot remain at rest when service is called for. Its inner nature ever seeks outward expression, and it finds its field of action amid the needs, and its arena of victory 
in the conflicts, of the actual and present world. Thus religion, while it certainly has two aspects, is neither an illogical "compromise" nor a distracting "oscillation." If the word "oscillation" is retained, it must be understood in the sense of that alternation which characterises all the energies of life. The alternation of the spiritual life is as the systole and diastole of the heart; for in its operation the powers of the soul are first withdrawn to the hidden centre of warmth and energy, that they may then go forth on their life-bearing mission to every part and member of the body of our common humanity. ${ }^{1}$

\section{V.}

It now remains only to gather into a single view those various characteristics of the Spiritual Order which have emerged one by one during our discussion; and this can be done very briefly. First, then, we found that in it those virtues which exist in isolation elsewhere are gathered into a complete and many-sided whole. We next considered that in the natural order the individual is lost among the crowd of his fellows, and dwarfed to nothingness by the immensity of the cosmic process in

1 We may compare the words of the Fourteenth Century mystic Ruysbroeck, "The interior (contemplative) man possesses his life according to these two manners : that is to say, in rest and in work. And in both of them he is wholly and undividedly, for he dwells altogether in God in virtue of his restful fruition, and altogether in himself in virtue of his active love ... and he dwells in God, and yet he goes out towards created things in a spirit of love towards all things; in the virtues and in works of righteousness." "These are the two movements of the perfect life, united as matter and form, as soul and body." (Quoted by Miss E. Underhill in the Contemporary Review, June 1911, p. 705, and Rufus M. Jones, Studies in Mystical Religion, p. 314.) 
whose midst he lives; but that in the higher order he comes to be known as possessing independent and absolute worth, and as having his own special and indispensable part to play in the divine economy of life. But we saw also that this emphasis on the Individual in the Spiritual Order does not separate him from his fellows, but that he finds his true life in union with them and in the service of a Common Good; and that this united service becomes possible because the conflict of interests and desires which marks the lower order is here transcended. Where the natural depresses man, the spiritual exalts him: where the natural separates, the spiritual unites. But the unity to which it leads is one in which the widest diversity of gifts and of functions finds a place. At a later stage in our argument we found that, while the lower stages of human progress are marked by constraint, the higher lead out into freedom; that while the compulsion first of force and then of law, the fear of punishment or the hope of reward, for long hold sway over man, he at length attains to that willing service of the Good which is the truest liberty. We found in this freedom, in which external constraint and obligation are replaced by a glad response to the claims of an ideal freely recognised and followed, another great characteristic of the Spiritual Order; and we saw how it opens the possibility of new beginnings in virtue and of a life exempt from decay, and enables men to serve no longer for recompense but for the love of what is noble and good.

And through all this there runs a single principle; for there is but one power that can penetrate beneath the poverty and littleness of human nature as it is seen 
from without, and discover and develop its hidden possibilities of greatness; that can overcome the deep-rooted rivalries and animosities of men, and bind them together in the service of an end which is common to all, to which each may bring his special contribution, and in which each may find his own need satisfied; that can free men from all need for a constraint from without, whether of force or hope or fear, and enable them to follow the higher law of a conscience devoted to the good and resolute in the effort to realise it. This principle, this higher, positive, all-inclusive Law, is the Law of Love. Thus we may come to see that it is true of virtue, not less than of knowledge, that its leaves "scattered through the universe" are at last "bound into one volume by love." 1

Such is the final idea to which our argument has led of the Good, as realised in an Order, rising above that of Nature. But the thought intrudes, and will not be banished, that this Order makes but a slow and uncertain progress in asserting its mastery over the world and human life. Time and again, the rude forces of earthquake or famine or pestilence have come to mock, not only our science and our boasted mastery over Nature, but even more bitterly our claim that Man, so pitiful in his helplessness before them, has an infinite value as the end towards which untold ages have painfully wrought. Time and again, the forces, not less cruel, of selfishness and strife have been suppressed in one

1 Dante, Paradiso, xxxiii. $85 \mathrm{f}$. The thought is the same as that of Col. iii. 14, "Above all these things put on love, which is the bond of

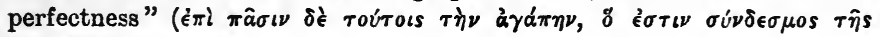

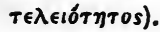


form, only to reappear in forms more subtle but not less deadly than before; and even now in the midst of our highest civilisation the imperious needs and the untamed desires of men seem to drive them into a rivalry as relentless as any in the past, and to turn to irony the doctrine that love and pity are the mightiest forces in the world. Love seems rather an infinitely weak thing. The Spiritual Order, for all its beauty, seems but a thin shadow compared with the stern material realities which press in upon man's life. Yet the truth of Christianity rests upon its strength, and would fall with its defeat.

Thus there is a constant need for the Faith which takes its stand upon this Order as the one thing finally true, and for the Hope which looks in spite of all that opposes it to its vindication and realisation in the future. And both Faith and Hope are founded most firmly, when they are based upon the greatest victory which the weapons of the Spiritual Order have ever won; nor can any voice speak with so great assurance and encouragement as that which comes to the Christian, "Be of good cheer; I have overcome the world." 1 And as his faith responds, he is enabled in his degree to renew that victory, and to make it his own in his own day and his own circumstances. ${ }^{2}$ But because he must so appropriate it, and thus make good his place in the Spiritual Order, neither Faith nor Hope can ever be merely a passive or an intellectual virtue. Both are militant in their very nature, not to be rested in, but rather to take stand upon in the battle of life. In the last resort, as Paul teaches, ${ }^{3}$ both may be transcended;
1 John xvi. 33.
21 John v. 4.
31 Cor. xiii. 8-13. 
THE NATURAL AND THE SPIRITUAL ORDER. 389

for they are in a sense external to the Spiritual Order, as the means through which its reality and power may be grasped by those who still are involved in the toils of the natural life. But the third and greatest of the Christian virtues is, in its being and power, none other than the Order itself. Wherefore we may conclude with Augustine that the best and the most comprehensive definition of Christian virtue is also the simplest of all-Ordo est amoris-It is the Order of Love. 


\section{NOTES.}

Note A to pp. 5, 37, The Positive and Negative Elements in the Greek Conception of Virtue.

That there is a double strain in Greek ethical thought has been shown in the preceding pages, where we have seen along with the Doctrine of the Mean, a view which might be described as the Doctrine of Moral Synthesis, which emphasises the addition of one virtuous tendency to another rather than the avoidance of vicious excess.

At the same time there are indications that the view of Virtue as a Mean between excess and defect cannot be described as purely negative in character. It is first clearly formulated in the dialogue in which we found the clearest statement of the other view which we have examined (Politicus, $283 \mathrm{f}$.); and although the discussion of the Mean is there introduced in a mere digression, in Plato's later manner, and has not the same bearing on the general course of the argument as the other theory, yet Plato does not seem to perceive any inconsistency between the two points of view. In the same way Aristotle speaks in one passage of the mean state as one in which both the extremes can be seen, and says that when this is so it is due to the success of the combination

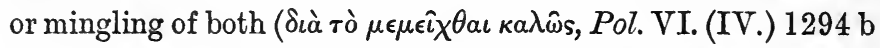
16-18). Elsewhere he states that " in temperance and courage 
there cannot be an excess or defect, because the Mean is in a

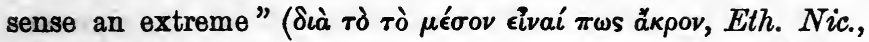
II., 1107 a 23). Professor Burnet illustrates this aspect of the Mean in his edition of the Ethics (p. 103-ad 1108 b 11) by a quotation from the Eudemian Ethics which is worth reproducing :- "The Mean is more opposed to the extremes than these are to one another, because it cannot co-exist with either of the extremes, while they may exist together; as sometimes men are foolhardy cowards ( $\theta \rho a \sigma v \delta \epsilon \iota \lambda \circ \iota)$, or are prodigal in some respects and miserly in others; and in general these are paradoxes of evil. 1 But whenever there are paradoxes of good

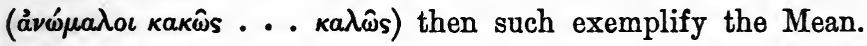
For in a certain sense the extremes are present in the Mean."

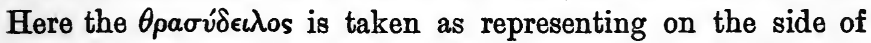
vice the same combination of opposites, as is exemplified on the side of virtue by the man who combines gentleness with courage, and who answers to the description in this passage of

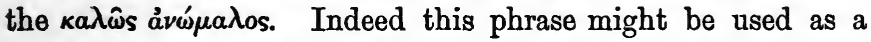
general characterisation of fully developed virtue, when virtue is viewed as a harmony of opposites.

But, apart from these refinements upon or additions to the theory of the Mean, the conception itself had a positive import for Greek thought. It involved more than a mere negative avoidance of contrary extremes: it involved the positive determination of virtue. As Professor Burnet says, the view of it "as a mere medio tutissimus ibis" is misleading. "The Mean is the regular Platonic and Aristotelian way of explaining the Formal Cause." Goodness is a Mean, because "it is the form which is the true nature of the human soul when fully developed." (The Ethics of Aristotle, p. 73 and note.) This idea certainly had a positive content for the Greek mind, just as the corresponding idea of the perfectly developed human body found a definite expression in the best Greek sculpture. But though it stood for a positive and definite 1 Or " displaying a bad combination of contrary qualities." 
conception of human nature, as opposed to any mere negation of its wilder impulses, yet just because it was so clear and definite, it was also limited (cf. the root meanings of the two words); and this brings us within sight of a principle of differentiation between Greek and Christian ethical thought.

But first it will be well to touch on this idea of the Limit; for one of the fundamental features of Greek thought is the

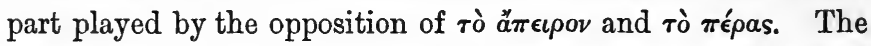
former term appears in the early Ionian thinkers, and as used by Anaximander, it probably means less the Infinite, as we understand it, than the Indefinite or Formless. In this "Hylicist" conception we have the first appearance of the $v \lambda_{\eta}$ which had so important a place in the thought of Aristotle. It is by limitation, the function of $\tau o$ ò $\pi$ épas, that this undifferentiated substrate of things, itself "without form and void," receives form and meaning. Thus, in the Greek conception of evolution, the principle by which the original Chaos

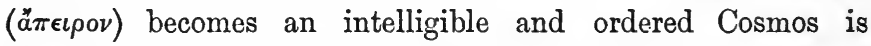

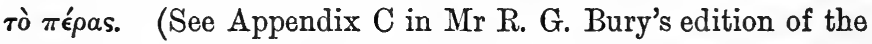

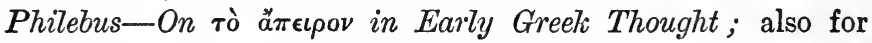
what follows, App. D and E.)

This emphasis on the importance of the Limit influences Greek thought in many directions. In one of the most striking sayings of Heraclitus, who is commonly said to be the first philosopher who applied his metaphysical ideas to ethics, the universal sway of Law is enforced by the words, "The sun will not exceed his measures; for if he does, the Erinyes, the avenging handmaids of Justice, will find him out." (Fr. 29, Burnet.) In the early religious thought of Greece no sin was so severely condemned as displeasing to the gods as that of $\tilde{v} \beta \rho s$, and, in the dealings of man with man $\pi \lambda \epsilon o \nu \epsilon \xi i a$ was held to be correspondingly blameworthy. In both cases the idea of Law is that of a restraining influence, imposing strict limits on thought and action. So also, wher- 
ever the Greek applied the wide conception of ápєтクं its rule and maxim was $\mu \eta \delta \dot{\nu} \nu$ a $\gamma a \nu$. In Plato, the same idea appears as early as the Protagoras (356, but cf. Phado, 69), in the suggestion that virtue is an art of measurement, and in the recurring application to ethics of mathematical ideas and analogies; and closely connected with this is the saying o $\theta$ єòs a' $\boldsymbol{\epsilon} \gamma \in \omega \mu \epsilon \tau \rho \epsilon \hat{\imath}$. But the best example of the Greek attitude in this respect is to be found in the long discussion regarding rò

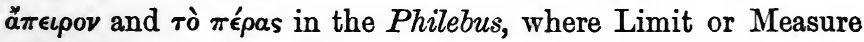
is described as the principle which brings Form into the Indefinite and " binds down " all its varying elements ( $\xi \nu \mu \pi \alpha$ ' $\nu \tau \omega \nu$

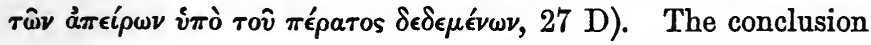
of the argument is that "the eternal nature is to be found in Measure, the Measured, the Suitable" (66 A). But it is worth remarking that the action of $\pi$ épas does not appear as wholly negative. Its result is the harmonious mingling of diverse elements-in this case, of knowledge and pleasure in the complete life. Thus the conclusion of the Philebus corresponds to that of the Politicus in the practical sphere.

The conclusion to which these facts point seems to be that, while the Greek conception of Virtue was a decidedly positive one, and was only with some difficulty comprised within the

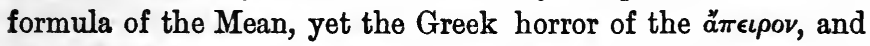
the idea that excellence of every sort was due to the action of measure and restraint, tended in some directions to confine and narrow that conception. The ideal of conduct, like the ideal of bodily beauty, was a definite formative influence among the Greeks; but its very definiteness and finitude appears as a limitation when it is judged by Christian standards. Dr Strong, in his Bampton Lectures (Christian Ethics, pp. 3133 ; cf. p. 99), has stated (perhaps with insufficient qualification) the view that Greek thought failed to give a positive ideal for the guidance of life and the subduing of passion. As against the old conventional antithesis of Hellenism and 
Hebraism, it is well that it should be clearly seen how large a part sheer restraint played in the moral attitude of the Greeks; but I should rather hold with Green, that the Greeks had a positive moral principle-positive, but when compared with that of Christianity, limited both in intensive force and in width of obligation. (Prolegomena to Ethics, Bk. III., ch. v. ; cf. ch. iii., $\$ 206$ ff.)

\section{Note B to p. 23, Newman on the Paradox of Christian Character.}

"It is by means of these strong contrasts that Scripture brings out to us what is the real meaning of its separate portions. If we had been told merely to fear, we should have mistaken a slavish dread, or the gloom of despair, for godly fear ; and if we had been told merely to rejoice, we should perhaps have mistaken a rude freedom and familiarity for joy ; but when we are told both to fear and to rejoice, we gain thus much at first sight, that our joy is not to be irreverent, nor our fear to be desponding; that though both feelings are to remain, neither is to be what it would be by itself. This is what we gain at once by such contrasts. I do not say that this makes it at all easier to combine the separate duties to which they relate; that is a further and higher work; but thus much we gain at once, a better knowledge of those separate duties themselves. . . . How joy and fear can be reconciled, words cannot show. Act and deed alone can show how. Let a man try both to fear and rejoice, as Christ and His Apostles tell him, and in time he will learn how; but when he has learned, he will be as little able to explain how it is he does both, as he was before. . . . He becomes the paradox which Scripture enjoins." (Parochial and Plain Sermons, V. 65-67. The italics are mine.) 
Note C to p. 28, The Union of Severity with Mercy in the Character of Jesus.

"It was Mercy, which is not Pity - a thing comparatively weak and vulgar-but Pity and Resentment blended at the highest power of each, the most powerful restorative agent known in the medicine of the soul; it was Mercy that revealed itself in Christ's words, the Pity slightly veiled under royal grace, the Resentment altogether unexpressed and yet not concealed because already too surely divined and anticipated by the roused conscience of the criminal." (Ecce Homo, ch. xx., "The Law of Mercy." Cf. the following chapters on the "Law of Resentment" and the "Law of Forgiveness.")

"For suffering, Jesus had a true compassion, but He knew that it could be borne; what was intolerable, because it was daily robbing men of life, was this habit of evil, and against that He daily measured Himself. . . . It was for that reason that men besought Him to depart out of their coasts. . . . There was in Jesus this element of the inexorable. He forgave sin, but no one ever supposed that $\mathrm{He}$ thought slightly of it, or that, even for a moment, He became less absolute in His demands." (W. M. Macgregor, Jesus Christ, the Son of God, pp. 139 f.)

\section{Note D to p. 56, Slavery in the Republic.}

Professor Gilbert Murray has advanced the argument that in the Republic Plato abolishes slavery "silently by merely constructing a state without slaves." (The Rise of the Greek Epic, p. 17.) But it is hard to reconcile this view with the argument against the enslavement of captives of Hellenic race (469 BC), which seems to imply that other captives may be enslaved. Even clearer is the statement in Book IV. (433 
D) that the virtue of the State consists in the presence of Justice " in every child and woman, in every slave, freeman, and artisan, in the ruler and in the ruled, requiring each to perform his own individual and proper task." Here slavery is explicitly admitted into the ideal polity ; but the essential point certainly is that the slave is given a definite place in its ethical relationships. On the whole question we may perhaps accept Professor Murray's conclusion that "the main point which distinguishes Greece from other ancient communities, here as elsewhere; is not something actually achieved, but something seen and sought for. In Greece alone men's consciences were troubled by slavery." (Il., p. 19.)

\section{Note E to p. 71, Economics and the Individual.}

I do not think that what is said in the text is inconsistent with Dr Bonar's argument that there is no necessary opposition between Political Economy and an Idealistic Ethic (Philosophy and Political Economy, pp. 218 ff.). Nor do I disregard the sympathetic statement of the Christian view of the individual by so distinguished an economist as Professor Marshall (Economics of Industry, p. 3). These may be taken as proofs that the polemic of Carlyle and Ruskin against the narrowness of the older economists, though necessary in their day, is not in the same degree necessary now. To the same effect one might cite the argument of another Cambridge economist (which practically reproduces the position of Kant referred to above) that the law of averages enables us to hold to the scientific postulate of predictability when dealing with the collective actions of bodies of men, while at the same time holding that individuals possess freedom from determination. (A. C. Pigou, The Problem of Theism and other Essays, pp. $74 \mathrm{ff}$.) But these references only point to a growing recognition of the one- 
sidedness of Political Economy taken in isolation. Professor Marshall still emphasises its characteristic method of abstraction. As economists, he says, "we take as little notice as possible of individual peculiarities of temper and character. We watch the conduct of a whole class of people." (Op. cit., p. 25.) Now, what I have tried to establish in the text is simply that the economic point of view, taken before its abstractions have been rectified by an idealistic and (if the term is permissible) personalistic philosophy, tends by its very neglect of the individual as such-necessary as this is for its own purposes-to act as a negative influence in regard to the Christian view. And while the leading economists of the present day are the first to proclaim that strictly economic facts need to be revised from the ethical point of view, yet the older and harsher form of economic doctrine continues to tell as a popular force, just because it is the theoretic formulation of the methods of a civilisation, which in practice is still largely materialistic and heedless of the welfare of its individual members.

$I$ add the following sentences from a recent article by $\mathrm{Dr}$ James Devon, Physician to H.M. Glasgow Prison, to show how a practical experience of the modern treatment of crime confirms the conclusion as to the "defect of Law through its generality," reached long ago by Plato and Aristotle: "The fact is that nearly all cases are exceptional in relation to a system founded on averages. An average is an abstraction and a man is not. It saves trouble to those who do not want to take trouble; it makes things easier for men in position, but it ensures serious loss in working." "There can be no equality of treatment possible in an institution where the rules are the main concern of the officials; for, while all men are unequal, uniformity of treatment means inequality of treatment. Each man will require to be treated as a man and without regard to others who have committed like crimes." (Hibbert Journal, July 1911, pp. 780 f., 795-italics are mine.) 
NOTES.

Note $\mathrm{F}$ to p. 74, The Two Conceptions of the Infinite.

It is worth while to quote the striking lines of Albr. von Haller, with which Hegel illustrates his argument :-

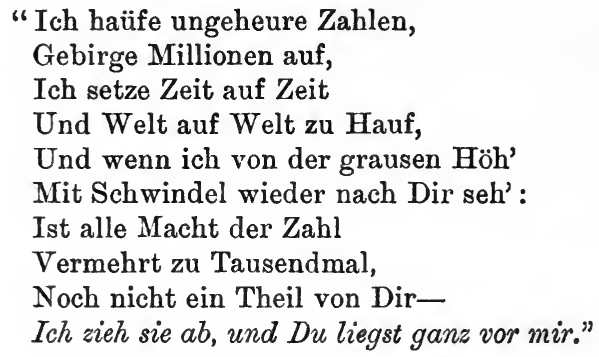

It is in this last line that Hegel finds the transition from the "false infinite" to the true.

Note G to p. 88, George Eliot on the Value of THE Individual.

This recognition of the artistic and ethical value of apparently commonplace lives is not only exemplified incidentally in the imaginative literature of the Nineteenth Century. It was consciously adopted and explicitly defended early in their careers by two writers so great in their different departments as Wordsworth and George Eliot. Cf. the opening paragraphs of Wordsworth's Preface to the second edition of Lyrical Ballads, and several passages in George Eliot's first work, Scenes from Clerical Life. (Amos Barton, c. v., Janet's Repentance, cc. x., xxii.) One passage may be quoted from the latter. "The only true knowledge of our fellow-man is that which enables us to feel with him-which gives us a 
fine ear for the heart-pulses that are beating under the mere clothes of circumstance and opinion. Our subtlest analysis must miss the essential truth, unless it be lit up by the love that sees in all forms of human thought and work, the life and death struggles of separate human beings."

\section{Note $H$ to p. 103, The Meaning of "Competition" AND "CoMpetitive."}

Throughout the discussion in Chapter IV., the terms " competition" and "competitive" are used in reference to material "goods," or, more generally, to those good things in regard to which the gain of one man is necessarily the loss of another. Such are the "goods" whose ethical inferiority Boethius signalises in the words, " $O$ angustas inopesque divitias quas nec habere totas pluribus licet, et ad quemlibet sine ceterorum paupertate non veniunt." (Cons. Phil., ii. 5, quoted by Butler ad Dante, Purg., xiv. 87.) It would be hard to find a more exact statement of what is meant by referring to goods or objects of desire as "competitive."

But it is of importance to observe that the theory that "virtue or the Good is non-competitive" does not exclude that wider sense of "competition," in which it refers to advancement in those activities in which there is no collision of interests, and which are closely related to the Common Good. It has been recognised even by convinced Socialists that "competition" of this kind cannot be dispensed with (cf. H. G. Wells, New Worlds for Old, p. 110). But this element in life seems to me to be better described as emulation than as competition. Cf. Heb. x. 24, "Let us consider one another to provoke unto love and good works," and 1 Cor. xii. 31 , xiv. 1 . 
Note I to p. 125, Green's Doctrine of the Common Good.

It is worth while to give the context of the sentence quoted in the text, as the passage is perhaps the most succinct statement of Green's position. "The only good in the pursuit of which there can be no competition of interests, the only good which is really common to all who may pursue it, is that which consists in the universal will to be good,-in the settled disposition on each man's part to make the most and best of humanity in his own person and in the persons of others. The conviction of a community of good for all men can never be really harmonised with our notion of what is good, so long as anything else than self-devotion to an ideal of mutual service is the end by reference to which these notions are formed." (Prol., § 244. Other passages of importance are $\$$ 199-205, 229-232, 247, 282 f., 288.)

It will be at once apparent to every student of the Prolegomena, how entirely I am indebted for anything of value in my own discussion to Green's fruitful and inspiring argument for the Community of the Good.

Note K to p. 139, Dante on the Community of the Good.

Dante devotes part of the fifteenth canto of the Purgatorio to a statement of the doctrine of the Common Good as it was held by the noblest minds in the Mediæval Church. The passage throws so much light on our argument that I transscribe it in full from Cary's translation (vv. 49-78). Vergil speaks in answer to Dante's question :-

"Because ye point your wishes at a mark, Where, by communion of possessors, part Is lessen'd, envy bloweth up men's sighs. No fear of that might touch ye, if the love Of higher sphere exalted your desire. 
For there, by how much more they call it ours,

So much propriety of each in good

Encreases more, and heighten'd charity

Wraps that fair cloister in a brighter flame."

"Now lack I satisfaction more," said I,

"Than if thou hadst been silent at the first;

And doubt more gathers on my lab'ring thought.

How can it chance, that good distributed,

The many, that possess it, makes more rich,

Than if 'twere shared by few?" He answering thus :

"Thy mind, reverting still to things of earth,

Strikes darkness from true light. The highest good

- Unlimited, ineffable, doth so speed

To love, as beam to lucid body darts,

Giving as much of ardour as it finds.

The sempiternal effluence streams abroad

Spreading, wherever charity extends.

So that the more aspirants to that bliss

Are multiplied, more good is there to love,

And more is loved; as mirrors that reflect,

Each unto other, propagated light.

If these my words avail not to allay

Thy thirsting, Beatrice thou shalt see,

Who of this want, and of all else thou hast,

Shall rid thee to the full."

The concluding lines of this passage suggest the ideal character of the principle which is the subject of discourse. Vergil, who represents human wisdom or Philosophy, can give a proof that the true Good is wholly common; but it is only a partial proof, and the full establishment of the truth belongs to the sphere of Beatrice, or Theology.

Note L to p. 145, The Place of Healing in Jesus' Ministry.

From the story of the healing of the palsied man, Mark ii. $2 \mathrm{ff}$, we may gain a clear insight into Jesus' view of the 
paramount importance of moral, as compared with physical, recovery. In the work of physical healing, Jesus was often the Sought rather than the Seeker. See Matt. ix., where there are two instances of this in three verses (18 to 20) and five in the chapter; while in vv. 9, $10 \mathrm{ff}$. (the call of Matthew and its sequel), $\mathrm{He}$ is represented as actively seeking out those who stood in need of spiritual healing (v. 12). On His withdrawal from the work of healing bodily illness at a later stage of His mission, cf. Bruce's notes in the Expositor's Greek Testament on Mark vii. 24 (the Syrophœnician woman) and 33. Jesus was " not weary of well-doing, but anxious to do other work, hitherto much hindered."

Note $M$ to p. 158, Christianity and the Use of Material Goods.

The teaching of the passage from First Peter quoted in the text harmonises with the practice of the early Christian community in Jerusalem as recorded in Acts ii. 45, iv. $34 \mathrm{ff}$. But it does not yield any support to the moral of one of Tolstoi's apologues, "that God and men can be served, not by gold, but only by deeds" (Ivan Ilyitch and Other Stories, p. 187). This conclusion seems to rest on an impossible abstraction of deeds from their instruments. Gold is far from being the most important medium, but it is one of the media, through which brotherly kindness expresses itself. It is even treated by Paul as a means of returning spiritual benefits, though not of course as fully equivalent to the latter. ("If the Gentiles have been made partakers of their spiritual things, they owe it to them also to minister to them in carnal things," Rom. xv. 27. Cf. 1 Cor. ix. 11.) The saying in the Third Gospel, "He that is faithful in a very little is faithful also in much" (Luke xvi. 10), and the words that follow seem clearly to indicate that Jesus attached no small importance to the faithful stewardship of material 
wealth, though treating it as of incomparably less value than spiritual wealth.

The succeeding paragraph (p. 159) may be illustrated by the passages in which Ritschl criticises the idea that the Christian life can be self-centred and self-contained; and by the saying which he quotes from Schleiermacher, that "in Christianity all pain and all joy are religious only in so far as they are related to activity in the Kingdom of God, and that every pious emotion, which arises from a passive state, ends in the consciousness of a transition to activity." (Justification and-Reconciliation, tr. Mackintosh and Macaulay, pp. 9 note, 21, 168.)

\section{Note $\mathrm{N}$ to p. 181, The Contrast between $G_{A B E}$ AND AUFGABE.}

Hegel's position is stated in $\$ 6$ and 142 of the Smaller Logic (tr. Wallace, pp. 12, 258). "The Idea is not so impotent as merely to have a right or an obligation to exist without actually existing." It is not "so feeble as to leave the question of its actualisation or non-actualisation dependent upon our will." Fichte is not mentioned in either passage, but there is little doubt that both are directed against his development of Kant's idealism of will, in which the ethical end is looked on as Aufgabe. Cf. also the Preface to Hegel's Philosophy of Right, towards the end. The two ideas of gift and task are already treated as inseparable, and given a theological application by Ritschl (op. cit., pp. 30, 35); and as to their union in recent Christian Ethics, I may quote a fow sentences from Professor Haering's treatment of the subject. "Because the Christian task has its grounds in the gift of God, and this gift is personal communion with an eternal personal God, the task is as eternal as God Himself, and yet is complete at every moment of its realisation." "Unless we make clear to ourselves this inseparability, 
because they are pairs, of 'gift' and 'task,' we cannot understand them at all. But still more: earnestly as Jesus insists that it means striving after righteousness, and that its result is the possession of righteousness, $\mathrm{He}$ leaves it in no doubt that this would be for ever in vain if God did not bestow it; that prevailing courage for the struggle has its source in the power of the joyful news of that which God does. Conversely, as ... emphatically does $\mathrm{He}$ accentuate that no one can rejoice in the gift who will not attempt the task ; that he who has received forgiving love without stint, should without stint practise forgiving love; that the very condition for understanding this task is to receive the gift." (The Ethïcs of the Christian Life, Eng. tr., pp. 107, 129 f.) The same position is clearly and more briefly stated by Kirn, Grundriss der Theologischen Ethik, S. 28 :- "Dieses Reich Gottes ist vor allem die Gabe, durch welche Gott seine Verheissungen erfüllt und das menschliche Verlangen nach Gottesgemeinschaft befriedigt, also das höchste Gut des Christlichen Glaubens. Aber es kann nur angeeignet werden in gleichzeitiger Übernahme der sittlichen Aufgaben, welche es einschliesst. Diese Aufgaben bestehen in der Durchführung der vollkommenen Gottesherrschaft, teils im persönlichen Leben, d.h. in der Heiligung, teils im Leben der Gemeinschaft, indem dieses im Sinn der Liebe geordnet wird."

\section{Note $O$ to p. 218, Kant on the Place of Happiness in Moral Philosophy.}

Beside the passages quoted in the text, in which Plato and Spinoza introduce the idea of immortality (with its implicate of the final happiness of the good man) as the copestone of their philosophies, we may place the following words of Kant:- "It follows that morality should never be treated as a doctrine of happiness, that is, an instruction how to become happy; for it has to do simply with the rational 
condition (conditio sine qua non) of happiness, not with the means of attaining it. But when morality has been completely expounded, .... then first, after the moral desire to promote the summum bonum (to bring the Kingdom of God to us) has been awakened, a desire founded on a law, and which could not previously arise in any selfish mind, and when for the behoof of this desire the step to religion has been taken, then this ethical doctrine may be also called a doctrine of happiness, because the hope of happiness first begins with religion only" (V. 130 ; tr. Abbott, p. 227).

The following passage from the Critique of Pure Reason (1st ed., pp. 814 f., 2nd ed., p. 841 ; tr. Max Müller, pp. 652 f.) throws considerable light on Kant's theory in its earlier stage of development:- "Our reason does by no means consider happiness alone as the perfect good. It does not approve of it (however much inclination may desire it), except as united with desert, that is, with perfect moral conduct. Nor is morality alone, and with it mere desert of being happy the perfect good. To make it perfect, he who has conducted himself as not unworthy of happiness, must be able to hope to participate in it. Even if freed from all private views and interests, reason, were it to put itself in the place of a being that had to distribute all happiness to others, could not judge otherwise; because in the practical idea both elements are essentially connected, though in such a way that our participation in happiness should be rendered possible by the moral character as a condition, and not conversely the moral character by the prospect of happiness." We have here the same idea as in the passages cited in the text that the connection of happiness with virtue is a postulate of impartial reason; as well as the idea that the point at which the idea of happiness is introduced into the moral life constitutes the difference between its moral and its "pathological" employment. (For the latter, cf. Pref. to the Metaphysical Elements of Ethics, tr. Abbott, pp. 287-289.) 
The position is clearly stated in Schleiermacher's Reden. "Every external incitement is alien to morality, whether it be hope or fear. To follow it where it concerns morality is unfree, therefore unmoral. But the Highest Being, particularly when he is thought of as free, cannot wish to make freedom itself not free, and morality not moral." This statement is supplemented in the explanatory note where Schleiermacher says, "In the strife on this point, especially as it is carried on between the Kantians and the Eudaimonists, the great difference between presenting divine recompense as an inducement and using it theoretically to explain the order of the world has very often been overlooked. The former is an immoral and therefore specially an unchristian procedure, and is never employed by true heralds of Christianity and has no place in the Scriptures; the other is natural and necessary, for it alone shows how the divine law extends over the whole nature of man, and so far from causing a rift in human nature, it most fully guards its unity." (Oman's translation, pp. 99, $116 \mathrm{f}$.)

It may be added that, while Plato and Kant introduced the ideas of reward and immortality in close connection, Spinoza represents them as less closely related, or rather as related in a more purely immanent way. He carefully guards against the idea that happiness is a reward added to virtue in any external sense (as Aristotle says, it is not "attached like an amulet," Eth. Nic., I. 1099 a 16); and his great saying that "Blessedness is not the reward of virtue, but virtue itself" (V. xlii.) must be applied to the moral life at every stage.

\section{Note $\mathrm{P}$ to p. 265, Lotze and Bergson on Spontaneous or Creative Action.}

The passage in which Lotze brings forward his idea of the spontaneity involved in all moral action is of importance in itself and bears closely on our argument :-

"What constitutes the absolute authority of the causal law 
is not that every part of the finite sum of things actual must in the finite sphere be produced by fixed causes, according to universal laws, but that each constituent once introduced into this actual course continues to act according to these laws. We commonly speak only of every effect having its cause, but we should on the contrary lay stress chiefly on the other form of the proposition-every cause infallibly has its effect. The meaning of causality consists not indeed exclusively, but (it seems to me) in its more essential part, in its securing to every element of the actual world, springing from no matter what source, means of acting energetically on the other constituents of the world to which it now belongs, at the same time preventing it from acting within that world otherwise than in harmony with the universal laws regulating all that takes place in it. Thus the world would be like a vortex swelled by new waves from all sides, which it does not itself attract or produce, but which, once within it, are forced to take part in its motion. . . The universal course of things may at every moment have innumerable beginnings whose origin lies outside of it, but can have none not necessarily continued within it. Where such beginnings are to be found we cannot beforehand say with certainty; but if experience convinces us that every event of external nature is at the same time an effect having its cause in preceding facts, it still remains possible that the cycle of inner mental life does not consist throughout of a rigid mechanism working necessarily, but that along with unlimited freedom of will it also possesses a limited power of absolute commencement."

(Microcosmus, Bk. II. ch. v. Eng. tr., I. 261.)

M. Bergson's brilliant argument in his Creative Evolution may be said to be a generalisation of this idea. He generalises it in that he does not limit it, with Lotze, to "inner mental life," or to the moral sphere alone, but applies it to the whole development and operation of life and consciousness. I may quote a single sentence from Creative Evolution to set 
beside the passage from the Microcosmus. "That each instant is a fresh endowment, that the new is ever upspringing, that the form just come into existence (although, when once produced, it may be regarded as an effect determined by its causes) could never have been foreseen-because the causes here, unique in their kind, are part of the effect, have come into existence with it, and are determined by it as much as they determine it,-all this we can feel within ourselves and also divine, by sympathy, outside ourselves, but we cannot think it, in the strict sense of the word, nor express it in terms of pure understanding." (Eng. tr., pp. 172 f.)

It is probably too soon to attempt fully to determine the relation of M. Bergson's thought to the Weltanschauung which underlies the doctrines of Christian Ethics. In his criticism of "finality," and his conception of the "vital impetus" as essentially a vis a tergo, and (we may perhaps say) as partaking of the nature of blind impulse, there seems some failure to appreciate the possibility of a higher and ethical teleology, the teleology which springs from experience of the moral ideal as an attractive and directing power, and as limiting and disciplining the natural impulses of man. It is here, in the sphere of ends consciously distinguished and pursued, that the principle of finality has its highest and most secure application. Perhaps M. Bergson's speculations are scarcely intended to be carried into this purely ethical sphere; but in regard to the foundations of morality, the suggestive and illuminating character of his thought cannot be questioned. The importance of seeking to know the life of the spirit in its actual essencevital, continuously striving upward while matter tends steadily downward-instead of measuring it from without by the fixed categories of the pure understanding; the fact that life presses forward to ever new forms, while intellect assimilates all things to an already known and classified past; the creation of new values which are known in a direct experience never fully expressible in terms of reason alone, - these are ideas of the 
greatest fruitfulness for Moral Philosophy as a whole, and especially for that part of it which seeks to express the element of spontaneity in the life of the spirit.

\section{Note $Q$ to p. 290, The Conception of Punishment AS ReformatoRY.}

To the quotation in the text I may add the following passage from the same work of Thomas Erskine:- "The intelligent belief that we are under a process of education in filial righteousness . . . would, if really held, necessarily involve the assurance that forgiveness is man's permanent condition, because such a purpose could not be carried on without a continual forgiveness; and it would at the same time help us to understand that it is however a forgiveness which by no means excludes punishment, though it uses all punishment for the correction and essential good of the transgressor." (The Spiritual Order, p. 240.) It is at once apparent how far this view modifies the absolute antithesis which the older theology drew between the divine mercy and justice (cf. op. cit., pp. $72 \mathrm{f}$.), and how completely it substitutes the "reformatory" for the "retributive" theory of punishment. And indeed the former is as obviously in place in a teleological system of ethics as the latter is in a legal system. For in the second case, recompense or retribution is the end of the law, while in the first, law and punishment are only two of the disciplines provided to strengthen the growth of the good character. The superiority of this view becomes apparent when we try to carry the legal or retributive view of the moral order to its logical conclusion; for while recompense may be a vindication of law, or may even be a conclusive termination of the legal process, it cannot in the deepest sense be the end of law. That end, it has been truly said, can be nothing short of its perfect observance. The 
object of Law is attained, not when its breach is punished but only when its commands are fully carried out. Thus a more adequate conception of the purpose of the Law leads us, not indeed to discard the retributive view of punishment, but to treat it as subordinate to the reformatory view. For the highest aim of punishment is that, when it is seen to be the proper and inevitable consequent and outcome of sin, men should turn against the sin whose grievousness is now clear to them, and seek after a better way. (Cf. Hegel, Philosophy of Right, §§ 99-102.)

It would be an interesting inquiry to trace the progress of the reformatory theory of punishment, from the time that Plato placed in the mouth of Protagoras the saying that rational punishment is not designed to retaliate for a past wrong which cannot be undone, but that it is designed to prevent such wrong-doing in the future (Prot., 324); or the time that the Hebrew prophet taught that even the horrors of an Assyrian invasion were "established for correction" (Hab. i. 12. Cf. Lam. iii. $32 \mathrm{ff}$., Mal. iii. $2 \mathrm{ff}$.). This would carry us into too wide a field for present discussion; but there can be no doubt that one leading feature in the advance of ethical thought has been the tendency to consider punishment, less as a sufficient end in itself, and more as a means to ends that are moral in the full sense.

Note $\mathrm{R}$ to pp. 297, 315, 321, 328, Kant's Final Theory of Law and Personality.

The references to Kant's views in the text are almost entirely based on his writings on the theory of ethics, i.e., the Fundamental Principles of the Metaphysic of Morals and the Critique of Practical Reason. I think that this limitation is justified on the ground that it is through these books that Kant has chiefly influenced ethical thought. If, however, 
we also take into account his Religion within the Bounds of Mere Reason, we find that the rigidity of the earlier theory is modified in more than one important respect, and that these modifications do much to soften the sharp antithesis between the Kantian and Christian conception of the moral standard.

(1) In his later work Kant does not so summarily dismiss the possibility that the Moral Law may find its expression in a human character. Indeed in more than one remarkable passage he goes far in the direction of the view of Christian Ethics. The most significant is perhaps the following:- "We cannot. render conceivable the ideal of a humanity well-pleasing to God (involving that of a moral perfection, so far as this is possible to a being subject to earthly needs and inclinations), except under the idea of a man, who should not only be prepared himself to carry out all the duties of man's estate, and at the same time to extend the domain of the Good to the widest possible range by his teaching and example; but should also be ready, though tempted by the greatest allurements, to suffer all ills, even to the most disgraceful death, for the sake of the world's highest good, and even for the good of his own enemies. For we cannot form a conception of the degree and strength of a force, such as that of a moral disposition, unless it shows itself victorious in a struggle against hindrances and in face of the strongest possible opposition" (ef. Plato's description of the suffering good man quoted above, p. 215). "By a practical faith in this Son of God (so far as he is represented as having himself assumed human nature) man can hope to become well-pleasing to God, and hence also to become blessed " (Religion Innerhalb der Grenzen der blossen Vernunft, 2 Stuck, 1 Abschn. (a)). When we remember how great is the part played in Kant's constructive ethic by the principle of practical faith or certainty, it might well seem that in the last sentence Kant concedes all that Christian Ethics demands. But in the next section, on the "Objective Reality of this Idea," he proceeds to qualify or neutralise this 
admission by the double argument that, after all, the real potency of the conception of a Perfect Man would lie not in the external example but in the idea, "which already lies in our own Reason"; and that such a person by his very perfection would suggest exemption from all human weakness, and hence lose all force as an example for us. (Cf. E. Caird, The Critical Philosophy of Immanuel Kant, II. 570 f., 578, and the briefer statement given by Professor Pringle-Pattison, The Philosophical Radicals and other Essays, pp. $241 \mathrm{f}$.) The first of these arguments - that the really effective and essential ideal is that which has its place within the soul of man-has been dealt with in the text (pp. 305-7). The second-that the personality of the Founder of Christianity by its very exaltation loses the character of a potent example-might indeed apply to the Christ of a theology tinged with Docetism, or entangled in discussions of the non posse peccare, but hardly to the Jesus of the Gospels. (Cf. Heb. ii. 16-18.)

(2) We have already seen (pp. 315 f., above) that, within a few pages, Kant speaks of the Moral Law as requiring a full obedience which it is in the power of all to render, and as an ideal to which man as still in part a natural being can at best only approximate. The only hint of a reconciliation of the two points of view afforded by the Critique of Practical Reason is to be found in the idea of an infinite progress in virtue, of an asymptotic approach to conformity with the Law. But, as Dr Edward Caird has pointed out, "infinite time is not enough for an impossible task," and if we start from an absolute opposition of passion and reason, no first step in the progress can ever be made (op. cit., II. 303). But even if we waive this objection, the difficulty remains that the doctrine of the infinite progress only safeguards one aspect of the Moral Law-its infinite ideality - while it negates rather than proves its immediately obligatory character ; for if full obedience is only possible after an infinite time, that directly disproves the statement that "it is always in every one's power to satisfy the 
categorical command of morality." Hence there is a sense of unreality in a theory which treats perfect obedience as at every moment the duty of the moral person, and yet fails to ask what are the consequences if the Law is constantly broken, i.e., how is its dignity and authority to be vindicated. This was the question which so burned itself into the heart of Paul that he could not leave it unanswered. Thus even Kant's noble treatment of the idea of the Moral Law seems incomplete and wanting in thoroughness when compared with Paul's ; for Paul cannot let the question rest-How is a being who always falls short of the requirements of the Law to escape the consequences of his failure and be set free to advance on the path of progress, the endless path of which Kant speaks ? It is of the greatest interest to note that, when Kant wrote his Philosophy of Religion, he faced this question, and his answer is largely drawn from the thought of Paul. -See Religion innerhalb der Grenzen u.s.w., 1 Stuck, Allg. Anmerkung (Abbott, p. 356); 2 Stuck, 1 Abschn. (c).

(3) I have tried to show in the text that, important as such a treatment of obligation on judicial or quasi-judicial lines undoubtedly is, yet it does not represent the most typically and centrally Christian view. That view emphasises the family in its varied relations and the authority of fatherhood as expressing a higher order of ethical truth than the authority of a judge. This position also is defended by Kant in a passage in which he maintains that the Christian idea of the Church cannot be adequately expressed in political terms. "An ethical community considered as a Church, i.e., simply as a representative of a Divine Polity, has properly no constitution resembling in its fundamental principles the political constitution. Its constitution is neither monarchical (under a Pope or patriarchs) nor aristocratic (under bishops and prelates) nor yet democratic (as in the case of sectarians who claim individual inspiration). It might best be compared to a Family united under a Father, who, though invisible, is 
the Father of all, in so far as His holy Son, who knows His will and stands in blood-relation to all the members, occupies the position within it of one who makes that will more fully known to them, while they for that reason honour the Father in Him, and so come mutually into a willing, a common, and an enduring fellowship of heart" (op. cit., 3 Stuck, 1 Abt., iv.). But if such be the character of the (invisible) Church, this conception of the Christian Law must be the governing one for Christianity in all its social bearings, and surely also as it controls the individual life.

(4) Ethical systems may be distinguished according as they draw an absolute or only a relative distinction between reason and the lower impulses. As a representative of the latter type we may take Aristotle, who says that the impulsive part of the soul also " partakes of reason; at all events in a continent person it obeys reason, while in a temperate or courageous person it is probably still more obedient, as being absolutely harmonious with reason" (Eth. Nic., I. 1102 b 25-28, tr. Welldon, p. 32). It would be not unnatural to cite Kant as representing the opposite, or rigoristic view. But in the introduction to the second part of the Religion innerhalb der Grenzen u.s.w. we find this significant sentence, "Natural inclinations are, when considered in themselves, good, i.e., not to be rejected; and it is not only vain, but it would also be harmful and blameworthy, to wish to extirpate them; much rather should they only be disciplined, that they may not themselves destroy one another, but that they may be brought together into harmony in that whole which we call blessedness." The phrase "that they may not destroy one another" ("damit sie sich untereinander nicht selbst aufreiben, sondern," which was given its present form only in the second edition of 1794, the original words being "untereinander selbst aufreiben und u.s.w.") gives pointed expression to a feeling that must often have occurred to readers of Kant-that of the waste of moral energy, the needless internal friction, supposed by a theory 
which treats feeling as essentially disparate with reason, and hence teaches that it can only be controlled and kept under, but cannot be taken up as an auxiliary into the higher life. If virtue consists in the negation of impulse, the moral force of the individual is exhausted in the control of his own feelings and desires, instead of being set free to carry on the work and battle of goodness in the world without. But in this final statement Kant seems to recognise this fact, and to approach the Aristotelian position. That it is also the Pauline position is evident. The ideal of the New Testament is liberation from sin in order to a free, spontaneous, unfettered service on the part of the whole man. (Cf. 1 Thess. v. 23 ; Rom. vi. 22 ; xii. 1 ; 1 Cor. xiv. 15.)

\section{Note $S$ to p. 303, The Character of Jesus as the UNIVERSAL IdEaL.}

I append a few sentences bearing on the subject of Chapter XI. from the late Dr Somerville's St Paul's Conception of Christ, as that fine book is now unfortunately out of print. They occur in the lecture entitled "Christ the Archetype of Humanity" (pp. 59-61). "He came to meet the moral and religious needs of the race that are far deeper and more imperative than those to which the scientist or artist makes his appeal. And it is in this moral and religious sphere that $\mathrm{He}$ is to be recognised as the Ideal, who lays on every man the obligation, and inspires in every man the hope of being what $\mathrm{He}$ is. For, while Newton and Shakespeare and Darwin obtain our admiration, they do not make us feel it is our duty to follow them, still less do they suggest that each one of us has that capacity of thought and imagination that can ever bring us into equality with them were we to make the attempt. But to understand what Christ is, and to have our eyes opened to His greatness, is to feel at the 
same time, amid all that humbles us in the discovery, this is what I was made for, what I ought to be,-to love as Jesus loved, to live as Jesus lived. What we mean by Christ being the Ideal Character is that $\mathrm{He}$ presents to us human nature in its typical or ideal form, related to God and to men as human nature ought to be, under which $\mathrm{He}$ is recognised to be the law for everyone, in obedience to which everyone reaches the true end of his being. There is no human being who may not see in Him the Divine Idea and Purpose, the true conception and end of himself.

" $\mathrm{He}$ is also the Moral Ideal. . . . In asserting the supremacy in Him of the Spirit over the flesh, Paul meant that in Him the Spirit of Love was supreme. The life and character of Christ were the incarnation of grace to sinners, of sympathy, of humble, loving service. And therein is $\mathrm{He}$ the ideal for us in our social relations. But neither on this does Paul enlarge. The history of Jesus was known to his readers. It was universally recognised as an imperishable memorial of pure unselfish love. $\mathrm{We}$ are surely not wrong in supposing that the apostle was drawing from his own impressions of that wonderful history when he sang the praises of Love in 1 Cor. xiii., and outlined the character that love inspires."

Note $T$ to p. 327, Positive and Negative Forms OF THE "Golden RULe."

It is natural that this rule in a complete or incomplete form should have found a place in ethical systems whose origins were widely separated. For it sets up a standard in the treatment of others which can always be readily applied-a man's feeling of what is due to himself from others. The rights, which he wishes them to allow to himself, he may clearly be expected to respect in their case also. But as a rule it is 
in the prohibitory sense that it has been enforced. So in the case of China,- "The Golden Rule in its negative form occurs four times in the Four Books or Confucian New Testament. In one instance the negative used differs from the negatives employed in the other three instances, and is held to imply spontaneity and benevolence: 'What I don't wish men to do to me, I also wish not to do to men"" (World Missionary Conf., Report of Comm. IV., ut supra, p. $55 \mathrm{n}$., ef. p. 101). But even in this fourth instance the negative form is still preserved. In Greece the maxim was

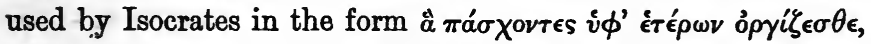

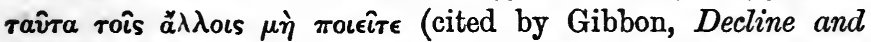
Fall, Ch. LIV., note 36). Finally, it is attributed in the same negative form to Rabbi Hillel- "Do not to others what ye would not that they should do to you" (Cf. Fairweather, The Background of the Gospels, pp. $18 \mathrm{f}$.). It is remarkable that this widely current ethical standard appears to have been given a positive form and content by Jesus alone, who proclaimed it as the summation of an active morality. "All things therefore whatsoever ye would that men should do unto you, even so do ye also unto them: for this is the law and the prophets" (Matt. vii. 12).

In regard to the substitution of a morality based on "Thou shalt" for one based on "Thou shalt not" in Christianity, familiar and forcible statements are Robert Louis Stevenson's in "A Christmas Sermon" (Across the Plains), and Seeley's in chapter xvi. of Ecce Homo. The latter says with much truth that "the sinner whom Christ habitually denounces is he who has done nothing," and refers in support of this statement to the figures in the parables of the priest and Levite, of Dives, and of the servant who hid his single talent in a napkin, as those who were condemned for what they had failed to do. (Luke x. $31 \mathrm{f}$., xvi. $19 \mathrm{ff}$; Matt. xxv. $24 \mathrm{ff}$; also Matt. xxv. 41 ff. ; Luke xvii. 10.) 
Note $U$ to p. 336 , Chalmers on the Defects of Mere Feeling as a Moral Dranamic.

To the opinions of Kant and Spinoza given in the text it may be of interest to add that of one of the greatest and most far-sighted of social reformers, Thomas Chalmers. He first speaks of "the mere feeling of compassion" as a "feeling which, however useful for the purpose of excitement, must be controlled and regulated"; and proceeds, "Feeling is but a faint and fluctuating security. Fancy may mislead it. The sober realities of life may disgust it. Disappointment may extinguish it. Ingratitude may embitter it. Deceit, with its counterfeit representations, may allure it to the wrong object. ... The Bible rescues the cause [of charity] from the mischief to which a heedless or unthinking sensibility would expose it. It brings it under the cognisance of a higher faculty, a faculty of steadier operation than to be weary in well-doing, and of sturdier endurance than to give it up in disgust. It calls you to consider the poor" (Chalmers on Charity, edited by N. Masterman, pp. 219 f. The passage is contained in the Ninth of the Sermons preached upon Public Occasions). This introduction of the objective element - the patient study of the real needs of those who are to be helped-to correct the deficiencies of the merely subjective feeling is directly in the line of the solution suggested in the text (supra, pp. 338 f.). 


\section{GENERAL INDEX.}

Absoluteness, the, of Christian morality, 309-11

Altruism, and egoism, 134 f., 360 ; conflict between the narrower and wider, 136-8

Eschylus, $260 \mathrm{n}$.

Anaxagoras, 65

Angels, belief in, and the transcendent Kingdom, 201-3

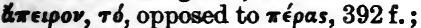
the attitude of Greek thought to, 37,42 f. ; see also Infinite

Apocalyptic Element in N.T., its ethical significance, $22,182 \mathrm{ff}$; ; see also Eschatology

ápeтt, $115 \mathrm{f}$., 125 ; see also Virtue

Aristippus, $115 \mathrm{n}$.

Aristotle, classification of virtues in the Ethics, 4 ; on the development of virtue, 5 ; negative tendency of his doctrine of the Mean, 5, $38 \mathrm{ff}$; indications of a more positive view, 9 f., 390 f. ; his doctrine of the " complete life," $40 \mathrm{f}$. ; of the finite nature of the Good, 42 ; of the $\kappa_{\mu} \psi v \chi \chi^{\circ \nu}$ opyavov, $53 \mathrm{f}$. ; exclusive idea of

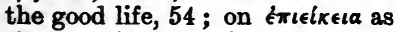

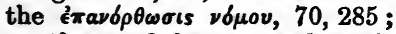
on the need for outward goods and friendship, 116-8, 147; on the self-sufficiency of the theoretic life, 119-21 ; on the use of pro- perty for the Common Good, 131 ; on the standard of liberal-

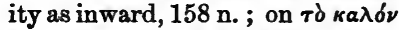
as the object of kingship, 324 ; on the true end of war, 375 ; on virtue and happiness, 406 ; on the possible moralisation of impulse, $414 \mathrm{f}$.

Arnold, Matthew, 100

Art, disinterested and universal character of true, $125 \mathrm{f}$. ; and the Common Good, 127 f. ; place of, in the Christian ideal, 177

Astronomy, modern, and the individual, 64-7, $75 \mathrm{f}$.

Athene, ideal character of, expressed in the Parthenon, $127 \mathrm{f}$.

Augustine, on the Good as social and common, 104 ; on the earthly and heavenly city, 202 ; on the sins of infancy, 312 ; on the Order of Love, 389

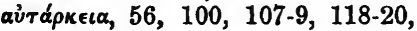
144

Autonomy, Kantian doctrine of, 81,86 ; in Christian Ethics, 345 f. ; see also Freedom

Averages, the law of, and the individual, 70-2, $396 \mathrm{f}$.

Barker, H., 219 n.

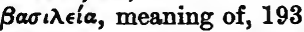

Beginnings, the possibility of new 
moral, chap. x. passim; their occurrence attested by experience, 257 f., $271 \mathrm{f}$. ; and the Spiritual Order, 283, 365-7

Beneficence, Christian, directed to the bettering of the present world, $198 \mathrm{f}$. ; disinterestedness of true, 234

Bentham, 70

Bergson, 269, 407-9

Body, the, Christian care for, 145 $50,401 \mathrm{f}$.; as the instrument of spiritual service, $153 \mathrm{n}$.

Boethius, 399

Bonar, J., 70 f., 396

Bousset, 200

Bradley, F. H., 123 f. ; 383

Browne, Sir Thomas, viii., 44, 75 n.

Browning, 27, 169

Bruce, A. B., 95, 145, 231, 402

Burnet, J., 391

Bury, R. G., 300 n., 392

Bushnell, 314 n., 323

Butcher, S. H., 11

Caird, Edward, 35, 412

Cairns, D. S., 184

Carlyle, 238 n.

Catastrophes, natural, 67 f., 387

Categories, ethical, the criticism of, $1 \mathrm{f}$. ; relation of, to Christian morality, 348-52

Causality, physical and spiritual, Lotze and Bergson on, 265.9, 406-9

Chalmers, 39, 67, 418

Charity, need for wisdom and constancy in, 336-8, 418

Chesterton, G. K., 36 n.

"Child-element in Christianity," the, central place of, in the teaching of Jesus, 95 f., 191 f., 320-2 ; recognition of, by Paul, 321 ; see also Fatherhood

China, religion of, 59 ; the "Golden Rule" in, 417

Christian Ethics, dependent for its form on Moral Philosophy, $2 \mathrm{f}$. ; positive character of, chap. i. passim, $326 \mathrm{ff}$., $393,416 \mathrm{f}$. ; the criterion of, practical rather than intellectual, 77, 259-63, 381-4 ; dynamical and redemptive character of, $97-102,162-6,207,331$ f. ; importance of non-competitive idea of true good for, $104 \mathrm{f}$. ; synthesis of inward and outward elements in the idea of service, $155 \mathrm{ff} ., 171,403$; universalism of, chap. vi. passim; synthesis of variety and unity in, 167, 1724 ; comprehensiveness of its ideal, 177-9; the eschatology of the N.T. and, 182-5 ; importance of the idea of recompense for, 209 ; its transmutation in, $233.6,245.51$; the ruling motive of, $238,250,275,324$; character of teleological, not legal, 285-9, $341,351 \mathrm{f}$.; but the idea of Law, in a higher sense, indispensable to, 293 f. ; the character of Jesus the central fact of, $300-3$, 309,338 ; appeal of, to feeling as well as intellect and will, 300 , 328-37 ; claim of, to absolute authority-how established, 310 f. ; inwardness and searching character of, $318,327-30$; transformation of ethical categories in, $348 \mathrm{f}$. ; in what sense morality is transcended in, 350-4; and the belief in the Good as ultimate Reality, $204 \mathrm{f}$., 377-80; the two moments of, and their final unity, $383-5$; unity of the different aspects of, in love, $386 \mathrm{f}$.

Church, the, and the State, $136 \mathrm{f}$., 374-6; in the Roman Empire, 174 ; Dante on, 175; Kant's comparison of, to a universal Divine Family, $413 \mathrm{f}$.

Church, the Early, courage of, 18 ; diversity of gifts and functions in, $172 \mathrm{f}$. ; significance of the appointment of the "Seven" for, 173 ; confidence in the reality of new beginnings in, 271 ; Paul's care for the upbuilding of, 342

Cleanthes, Prayer of, 25 n.

Coleridge, 331, 382

Common Good, Doctrine of the, importance of, for Christian 
Ethics, 103-5 ; basis of, in experience, $105 \mathrm{f}$. ; founded on the idea of virtue as inward, $107 \mathrm{ff}$. ; Spinoza and Kant on, 112-4, 138 ; form of, in Greek Ethics, 114-22; contribution to, as the ethical standard, 129-35, $155 \mathrm{f}$.; ideal character of, $137 \mathrm{f} ., 401$; place of, in the N.T., and final form of, 157.61, $369 \mathrm{f}$. ; as the unifying principle of Law and Freedom, 340 f. ; Dante and T. H. Green on, $400 \mathrm{f}$.

Communism, 131

Community, the, and the Individual, 102-5, 117-22, 131-7, 160,166

Community of the Good, chaps. iv. and v. passim; and see Common Good

"Competitive" and "non-competitive," meaning of, 399 ; and see Common Good

Conscience, universality of, $303 \mathrm{f}$. ; relation of, to the character of Jesus, 304-7

Contemplation, the life of, in Spinoza, 113 ; in Aristotle, 119. 21 ; not the complete Christian ideal, 159 f., 206 f. ; organic relation of, to the life of action, 381-5

Continuity, in goodness as the greatest reward, 220 f., 242 ; in $\sin$ as the greatest punishment, 222 ; development of the idea of moral, 254 f. ; antithetic to the idea of redemption, 256, 260, 270 f. ; predominantly theoretic character of the idea of, $260 \mathrm{ff}$. ; true use of, positive, not negative, 268 f., $281-4$; see also Legal Order

Contribution, not acquisition, the true ethical principle, 129-31, $155 \mathrm{f}$. ; and the Common Good, 133-9

Conversion, central place of, in Christian Ethics, 256 f., 271 f.; the reality of, attested by experience, $257 \mathrm{f}$.; specific form of, in Christianity, 273.5 ; how far a normative and universal Christian experience, 277-9

Cosmology, see Universe

Courage, union of, with gentleness in Greek thought, $7 \mathrm{ff}$. ; in N.T., $13 \mathrm{ff}$; exemplified in the life of Jesus, $16 \mathrm{f}$.

Creative character of moral action, 264-9 ; Lotze and Bergson on, ibid., $407 \mathrm{f}$.

Cromwell, 130 n.

Cynic philosophy, 57, 308; compared with Cyrenaic, 115

Dante, cosmology of, 64 ; on contribution to the public weal, and on the true Good as common, 128, 160, $400 \mathrm{f}$.; on the complementary functions of Church and Empire, 175; on new beginnings in life, 258 ; on the Freedom of goodness, 347 ; on love as the final principle of unity, 387. Other reference, $211 \mathrm{n}$.

Dark Ages, preservation and progress of Christianity in the, 376

Darwinianism, 68

Denney, 153 n., 165 n., 335 n.

Desert, see Merit

Determinism, not accepted by Christian Ethics, 32, 264-8

Devon, J., 397

Diaspora, the, 62

Dignity (Würde) of Man in Kant's Ethics, $80 \mathrm{f}$.

Disciples, the, Jesus' appeal to loyalty of, 238, 245; promise of reward for encouragement of, 239, $245 \mathrm{f}$.

Discipline, diversity of, in the Christian life, 167 f.; as providing needful diversity of character, 169-72

Disinterestedness of true art, 126-8

Disinterestedness of virtue, chap. viii., 238, 244 ; and the universality of the Good (Spinoza and Kant), 113 f. ; see also Virtue

Diversity of character, necessary to the Christian ideal, 43, $177 \mathrm{f}$.; its evolutionary genesis, $48 \mathrm{f}$.; 
dependent on diversity of outward circumstance, 168-70; leading to diversity of function, 171 f.; consistent with Christian unity, 172

Drummond, Henry, 47 f., 62

Duff, R. A., 114 n.

Duty, see Law, Obligation

Dynamical character of Christian Ethics, 97-9, 166, 207, 331 f., 382,388

Earnestness and equanimity, equal emphasis on, in the N.T., $20 \mathrm{ff}$., 152, 194 f., 344-7, 381-4

Ecce Homo, 149 f., 165 f., 184, 244, $257,395,417$

Economics, and the individual, 68 . $72,85,101,396 \mathrm{f}$.

Egoism, see Altruism

Egypt, 59, 64

Eliot, George, 364, 398

Emotional element in morality, see Feeling

Empire, the Church and the Roman, $174 \mathrm{f}$.

Epictetus, on the union of confidence and caution, $23 \mathrm{f}$.; on the dignity and brotherhood of man, 58 ; on virtue as inward and in. alienable, $110 \mathrm{f}$.

Epicureanism, 263

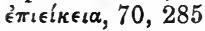

Equanimity, 20 ff.; see also Earnestness, Trust

Erskine, Thomas, 290, 301, 409

Eschatology in the N.T., importance of increasingly recognised, $182 \mathrm{f}$. ; yet not to be regarded as dominating the ethical, $184 \mathrm{f}$.; its specific character and recognition of the individual, 22, 199-201; and the conception of reward as essentially spiritual, 230 f. ; Jesus' appeal to, as support under trial, 239

Eucken, 381 n.

Evolution, growing place of the individual in, 46-50

Evolutionary ethics, 360

Example, the Law as embodied in, 300-3; the character of
Jesus, the supreme, 309, 338, $415 \mathrm{f}$.

Exile, the, its effect on the Jewish estimate of the individual, $60 \mathrm{f}$.

Fairweather, 62, 417

Faith, and works, 153 ; as apprehension of the Spiritual Order, 203 f., 381 ; as active and practical - the effort to realise this Order on earth, 206 f., 382 f., 388 ; Paul's doctrine of Justification by, and Jesus' teaching on Trust, 321 ; relation of, to Revelation, $381 \mathrm{f}$.

Family, the, and the State, 136 $286 \mathrm{f}$.; see also Child-element, Fatherhood

Fatherhood, of God and Jesus' estimate of the individual, 95-7 ; as the highest expression of the Christian view of morality, 96 , 286-90; relation to the infinite standard of duty, 320 f. ; and the principle of trust, 287, $321-4$

Feeling, as an element in morality, Kant's rejection of, $295 \mathrm{f}$. ; emphasis on, in Christian Ethics, $298-301,307,328-32$; alleged particularity and inconstancy of, 295, 335-7 ; two-fold discipline of, in the Christian life, 338.42 ; Aristotle and Kant on the moralisation of, $414 \mathrm{f}$.

Fénelon, 212

Fichte, 181, 403

Fiske, 48.

Flinders Petrie, 55 n.

Fogazzaro, 207

Fontenelle, 82

Force, the justifiable use of, by the State, 372-5; not the true instrument of Christian warfare, $370 \mathrm{f} ., 375 \mathrm{f}$.

Forgiveness, as a Christian duty, $29,276,370-2$; and the Kingdom, $189 \mathrm{f}$. ; and the experience of new beginnings, 267, 409 ; sense of, the great moral dynamic, 274-9, 289 f.; see also Redemption 
Formal and material criteria, distinguished in their application to Christian Ethics, 2 f., 124, 351 f.

Forrest, D. W., 321, 353 n.

Francis of Assisi, St, 140, 300

Freedom, two senses of defined, 267 n. ; (1) Freedom of moral action (opposed to determinism), $81,264-9$; (2) Freedom in service of the Good, 211 f., 323 ; Christian, how conditioned, 334, $338-40$; realised and reconciled with Law, in devotion to the Common Good, 340-5; a task as well as a gift, 344 n., 347

Friendship, Aristotle on, 118, 147

Gabe and Aufgabe, 181, 403 f. ; see also Gift, Task

Galileo, 65

Gentleness, union of, with courage ; see Courage

Gibbon, $128 \mathrm{n}$.

Gibson, W. R. Boyce, 267, 381 n.

Gift, the Christian Good as, 181, 185 ff., 193 n., 204, 247-50, 403 ; the sense of, as ground of Christian morality, 250-2, 404; see also Task

Goethe, conclusion of Faust, 129

Good, Christian conception of the true; see Christian Ethics, Common Good

"Good Will," the, Kant's doctrine of, 78 ; concrete activity of, 125 , 129,155

Goodness, see Virtue

"Goods," external, competitive character of, 105, $399 \mathrm{f}$.; treated as "preferable" rather than good by Stoicism, 111 f. ; Christian view of their right place and use, 94, 158, 402

Gore, 43

Gratitude, place of, in Christian Ethics, 250 f., 275 f.

Greek Ethics, positive and negative elements in, $5 \mathrm{ff}$., 390-4; place of limitation in, $37 \mathrm{ff}$., $392 \mathrm{f}$. ; recognition of the value of external goods in, 115-7; the individual and the State in, 118,
122, $130 \mathrm{f}$. ; place of art in, $127 \mathrm{f}$. ; emphasis on free allegiance to Law, and the infinity of obligation in, 323 ; the chief motive of, 324 ; see also Socrates, Plato, Aristotle

Greek religion, and the individual, 59 f., 89

Green, T. H., doctrine of the Common Good, 104, 125, 400 ; criticism of, by Sidgwick, 123 f. ; on the Common Good as a demand, 137 ; on Greek Ethics, 394

Haering, 27, 181, 403 f.

Haller, A. von, 398

Happiness, the place of, in Moral Philosophy, 213 f., 222-4, 404-6 ; its transfigured character, 225 ; see also Reward

Harnack, 92 n., 100 f., 181, 188

Hazlitt, 126 f.

Healing, importance of Jesus' ministry of, 145-7, 188, $401 \mathrm{f}$.

"Hebraism and Hellenism," 37, 393 f.; see also Greek Ethics, Jewish religion

Hedonism, 106

Hegel ; on History as the extension of Freedom from one to all, $51 \mathrm{f}$. ; on Eastern religions and the individual, 59 ; on the false infinite and the true, 74,398 ; on the universal in Art, 127; on inward and outward virtue, 153 n., 161 ; on the Good as Gabe, 181,403 ; on old age, as the strength] of Spirit, 366 n.; on punishment, 410

Heine, 97

Heracles, in Cynic preaching, 300 n., 308

Heraclitus, 366, 392

Herodotus, 52, 59, 64, 323

Herrmann, $347 \mathrm{n}$.

Hillel, Rabbi, 417

Höffding, 67, 221, 383

Hogg, A. G., 289

Hope, of reward not the true moral motive, $210 \mathrm{ff}$., $231 \mathrm{ff}$; ; real place of, in Christian Ethics, 239-45, 249-52, 365-7, 388, $405 \mathrm{f}$. 
Horace, $364 \mathrm{n}$.

Hort, 301 n., 357, 366

Human nature, unity of, $153 \mathrm{f}$.

Hume, 71, 378

Huxley, 360

Idealism, relation of philosophical, to Christian Ethics, 378-81

Immanence and transcendence, 380

Immanent, view of recompense as, 254 f., 406

Immortality, the belief in, as a postulate of the moral life, 41, 220 f., 362 ; as attested by present experience of the Spiritual Order, 359, 363-9; the Platonic doctrine of, and the individual, $55 \mathrm{f}$.

Independence, see aù $\alpha \dot{\rho} \kappa \epsilon \iota \alpha$

Indian thought, $210 \mathrm{f}$., $255 \mathrm{n}$.

Individual, doctrine of the Value of the, as principle of synthesis in Christian Ethics, 19, 33 ; growing importance of, in evolution, $46-50$; relation of, to sympathy and to self-consciousness, $50 \mathrm{f}$.; historical development of, 51-62 ; Hegel on, 51 f. ; in Greek life and thought, 52-8; religion and the, 58.62; challenged by the infinity of the material universe, 63 ff., 398 ; by economic forces, 68 ff., 396 f. ; philosophical defence of, based on the greatness of man as a thinking being (Hegel, Pascal), 73-7 ; as a moral being (Kant), 78.84; uniqueness of every personality, subjectively and objectively, 84-7 ; defence of, in tragedy and modern literature, 88 , 398; in Jewish religion, $60-2,89 \mathrm{f}$. ; in the teaching of Jesus, 90 ff.; based on His belief in the Fatherhood of God and the Child-element in religion, 95-7; proclaimed as potential rather than actual, 97 $100,162.5$; connected with the work of Jesus, 97, $165 \mathrm{f}$. ; realised only in the common life, 102,160 ; place of, in the eschat- ology of the Gospels, $199 \mathrm{f}$. ; and redemption, $98 \mathrm{f}$., $261 \mathrm{f}$.

Infinite, Greek suspicion of the, 37,41 f., 392 f. ; positive interpretation of, in Christian Ethics, 41 ff.; the "false" and the "true," 74-6, 398; the character of virtue and moral obligation as, $43,315-8$

Inge, $330 \mathrm{n}$.

Intellectualism, 77, 260-9

Ionian "Hylicism," 392

Isocrates, 417

James, William, 86 f., 257

Jeremiah, the character of, 15

Jesus, the Character of, as the perfect harmony of opposite virtues, $16 \mathrm{f} ., 309$; His courage, 17 ; $\mathrm{His}$ sternness in judging sin, 27-32, 395 ; His sympathy for and understanding of individuals, 91,167 , 338 ; His sacrifice as proof of their value, 97 ; His work as that of recovery, 98-102, 271-3 ; the example of His poverty, $141 \mathrm{n}$.; the place of healing in $\mathrm{His}$ ministry, 145, 188, 401 f. ; import

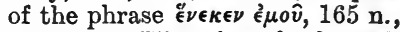
245,324 ; His triumph through apparent failure, 168 ; genuineness and naturalness of His sympathy with suffering, 198 f. ; His dependence on prayer and the Divine Will, 203 f. ; power of contact with, to change men's lives, 273 ; as the supreme Ideal and Law, 238 f., 301 f., 309, 338,415 f. ; universal appeal of, proved by experience, 310 f.; influence of, on the modern conscience, 312-4; as the example of constancy and the wise direction of good impulse, $338 \mathrm{f}$.; as "overcoming evil with good," $370 \mathrm{f}$., 376 ; as the strength of the Christian life, 388

Jesus, the Teaching of - emphasis laid on courage, 16 ; on earnest endeavour, 20-22, 194-9 ; on quietness and trust, 22, 95, 321 ; on forgiveness, 29,276 ; 
originality combined with reverence for the past, 33.5 ; on the value of the individual soul (life), $90 \mathrm{ff}, 271$; of the life of woman, 95 ; on the Childelement in religion and the Fatherhood of God, 95.7; on wealth and poverty in relation to the Spiritual life, 92-4, 147, 402 ; on the simplicity and immediacy of the highest good, $141 \mathrm{f}$. ; recognition of the need for leisure and quiet, 148; use of illustrations from Nature in, 149; standards of judgment in, $153 \mathrm{f}$. ; their underlying unity based on the unity of human nature, 154 ; on service as the supreme law, 156, 171 ; universalism of, 163 ff.; on the Kingdom of God, ch. vii. passim (and see Kingdom); temporary and permanent aspects of, 183 ; place of eschatology in, 184; continuity with the ethical teaching of the prophets, 197 ; opposition to Pharisaism, 185, 197, 270 f., 327 ; emphasis on the Will of God, and the absolute reality of goodness in, 203 f.; use of the idea of reward in, $231 \mathrm{ff}$.; reward not the main motive to service, 235.8 ; its socialised and spiritualised form in, $235 \mathrm{f}$., $241 \mathrm{f}$. ; on the possibility of new beginnings, $269-71,281 \mathrm{f}$; on continuity in the spiritual life, 280 ; the two principles complementary, 283 f. ; unity of, with $\mathrm{His}$ character and example, 301 ; on the infinity of virtue and duty, 317 f.; on small and practical duties, 319 ; unity of these elements in the thought of childlike service and trust, $320 \mathrm{f}$.; on morality as positive and inward, $326-8$; on non-resistance and the conquest of evil by lore, $371 \mathrm{f}$.

Jewish Religion, growing recognition of the value of the individual in, 60 f., 89 f.; uni- versalism of, in the post-exilic period, 62; respect for the stranger and defenceless inculcated by, 89 ; place of eschatology in, 183-5; development and spiritualisation of the idea of reward in, 226.30; emphasis on Fatherhood and Sonshipand their relation to redemption in, $287 \mathrm{f}$. ; abstract and remote conception of the Law in, 296 ; emphasis on God's reality and truth in, 362 n. ; thought of the perennial freshness of the spiritual life in, 365-7

Johannine writings, the conception of the true and eternal life in, $362 \mathrm{n}$.

Joinville, story of Saracen woman in, 210

John the Baptist, 19 f., 29, 188 f.

Jowett, 348

Jülicher, 302 n.

Justice, as the expression of moral continuity, 259 ; not the complete ethical ideal, $260-2,285$; subordinated in the last resort to redemption, $286-90,409$; see also Law, Legal Order, Merit

$\kappa \alpha \lambda \delta \nu, \tau \delta$, in Greek ethics, 324

Kant, on the law of averages, 71 ; on the Good Will, 78; distinction between things and persons, ibid. ; infinite value of the latter, $79 \mathrm{f}$. ; doctrine of Autonomy and the Moral Law, 81-4; conclusion of the Critique of Practical Reason, 83 ; on the Common Good, $113 \mathrm{f}$.; on the ethical value of external goods, 117 n.; on the Common Good as an ideal principle, 138 ; twofold emphasis on the disinterestedness of virtue and its independence of reward ("Analytic"), 212 ; and on happiness as the reward of virtue ("Dialectic"), 213 f., 404 f.; harmony of the two aspects, $217 \mathrm{f} ., 225,405 \mathrm{f}$. ; on the transition from morality to religion, 219,221 n. ; on reward as the 
opportunity of moral progress, $220 \mathrm{f}$. ; on the happiness of others as ethical end, 223 f. ; threefold criterion of morality : -(1) purity, 252 ; (2) universality, 294 ff. ; (3) autonomy, $345 \mathrm{f}$. ; suspicion of feeling and "moral sense," 294-7, 336 ; abstract conception of the Moral Law, ibid. ; view of the highest example of goodness as subordinate to the inner voice of conscience, $304 \mathrm{f}$. ; criticism of this view, $297 \mathrm{f}$., 305-7; doctrine of original, timeless act of free-will, 312 ; on the noumenal and phenomenal worlds, 359 ; development of his views in the Religion innerhalb u.s.vo., 411-3 ; on the Church as the universal Divine Family, 413 f. ; on the moralisation of impulse, $414 \mathrm{f}$.

Karma, 255 n.

Keats, 169

"Kingdom of Ends," 81, 298 n., 359

Kingdom of God, the various aspects of, chap. vii. passim; place of human effort in its realisation, 20, 193 ff.; spiritual poverty as preparation for, 92,141 ; as both " gift" and "task," present and future, 181-6, 404; four aspects of-(1) a present gift, $186-93$; (2) an ethical task, $193-9,206$; (3) a future (eschatological) consummation, $199 \mathrm{f}$; (4) a transcendent reality, 2015 ; comparison with the aspects of Plato's Republic, 204-7 ; and future recompense, 209, 235, 241 ; relation of, to the conception of Law, 293, 342; and the kingdom of sin, 356 ; as founded on the Spiritual Order, 204, 357, $377-9$

Kirn, 404

Law, defects of, owing to its rigidity, 70 f.; difficulty of applying to individual cases, ibid., 397 ; its aim not merely the doing of justice, but the production of goodness, $285 \mathrm{f}$., $409 \mathrm{f}$. ; its supersession or modification when it fails in this end, 287-91, 333-5, $353 \mathrm{f}$. ; the higher, and the legal system, 292-4, 349 $\mathrm{f}$.; the lower and the higher in the N. T., $356 \mathrm{f}$., $369 \mathrm{n}$.

Law, the Christian, personal character of, 299-304, $415 \mathrm{f}$. ; appeal of, to feeling as well as to abstract reason, 299 f., 307, 314 ; appeal of, from above, not from below, 306 f. ; universality of, proved by the experience of different ages and countries, $310 \mathrm{f}$. ; special adaptation of, to the present day, 311-4 ; infinite character of, 317 f. ; emphasis on small practical duties, 319 ; harmony of these characteristics, 320-4; as positive in two senses, (1) as enjoining a positive morality of love, $326-30$; (2) as providing an impulse and a dynamic, 331 f. ; as based upon the character of Jesus, and directed to the Common Good, 338 f. ; synthesis of, with Freedom, $340-7$; as the fulfilment of the ends of history and of the legal dispensation, 354 ; and the Spiritual Order, $356 \mathrm{f}$.

Law, the Moral, Kant's doctrine of the, 79-84, 212; double character of, as infinite and strictly binding, $314 \mathrm{ff}$.

J awrence, Brother, 178, 272 n.

Legal Order, the, and the ideals of justice and continuity, 285 ; subordination to the Spiritual (redemptive) Order, 289, $349 \mathrm{f}$.

Leibnitz, 86

Leisure, need of, for the good life, 119 f., $147-9$

Liberality, 158, 402

Liberty, see Freedom

Life, see Immortality

Life, the Christian, its two moments, 20 ff. ; their underlying unity, 382-5 ; see also Virtue

Limitation, as the method of Greek 
Ethics, 37 ff., 392 f. ; contrasted with the Christian Synthesis, 39 ff.

Lotze, 265, 268, $406 \mathrm{f}$.

Love, as the common ground of courage and gentleness, $18 \mathrm{f}$.; and the value of the individual, 87,91 ; as the inspiring principle of Christian service, $155-9$; as necessarily passing from the inner to the outer life, ibid., 161, 384 ; of God, as the one true motive of virtue, $210-2$; as the fulfilment of the Christian Law, $327-9,338-40$; as the unifying principle of Christian Ethics and the Spiritual Order, $386 \mathrm{f}$. ; com. pared with Faith and Hope, $388 \mathrm{f}$.

Loyalty, place of, in Christian Ethics, 238 ; and the infinity of duty, 322 f. ; contrasted with legality, 323

\section{Lucretius, 263}

Luther, on the inward good, 141 n. ; on the disinterested service of God, 211 ; and Staupitz, 312 ; on Christian Freedom, 341 ; on Christian virtue as the effortless result of faith, 347

Macgregor, W. M., 150, 395

Mackintosh, R., 35

Macrocosm and microcosm, 75

M'Taggart, J. E., 51 n., 87

Malthusianism, $68 \mathrm{f}$., 101

Man, see Individual, Value of the

Marcus Aurelius, 31 f., 111

Marshall, A., $396 \mathrm{f}$.

Mathematics, as type of abstract, formal truth, 297 ; contrasted with moral truth, 298 f.

Mathews, Shailer, 14 n., 195 n., 196

Maurice, F. D., 130

Mazzini, 107, 130

Mean, doctrine of the, $4 \mathrm{f}$., $37 \mathrm{ff}$., 390 f. ; see also Aristotle

Mercy, place and conception of, in the N. T., 27-33, 395

Meredith, George, 263

Merit, the idea of, connected with
Law and Reward, 246-9; how transcended in the N. T., 247, 250 f., 349

Messianic Hope, the, 183-5, 231

Michael Angelo, 177

Mill, J. S., 71, 378

Milton, 111, 177

Moral Philosophy, relation of, to Christian Ethics, 2 f., 378 f.; as a "normative science," 138 ; the two great interests of, 209 f., $218,224 \mathrm{f}$. ; modification of its categories in Christian thought, $349 \mathrm{f}$.

"Moral Sense," Kant's criticism of, $295 \mathrm{f}$. ; place of, in Christian Ethics, 299 f.

Muirhead, J. H., 380 n.

Muirhead, L. A., 200

Murray, Gilbert, 128, 395 f.

Murray, J. Clark, 75, 89

Myers, F. W. H., 25 n., 32, 241

Natural order, the, chap xiii. passim

Nature, and the individual, $47 \mathrm{ff}$., $63 \mathrm{ff}$.

Newman, 26, 394

Newton, 177, 415

Nietzsche, 13, 199, 351 n.

Non-resistance, 372-7

Obligation, moral, how enforced by Christianity, 311-4 ; antinomy of (1) as definite and limited, (2) as infinite, $314-20$; in Roman Catholic Ethics, 316 f.; synthesis in the N. T., 320-2; the Greek idea of, $323 \mathrm{f}$; the

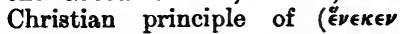
$\left.\epsilon_{\mu o v}\right), 238-40,324 \mathrm{f}$. ; the needs of others, the standard of, 339-42

Order, see Spiritual Order

Original $\sin , 312$

Orphism, 59 n., 62

Paley, 211

"Parables of the Kingdom," the, 194-6

"Paradox of Christian Character," the, 23 f., 36, 144, 394

Parental affection, and the dawn 
of individuality, 48 ; see also Fatherhood

Parousia, see Eschatology

Pascal, on virtue as the union of opposites, $12 \mathrm{f}$. ; on the greatness and littleness of man, 67, $76 \mathrm{f}$.

Past, reverence for the, 33-5; as not wholly immutable, 266; transformation of, in moral experience, $267 \mathrm{f}$. ; in the experience of conversion, 271-3

Patience, place of, in Christian Ethics, 21 f., 194, 342

Paul, St, on the union of trust with strenuous endeavour, $20-26,344$ $\mathrm{n}$. ; on the positive principle of the Christian life, 39 f., 332 ; on consideration for the good of others, 105, 344 ; on the immediacy of the Christian good, $142 \mathrm{f}$. ; on the paradox of the Christian life, 144 ; on the use of outward agencies in the spread of Christianity, $151 \mathrm{f}$. ; on service and liberality as the expression of love, 154-8; on outward circumstance as furthering the Christian life, 168 ; on diversity of gifts in the Church, 44, 171-3 ; references to the Christian good as present, $192 \mathrm{f}$. ; treatment of the idea of reward, $247 \mathrm{f}$. ; subordination of it to those of free gift, gratitude, and stewardship, 248.51; his experience of a radical change, 273 , 331 ; its power as a motive to goodness, 274 ; on continuity and redemption, $282 \mathrm{f}$. ; his development of the Gospel teaching, 293 n. ; on Christ as the Christian Law, 302-4; his sense of obligation to keep the whole law, 312,318 ; kinship of his doctrine of Faith and Sonship to Jesus' teaching, 321 ; on Love as the end of the Law, 328 ; his conversion and subsequent sense of moral power, $330-2$; his doctrine of Freedom, 334 f. ; conditioned by the Spirit of Christ and the needs of his fellow-men, 340-5; on the superseding of the old
Law, 333, 353 f.; on the two orders (natural and spiritual) and the double law, $356,365-8$; on the weapons of the Spiritual Order, $370-5$; on the right use of force by the State, 373 ; on love as the supreme virtue, 388 ; on the service of the whole man, 153 n., 415

Paulsen, $82 \mathrm{f}$.

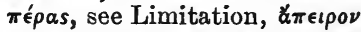

"Perfection, Counsels of," 316

Pericles, funeral oration of, 10

Persia, 52, 59

Person, distinguished from Thing, 78 ; see also Individual

Pharisees, the $28,185,197,270 \mathrm{f}$., 327

Phidias and the Parthenon, $127 \mathrm{f}$.

Phillips, Stephen, 75

Philosophy, see Idealism, Moral Philosophy

Pigou, A. C., 396

Plato, theory of virtue as a harmony of opposites, $6 \mathrm{ff}$; the "royal web" in the Politicus, $8 \mathrm{f}$.; on contemplation of the Good, 40; Theory of Reminiscence and the value of the individual, $55 \mathrm{f}$. ; on the defect of pure law, 70 ; on the inwardness and independence of virtue, $109 \mathrm{f}$. ; on the will to serve in the Republic, 130 ; on the education of the Guardians, 135; use of the metaphor of the body and its members, 157 ; on the divine care for individuals, 169 f. ; various aspects of the $R e$ public compared with those of the Kingdom in the N. T., 204-6; on the Good as supreme reality, 205,379 ; description of the suffering just man (Rep. II.), 215 and note; on the reward of virtue (Rep. X.), 216-8; parallel with Kant's view of reward, 217 ; on punishment as continuance in sin (Gorg.), 222 ; on "the soul's revolution" and the drawing out of its powers by the objective Good, 272, 305 
f. ; on the reality of the ideal world and the immortality of the soul, 358-61; on non-resistance to evil, $374 \mathrm{n}$.; on the Mean, and the relation of measure to virtue, $390-3$; place assigned to slavery by, $395 \mathrm{f}$. ; on the end of punishment as reformation, 410

Plato, dialogues referred to :-

$A$ pology, 15 n., 110

Gorgias, 15 n., 110, 222, $374 \mathrm{n}$.

Lawos, 9 n., 89, 170

Meno, 55

Parmenides, 57

Phoedo, 358-60, 393

Phoedrus, 40

Philebus, 393

Politicus, 6-9, 70, 390

Protagoras, 393, 410

Republic, 6-8, 40, 109, 130-5, 157, 169, 204-6, 214-8, 215 n., 272, 305 f., 358 f., 395 f.

Symposium, $56 \mathrm{f}$.

Theatetus, 6, $206 \mathrm{n}$.

Timceus, 64

Political action, as tending to disregard the individual, 70 f., 96 ; positive relation of, to the Christian ideal, 174-7

Positive character of Christian Ethics, chap. i. and xii. passim, 414-7

Poverty, the idea of spiritual, in the later prophets, 61; in the Gospels, 92 f. ; as a preparation for the Kingdom, ibid., 141

Practical character of the Christian ideal, 77 f., 259-63, 380-4

"Practical Reason, Primacy of the," $78 \mathrm{ff}$.

Pragmatism, 380, $381 \mathrm{n}$.

Prayer, as witness to the transcendent kingdom, 204

Property, Aristotle on the right use of, 131 ; see also Wealth

Protagoras, and the Homo Mensura, 79

Providence, the Christian idea of, $168 \mathrm{f}$; ; as neccessarily "particular" and dealing with individu- als, 170 ; Plato's later idea of, ibid.

Psychology, religious, and conversion, 257 f.; deterministic tendency of ordinary, 260-5

Punishment, Plato's view of, as the opportunity to continue in sin, 222; not a final end, but a means to truly moral ends, 28591 ; theory of, as reformatory, $409 \mathrm{f}$.

Purity of motive, in Kant and in Christian Ethics, 252 f.

Pythagorean doctrine, of evil as infinite, $41 \mathrm{f}$. ; of transmigration, 55 ; of communism, 131

Rainy, $42 \mathrm{f}$.

Raphael, 126

Reality, Christian belief in goodness as the ultimate, 203-6; the Spiritual Order and, $358 \mathrm{ff}$., 377.84

Recompense, importance of the idea of, 209 ; see also Reward, Punishment

Redemption, emphasis on, in the Gospels, 97-102, 164-6, 270 f. ; antithesis between moral continuity and, 256, 262; as the dominating principle of Christian Ethics, 282, 287-9

Reformation, the, and the individual, 64 ; and the life of the world, 159

Religion, distinguised from The$\operatorname{ology}, 1$; and the value of the individual, 58-62; and the conservation of values, 221 ; Kant on the transition from morality to, 221 n., 405 ; as the completion of Christian Ethics, 377-82 ; two aspects of, and their union, $383-5$; see also Greek, Jewish Religion

Repentance, and the Kingdom, $189 \mathrm{f}$.

Retribution, see Punishment

Revelation, and the transcendent Kingdom (Order), 201 f., 377 f.; as the correlative of faith, 381 ; relation of, to the will, $380-3$ 
Reverence for the past, $33 \mathrm{f}$.

Reward, and the disinterestedness of virtue, $209 \mathrm{f}$., 225 ; place of, in Plato and Kant, 213-8, 405 f.; as the recognition of virtue by the cosmic powers, $219 \mathrm{f}$. ; as the opportunity of moral progress, 220 f., 242 ; as a disinterested demand on behalf of others, 222-4 ; development and purification of the idea of, in the 0 . T., 226-9; in the Wisdom literature, $229 \mathrm{f}$.; its inward and spiritual character in Jesus' teaching, 231-6, 241, 246 ; sparingly used by Jesus as an initial motive, 237 f. ; positive place of, in His teaching, 239-45 ; not exactly proportioned to merit, $246 \mathrm{f}$.; as passing over into the thought of a free gift (Jesus and Paul), 247-52; in what sense used by Paul, ibid.

Ritschl, on law and forgiveness, 286 ; on the relations of the family as the most adequate representation of Christian morality, 287 ; on the continued need for effort in the Christian life, 345 n. ; on Christian autonony, 346 n. ; on the kingdom of sin, 356 ; on the objective character of the good life, 403

Roman Catholic idea of Law, 316 f., 322

Ross, D. M., 96 f.

Royce, 49

Ruskin, 94 n., 101

Ruysbroeck, 385 n.

Sabatier, Auguste, 66

Sabatier, Paul, 300

Sabbath-rest, need of, 148

Sage, the Stoic ideal of the, 15, $109-11,119,263 \mathrm{f}$.; parallel in Hebrew thought, 15

Sacrifice, place of, in Jesus' life, 97, 156 ; His demand for, from $\mathrm{His}$ disciples, 237 f., 245

Sanctification, as a social progress, $159 \mathrm{f}$.

Sanday, 357, 371 n.
Saracenic invasions, the, 374-6

Schleiermacher, 356, 403, 406

Schweitzer, 184, 195 n.

Scott, C. Anderson, 192

Scott, E. F., 188 n., 193

Seeley, see Ecce Homo

Self-consciousness, 50,52

Self-realisation and Self-sacrifice, alleged dualism of, 123-6 ; transcended in the idea of contribution to the Common Good, 129-35

Service, central place of, in Christian Ethics, 155-60; as the outward expression of Love, 161, 180 ; varieties of, in the Christian life, 171-9; the cost of, $237 \mathrm{f}$.

Severity, joined with Mercy in the Gospels, 27-33, 395

Shakespeare, Hamlet, 77 ; King Lear, 88 ; Hazlitt on, 126

Sidgwick, 106 n., 123.5, 136 n., 257

Sin, Jesus' sternness in judging, 28 ff. ; character of, as limiting and enslaving, $42 \mathrm{f}$., 343 ; continuance in, as the greatest punishment, 222,259 n. ; weakened sense of, at the present time, $311 \mathrm{f}$. ; conviction of, in the sight of Jesus' character, $313 \mathrm{f}$. ; idea of the kingdom of, 356

Slavery in Greek Ethics, 53-5, 58, $395 \mathrm{f}$.

Smith, G. A., 28, 61 n.

Social character of Christianity, $102-4,147$ f., 159 f.; of the Christian idea of reward, 240-2 ; see also Community, Common Good

Socrates, union of opposite virtues in the character of, 11 ; courage of, $15 \mathrm{n}$.; influence of, on the ideal of the Sage, 15, 109 ; à̀ $\tau \alpha$ p. $\kappa \in \iota \alpha, 56$; teaching of, on the value of the individual, $55 \mathrm{ff}$.; other references, 59,314

Somerville, D., 144, 181, 415 f.

Sonship, see Fatherhood

Sophocles, Edipus Coloneus, 88

Space and Time, see Universe

Spencer, Herbert, $134 \mathrm{f}$.

Spinoza, on the supreme good as 
inward and common, 112-4, 120 $f$; on the disinterested love of God, 113, 212 ; points of contact with Kant, 114 n., 217 ; on virtue as independent of reward, 212 ; use of the ideas of reward and immortality, 216 f., 406 ; on the defects of feeling as the principle of virtue, 336 ; on the eternal life, 359 ; on the conquest of evil by love and patience, 376

Spirit, Pauline doctrine of the, as harmonising diverse gifts and characters, 172 ; as a present gift, $192 \mathrm{f}$.; as the principle of true freedom, $344 \mathrm{f}$.

Spiritial Order, the, and the Kingdom of God, $204 \mathrm{f}$., $356 \mathrm{f}$. ; as embodying the Divine Will, 204 ; the Christian life as the endeavour to realise and actualise, $206 \mathrm{f}$., 388 ; relation of, to the natural and ethical orders, 354 f. ; threefold character of, in philosophy, 358-61 ; in Christian Ethics, as the order (1) of permanence, $362-9$; (2) of unselfishness and harmony, $369 \mathrm{f}$. ; (3) as the ultimate Reality, 362, 377-83 ; the true methods of its advance, $370-6$; how related to the use of force, ibid.; rest in, essential to the highest activity, 383-5; the inner power of, exemplified in the work of Jesus, 388 ; the supreme principle of, 386-9

Spontaneity, see Freedom

Stalker, 35 n., 147, 232 n.

State, the, place of, in Greek thought, $117 \mathrm{f}$., 130 ; limitations and advantages of the action of, 70 f., 176, 288 ; and the family, 136 f., 285 f. ; Greek conception of virtue in, $323 \mathrm{f}$. ; true place and methods of, in the Christian scheme, 175-7, $373 \mathrm{f}$.

Stevenson, R. L., 417

Stewart, G. W., $231 \mathrm{n}$.

Stoicism, 15, 23-5, 31 f., 58, $109 \mathrm{f}$., 145,167 f., 243,263

Strong, T. B., 329 n., 393
"Suffering Servant," the, 15, $215 \mathrm{n}$.

Summun bonum, Kant's doctrine of the, 213

Swinburne, $364 \mathrm{n}$.

Sympathy, and the value of the individual, 48-51, 85-90, $398 \mathrm{f}$.; relation of, to active help, $90 \mathrm{f}$.

Synthesis, the ideal of moral, chap. i. passim; expressed by Plato, $6 \mathrm{ff}$; and in Hegelian thought, 6,36 ; of inward and outward aspects of goodness, $129 \mathrm{ff}$., $155 \mathrm{f}$., $384 \mathrm{f}$., 403 ; of Law and Freedom, 340-7; the final, of Christian Ethics, 385-7

Task, the Christian good as a, 100 f., $178,193-9,347$ f., 379 ; contrast of "gift" and "task," 181, 403 ; their unity, 193, 404

Taylor, A. E., 126, $314 \mathrm{f}$.

Teleological character of Christian Ethics, 285-9, 341, 351-4 ; and the view of punishment as reformatory, 409

Tennyson, 67, 220, 307

Tertullian, $248 \mathrm{n}$.

Theologia Germanica, 211

Theoretic life, see Contemplation

Thucydides, funeral oration in, 10

Tolstoi, 140, 374 n., 402

Tragedy, and the value of the individual, 88

Transcendent, the Kingdom as, 201-4, 380

"Transvaluation of Values," $13 \mathrm{f}$.

Trust, as an element in Christian Virtue, 21-27, 95, 321-4

Truthfulness and considerateness, 35,319

Universalism, Christian, as resting on the value of the individual, 45 ; preparation for, in Jewish thought, $61 \mathrm{f}$., 346 ; form of, in the teaching of Jesus, $163 \mathrm{f}$. ; character of, as dynamical and redemptive, $97-9,162-6$; as including the widest diversity of gifts and functions, 167-79

Universality of the Christian Law, not reached through abstraction, 
294 ff. ; comparison with Jewish religion and Kantian Ethics, 295. 7 ; reached through the appeal of the character of Jesus, $301 \mathrm{f}$., 307-14, $415 \mathrm{f}$.

Universe, the material, ancient and modern conception of, $63 \mathrm{f}$. ; infinite extension of, and the individual, 65-7, 73-6 ; the forces of, and individual virtue, 67, 168, 387 f.; demand for its adjustment to moral issues, 219-24

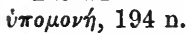

Value of the individual soul, see Individual

"Values, conservation of," 221, 268

Variety of character, see Diversity Virtue, positive character of Christian, chap. i. passim, 326-32, 415-7; and "the virtues," 4 ff.; development of, 5; Plato's theory of, as a union of opposites, $6 \mathrm{ff}$. ; variety and infinity of, $42 \mathrm{f}$. ; view of, as inward and inalienable, 109-12, $141 \mathrm{f}$; ; as social, 118,122 ; as depending on external things, 115-7, 147-9; final unity of its inward and outward aspects, $129 \mathrm{ff}$., 152-5, 161,384 f., 402 f.; the disinterestedness of, as the first ethical demand, 209-12, 244 ; in
Spinoza, Kant, and Plato, 213-7 ; how reconciled with the demand for reward, 218-25, 404-6 ; and prosperity in the O. T., 226-9; nature of new beginnings in, chap. $\mathbf{x}$. passim; the motives of Greek and Christian compared, 324 ; all sides of human nature embraced in Christian, 326-9; the relation of Christian, to "morality," 350-4; positive and negative elements in the Greek idea of, 390-4

War, $374 \mathrm{f}$.

Watts, G. F., 128

Weiss, Johannes, $192 \mathrm{n}$.

Wealth, as a hindrance in the spiritual life, 92 f., 115 ; as deriving value from its user, 94 ; as an instrument of service, 131, 158, 402

Whyte, 77

Will, see Freedom, "Good Will "

Will of God, the, in the thought of Jesus, 203 ; perfect realisation of, in the heavenly (transcendent) Kingdom, 201-4

Woman, exaltation of, by Jesus, 95

Wordsworth, 337, 398

\section{Zeller, 57, 116}

Zeus, Stoic conception of, as Father of all men, 58 ; as the protector of strangers and suppliants, 89 


\section{INDEX OF BIBLICAL REFERENCES.}

Genesisxviii. 25

Exodus-

xiv. $13 \quad$. $\quad$. 21

xxii. $21 \quad \cdot \quad \cdot \quad \cdot \quad 89$

$\begin{array}{lll}\text { Ixiii. } 9 & \cdot \quad \cdot \quad 89\end{array}$

Leviticus-

xix. 34

Deuteronomy-

iv. $11 \mathrm{f}$.

$\begin{array}{ll}\text { v. } 15 & 89 \\ \text { viii. } 3 \text { ff. : : : } \quad 227\end{array}$

x. $19 \cdot \div \quad 89$

xxx.11-14 . . 84,380

Ixxii. 6-18 . . . 227

2 Samuel-

xii. 6 . $\quad \cdot \quad \cdot \quad \cdot 29$

1 Kings-

xiv. 13

Job-

i. 9 ff. . . . . 228

ii. $3 \mathrm{ff.}$. . $\quad 228$

xxiii. 10 . $\quad 228$

sxvi. 14 . $\quad$. 65

xxxi. 13-22: : $: 90$

xxxvi. $26:$ : 65
Psalms-

viii. $3 \mathrm{f} . \quad$ - $\quad$. 66

xvi. 2 - . . 232

10 . . 363

xxvii. $4 \quad$. $\quad 229$

xxxvi. $9 \quad$. $\quad 366 \mathrm{n}$.

xxxvii. $2,10 \mathrm{ff}$. $\quad .229 \mathrm{n}$. $11 . \quad .231 \mathrm{n}$.

li. $16 \mathrm{f}: \quad$. 60

lxxiii. 25 : $\quad$. 229

lxxxiv. 10 . . 229

xcii. $14 \div . \quad .366 \mathrm{n}$.

xcri. 5 . $\quad .362 \mathrm{n}$.

cii. $25 \mathrm{ff}$. . . $.362 \mathrm{n}$.

ciii. $4 \mathrm{f}$. $\quad$. 367

$8-12 \cdot . \quad . \quad 365$

$12 \mathrm{f} . \quad \cdot \quad 287$

$19-21$. . 201

Proverbs-

xiii. 13,21 . $\quad$. $\quad 229$

Isaiah-

xxvi. 16-19 . . . 61

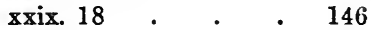

xxx. 15 . . 21

XXXv. 5 f. - . . 146

xl. $18 \mathrm{ff.} . \quad . \quad 362 \mathrm{n}$.

$26 \mathrm{f} . \quad \cdot \quad \cdot 66$

$30 \mathrm{f} . \quad$. $\quad . \quad 367$

xlii. 3 . $\quad . \quad 91$

liii. $\quad \cdot \quad 15,146,215 \mathrm{n}$. 
[saiah-

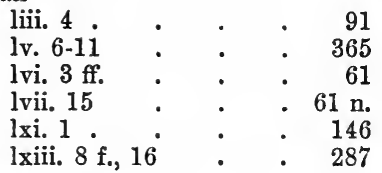

Jeremiah-

vi. 14 . . . 28

viii. 11 . $\quad . \quad 28$

x. $10 \mathrm{ff} . \quad$. $\quad .362 \mathrm{n}$.

xxxi. $20 \quad$. 287

$29 \mathrm{f.} \quad . \quad \cdot 61$

$31 \mathrm{f.} . \quad . \quad 60$

$33 \mathrm{f} . \quad$. $\quad . \quad 346$

Lamentations-

iii. $32 \mathrm{ff}$.

410

Ezekiel-

xviii. 4,20 . $\quad$. 61 20,23 . $\quad . \quad 288$

Daniel-

iv. 35 . . . 201

xii. 12 . $\quad$. $\quad$. 22

Hosea-

viii. $7,11 \quad$. $\quad$. 259

x. 13 . . $.259 \mathrm{n}$.

xi. 1,8 f. . . . 287

4 . $\quad . \quad$. 301

Micah-

vi. $6-8$

60

Habakkuk-

i. 12

410

Malachi-

iii. $2 \mathrm{ff}$.

410

Ecclesiasticus-

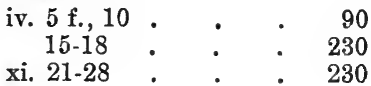

Wisdom-

ii. 23 -iii. 8 . . . 230

v. $15 \mathrm{f}$.
Matthew-

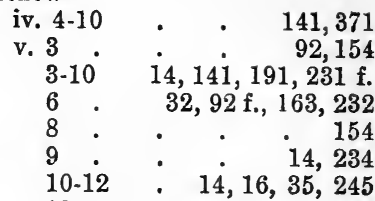

$13 . .196$

$15 \mathrm{f.} \quad . \quad$. 155

16 . . $35 \mathrm{n}$.

$17 \mathrm{ff} . \quad$. $\quad 33,335$

$20 . \quad . \quad 318$

$20-44$. . 327

21 ff., 27 ff. . $\quad 34,154$

22 . $\quad$. $\quad 154,319$

37 . $\quad . \quad$. 319

$38-48 \quad$. $\quad 371$

45 - . $\quad 234,378$

$47 . \quad . \quad . \quad 319$

$48 . \quad . \quad 378$

vi. $1-6 . \quad$. $\quad 35$ n., 232

$6 . \quad . \quad 148$

$10 . \quad . \quad 203$

$11 . \quad . \quad . \quad 147$

$12,14 \mathrm{f}$. $\quad$. 276,371

13 . . . . 39

$15 . \quad . \quad . \quad 29$

$16-18$. . . 232

19-21 . . 196 n., 369

$25-34 \quad$. . 22,96

$26,28 \quad$. $\quad . \quad 149$

32 ..$\quad 147$

33 . $24,196,244,320$

vii. $1 \mathrm{f} . \quad$. $\quad 276$

$6 . \quad . \quad 35 \mathrm{n}$.

$7 \mathrm{f.} \quad . \quad .320$

11 . . . 204

12 . . . 90, 327, 417

$13 \mathrm{f} . \quad$. $\quad 237,320$

$16-27$. . 154

20 . . . $153 \mathrm{n}$.

$24 \mathrm{f}$. $\quad 204,301$

viii. $10 \mathrm{ff}$. $\quad 154,163,256$

$17 \quad$. $\quad 91,146$

$19-22$. . . 237

ix. $8^{20} \cdot .141 \mathrm{n}$.

$9 \mathrm{ff.} \cdot 188 \mathrm{n}$.

$13 . \quad . \quad .163$

$18-20$. . . 402

$35 \quad$. $\quad . \quad 34$ 
Mattliew-

$$
\begin{aligned}
& \text { ix. } 36 \cdot 38 \quad \text { - . } 197 \\
& \text { x. } 1 \text {. } \quad . \quad \cdot 197 \\
& 5 . \quad . \quad 238 \mathrm{n} \text {. } \\
& 8 . . \quad . \quad 252 \\
& 16 . \quad . \quad . \quad 372 \\
& 19 \text {. . . } 22 \\
& 24 \mathrm{f} \text {. } \quad \text {. } 238,318 \\
& 26-33 \quad \text {. . . } 19,22 \\
& 27 \text {. . . } 35 \text { n. } \\
& 28 \text {. . . . } 142 \\
& 28 \text { f. . . } 96,245 \\
& 34 \text { - . . } 28 \\
& 37 \text { f. . . . } 318 \\
& 38 \text {. . . . } 238 \mathrm{n} \text {. }
\end{aligned}
$$

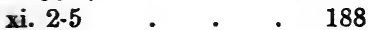

$5 . \quad . \quad 146$

$11 \mathrm{f} . \quad . \quad .188 \mathrm{n}$.

$20 . \quad$. $\quad . \quad$. 189

$25 . \quad . \quad . \quad 93$

28 f. $\quad . \quad 91,149,301$

xii. $11 \mathrm{f}$. . . 146

$$
20 \text {. } \quad . \quad \text {. } 91
$$

$28 \quad$. $\quad$. 188

$33-35 \quad$ - $\quad 153,154$

$37 \quad$. $\quad .154$

$43 \mathrm{ff.} \quad . \quad$. $\quad 39$

xiii. $\quad . \quad$. $\quad . \quad 195$

$8, \dot{23} \quad \cdot \quad \cdot \quad \cdot \quad 171$

12 . . . 280

f. $\cdot$. $\cdot 191$

xvi. $24 \quad$. $\quad . \quad 238 \mathrm{n}$.

xviii. 2 ff., 92,165 n., 192, 320

$6 \mathrm{f}$. . . 19,29

$8 \quad . \quad 39$

10 - 19,96 n., 203

14 . 96 n., 204

20 . . . 144

21 f. . . . 371

$21-35$. $\quad 29,274$

xix. $3 \mathrm{ff} . \quad$. $\quad$. 95

$27-30$. $\quad 240,281$

xx. $1-16$. $\quad$. 246

16 . . . 281

xxi. 28-46 . . 164

$30 \mathrm{ff} . \quad$. $\quad 154,256$

xxii. $1-10 \quad$. $\quad . \quad 164$

$30 \quad . \quad 203$

$40 \quad . \quad$. $\quad . \quad 328$

xxiii. $3 \quad$. $\quad . \quad$. 34

34
318
Matthew-

xxiii. $11 \quad$. $\quad$. 156

13 . $\quad 29,270$

$23 \quad$ - $\quad 197,327$

25 f. . . $\quad 318$

$27 \mathrm{f} . \quad . \quad . \quad 154$

37 ff. . . . 30

xxiv. $13 \quad . \quad . \quad .194 \mathrm{n}$.

$40 \mathrm{f} . \quad . \quad . .200$

$48 \mathrm{ff}$. . . 194

xxv. $1-13 \quad$. $\quad 30,198$

14 ff. $\quad . \quad 20,171,198$

21,23 . $\quad 242,319$

$24 \mathrm{ff}$ - . $\quad 417$

$29 \quad$ - $\quad 243,280$

$31 \mathrm{ff}$. $\quad 90$ f., 154, 200

34 . . 201, 319

$40 \quad . \quad .165$

xxvi. $53 \quad$. $\quad . \quad .203 \mathrm{n}$.

xxviii. $20 \quad$. $\quad . \quad 144$

Mark-

i. $4,14 \mathrm{ff}$. . . 29

15 . . . 189

17 . $\quad . \quad 238,301$

27 . . . $188 \mathrm{n}$.

$39,44^{\circ}$. $\quad$. 34

ii. $2 \mathrm{ff} . \quad$. $\quad . \quad$. 401

$14 . \quad . \quad .238$

$16 \mathrm{f} . \quad$. $\quad 270$

17 • $\quad$. 98,163

$18-22$. . . 34

$23 \mathrm{ff} . \quad$. $\quad . \quad 34$

$27 \mathrm{f} . \quad$. $\quad$. 148

iii. $4 \mathrm{f}$. $\quad$. $\quad$. $\quad$ - 146

$22 \mathrm{ff}$. $\quad . \quad .356 \mathrm{n}$.

29 . . . 28

$35: \quad 165,204,240$

iv. $5 \mathrm{f}$. . . 237

$7,19 \quad$. $\quad .92$

$8,20 \quad$ - . 154,171

25 . . . 280

26-29 . . 195 and $n$.

v. 34 . $\quad \cdot 147,190$

vi. $2 \cdot$. . 34

$31: \div \quad 148$

vii. $1-23$. . $\quad 34$

$18.23 \div$. 154

24,33 . $\quad 402$

viii. $31 \mathrm{ff}$. $\quad 338$

34. 142,237 f., 301,318 
Mark-

viii. 35 . . . 244,372

$36 \mathrm{f} . \quad . \quad . \quad 92$

ix. 23 f., 29 . $\quad$. $\quad . \quad 147$

35 ..$\quad$. 156

$37 . \quad . \quad . \quad 165$

41 f. $\quad 19,165$ n., 319

$43 \mathrm{ff.} \quad$. $\quad$. 39

x. 2 ff. $\quad$. $\quad .34,95$

$13 . \quad . \quad 17$

14 ff. $\quad 92,191$ f., 319

15 . . . 320

$21 . \quad 30,94,142,301$

24 . $\quad 92,238$

$28-31 . \quad . \quad 240$

31 . . $\quad 243,281$

$35 \mathrm{ff} . \quad$. $\quad 201,242$

39 ff. . . . 301

42-5 . $156,242,371$

$45 . \quad . \quad .97$

xi. $15 \mathrm{ff} . \quad$. $\quad$. $\quad 28$

$25 . \quad . \quad .276$

xii. 6 ff. . $\quad$. 330

$25 \quad$. 203,242

$28 \mathrm{ff} . \quad$. $\quad . \quad 328$

$34 \quad . \quad . \quad 190$

$37 . \quad . \quad 77$

$40 \quad . \quad . \quad . \quad 197$

$43 \mathrm{f} . \quad$. $\quad 94,154$

xiii. $7 \mathrm{ff}$. . . . 16

13 . . . 194

$32 \quad . \quad . \quad . \quad 198$

xiv. 6,8 f. $\quad$. $\quad$. $\quad 94,319$

xv. $31 \quad$. $\quad . \quad$. 18

\section{Luke-}

iii. $8 \mathrm{ff}$.

29

iv. $6 . \quad . \quad .356 \mathrm{n}$.

$16 \mathrm{ff}$. . . . 34

18 . . . 146

$21 . \quad . \quad .188 \mathrm{n}$.

$36 \mathrm{ff}$. . . $.188 \mathrm{n}$.

v. $37-39 \quad$. $\quad$. 34

vi. 20 . . . $92 \mathrm{n}$.

$24 . \quad . \quad 93,233$

$33-35$. . . 234

$37 . \quad$. $\quad 276$

$38 . \quad . \quad .232 \mathrm{n}$.

vii. $21 \mathrm{f} . \quad$. $\quad . \quad$. 146

35 ..$\quad 20$

$47,50 \div 33,190,274$
Luke-

viii. $15 \quad$. $\quad$. 233

18 . . . 280

ix. 23 . . . . $238 \mathrm{n}$.

$51 . \quad$. $\quad 338$

$57-62 \quad . \quad 21,30,237$

58 . . . . $141 \mathrm{n}$.

x. $25 \mathrm{ff} . \quad$. $\quad$. 34

30-37 . 154, 164, 319

$31 \mathrm{f} . \quad . \quad . \quad 417$

$41 \mathrm{f}: 142$

xi. 13 . $\quad$. $\quad$. 204

$28 . \quad . \quad . \quad 154$

$42 . \quad . \quad 327$

xii. $13-21 \quad$ • $\quad$. 92,235

$31 \mathrm{f} . \quad . \quad . \quad .196 \mathrm{n}$.

$32 \quad . \quad . \quad .22,96$

33 f. $\quad$. 235,369

$47 \quad$. $\quad . \quad 32$

$48 \quad$. $\quad 171,325$

xiii. $3,5 \quad$. $\quad$. $\quad$. 29

9. . . $\quad 30$

16 . 102,149

$23 \mathrm{f} . \quad$. $\quad 22,382$

30 . . . 281

xiv. 3 ff. $\quad . \quad$. $\quad . \quad 146$

$12-14$. . 234

$25,27 . \quad .238$ n.

$28-33$. . . 237

xv. $7,10 \quad$. $\quad 98,203$

$29 \mathrm{f} . \quad . \quad .270$

$31 \quad$. $\quad . \quad 282$

$32 \quad . \quad . \quad .98$

$\begin{array}{llll}\text { xvi. } 10 \quad \text {. } & \text {. } 402\end{array}$

19 ff. . . . 417

31 . $\quad . \quad 380$

xvii. $10 \quad$ - $\quad 41,318,417$

$21 . \quad 187$

xviii. $9-14$. $\quad$. $93,270 \mathrm{f}$.

xix. 9 f. $\quad . \quad$. 98,102

12 ff. . . . 20

$17 . \quad . \quad 242$

$26 . \quad$. 280

xx. $35 \quad$ • $\quad$. 194

xxi. 19,36 . $\quad$. 194

xxii. 28 f. . $\quad$. 239

32 . . . 274

$\begin{array}{llll}\text { xxiii. } 28 \quad & . & . & \end{array}$

John-

i. $1-9$. . . . $362 \mathrm{n}$.

$11 \div \quad . \quad 307$ 
John-

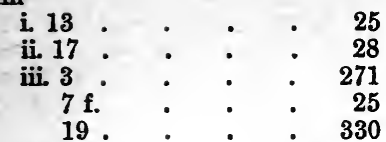

iv. $13 \mathrm{f}$. $\quad . \quad .366 \mathrm{n}$.

$34 . \quad . \quad$. 204

vi. 15 - . $\quad$. $\quad 338$

38 . . . . 204

vii. 1 ? $\quad$ : $\quad 382$

viii. $32 \mathrm{ff}$. $\quad$. 42,343

ix. 4 . . . 21 $41 . \quad$. 32,330

xii. 31 . . . $\quad .356 \mathrm{n}$.

- 32. . . . 144

. 48 . . . 330

xiii. 12-14 • . . 156

$$
15 \text {. } \quad . \quad 301
$$

iv 34 f. $\quad 35,301,328$

xiv. 19 - 369

xv. 5 . $\quad .25,165 \mathrm{n}$.

$8 \div . \quad 154$

12,17 . $\quad . \quad 328$

$14 \mathrm{f} . \quad$. $\quad 322$

$20 . \quad . \quad 238$

22,24 - . $\quad 330$

xvi. 7 . $\quad$. $\quad$. 144

8-11 . . . 330

$33 \quad$ - . $\quad 16,388$

xvii. $3 \quad$. $\quad . \quad 362 \mathrm{n}$.

$\begin{array}{lllll}\text { xviii. } 8 & \text {. } & \text {. } & 17\end{array}$

xix. $26 \quad$. $\quad . \quad 17$

xxi. $15 \mathrm{ff} . \quad$. $\quad$. 274

Acts-

ii. 44-47 . $\quad 241,402$

iv. $13,19 \mathrm{ff}$. $\quad$. 18

$34 \mathrm{ff.}$. . . 402

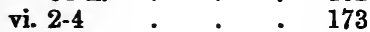

ix. $3 \mathrm{ff}$. $\quad$. 331

xvi. $23 \mathrm{ff}$. $\quad$. 16

xvii. 27,30 . $\quad$. $\quad$. 304

xx. $35 \quad$. $\quad . \quad 157$

xxvi. 12 ff. . . . 331

\section{Romans-}

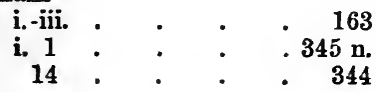

Romans-

i. 16 . . . 207

28 . . . . 259

ii. $14-16$ - . 304

$28 \mathrm{f} . \quad . \quad .163 \mathrm{n}$.

iii. 20 . . . . 318

$27 . \quad . \quad$. 333

$27 \mathrm{ff} . \quad$ - $\quad 193,333$

$31 . \quad . \quad . \quad 335$

iv. 15 . . . . 333

v. $2-5$. $\quad . \quad$. 250

$3 . \quad . \quad 16$

$5 . \quad . \quad . \quad . \quad 192$

$12 \mathrm{ff} . \quad . \quad . \quad 312$

$19 . \quad . \quad . \quad 302$

20 . . . . 330

$21 . \quad . \quad .369 \mathrm{n}$.

vi. 4 ff. $\quad$. $\quad$. $\quad 369$

$16 \mathrm{ff} . \quad . \quad . \quad 42,343$

22 . $\quad . \quad 344,415$

23 . . . 248,343

vii. $7-14 \quad$. $\quad 330$

$12-16$. $\quad . \quad 354$

$23 . \quad 343$

viii. 2 . $\quad$. $\quad 302,333,356$

3 . $\quad 333$

4. $\quad 335,354,373$

6-10 . . . 344

$14 \mathrm{ff} . \quad$. $\quad 321$

16 ff. . . 250,344

18 ff. : . 192,365

24 . . . 249

26 . . . 344

$28 \quad . \quad . \quad 168$

x. 3 ・ $\cdot 163$

$4 . \quad . \quad 302 \mathrm{n}$.

$8,12-15$. . . 151

xi. $20-23 \quad$. $\quad$. 281

xii. 1 . . . 153 n., 415

4-6 . . . 172

$11 \quad . \quad . \quad . \quad 21$

12 . . . 249

$19.21 \quad$ - $\quad 371,378$

xiii. $4 \quad$. $\quad$. 373

$8-10$. $\quad 328,340$

$13 \div \quad . \quad 21$

xiv. $\quad . \quad \cdot \quad \cdot 342$

$17 . \quad . \quad 193$

$21 . \quad . \quad 105$

xv. $1-3 \quad$. $\quad$ i 105,302

$27 \quad . \quad . \quad 402$ 
1 Corinthians-

$$
\begin{aligned}
& \text { i. } 18 \mathrm{ff} . \quad \text {. } \quad \text {. } 93 \\
& 20 \text {. . . } 77 \\
& \text { 27-29 } \quad . \quad . \quad 372
\end{aligned}
$$

ii. 2 . . . 143

$4 . \quad . \quad 77$

$14 \mathrm{f.} \quad \cdot \quad \cdot \quad 356$

iii. 3 . . . 375

$10-14$. . . 364

$14 . \quad . \quad .248$

22 . . . . 42

iv. 2 . . . 251

7 . . . $193 \mathrm{n}$.

$12 \mathrm{f} . \quad . \quad . \quad .371$

$16 \mathrm{f.} \quad . \quad 302$

vi. 12 . 342

$13,19 \mathrm{f} . \quad . \quad 153 \mathrm{n}$.

vii. 1<smiles>[131In]</smiles>

342

$.163 \mathrm{n}$.

22 f. . . 341 n., 344

viii. 1 . . . 342

$9,11 \quad . \quad .105$

$10 \mathrm{ff} . \quad$. . 342

ix. 11 .

$16-18 \cdot . \quad 402$

19 . . . . 342

$21 . \quad . \quad .344$

$26 . \quad . \quad 21$

$27 . \quad . \quad 39$

x. $12 . \quad . \quad . \quad 281$

23-33 . $\quad 105,342$

xi. 1 . . $\quad 302$

xii. $4-7 \quad$. $\quad . \quad 172$

24 f. . . 172

26 . . . . $157 \mathrm{n}$.

28 . . . . 173

31. . . . 399

xiii. . . 77 n., 328, 416

$2 . \quad . \quad 77$

$3 . \quad$. $\quad 158,328$

$4 \mathrm{f.} . \quad 40 \mathrm{n}$.

$4,7 . \quad . \quad 377$

$5 . \quad . \quad 253$

$8 \mathrm{ff}, \quad$. $\quad 339,368,388$

xiv. 1 . . . 399

$15 . \quad . \quad .415$

xv. $9 \mathrm{f} . \quad$. $\quad . \quad 274$

$10 . \quad .344 \mathrm{n}$.

36 . . . 365

$44 \mathrm{ff.} \quad . \quad$. $\quad . \quad 356$

56 . . . 333

xvi. 13

16
2 Corinthians-

iii. 5 • $\quad$ - $\quad 144$

$7-18 \div \quad . \quad 331$

17 . . . 42,340

18 . . . 40,333

iv. 1 . . . 21

4,6 . . $\quad$. 192,331

$5 . \quad . \quad .341$

$7 . \quad . \quad 143$

$8-11 \quad . \quad . \quad . \quad 368$

$16-18$. . . 368

. $17 . \quad . \quad . \quad 249$

จ. $5 . \quad . \quad 192$

$14 \mathrm{f} . \quad . \quad . \quad . \quad 344$

17 . $\quad 154,273$

vi. 7 . . . $20 \mathrm{n}$.

$8,10 \quad . \quad . \quad 144$

viii. $5 . \quad . \quad . \quad . \quad 158$

$9 . \quad . \quad 157$

12 . . 158,325

ix. 8-13 . . . 158

x. $1,3 \mathrm{f} . \quad$. $\quad . \quad 370$

xi. $23 \mathrm{ff} . \quad$. $\quad . \quad 18$

xii. 10 . . . 16, 143

Galatians-

i. 10 . . . $345 \mathrm{n}$.

$14 . \quad . \quad . \quad 318$

ii. 19 . $\quad . \quad 333$

$20 . \quad . \quad .344 \mathrm{n}$.

iii. $10 \mathrm{ff.}$. . . 318

$12,21 \cdot . \quad . \quad 333$

$24 \mathrm{f.} . \quad . \quad . \quad 354$

iv. $5 \mathrm{ff}$. . . . 321

v. $1 \quad$ - $\quad 42,333,343$

$3 . \quad . \quad .313$

6 . . . 154

$13,15 \quad$. $42,157,341$

$14 . \quad . \quad$. 328

$16 . \quad . \quad . \quad 39$

19 f. . . . 375

$22 \mathrm{f} . \quad . \quad 340$

$24 . \quad . \quad 39$

vi. $2 . \quad$. $\quad . \quad 302$

$7-9 . \quad . \quad 282$

$9 \mathrm{f.} . \quad . \quad . \quad 21$

$15 . \quad . \quad 154$

Ephesians-

i. $13 \mathrm{f} . \quad$. $\quad . \quad 192$

ii. 2 . . . 356 n. 
INDEX OF BIBLICAL REFERENCES.

Ephesians-

iv. 7 .

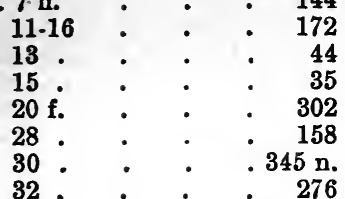

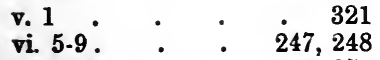
$10 \mathrm{ff} . \quad$. $\quad 16,371$ 12 . . . $356 \mathrm{n}$. $16 \mathrm{f.} . \quad . \quad 20$

Philippians-

i. $12, \quad$. $\quad . \quad 168$

ii. $3,7,8$. . $\quad 157$ $4 . \quad . \quad 253$ $5 . \quad . \quad$. 302

12 f. . . . 26

iii. 4-7. . . 279,318

$7 \cdot:$ : 272

$8 \div$. . 143

iv.

$12-14$. $21,41,251,380$ 6.6 .23 $8 \div \quad 40,332$ $11.13 \quad$. 144 n., 151

Colossians-

i. $13 \quad . \quad . \quad 356 \mathrm{n}$. $15 \mathrm{ff.} . \quad . \quad . \quad 362 \mathrm{n}$.

iii. $1 \mathrm{f.} \quad$ • $\quad$. $\quad 369$

$$
\begin{aligned}
& 5 \quad . \quad \text {. } \quad 39 \\
& 12 \mathrm{f} . \quad \text {. } \quad .276 \\
& 14 \text {. . . . } 387 \mathrm{n} \text {. }
\end{aligned}
$$

1 Thessalonians-

$$
\begin{aligned}
& \text { iv. } 9 \quad \text { - . . . } 328 \\
& \text { v. } 15 \text { : * : } 371 \\
& 19 . \quad . \quad .345 \mathrm{n} \text {. } \\
& 23 \text {. . . } 153 \text { n., } 415
\end{aligned}
$$

2 Timothy-

$$
\begin{aligned}
& \text { i. } 8 \\
& 12: \div \quad: \quad \cdot \quad 369
\end{aligned}
$$

Hebrews-

ii. 1
Hebrews-

ii. 8

$17 f^{\circ} \cdot \quad \cdot 101$

vii. $16 \cdot \quad \cdot \quad 354369$

$18 \mathrm{f}$.

х. $23 \mathrm{f.} \quad . \quad$. $16,21,399$

xi. $32 \mathrm{ff}$. $\quad 18$

xii. 2 - . 40,302

$3 . \quad . \quad$. 16

$5-11 \cdot$. 290

17. . . . 282

James-

i. 2 f. . . . $\quad 16$

$5.8 . \quad . \quad .343 \mathrm{n}$

$17 \div \quad: \quad \div 204$

$25 \cdot . \cdot 5343$

ii. 8 . . . $\quad 328$

$13 \div . \quad$. 276

$15 \mathrm{f} . \quad$. $\quad . \quad 155$

iii. 2 . $\quad$. 154

$11 \mathrm{f} . \quad \cdot \quad . \quad 153$

iii. 14-iv. 2 - $\quad$. 375

iv. 17 . . . 330

จ. 3,5 . . . 233

11 . . . 16

1 Peter-

i. 8 f. . . . . 192

22 ff. $\quad . \quad+363$

23 . . . . 271

ii. $6-8$. . . 330

$15,19 \mathrm{ff} . \quad$. $\quad 372$

16 . . . 341

21 . . . . 302

iii. 8 . . . 319

$14 \mathrm{ff} . \quad$. $\quad 16,372$

iv. $8,10 \quad \cdot \quad \cdot \quad 158,170$

13 . . . 16

จ. $5 . \quad . \quad .156 \mathrm{n}$.

2 Peter-

i. 5 ff. .

41

61 John-

i. $1 \mathrm{ff}$. . . . $269 \mathrm{n}$.

ii. 1 . . . 321

$6 \div: \div \quad 302$

$7 \mathrm{f.} \quad \cdot \quad \cdot \quad 35$

10 . . . $\quad . \quad 328$

$17 \div: \div \quad 363$

iii. 14 . $\quad \cdot \quad \cdot 363$ 
INDEX OF BIBLICAL REFERENCES.

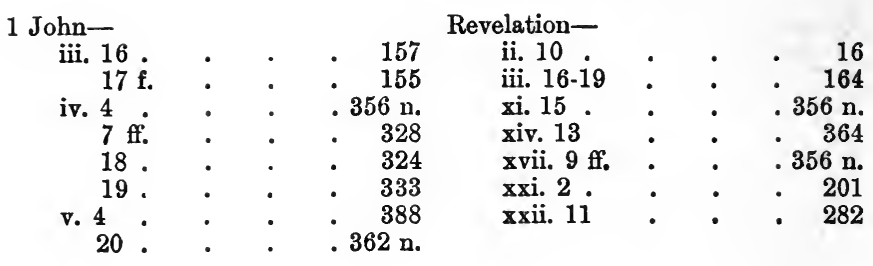





\section{UNIVERSITY OF CALIFORNIA LIBRARY}

BERKELEY

Return to desk from which borrowed.

This book is DUE on the last date stamped below.

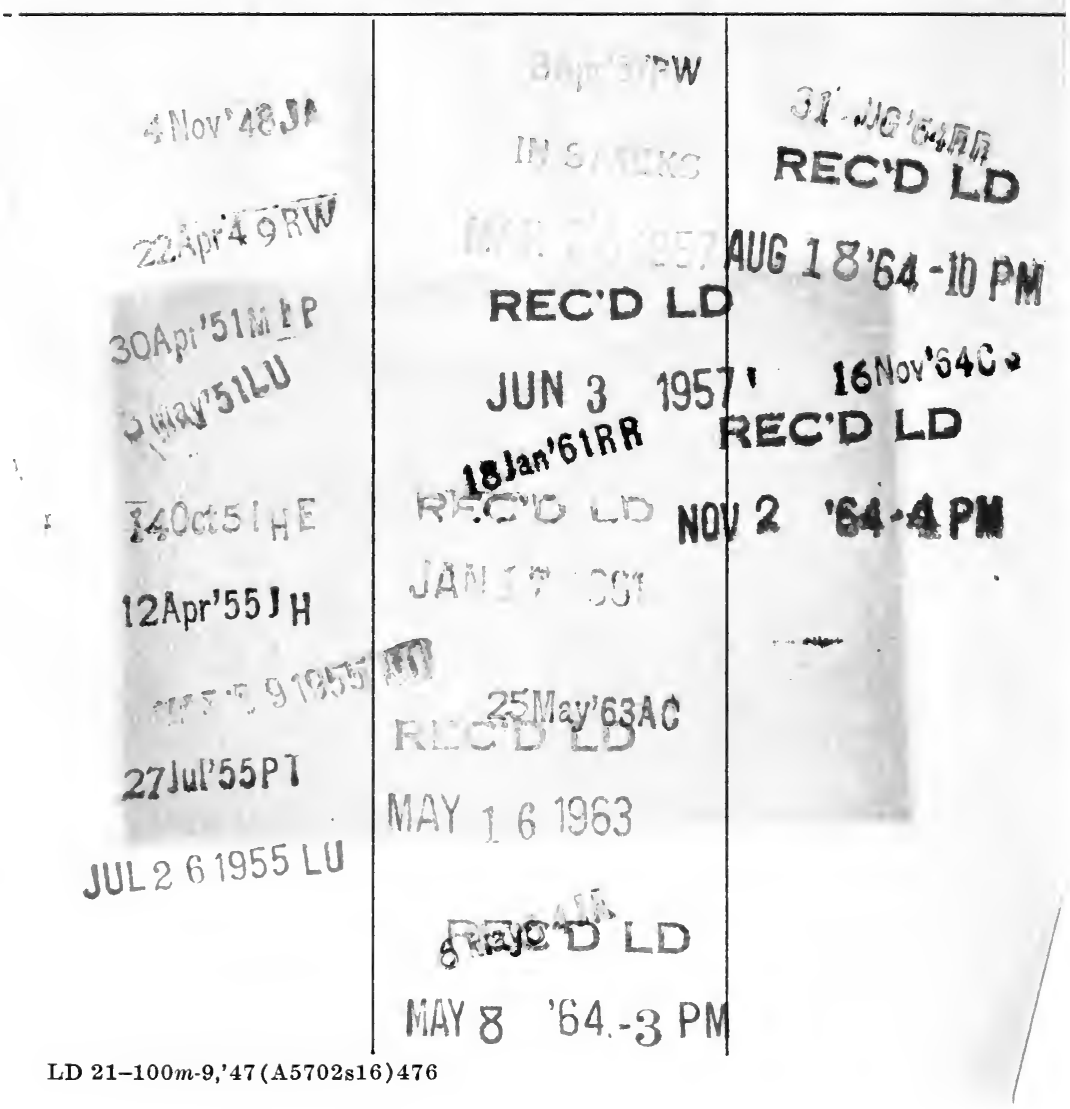




\section{YC 30377}

2

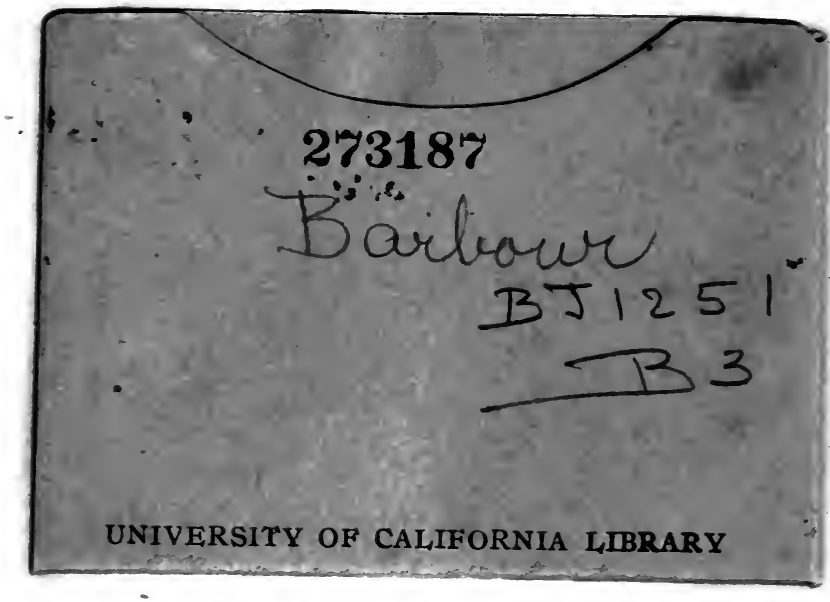


